\title{
Learning to innovate : agricultural innovation and entrepreneurship : the case of Songhaï farmers in Benin
}

Citation for published version (APA):

Dalohoun, D. (2005). Learning to innovate : agricultural innovation and entrepreneurship : the case of Songhaï farmers in Benin. [Doctoral Thesis, Maastricht University]. Universitaire Pers Maastricht. https://doi.org/10.26481/dis.20050907dd

Document status and date:

Published: 01/01/2005

DOI:

10.26481/dis.20050907dd

Document Version:

Publisher's PDF, also known as Version of record

\section{Please check the document version of this publication:}

- A submitted manuscript is the version of the article upon submission and before peer-review. There can be important differences between the submitted version and the official published version of record.

People interested in the research are advised to contact the author for the final version of the publication, or visit the DOI to the publisher's website.

- The final author version and the galley proof are versions of the publication after peer review.

- The final published version features the final layout of the paper including the volume, issue and page numbers.

Link to publication

\footnotetext{
General rights rights.

- You may freely distribute the URL identifying the publication in the public portal. please follow below link for the End User Agreement:

www.umlib.nl/taverne-license

Take down policy

If you believe that this document breaches copyright please contact us at:

repository@maastrichtuniversity.nl

providing details and we will investigate your claim.
}

Copyright and moral rights for the publications made accessible in the public portal are retained by the authors and/or other copyright owners and it is a condition of accessing publications that users recognise and abide by the legal requirements associated with these

- Users may download and print one copy of any publication from the public portal for the purpose of private study or research.

- You may not further distribute the material or use it for any profit-making activity or commercial gain

If the publication is distributed under the terms of Article $25 \mathrm{fa}$ of the Dutch Copyright Act, indicated by the "Taverne" license above, 


\section{Learning to Innovate}

Agricultural Innovation and Entrepreneurship

The Case of Songhaï Farmers in Benin

Daniel Nougbégnon Dalohoun 
O 2005 D. N. Dalohoun

All rights reserved

Cover design by Jacqueline van Kesteren

Published by Universitaire Pers Maastricht ISBN 9052784817

Printed in the Netherlands by Datawyse Maastricht 


\section{Learning to Innovate}

Agricultural Innovation and Entrepreneurship The Case of Songhaï Farmers in Benin

PROEFSCHRIFT

ter verkrijging van de graad van doctor aan de Universiteit Maastricht,

op gezag van de Rector Magnificus, Prof. Mr. G.P.M.F. Mols, volgens het besluit van het College van Decanen, in het openbaar te verdedigen op woensdag 7 September 2005 om 12.00 uur

door

\section{Daniel Nougbégnon Dalohoun}

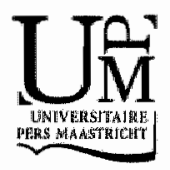


Promotor:

Co-promotor:

Prof. Dr. Lea L.M.S. Velho, University of Campinas,

Brazil

Beooderlingscommissie: Prof. Dr. Ir. Wiebe E. Bijker (voorzitter)

Prof. Dr. Pierre A. Mohnen.

Prof. Dr. Paul T. Perrault, Angoisse, France

Prof. Dr. Luc L.G. Soete

The following institution fully sponsored the Ph.D. thesis research:

United Nations University, Institute for New Technologies,

Maastricht the Netherlands 
"... What I mean by the term "wall"

has to do with the experiences I have had with it..."

(Charles Sanders Peirce: 1839-1914) 


\section{Acknowledgement}

The process of writing this Ph.D. has been more demanding than intially thought. It required a wide range of input resources that 1 didn't personally possess. Owing to the countless deal of so many good people and institutions that have generously helped me, I have completed it.

I feel greatly indebted to my supervisors. I am grateful to my promoter, Prof. Dr. Louk de la Rive Box (Professor at the University of Maastricht and Rector of Institute of Social Studies, The Hague) and to my co-promoter, Prof. Dr. Lea S. Velho (Professor of Science and technology Policy, University of Campinas, Brazil and Former Researcher at UNU/NTECH - United Nations University, Institute for New Technologies). Your contributions have been critical to the achievement of this work. Your continuous and tireless advice, interest and knowledge, immensely enhanced my understanding of the subject matter. When I was very close to the completion of this thesis, you both left: Maastricht. However, you remained close to me as before. The most meaningful lesson I learned from you came not only from our academic debates, but also from your personal integrity and understanding of human nature. My utmost words of thanks infinitely go to you.

Many other people took a keen interest and provided enormously valuable inputs to this thesis at its various stages. In particular, I want to register iny great appreciations to Prof. Dr. Lym K. Mytelka (Former Dírector, UNU-INTECH), Prof. Dr. Banji OyelaranOyeyinka (Senior Researcher, UNU-INTECH), Prof. Dr. Paul Perrault (Professor of Agricultural Economics and Former Senior Researcher, ISNAR - The Hague), Dr. Helen Hambly Odame (Professor of Rural Extension Studies, University of Guelph, Canada and Former Researcher, ISNAR - The Hague), Dr. Dominique Hounkonnou (Connecting Development Partners: CDP-International, Benin), Prof. Dr. Rigobert Tossou (Faculty" of Agronomic Sciences, University of Calavi, Benin), Dr. Annemarie Mathess (GTZ, Benin). At an earlier stage your ideas, comments, and suggestions were also vital to the formulation and the orientation of this research.

I wish to express my gratitude to institutions and their staff that facilitated the stage of field research, namely, the "Institut National des Recherches Agricoles du Benin -INRAB" and the "Songhail Centre-Somghar". In particular, I felt that Dr. David Arodokoun (General Director-INRAB), Mr. Gaston Kokodé (INRAB), Mr. Patrice Adégbola (Director"Programme d"Analyse de la Politique Agricole - PAPA/ INRAB), Dr. Kiki (PAPAINRAB) and Madame Capo-Chichi (INRAB) had an overwhelming desire to contribute to the achievement of my thesis. The INRAB staff at its headquarters and in its branches of Porto-Novo, Niaouli, Bohicon and Save was as well very enthusiastic.

I am indebted to Father Godfrey Nzamujo (the founding director of Songhai), Mr. Guy Loueke (technical director - Songhai), Mr. Paulin Noumado (Production \& Human Resources Manager- Songhai), Mr. Justin Lekoto (training director - Songhaii), Mr. 
Vincent Gbaglo (follow-up team manager - Songhai) and the sites managers in Lokossa, Savalou and Parakou). Thanks to you all for your facilitation and making sure I could get what I needed from the fieldwork. I highly appreciate the contribution of Songhai farmers who generously lent themselves to improvised face-to-face in-depth interviews. You have been open-minded, very friendly and I was also privilleged to enjoy from your hospitality. Without your unreserved co-operation and support, my Ph.D. journey would not have resulted in a successful achievement. Dear Songhai farmers, more people will know more about you. They will know that you have learned to innovate and that you are entrepreneurs (constantly innovators) and premise for agricultural development in Benin.

After the fieldwork, I had to compile the data, analyse them and refine the research issues. During this stage, I benefited a lot from critical and stimulating comments from researchers and, I am delighted to acknowledge their vital contributions. I had the opportunity to work with Prof. Dr. Pierre Mohnen (MERIT, University of Maastricht), who devoted a lot of his precious time reading my chapter on quantitative analysis with sound guidance. The topical area of my research falls under the expertise of Dr. Andy Hall (Researcher, UNU-INTECH). I had vivid discussions with him. Fe was able to read many chapters and provided insights that enlightened many shadows in my research. Mr. Geoffrey G. Gachino (Ph.D. Candidate, UNU-INTECH/MERIT), in addition to being a real friend and brother, he has mostly been a regular discussant. Whenever I needed, I could approach him and he did not save himself of sharing his excellent academic knowledge with me. His suggestions considerably helped improve my analysis . Another key person was Mr. Alexis Habiyaremye (Ph.D. Candidate, UNU-INTECH/MERIT). He accepted and committed to read the whole thesis with critical corrections and additional comments. And that was not all.. Without any charge, Alexis Habiyaremye generously translated the summary of this thesis into Dutch. Dear all, it has been so exciting to work with you in an atmosphere of marvellous friendship. I wish to express my deep and everlasting gratitude.

It was certain. I could not get involved in the Ph.D. programme and achieve this research without full sponsorship of UNU-INTECH. Initially set to be only a twoyear financial support, it has been extended to two more years under the directorship of Prof.. Dr. Lynn K. Mytelka. I would like to acknowledge with thanks this four year funding UNLINTECH awarded me with contimuous institutional provision through the work of its support staff whose precious contribution I am also grateful to acknowledge. None of the staffs' contribution was the least. In this regard, my special thanks go to Mr. Marc Vleugels, Ms. Wilma Coenegrachts, Mr. Ad Notten, Ms. Corien Gijbers, Ms. Silvana de Sanctis, Mr. Mourik Jan Heupink, Ms. Jacqueline van Kesteren, and Ms. Evelyn in de Braek. You have always helped with a disinterested mind and beyond expectations. Needless to belabour, I had constantly relied on your advice and practical assistance in many instances. 
I am indebred to Prof. Dr. Luc Soete (Director, UNU-INTECH/MERIT), Prof. Dr. Robin Cowan (Director, UNU-INTECH/MERIT Ph.D. Programme), the Faculty of Art and Culture, the Faculty Economics and Business Administration and the University of Maastricht for facilitating the whole Ph.D. process. In all measures, you endeavoured to make this event reall, you were eager to acknowledge and record it as the result of an excellent academic environment. Your support was overwhelming and thus highly acknowledged.

Another rewarding aspect of the MERIT/UNU-INTECH Ph.D. Programme is its interdisciplinary and multicultural enviromment. I had the possibility to meet and socialise with individuals from many part of the world who were not only outstanding intellectually but also possessed admirable personal qualities. They were entertaining, sympathetic and I could learn much from them. Just to mention those in my group, I was privileged to have met and delighted to thank (in alphabetic order) Francisco Aguayo (Mexico), Saurabh Arora (India), Teresa Caparas (Philippines), Marcia da Mota Darós (Brazil), Fulvia Farinelli (Italia), Abraham Garcia (Spain), Victoria Kravtsova (Ukraine), Sandra Leitner (Austria), Ngoc Pham Quang (Vietnam), Davide Stroppa (Italia) and Berta Vallejo (Mexico).

In my country (Benin) and elsewhere, I have genuine friends whose support was also necessary to this achievement. Dear Dr. Serge Adéromou (France), Théophile Aguiard (Australia), Marie Ahouansou, Emmanuel Akoueikou, Dr. Mamadou Bassadin (Slovakia), David Dansou (The Netherlands), Gérard Gbénonchi, Benoit Hounsa, Isidore Kouton, Ing. Mathieu Monnou, Dr. Emile Padonou, Rev. Gervais Sossoukpe and Christophe Tozo, in different ways, you have demonstrated an impressive solidarity encouraging and assisting me whenever and wherever I needed. Your lent hand reached the target.

Dear brothers André and René, thanks to your sustained care I have achieved this work, which is one of the utmost aspirations of our lovely father. Yes, some years ago, the man Illoved the most passed away, he is gone because he had to... But this dexterity sown in me grew and coupled with an overwhelming and amazing grace of God... The Living God I personally sought and found... With God in Jesus-Christ, the Holy Spirit will continually guide me and I will always securely go. 


\section{Contents}

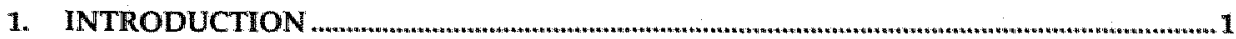

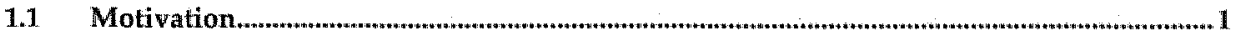

1.2 Economic development theories as diagnoses and medications ...............................................

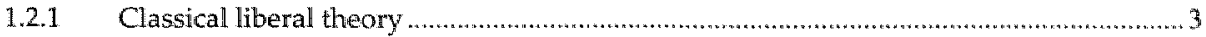

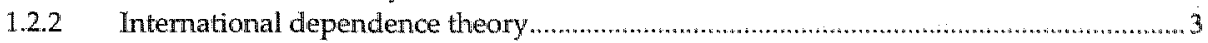

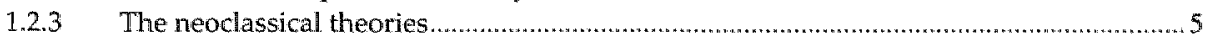

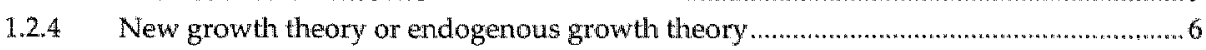

1.2.5 Rethinking economic development and innovation system approach .............................. 7

1.3 Some recent approaches to agricultural innowations ........................................................................9

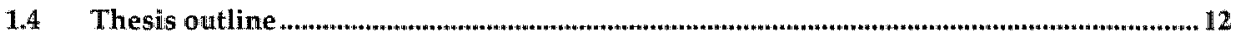

2 RESEARCH ISSUES ARTICULATED $\ldots$

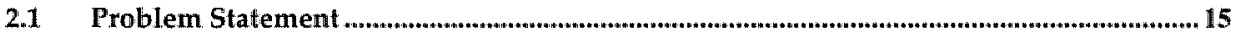

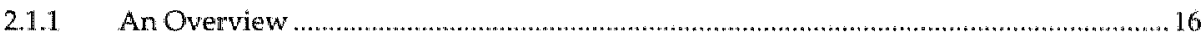

2.1.2 Some Sub-Saharan African experiences in agricultural R\&D, extension and

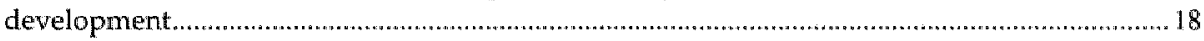

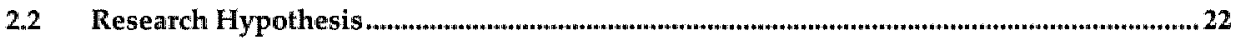

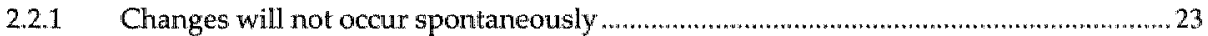

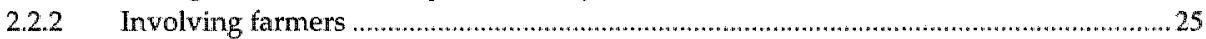

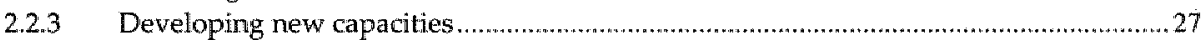

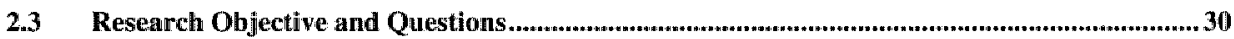

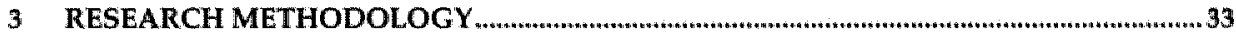

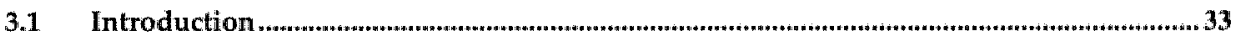

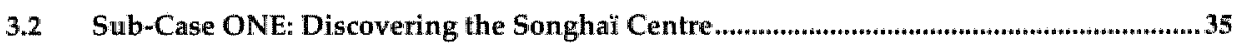

3.2.1 The Songhai Centre as a unit of analysis ..................................................................... 35

3.2.2 Sources of evidence, nature of the data and collection procedure...................................36

3.2.3 Data analysis ................................................................................................................. 37

3.3 Sub-Case TWO: The Songhail Training Framework ..................................................................39

3.3.1 The training programme as a unit of analysis ................................................................. 39

3.3.2 Sources of evidence, nature of the data and collection procedure.................................. 40

3.4 Sub-Case Study THREE: Farmers' Innovative Capacity .....................................................42

3.4.1 The Songhai farmers as units of analysis .................................................................42

3.4.2 Sources of evidence of the data and collection procedure ..........................................4. 43

3.4 .2 .1 The interview guide - research questionnaire .....................................................43 


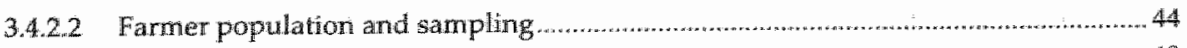

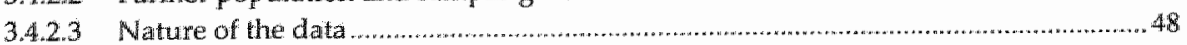

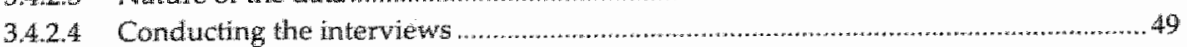

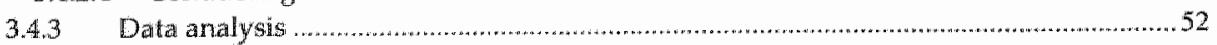

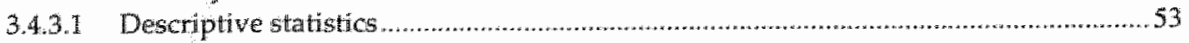

3.4.3.2 Inferential statistics................................................................................................. 53

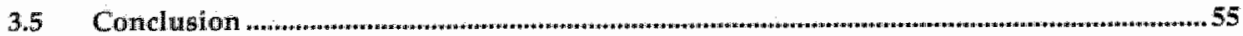

4 INNOVATION AND ENTREPRENEURSHIP THEORIES ...................................................... 56

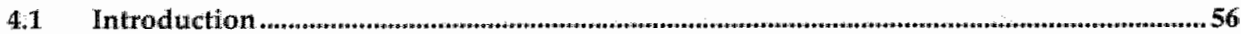

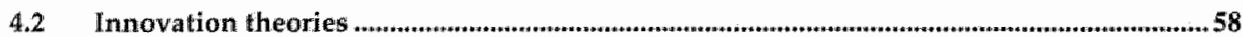

4.2.1 The role of agriculture in the development process ............................................................58

4.2.2 Theories of agricultural development in poor countries ............., .................................59

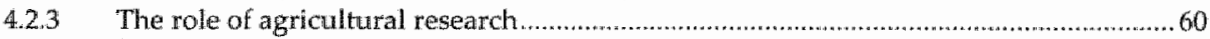

4.2.4 Definition and domains of innovation.........................................................................61

4.2 .5 Contextual definition of innovation ..................................................................................63

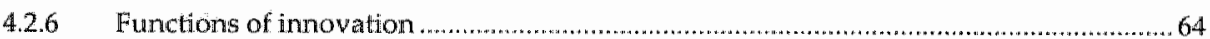

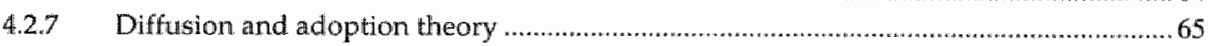

4.2 .8 Channel for agriculltural innovation diffusion ............................................................67

42.9 Linear models of innovation: An overview .......................................................................68 68

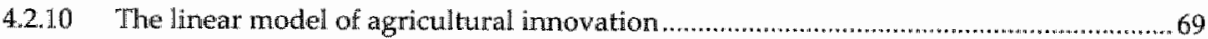

4.2.11 Participatory approaches in agricultural innowation processes.....................................70

4.2.11.1 Farming Systems Research (FSR) ................................................................................

4.211.2 Participatory Technology Development (PTD) and On Farm Research (OER) .............. 72

4.2.11.3 Participatory Action Research (PAR) .........................................................................72

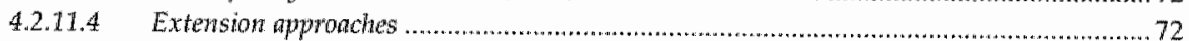

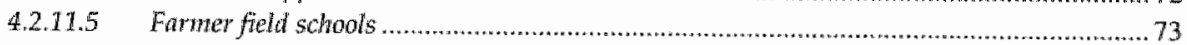

4.2.12 Impacts of participatory research and extension approaches .........................................73

4.2.13 Questioning participatory research and extension approarlizes .......................................74

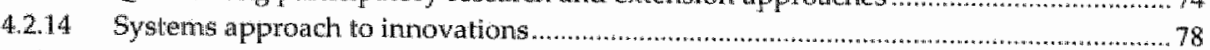

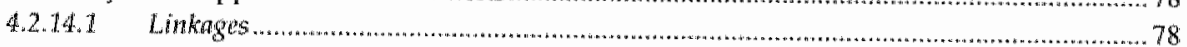

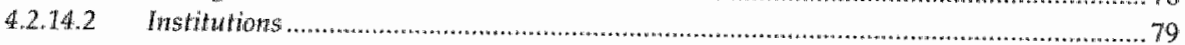

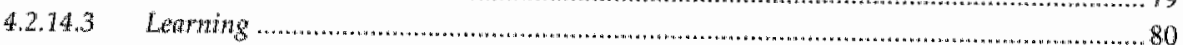

4.2.15 Applying the National System of Innovation (NSI) Approach in developing countries 81

4.2.15.1 National agricultural innovation systems (NASS) .............................................. 8

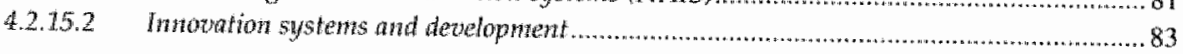

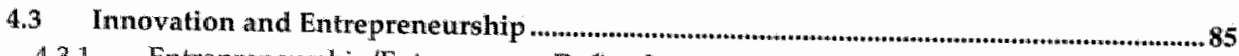

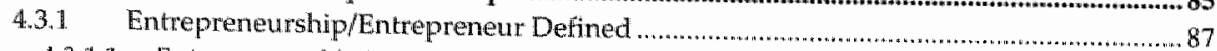

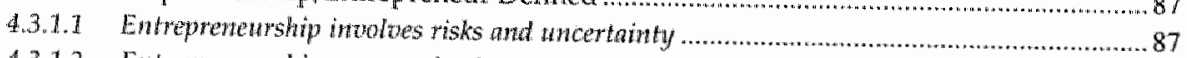

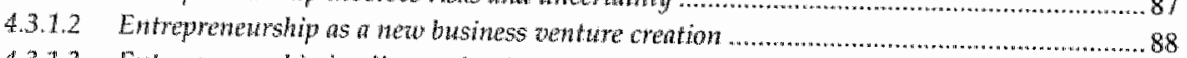

43.1 .3 Entreprenewrship implies production and distribution mangement activities .....................88

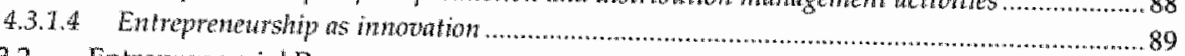

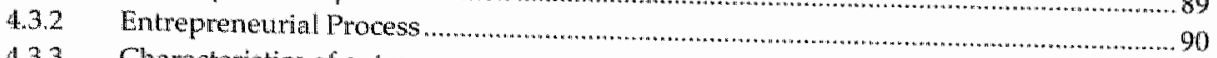

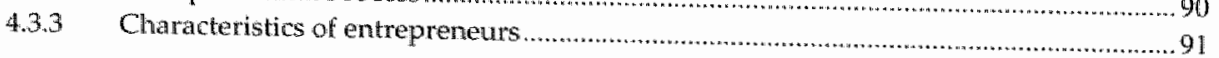


4.3.4 Promoting entrepreneurship ....................................................................................... 91

4.3.4.1 Entrepreneurs are "born" ............................................................................................... 91

4.3.4.2 Entrepreneurs are "made"

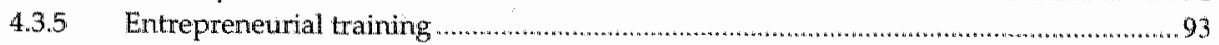

4.3.5.1 The pedngogical process of entreprenential training ..................................................... 93

4.3.5.2 Pedagogical content of entreprenetrial training ................................................................95

4.4 Discussion and concluding remarks................................................................................................97

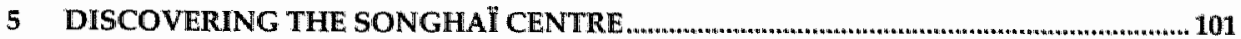

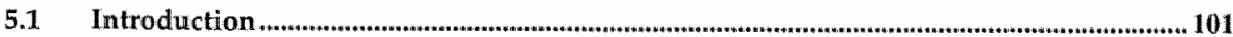

5.2 Genesis of Songhaï and its expansion................................................................................... 104

5.2.1 Rationale for founding Songhaï ............................................................................... 104.

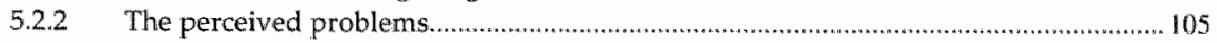

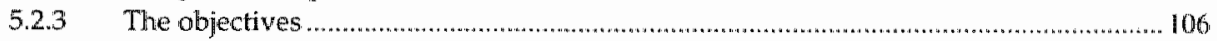

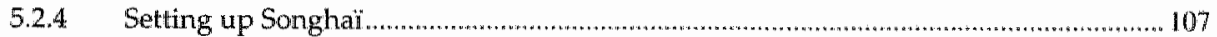

5.2.4.1. Sources of inspiration ........................................................................................... 108

5.2 .4 .2 Beginning from Benin ................................................................................................. 109

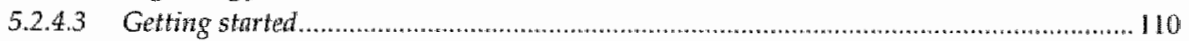

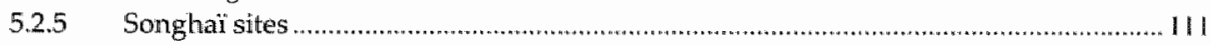

5.2.5.1 The Songhai site of Porto-Novo ..................................................................... 111

5.2.5.2 The Songhai site of Savalou .........................................................................................112

5.2.5.3 The Songhaï site of Parakou ..................................................................................... 112

5.2.5.4 The Songhai site of Lokossa and Kinwedji ................................................................ 112

5.2 .5 .5 The Songhai site of Kpomasse .............................................................................. 113

5.2.5.6 The Songhai site of Delta Amukpe (Nigeria) ............................................................. 113

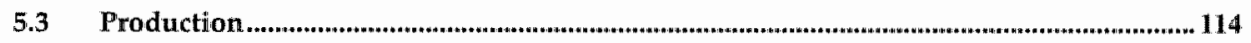

5.3 .1 The basic integrated production system ......................................................................... 114

5.3 .2 Processing and mechanical production .................................................................. $\| 18$

5.3.3 The complete integrated production system ........................................................ 118

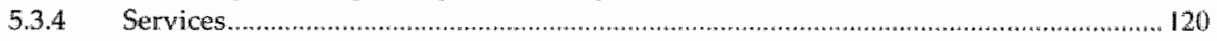

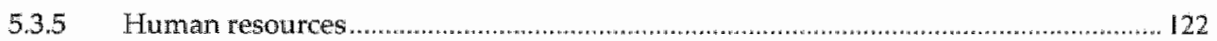

5.3.6 Organisation and managerial structure ................................................................. 126

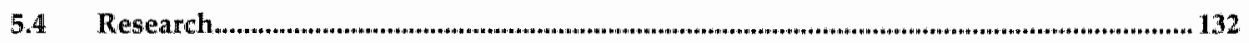

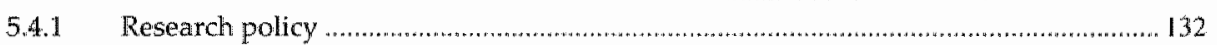

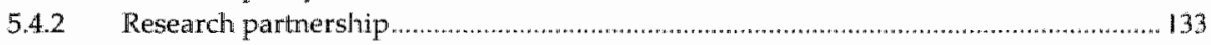

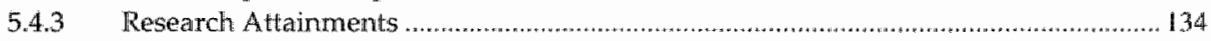

5.4.3.1 Reseanch results in terns of technologies and innovations .......................................... 134.

5.4.3.2 Simple machines and tools. socio-economic context friendly ........................................ 135

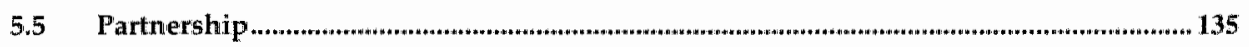

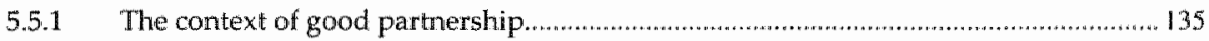

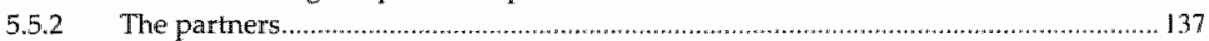

The African Foundation for Development (AFD) .................................................................. 137

The Cathalic Commission against Hunger and for Development (CCFD) .................................. 137 


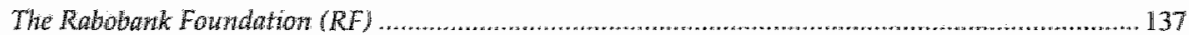

Association Solidarité Songhait - France ............................................................................................ 138

United States Agency for International Development (USAID) ................................................... 138

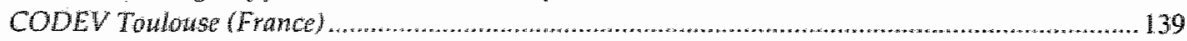

Society for International Development (SID): Experience sharing parthership ................................... 140

Writed Nations, Office of the High Commission of the Refugees (UNHCR) ....................................... 140

Colorado State University (CSU) ................................................................................................141

Research Centre for International Developntent (CRDD) and the Renewable Energies and

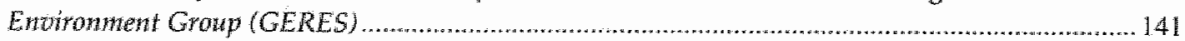

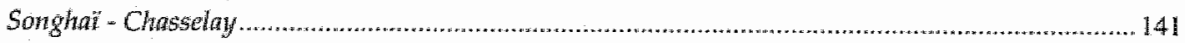

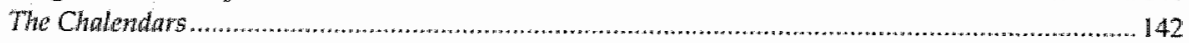

Programme d'Insertion des Sans Enplot dans l'Agriculture (PISEA) ........................................ 142

Appropriate Technology International (ATI) ....................................................................... 143

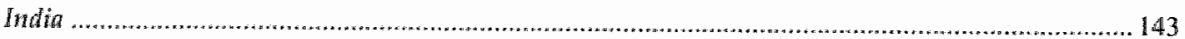

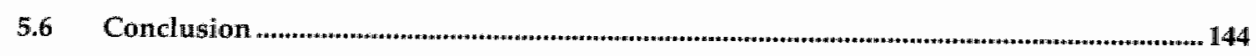

6 THE SONGHAII ENTREPRENEURIAL TRAINING PROCESS

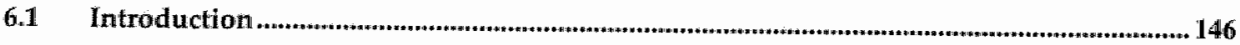

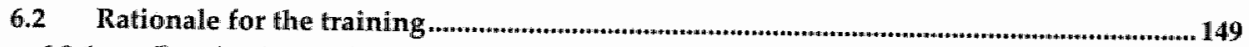

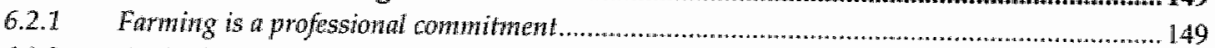

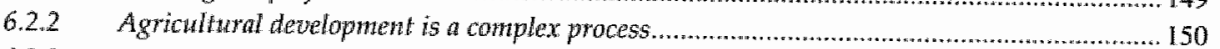

6.2 .3 An effective development of agriculture is a system work....................................................... 150

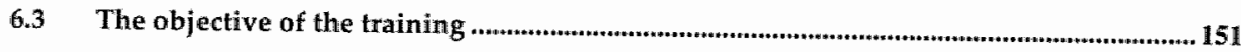

6.4 The content of the training/learning programme ............................................................... 153

6.5 The students - trainees - apprentices - learners ......................................................................158

6.5.1 Evolution of admission conditions and rationale for the changes................................. 158

6.5.2 Evolution of the tests and methods of selection of the candidates ................................... 159 6.5.3. Evolution of the number of admitted candidates and factors determining the changes
160

6.6 The training process: How one teaches and how one learns at Songhail

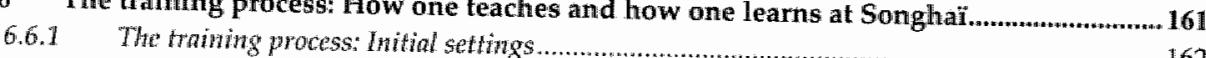

6.6.2 The training process: Current setting

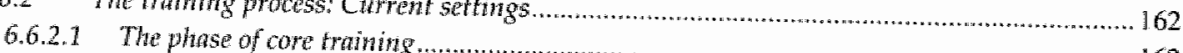

6.6 .2 .2 The phase of specialisation

6.6 .2 .3 The phase of applioation

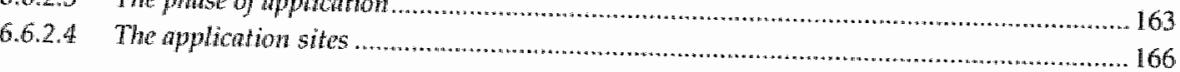

6.7 Evolution of methods of assessment during the training process........................................ 166

6.8 The educators - trainers - teachers - masters ...................................................................... 168

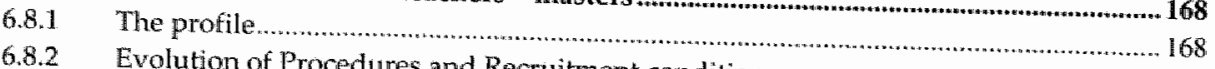

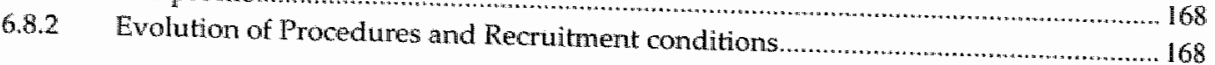


6.10 Some performance assessment during the training process................................................ 170

6.11 Short term training programmes

6.12 The follow-up or continuous training .................................................................................... 172

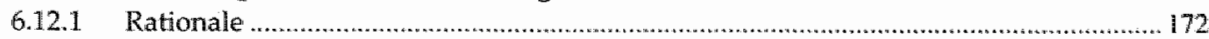

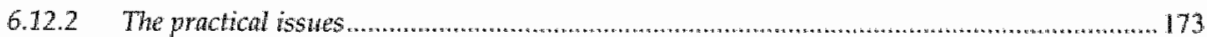

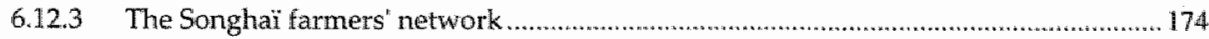

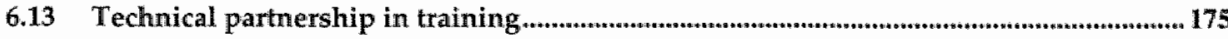

6.14 New prospects for the training process since January 2004 ................................................... 175

6.15 History and evolution of the subsidies and credits ............................................................ 177

6.15.1 Rationale of the subsidies and credits of Songhaii ....................................................... 177

6.15 .2 Objectives of the subsidies and credits ................................................................... 178

6.15 .3 First sources of financing ......................................................................................... 180

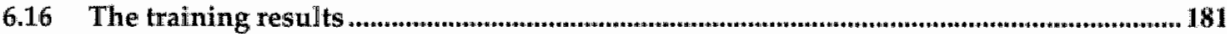

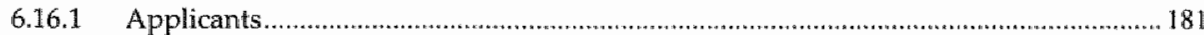

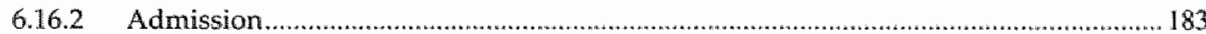

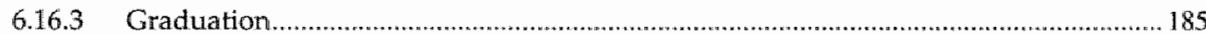

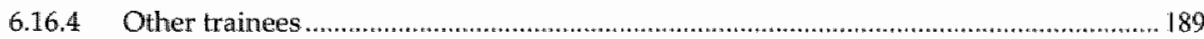

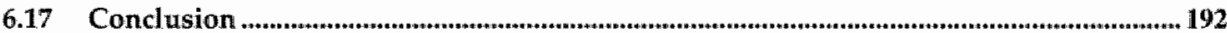

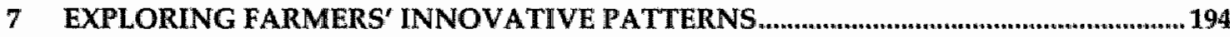

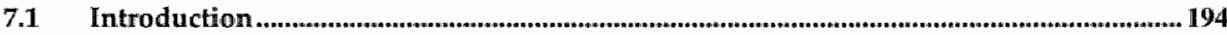

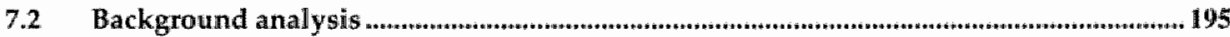

7.2.1 Regional distribution of the sample farmers................................................................ 195

7.2 .2 Educational level of the farmers .............................................................................. 196

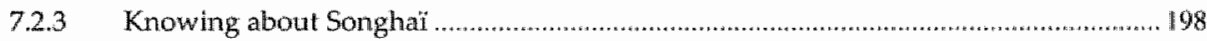

7.2.4 Facing the realities of the training process ....................................................................200

7.3 Getting started: mastering the means of production ...................................................................204

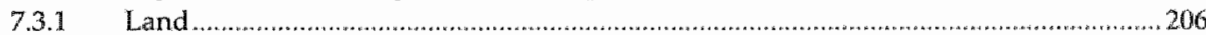

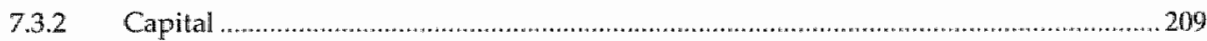

7.3.3 Production activities......................................................................................................... $2 \|$

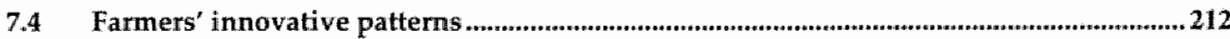

7.4.1 First producers and suppliers as innovators ........................................................... 212

7.4 .2 Integrated production practitioners as Innovators .................................................215

7.4.3 New Technology Users as Innovators ....................................................................217

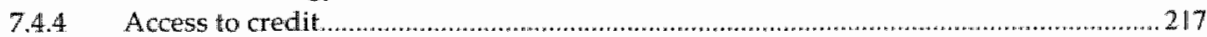

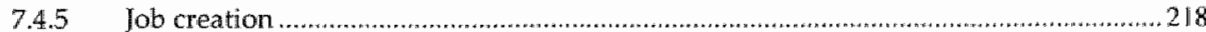

7.4.6 Surmounting competition: access to output markets ............................................220 
7.4.7 New ways of sourcing and harnessing information

7.4 .8 Farming enterprise function against farming production function.

7.5 Discussion and Conclusion. 230

8 ECONOMETRICAL ANALYSIS OF THE EMPIRICAL DATA. 233

8.1. Introduction 233

8.2 Specification of the variables.

8.21 LINNOV of the farmers.

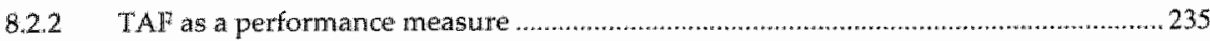

8.2.3 The independent variables ............................................................................................ 237

8.3 Empirical model specification for the analysis of variable TAF...........................................240

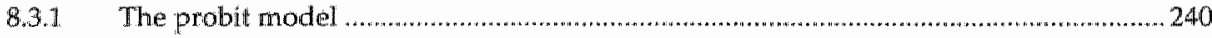

8.3.2 Empirical specification ................................................................................................241

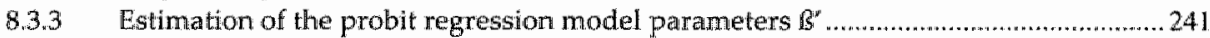

8.3.4 Clarification of some basic concepts ........................................................................... 242

8.3.5 Analysis and Interpretation of empirical results ...........................................................24 244

8.3.5.1 Goodness-of-fit or statistical significance testing for the whole model ................................. 244

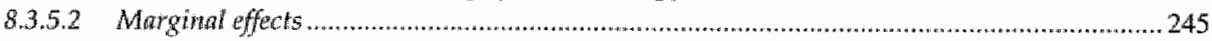

8.3.5.3 The inpact of information (ACD) on the variable TAF .......................................................247

8.3.5.4 The impact of access to credit or financial assistance (ACC) on TAF ...................................247

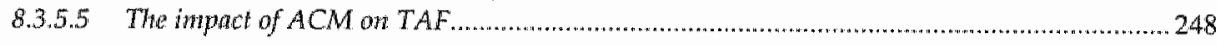

8.4 Empirical model specification for the analysis of variable LINNOV ...............................248

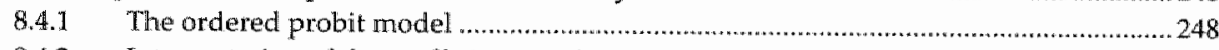

8.4.2 Interpretation of the coefficients and marginal effects in the ordered probit model ..250

8.4.3 Goodness-of-fit or statistical significance testing for the whole model ...................... 251

8.4.4 Impacts of variables IIC, ACC, ACI and ACM on dependent variable LINNOV ........ 251

8.4 .5 Impact of foctor zone (regron on LINNOV................................................................ 254

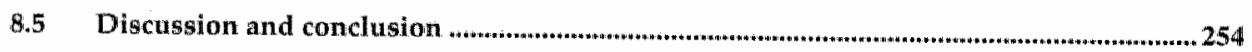

9 DISCUSSION AND CONCLUSION.

9.1 Introduction

9.2 Restating the problem.

9.3 Systern of innovation as a conceptual framework

9.4 Entrepreneurship theory as conceptual framework.

9.5 Empirical results

9.5 .1 The Songhai centre as unit of amaty

9.5 .2 The Songhaï training as unit of and

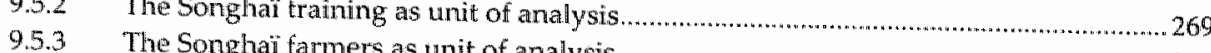

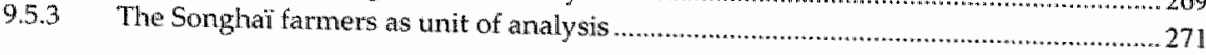




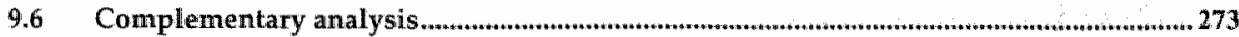

9.6.1 The strength of the Songhai training learning tranework ........................................ 274

9.6.2. Innovations drive innovations ............................................................................. 275

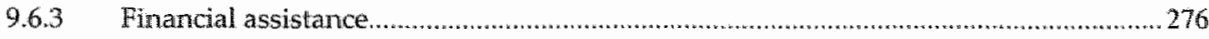

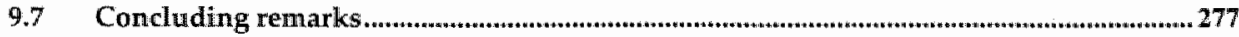

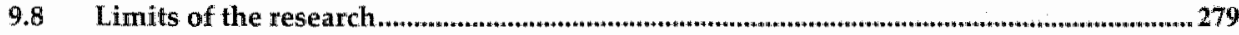

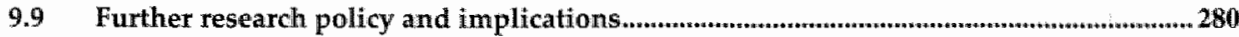

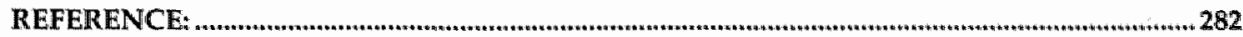

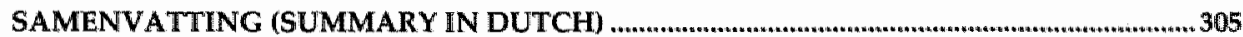

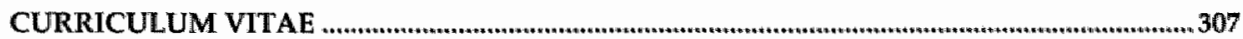




\section{List of tables}

Table 3.1: Distribution of farmers atcross their of settlement, 47

Table 5.1: Distribution of workers according to level of education and across production units, 124

Table 6.1. Admission patterns of all sites together - period of July/August 1999 to July 2003,183

Table 6.2: Shortterm trainees, 190

Table 6.3: Countries of origin of the short tem trainees, 190

Table 6.4: Summary data on application, admission and graduation at Songhaï, 191

Table 7.1: Regional and gender distribution of sampled farmers, 196

Table 7.2: Source of information about Songhai and its training programme, 198

Table 7.3: Additional training or course participation after graduation form Songhaï, 201

Table 7.4; distribution of farmers according to the sources and amount of their initial investment capital (IIC), 212

Table 7.5 Main production areas of the farmers, 214

Table 7.6: First producers and suppliers as innovators - distribution according to production activities and with respect to regions, 214

Table 7.7: Distribution of farmers engaged in ar integrated production system, 216

Table 8.1: Identified innovations at farmers' level and which serve for the base for the determination of variable LINNOV, 234

Table 8.2: Probit estimates of the empirical model for variable TAF, 244

Table 8.3: Marginal effects after probit for variable TAF, 246

Table 8.4: Ordered probit estimates for dependent variable LINNOV, 250

Table 8.5: Marginal effects after ordered probit estimates, 253

\section{List of figures/diagrams}

Diagram 5.1: The basic integrated production system, 116

Diagram 5.2: The complete integrated production system, 120

Figure 5.1: Relative distribution of the staff according to educational level, 123

Fugure 5.2: relative distribution of the Songhai staff across production departments, 125

Diagram 5.3: Organisational structure of Songhai until 1998, 128

Diagram 5.4: Organisational structure of Songhaï from 1999 to 2003,129

Diagram 5.5: Organisational structure of Songhail from 2003 onward, 131

Diagram 6.1: Songhaï training framework 152

Figure 6.1: Evolution of applications to the Songhai training programme, 182

Figure 6.2 Evolution of the number of female applicants, 182

Figure 6.3: Comparison of application and Admission patterns, 185

Figure 6.4: Comparison of trend of admission and graduation, 185

Figure 6.5: Comparison of the evolution of male and female farmer graduation rates, 186

Figure 6.6: Trend of female graduation rate on the three sites, 187

Figure 6.7: Trend of success and fiailure rates, 188

Figure 7.1: Percentage distribution of the farmers according to their level of education, 197 
Figure 7.2: Distribution of farmers according to the years of settlement, 205

Figure 7.3: Source of exploited lands, 208

Figure 7.4: Materialising farmers" enterprise function, 226

Figure 7.5: Materialising farmers' enterprise function continued, 229

\section{List of boxes}

Box 2.1: Summing up the problem, 21

Box 2.2: Summing up the hypothesis, 29

Box 2.3: Research questions, 32

Box 6.1: Is farming gender specific? 184

Box 7.1 Agricultural production requires endurance at work, 202

Box 7.2: The Songhai training has a payoff, 204

Box 7.3: Labour force matters, 218

Box 7.3: Credit and agricultural production cycle: some mismatches, 219

Box 7.5: They don't learn how to commercialise what they learn to produce, 222

Box 7.6: Farmers piercing new sources of information and knowledge 224

Box 7.7: Born entrepreneur or trained entrepreneur? 227

\section{Acronyms and abbreviations}

$\begin{array}{ll}\text { CBC } & \text { The Conference Board of Canada } \\ \text { CGIAR } & \text { Consultative Group on International Agricultural Research } \\ \text { CIRAD } & \text { Centre de Coopération International en Recherche Agronomique pour le } \\ & \text { Développement } \\ \text { CMAWCA } & \text { Conference of Ministries of Agriculture of West and Central Africa } \\ \text { DANIDA } & \text { Danish International Development Agency } \\ \text { FAO } & \text { Food and Agriculture Organisation } \\ \text { IITA } & \text { International Institute for Tropical Agriculture } \\ \text { ILO } & \text { International Labour Organisation } \\ \text { INRAB } & \text { Institut National des recherches Agricoles du Bénin } \\ \text { ISNAR } & \text { International Service for National Agricultural Research } \\ \text { LDC } & \text { Least Developed Country } \\ \text { NARS } & \text { National Agricultural Research System } \\ \text { NGO } & \text { Non Government Organisation } \\ \text { RENAFERS } & \text { Réseau National des. Fermiers Songhaï } \\ \text { SPAAR } & \text { Special Programme for African Agricultural Research } \\ \text { SSA } & \text { Sub-Saharan Africa } \\ \text { UNDP } & \text { United Nations Development Programme } \\ \text { USAID } & \text { United States Agency for International Development } \\ \text { WARDA } & \text { West Africa Rice Development Association }\end{array}$




\section{Executive Summary}

The Ph.D. is entitled "Learning to Innovate: The Case of Songhail Agricultural Entrepreneurs in Benin". In essence, it is about how to enhance economic growth and development at the grassroots in the poorest countries. At the outset, the study reviews several theories of economic development. It draws the view that the least developed countries, mostly those in which agriculture and related activities employ the bulk of the active population, cannot take off economically unless their developmental policies adequately address the sector. Hence, it poses the question of how agriculture develops. It argues that this can happen when actors concerned with agricultural production and development successfully create, develop, diffuse and apply new knowledge to dismantle unproductive practices and replace them with more efficient ones.

Yet, most of the existing approaches to agricultural innovation processes, defined as those allowing farmers to gain and apply new knowledge on their farms, are flawed. They encompass some mythical baggage that shifted attention from the real needs of the farmers in developing countries. The institutional settings in which they are embedded have done little to allow farmers to become innovators. People substitute themselves to the farmers who they want to empower and whose problems they want to solve through "artificial" mechanisms of involving them in research, listening to them and giving them voice. Inescapably, the processes of agricultural innovation are weak and inefficient while innovations are not spread to the majority of the farmers.

In effect, new technologies and practices are unfamiliar by definition and their adoption is not the terminal stage in a multi-step process. New technologies lead to the expansion of production beyond subsistence level requiring conservation, processing, packaging and marketing of the excess. They have a wider impact and require more abilities and competencies that farmers may not have been able to build alone. Farmers need inmovative skills, which are the underlying factor of the advancement of human undertakings. Participation in research and extension activities does not make the farmers into innowators. Listening to farmers or giving them a voice is not what enables them to gain new knowledge and apply it to their businesses.

In essence, each individual in a society has a voice that he must endeavour to make heard. For example, history teaches that in today's most advanced democracies, men didn't give women the right to vote. Women had to fight to make their voice heard as they were becoming more educated, learned and knowledgeable. One needs to fight to make his voice heard. To win the battle, individuals need to have and use the right weapon. Knowledge of all kinds is, by excellence, what represents the entire weapon. No one can empower farmers; only the knowledge that farmers can acquire and apply can empower them. Farmers need institutions that embed them in training processes whereby they can learn and gain skills and competencies defined as innovative capacities. These capacities are dynamic, meaning that the skills and competencies should be perpetually updated to cope with the dynamics of the overall social and 
economic changes. The study conceptualises agricultural development as challenges to surmount instead of problems to solve. It argues for the "unplugging" of development processes. This means "getting back to basics", which implies examining knowledge and its application as the comerstone for innovation processes.

This study investigates new ways of enhancing innovations to all categories of farmers. It argues that much of the basic knowledge farmers need could be imparted through training programmes that prepare them to operate in increasingly sophisticated input and output markets. The main objective of the study is to determine how a training model can become a major contributor towards enhancing farmers' innovative capacities. This is made an explicit case through the lens of a systems approach to innovations and entrepreneurship theories.

Taking an innovation systems perspective, the study suggests that the capacity to innovate involves creating linkages, institutions, policies and incentives that encourage learning and knowledge sharing. It is neither enough to admit multiple sources for agricultural innovations nor it is sufficient to acknowledge that socio-economic and political factors have a bearing on innovation processes. The recognition that interactions between actors that comprise the innovation system affect its performance is just a necessary condition. The strong correlation between innovative performance and the institutional environments that trigger interactions and promote learning lies in the importance of knowledge as the factor driving innovations and development. As elements of the agricultural innovation system, farmers must have certain knowledge that grants them capacity to make sense of the information (as an input resource) they receive by interacting with others.

However, the innovation system approach lacks clarity about the notions of interactions and relationships. This study argues that interactions are purposive and needs-based. It is the economic agents going about their own production and innovative activities who find themselves in the position to get involved in relationships (of receiving or offering something) if they are to succeed. Further, it contends that even if institutions can emerge spontaneously as self-grown, they stem from the system components and cannot survive if they do not promote innovations and if they are not desired by the elements of the system. Arguing that neither institutions nor organisations exist without people, the study puts individuals at the heart of innovation processes.

Because entrepreneurial behaviours are innovative by definition, entrepreneurship theory is used to supplement the innovation system framework. Innovations constitute the underlying factor of entrepreneurship defined as a process of search, discovery and economic exploitation of what people have so far overlooked. It means that those involved in the process have the ability to carry out new combinations that meet market needs. It implies that market deficiencies exist and can be perceived only by those capable of transforming them into supply. What make individuals into entrepreneurs are their innovative activities. 
Though many factors affect entrepreneurship, entrepreneurial education constitutes a key determinant for successful entrepreneurship. The desired training should focus on both theoretical and practical aspects of entrepreneurial behaviour but with greater emphasis on practical issues in a real environment. The belief is that entrepreneurial dynamics at farmers" level will revitalise interactions among national agricultural innovation system components while contributing to strengthening linkages. With entrepreneurial skills, farmers gain innovation capacities and economic competencies. Thus, the promotion of agricultural entrepreneurship is the direct enhancement of successful agricultural innovation processes.

Finally, what this study aims at and stresses is that, in addition to technical "know-how", farmers need the "know-who", "know-where", "know-what", "know-when" and "know-why". As a matter of academic research requirement, an empirical study was carried out to investigate the consistency of what $I$ believe to be true when contrasted to field realities. An appropriate educational institution was identified: the "Songhai Centre" or "Songha" provides the expected framework for analysis. The empirical research design follows the case study method. While it wants to investigate the innovative capacity of Songhai farmers (the targeted case) as a result of their full-time enrolment in the training programme, it first describes and presents the Songhail Centre as a first sub-case, followed by the traming programme as a second sub-case.

The Songhai centre is a socio-economic and rural development actor specialising in agricultural production, research and training. It is an integrated production system based on minimal imputs and the use of local resources. Wastes from one production unit become inputs for others, and production activities become more profitable because they belong to the system in which the different components strengthen each other through what they provide to, or receive from, others. Yet, the main goal of Songhai lies in the founder's conviction that the best way to help poor people is to transform them into dynamic producers struggling for permanent effectiveness. The social process through which this transformation happens is central to Songhaï undertakings: agricultural entrepreneurial training.

Songhai training aims at promoting agricultural entrepreneurs and professionals technically prepared in agricultural and related activities while strongly equipped with ethic and moral values. They are general-purpose managers with leadership capacities and who are willing to transmit their knowledge to others. The principal merit of the Songhaï training process consists of setring up an apprenticeship framework and pedagogical follow-up based on traditional systems, which combines new knowledge, know-how and know-being. The peculiarities and efficacy of the training lie in the fact that it is truly based on the realities of a business organisation. The range of activities carried out in the various production units constitute the framework and support for the teaching. Songhai seems to shine by the uniqueness of its production and training frameworks. The question arises about how its graduates, who have set up their own farming enterprises, have demonstrated innovative behaviours. 
The concept of innovation is broad and generally denotes commercial exploitation of something new or its exploitation for commercial purpose. This spectic character of innovation, explains why the analysis placed it in its historical context of entrepreneurship. The argument is that whatever the source of any "new thing", in general, it is through business mechanisms it becomes innovation - in addition to technical and production knowledge, access to input and output markets and information matters. Empirical data was obtained from in-depth intervews based on an open-ended questionnaire with 75 randomly sampled farmers who were trained in agricultural entrepreneurship at the Songhaï Centre in Benin. Both qualitative and quantitative analyses were performed.

The qualitative analysis of the data concludes that the entrepreneurial training has built up the innovative capacity of farmers. "This includes their ability to adopt new "peadymade" agricultural technologies and handle the resulted outputs, in addition to implementing new combinations of existing farming production inputs or combining new agricultural inputs in the production of goods and services, some of which are new to the localities or the farmers themselves. The analysis equally reveals that many farmers have demonstrated abilities in mastering inpul resources needed for their businesses; they have been competitive, owing to the quality of their products, new distribution channels or new marketing tools they use. Most of the farmers could deliberately search and connect to networks of information at various levels.

The quantitative analysis builds upon two defined innovation performance variables. They constitute the dependent variables and include the farmers" "level of innowativeness" and the "trend of farmers" assets". Ordered probit model and probit model are used respectively to predict the probability that change in a selected explanatory variable will affect them. Variables embodying the past skills of the farmers and the characteristics of their environment of settlement have shown no statistical significant effects. Variables reflecting post-training competencies do affect both dependent variables.

"The study also brings highlights that entrepreneurship training breaks the mould of traditional methods of obtaining information and learning based on inter-generational transfer of farming knowledge and skills. Many people who are considering a farming career may not come from farm families and thus, lack the tools or experience to make effective decisions about farm entry. Finally, conceptualising innovation in system terms, the study shows that agricultural entreprenewrial training grants the learned farmers innovative capacities, without which other attempts to enhance continuous innovation processes at the level of all categories farmers would be unfruitful. 



\section{Introduction}

\subsection{Motivation}

My strong interest in economic development studies is rooted to my time in the Slovak republic from 1988-1995, where I undertook Master of Sciences degree studies at University of Economics in Bratislava after being awarded a scholarship by the government of Benin. In comparison with Africa, the level of economic development in the European countries I visited, both Eastern and Western, amazed me. Once back home and working in Benin, I was constantly preoccupied with understanding the process by which sound economic growth leading to development emerges, and how it can be applied to the least developed countries. My field of specialisation did not provide answers to the many questions I had, and I needed to abandon it. I had to turn my back on Accounting \& Management, Statistics and Progranming, though these important tools granted me an advantage in my new field of interest: "I search for the concrete within the abstract"; and I look for the practical within the theoretical.

\section{Becoming a "Doctor of Economy"?}

Above this desire and enthusiasm to bring an intellectual contribution to, at lleast, part of my region, the situation itself has long-been a compelling topic. A joint report (quoted in Todaro and Smith, 2002, p.C18.12) by the International Institute for Environment and Development and the World Resources Institute expressed it well: 
"Sub-Sahtaran Africa poses the greatest challenge to world development efforts to the end of the century and beyond. Recurrent famine there is only the symptom of much deeper ills. Africa is the only major region where per capita income, food prodnction, and industrial production haze declined over an extended period: the only developing region where development appears to be moving in reverse. . In recent years, Africa's farners and herders, its soils and forests, hawe been chasing each othey down aicious spiral of environmental degradation and deepering poxerty. Conven wional development efforis by donors and governments hase largely failed to halt the spital, indeed in some cases have aggravated it."

Todaro and Smith (2002) restate and comment on the issues as follows:

"While most of the developing world has registered significant development progress since 1990 ... By the early twenty-first century, no clear sign of a twrnaround had yet been seew. At the heart of the African dilemm is an inexorable economic decline... and the inability of many countries even to feed their people and weet other basic fumam needs" (Todaro and Smith, 2002, P.C18.12).

In effect, as I was explaining to some people in my village that I was going for further studies in order to become doctor in "how to advance a country", their reactions were very pertinent and can be expressed and summarised in two questions:

a) Will you be able to make the right diagnosis about what went wrong in our country's economy?

b) Will you be able to prescribe the right medicines to cure the illness?

Similar reactions came from other villagers I met during my field research. The overall awareness that something was wrong in the country was obvious. They were also aware that there were attempts to address the issues, which had little effect or resulted in failure. They showed little concern for aggregate indicators that may not have direct impacts on their daily lives; instead, they were interested in knowing what they could do to meet the basic needs of their families. Naively I dreamed of learning about some package of tools enabling a precise diagnosis of constraints to a country's economic development. I dreamed of knowing the best remedies...

Yet, understanding the causes of economic development and the formulation of specific prescriptions to generate economic growth in an interdependent world is more complex. As Todaro and Smith (2002) put it, development economics has no universally accepted paradigm. Insights and understandings are continually evolving while each theory, principle or concept has some strengths and weaknesses. Indeed, by the end of World War II, the time was ripe for development studies to flourish: economies had to be reconstructed, colonies 
were emancipating themselves, and the two superpowers (the USA and Soviet Union) competed with each other to extend their influence throughout the developing world (Guillén, 2001). From the linear theory (1950s and 1960s) to neoclassical, free-market theories (late 1980 s and 1990s), through structural change models (1960s and 1970s) and international dependence theory (Todaro and Smith, 2002), it also includes some recent approaches such as globalisation theories (Guillén, 2001), the innovation systems approach to development (Johnson et al., 2003), and the new trends in development rethinking (Stein, 2003; Gregersen, 2004). For the purpose of this research, I will provide a fundamental brief of the theoretical approaches that have guided development practitioner thought through different periods.

\subsection{Economic development theories as diagnoses and medications}

\subsubsection{Classical liberal theory}

In classical liberal theory, development is understood as economic growth and capital-formation. The right quantity and mixture of savings, investments and foreign aid is necessary to enable developing nations to proceed along an economic growth path historically followed by the more developed countries (Todaro and Smith, 2002). Rostow (1960) is viewed as the most influential and outspoken advocate of the doctrine of stages-of growth model of development. He assumed that countries evolve from "undeveloped" to "developed" via five stages as long as the right value incentives are in place: traditional society, preconditions for take-off, take-off, maturity, and high mass-consumption. Each stage is a prerequisite for the next because new political, economic, and social institutions enable more economically advanced and differentiated activities over time (Guillén, 2001). Unfortunately, this model has revealed its limitations as a developmental path for the current third world. Though necessary, savings and investments are not sufficient conditions for for growth (Todaro and Smith, 2002).

\subsubsection{International dependence theory}

During the 1970s, international dependence theories viewed developing countries as being beset by institutional, political and economic rigidities, both domestic and international, and caught up in dependence and dominance relationships with rich countries, with three major streams of thought (Todaro and Smith, 2002). Dependence is defined as the conditioning situation in which economies of one group of countries are conditioned by the development and 
expansion of others (Todaro and Smith, 2002). Neo-coloniall dependence models, false paradigm models and the dualistic development thesis constitute the three major streams of thought in international dependence theories.

Neo-colonial dependenice models, for example as Theotonio Dos Santos (1969) has developed (Todaro and Smith, 2002), view underdevelopment as a consequence and a particular form of capitalist development. Rich and poor countries are involved in a relationship of interdependence within a world trading system. Dominant countries are endowed with technological ${ }_{x}$ commercial capital and socio-political predominance over poor countries and can therefore exploit them, and extract part of the locally produced surplus (Todaro and Smith, 2002, p.124). At the end, an automatic mechanism is created, which accentuates the situation of wealth of advanced countries while it suffocates the economies of the less developed countries.

The False Paradigm Models attribute backwardness of poor countries to faulty and inappropriate advice provided by well-meaning but uninformed, biased and ethnocentric international experts and advisers from assistance agencies in developed countries and international donor organisations. They offered sophisticated concepts, elegant theoretical structures and complex econometric models that often lead to inappropriate or incorrect policies (Guillén, 2001). The False Paradigm Model contends that developed countries have good intentions of helping the developing countries, but their policy advice is simply inappropriate in the context of developing countries. It is argued that these policies failed to incorporate the unique social, cultural, and institutional characteristics of the developing countries (Todaro and Smith, 2002).

The dualistic development thesis conceives dualism as representing the existence and persistence of increasing divergences between rich and poor nations, and rich and poor people on various levels. The coexistence and interaction of powerful and wealthy industrialised nations with weak impoverished peasant societies is also described as the relations interactions between superior and inferior elements in the world economy. It is argued that the existence of the superior element does little or nothing to pull up the inferior element, let alone "trickle down" to it. In fact, it may actually serve to push it down to exacerbate its underdevelopment (Todaro and Smith, 2002, p.126).

Finally, dependence theorists believe that only an autonomous state bureaucracy capable of imposing logic of import-substitution industrialisation can offer a feasible solution to dependency in the long term (Guillén, 2001, Todaro and 
Smith, 2002). Consequently, policies were consciously designed to discourage imports and promote local production. In practice however import-substitution appeared inefficient due to lack of experience in applying new technology, limited competition, insufficient scale of production, and diversion of resources away from agriculture and export-oriented activities (Guillén, 2001).

\subsubsection{The neoclassical theories}

The central argument of neoclassical theories is that underdevelopment results from poor resource allocation due to incorrect pricing policies and too much state intervention by overly active developing-nation governments. Neo-liberals contend that both economic efficiency and economic growth will be stimulated by permitting competitive free-markets to flourish, privatising state owned enterprises, promoting free trade and export expansion, encouraging foreign direct investments (FDI) from developed countries and eliminating the plethora of government regulations and price distortions (Guillén, 2001; Todaro and Smith, 2002). The free-market approach, the public choice or new political economy approach, and the market-friendly approach are three approaches that underlie the neo-liberal theories (Todaro and Smith, p.128-129):

Free-market analysis argues that markets alone are efficient. They provide the best signals for investments in new activities in an automatic way. Labour markets respond to new industries in appropriate ways. Producers know best what to produce and how to produce it efficiently. Product and factor prices reflect accurate scarcity values of goods and resources now and in the future. Competition is effective, if not perfect; technology is freely available and nearly costless to absorb. Information is also perfect and nearly costless to obtain. Under these circumstances, any government intervention in the economy provokes distortion and is counterproductive. Free-market development economists have tended to assume that developing-world markets are efficient and that whatever imperfections exist are of little consequence.

Public-choice theory, also known as the new political economy approach, goes even further to argue that governments can do nothing right. It assumes that politicians, bureaucrats, citizens, and states act solely from a self-interested perspective, using their power and the authority of government for their own selfish ends. The net result is not only a misallocation of resources but also a general reduction of individual freedoms. The conclusion, therefore, is that minimal government is the best government. 
The market-friendly approach is the most recent variant on the neo-liberal theories. It recognises that there are many imperfections in least-developed countries (LDC) product and factor markets. It also recognises that governments do have a key role to play in facilitating the operation of markets through "non-sellective" (market-friendly) interventions. Governments may intervene for example, by investing in physical and social infrastructure, health care facilities, and educational institutions and by providing a suitable climate for private enterprise.

Robert Solow (1957) crafted a model (theory) that kept diminishing returns to capital and labour, but which added technical knowledge as a third factor. The model pictured technology as a continuous, ever-expanding set of knowledge elements that simply became evident over time and not something that was specifically created by economic forces (Cortright, 2001). Because technology was assumed to be determined by forces outside the economy, the Solow's model is often referred to as an "exogenous" model of growth.

This model, as well as other neoclassical theories, implies that there are relatively limited opportunities for governments to promote economic ends, other than encouraging market competition, providing adequate schooling and encouraging savings and investment (Cortright, 2001). Moreover, phenomena such as missing and incomplete information, externalities in skill creation and learning, and economies of scale in production are also endemic to LDC markets. In fact, it is the recognition of these last three phenomena that gives rise to the newest schools of development theory, the endogenous growth school of thought.

\subsubsection{New growth theory or endogenous growth theory}

The new growth theory is meant to explain persistent economic growth. Romer (1986) is credited with stimulating new growth theory (Cortright, 2001). It views technological progress as a product of economic activity. New growth theory is often called endogenous growth theory because it internalises technology into a model of how markets function. It also holds that unlike physical objects, knowledge and technology are characterised by increasing returns, and these increasing returns drive the process of growth. Hence, increasing knowledge rather than labour or capital creates opportunities for nearly boundless growth. New grow th theory helps us understand the ongoing shift from a resource-based economy to a knowledge-based economy. It underscores the point that the economic processes which create and diffuse new knowledge are critical to shaping the growth of nations, communities and individual firms. 
The new growth theory challenges the neoclassical model in many important ways as Romer, himself, points out:

"... No anount of savings and imvesthent, wo policy of macrocconomic fine-turning, no set of thax and spending incentives can generate sustaned economic growth whess it is accompantied by the countless large and small discoveries that are required to create more walke from a fixed set of natwral resources" (Romer 1993b, p. 345 quoted in Cortright, 2001).

New growth theory implies that knowledge constitutes the source of economic progress. Indeed, Grossman and Helpman (1994) point out that, basically, there has always been the same stock of physical resources in the economy. Higher standard of living stems from improved ability to rearrange these physical objects into forms that provide greater value. New growth theory implies an increase in living standards for centuries to come by steadily improving knowledge of how to increase production and quality of goods and services with ever smaller amounts of physical resources. Competition is not based on cutting prices, but on augmenting product characteristics such as variety, quality, features and introducing new products (Cortright, 2001).

New growth theory has a number of practical implications for economic development policy. It underscores the importance of investing in new knowledge creation to sustain growth. It emphasises the role that institutions and policies can play in creating the circumstances for innovation and the diffusion of knowledge (Cortright, 2001). Policymakers will need to pay careful attention to factors that provide incentives for knowledge creation and utilisation. These include research and development, education, business and the tolerance for diversity, macroeconomic expectations, and openness to trade. New growth. theory asserts that ideas of all kinds, large and small, play a role in economic growth while states and communities have the power to influence their economic destiny (Cortright (2001).

\subsubsection{Rethinking economic development and innovation system approach}

Markets alone cannot produce the set of conditions needed for the efficient function of a market economy (Olson 1996). New trends in development thinking and innovation system approaches assume and converge in putting learning for knowledge and capability building together with institutions and interactions between them at the heart of the economic development process (Johnson et al.; 2003). The issue is to shift the focus from market-supporting institutions to institutions supporting learning and innovation capabilities. That is, if institutions are at the root of economic development, they must create an 
enabling environment that triggers learning and innovation capabilities. The underlying argument is that economic growth and development rest on innovations as Jacobs (1969) put it some decades ago.

Our renote ancestors did not expand their economies much by sintyly doing more of what they had beert doing... They expanded their economies by adding new kinds of work... Innovating economies expand and develop. Economies that do not add new kinds of goods and services, but continue only to repeat old work, do not expand much nor do they, by definition, develop (Jacobs $1969 ;$ p. 49 quoted in Cortright, 2001).

North (1990) argues that the problem with neoclassical theory is that it fails to explain how successful economies come into being, and how they develop over time. Olson (1996) contends that the cumulative learning of societies reflected in culture, and the shared mental models of how the world works, guide people's interpretations of economic and political problems and opportunities. He stresses that beliefs about the value of new knowledge, risk taking, and the trust in social institutions influence the rate and type of economic growth in a society. In this respect, Romer (1994a) stresses that the creation of an institutional environment that supports technological change is of paramount importance for economic policy.

The condition is that not only are institutions important for the effective functioning of an economy at any point in time, institutions have had to change over time to produce the incentives and rules required by new markets and technology. The ability of institutions to adapt to the changing economic situation and to develop new rules and practices to guide transactions shapes the ability of economies to continue to progress (Cortright, 2001). In effect, North (1990) has argued that this adaptive efficiency, the ability of economies and institutions to change over time to respond to successive new situations, is the critical factor shaping economic development.

"Adaptive efficiency ... is concerned with the willingness of a society to acquire knowledge and learning, to induce innowation, to whtertake risk and creative activity of all sorts... The incentives embedded in the institutional framenork direct the process of learning by doing awd the development of tacil knowletge that will lead individuals in decision-making processes to evoline systems that are different from the ones that they had to begin with" (North 1990, p. 80-81).

Porter (1990) brought the insights that societies that sustain economic growth are those which create appropriate institutional conditions for the generation and use of new ideas and continuous adaptation to changing economic and technological circumstances. Thus, the process of creating skills and the important influences on the rate of improvement and innovation are, according to Porter (1990), 
intensely local. North (1995) espoused this view and pointed out that the set of feasible and effective policies and economic oppontunities available to one economy are likely to be very different from those in another. For communities, countries or regions, it is important to identify the existing and emerging knowledge strengths on which future development is likely to build. Within the framework of this research, follow this line of thought.

\subsection{Some recent approaches to agricultural innovations}

The role innovations play in economic development raised a growing recognition among researchers and policymakers that attention needs to be given to the circumstances from which these innovations emerge. Innovations are more than just new technologies and cover activities and processes associated with the generation, production, distribution, adaptation and use of new technical, institutional and organisational or managerial knowledge. Innovations also mean new ways of carrying out these activities and processes.

Actors concerned with agricultural development have recognised the limits of the conventional model of formal agricultural research and development (R\&D) as the central source of innovation (Hall et al., 2001). According to Biggs and Matsaert (1999), the contemporary setting in which agricultural research and rural development are embedded, poses some constraints on managers of R\&D systems in making a range of decisions for which old frameworks of analysis are inadequate. These old frameworks include economic rate of return, computer simulation models and conventional monitoring and evaluation. The induced model that Hayami and Ruttan (1981) have developed is an example. They assume that factor prices and user demand would induce scientists to develop technologies appropriate to farming contexts. As the model ignores the political and institutional context in which resource allocation decisions are made in R\&D, it did not yield the expected results (Hall et al., 2003).

A new way of dealing with the issue was to grant farmers some rolle in the process of technology development through participatory research and extension approaches. However, according to Biggs and Smith (1998), it is not the concept of participation that would give farmers a greater role in agricultural innovation processes. They argue that participatory methods would not lead to expected results unless the institutional context of research changes. Roling (1994) therefore developed the concept of Agricultural knowledge and information System (AKIS) while Lynam and Blackie (1994) provided a similar view and focused on the chain of technologies, institutions and policy that function as an 
effective system rather than as disarticulated parts (Hall et al., 2003). A recent way of thinking about the institutional context that will trigger agricultural innovation processes is the concept of innovation systems.

Innovation system framework emphasises the political, economic and social dimensions of knowledge production and use (Hall, 2002). An innovation system is defined as the set of organisations and individuals involved in the generation, diffusion, adaptation and use of knowledge of socio-economic significance and the institutional context that govern the way the interactions and processes take place (Hall et al., 2003). Research is part of a wider process involving a range of actors that have a bearing on innovation processes. Learning processes are seen as a way of evolving new arrangements specific to local contexts. Following Edquist (1997), Hall et al. (2003) argue that there is much empirical evidence to suggest that innovation performance is strongly correlated to institutional environments that promote learning. Consequently capacity development becomes a much more important objective of interventions that support innovation processes.

According to Clark and Mugabe (2003), the notion of capacity building has become a part of the developmental agenda comparatively recently and is now a primary objective in the mission statements of numerous international bodies. They argue that formerly, capacity was about management of structural adjustment through local ownership of resources, local human resources development and the relative avoidance of expatriate influences. However, capacity has more to do with governance and how institutional innovations can help ensure greater efficiency and accountability in mobilisation and comtrol of national resources (King, 1992). According to Clark and Mugabe (2003, p.68), production capacity incorporates resources used to produce goods at a given level of efficiency and given input combinations. These include equipment (capilal embodied technology), labour skills (operating and managerial knowhow and experience), product and input specifications and the organisational methods and system used. Technological capability building implies the process of acquisition, validation and use of knowledge, which has to be adapted to the context in which it is to be used within a changing institutional structure (Clark and Mugabe, 2003).

In general, an organisation's capacity is its ability to successfully apply its skills and resources to accomplish its goals and satisfy stakeholder expectations. The aim of capacity development is therefore, to improve the potential performance of the organisation (Horton et al., 2003). Capacity development is an ongoing 
process aiming at increasing one's ability to learn and solve problems, to carry out functions and achieve objectives. It includes being able to address current issues while also remaining relevant in the future (Horton et al., 2003).

Capacity development can take place at the micro level of individuals and project teams, at the meso level of organisations, and at the macro level of national economic and legal institutions. In his popular book entitled The Fifth Discipline (1990), Peter Senge championed the idea of organisational learning based on the notion that human minds in interaction are capable of transcending individual limitations (Horton et al,, 2003). Since then, many organisational specialists have emphasised the importance of strengthening the "soft side' of organisational capacity, including negotiation, communication, knowledge management, organisational learning and empowerment (Horton et al., 2003).

Evaluation studies conducted by ISNAR confirmed the observation that capacity development in research and development organisations is seldom systematically planned or managed (Horton et al., 2003). Capacities are usually built up over time as staff members are trained and gain experience as formal procedures are established. Where concerted efforts have been made to develop capacity, they have often been externally motivated and led (Horton et al., 2003).

Development agencies and donors have used numerous mechanisms to deliver capacity development programmes. Early attempts to develop capacity at the national agricultural research systems level often focused on 'hardware', such as the construction of facilities and the provision of basic equipment. Technical advisors from the North were often sent to lead capacity development programs in the South. Later on, capacity development efforts shifted to focus on 'software', including staff knowledge, skills, and attitudes. Major investments were made in personnel development through the provision of university-level education for developing country nationals in industrialised nations (Horton et al., 2003).

Formal education was later replaced with an emphasis on short-term technical training. Workshops were frequently organised to plan, undertake, or review capacity development efforts. This resulted in the proliferation of a "workshop culture' among research and development organisations, which increases dependency on external resources to convene these meetings and moderators to help plan and facilitate them. External agencies have also supported the dissemination of technical information to professionals in the South through scientific publications and, more recently, access to the Internet (Horton et al., 
2003). With increasing frequency, collaborative research and networking projects are being used as capacity development strategies. More recently, collaborative projects have tended to emphasize joint learning and sharing of experiences. Networks employing various mixes of face-to-face interaction and Internet exchange are greatly expanding possibilities for information exchange and learning within and between the South and North (Horton et al., 2003).

Development agencies have employed a variety of these delivery mechanisms in attempts to strengthen the capacities of research and development organisations in the South. However, both client and provider have often been disappointed by the results. In the field of agriculture, in particular, it is assumed that the agricultural innovation systems perform very poorly in Sub-Saharan Africa. Reasons for this frustration, and an alternative approach, are the focus of this research.

\subsection{Thesis outline}

The thesis is organised as follows. The opening three chapters introduce the topic; they identify the issues that should be borne in mind throughout the dissertation and how they are carried out. The theoretical chapter follows, which serves for the framework for analysis. Four empirical chapters precede the discussion and the conclusion.

Following the general introduction of Chapter one, Chapter two defines and articulates the research issues. It states the main problem the study addresses and presents the research hypothesis. It formulates the study objective and research questions. Chapter three then describes the empirical research design, which follows the case study method.

Chapter four discusses the theories and concepts that support the study. From a general definition of innovations, their domains and functions, it debates the diffusion and adoption theories with reference to agriculture. Essential in the debate is the sources of innovation that impels building upon a systems approach to innovations, highlighting its underlying concepts of institutions, linkages and learning. The chapter also discusses the national dimension of innovation systems and explores its applicability in the context of agriculture in developing countries. It follows that institutional settings that favour leaming to build innovative capacities at farmers level are required. Further, it is assumed that a way to enhance innovations for all categories of farmers is the link to agricultural entrepreneurship. The chapter reviews entrepreneurship theories and sets out a 
framework for identifying the skills, capacities and competencies that characterise an entrepreneur innovator. The question of whether entrepreneurs are "born" or "made" is discussed, leading to the argument that training can constitute a major determinant for the supply of entrepreneurs. Finally, it briefs some pedagogical models and contents of entrepreneurial training programmes.

The empirical research builds upon a study of farmers that have been trained in agricultural entrepreneurship in a given production, research and training centre in Benin: Songhaï. It uses a case study method to determine the innovation patterns of Songhaï farmers as "made" agricultural entrepreneurs. Three units of analysis compose the case study, including the Songhai Centre, the Songhai training/learning framework and the Songhaï farmers. A case study involving more than one unit of analysis is called an embedded case study. Within an embedded case study, each unit of analysis represents a subset called a sub-case study. In this research, each sub-case study is represented as an independent chapter.

Chapter five presents the sub-case of the Songhaï Centre, whose founding director assumed that raising living standards can go along agricultural development. In order to develop, agriculture itself requires embedding people in processes, which ensure them innovation capabilities, which cannot be the result of spontaneous or instinctive actions. It requires clear vision from which sound objectives can be derived.

In chapter six, the Songhail entrepreneurial training process is presented as a unit of analysis. It describes the illustration of how social and economic development objectives centred on agriculture are translated into actions. Entrepreneurship training is seen as a key factor for building up agricultural entrepreneurial skills and enterprise culture, as much as within an appropriate pedagogical framework adequate tools are used. More specifically, it is assumed that entrepreneurial behaviours are innovative, by definition, and the primary objective is to develop the trainee's capacities to innovate. By exposing its attributes, this sub-case also tries to understand the underlying philosophy.

Chapter seven analyses how the type of training matters in ensuring continuous flows of innovations at farmers" level. Using the Songhail farmers as units of analysis, it discusses evidence of their innovative behaviours as the results of their participation in the Songhail entrepreneurial training programme. The case answers the question: How have the Songhai farmers innovated? It assumes that the conditions in which the graduate farmers set up their agricultural businesses (the 
means and how they are acquired), the types of the activities and their evolution provide the ground to identify their innovation capacities.

Chapter eight is the last of the four that compose the case study. To supplement findings discussed in seven, it highlights other determinants of innovations. It defines two innovative performance variables and looks at a set factors likely to affect them within the farmers' business undertakings. Due to the difference in dependent variables two statistical models (probit and ordered probit) are considered, and the statistical package STATA is used to complete the computations. The ninth chapter discusses the results and serves as the concluding chapter of the stwdy. 


\section{Research Issues Articulated}

\subsection{Problem Statement}

The principal reason for economists to study science is the link between science and economic growth with technology as an intermediate step (Stephan, 1996). Science, technology and innovation have a history of advancements that have led to healthier, longer, wealthier and more productive lives. They are of strategic importance to economic opportunities, growth and economic development challenges (World Bank, 2003). Without scientific and technological knowledge and its supporting infrastructure, improved outcomes are not possible. The needed infrastructure is a mix of human capacity", hardware, institutions, incentives, policies and investments. Countries wishing to reap the benefits of science and technology should seek to put in place this broad infrastructure that captures existing knowledge, and employs it in wealth-enhancing investments and technology development for economic opportunities. Furthermore, the interaction between technology and skill is critical in determining productivity and growth. In the domain of agriculture, improved knowledge of plant biology and breeding techniques led to better seeds and cultivation practices that drastically increased yields. Advances in science and technology have also enhanced efficiency, and nutritional content in the world's food supply.

\footnotetext{
' Science and technology capacity is a multi-faceted ensemble of human, physical, organisational, institutional, and financial capital, which defies reduction to a single set of indicators (World Bank, 2003).
} 
For decades Sub-Saharan Africa (SSA) has faced the challenges of agricultural development. Even with a harsh and increasingly degraded physical environment characterised by climatic variability, marked dry seasons, fragile ecosystems and chronically low levels of soil fertility (Harrison, 1991), the continent could however, count on technical change to increase agricultural productivity and outputs. Indeed, conventional analysis asserts that to increase output, emphasis must be put on new technology generation and diffusion (Mellor, 1986). The premise for such optimism was that carefully implemented agricultural research could be an efficient source of agricultural knowledge, including better farming practices, biochemical products, mechanical equipment, crop varieties and animal species. Along the same lines, traditional thinking makes it clear that strong and effective extension systems and other agricultural support services must accompany research (World Bank, 1996). Schuh (1997) followed with the view that agricultural research constitutes the core of technological improvement and stressed the need of capacity development in research and extension. Logically, it was believed that poor countries aiming to develop agriculture must substantially increase investments to improve the capacity to conduct research. It was also thought that the transfer of technology from one country to another or from an international centre to a national research institute could reduce research costs.

\subsubsection{An Overview}

The reductionist conceptualisation that equates agricultural innovation with agricultural technology adoption (Rogers, 1995) has been an important underpinning principle of agricultural development issues in poor countries. The conceptual foundation defines a linear relationship between investment in research, the development of agricultural technology, its subsequent adoption by farmers and the impact of this on economic production (Hall et al., 2000). Indeed, in the 1950 s and 1960 s a prevailing view was that scientific knowledge applied to problems of rural poverty in developing countries would provide the necessary impetus needed to transform rural people's lives and increase their welfare. New technologies were generated and transferred to extension services for dissemination to farmers. The flow of knowledge was one-way: from scientifically-trained researchers via extension to farmers, with little direct feedback from local people into research and development (Warburton and Martin, 1999).

Thus, an understanding of the processes leading to the adoption of new technologies by smallholders has long been seen as important to the planning 
and implementation of successful research and extension programs. Many studies have examined the particular farm-level factors affecting smallholders' adoption of new technologies (Petheram and Clark, 1998). The debates concentrate on the sources of technologies and the delivery of innovations relevant to diverse farming environments (Biggs, 1990). The following brief review highlights a process, which starts from technology development and ends with adoption through its dissemination. It then traces the emergence of various approaches that were supposed to motivate a breakthrough at the level of the poor farmers. The review sheds some light on the institutional settings that govern agricultural $R \& D$ and extension regarding their potentials of providing technical knowledge-enhancing improvements in farming production. It also exposes their ambiguity concerning the real task of agricultural development.

Technology development - Before raising his arguments against it, Biggs (1990) explains that in the conventional view of agricultural research and development, technology emanates from upstrean activities in the formal research system and is adapted by downstream research until it is ready for dissemination to farmers. Following this approach, agricultural innovation is driven by research being the origin of new technology. Agricultural research is believed to be the only active force pushing the innovation process by providing technology, while farmers are rather passive receivers, of preconceived solutions. The innovation process is seen as linear and unidirectional, leading from research to farm-level change. The linear model is the foundation for the transfer-of-technology (TOT) concept in research and extension.

Technology dissemination - Agricultural extension has been an important channel for the diffusion of agricultural innovations as far as the transfer of technology is concerned. Various organizational arrangements and communication techniques are set to persuade farmers to adopt a recommended technology (Van den Ban and Hawkins 1996). Agricultural extension workers are most often identified in the diffusion process, as change agents or training and visits agents needed to bridge the communication gap between research and technology development institutes and farmers. Rogers (1995) defines an extension worker as an individual who influences farmers' innovation-decisions in a direction deemed desirable by the technology development institute. He must be able to understand and work with both research institutes and farmers. Extension agents seek either to educate farmers so that they may make their own informed decisions or inform farmers of new practices and innovations and persuade the farmers to adlapt and adopt them. An extension worker needs to keep in mind the characteristics of the innovations $s /$ he intends to disseminate (Clarke, 1999). 
Technology adoption - If technological change can affect the level of output, product quality, employment, trade, real wages and profits, it can do so only if new technologies that offer economic opportunities and challenges are adopted. Consequently, understanding the adoption process continues to be of interest to economists, sociologists, and policymakers. Empirical studies based on conventional research into farmer adoption of new technologies divide the population into adopter innovators at one extreme and laggards at the other (Rogers 1995). Indeed, according to Rogers (1995) it is the perceived characteristics of the new innovation that influence the adoption decision of the farmers. Five technology attributes affect the rate of adoption, which are relative advantage, compatibility, complexity, trialability and observability. Against this backdrop, Kline and Rosenberg (1986) assert that, in reality, technology adoption is generally more complex than this implies. They emphasise that adoption is a dynamic process involving more factors than the characteristics relating to the new technology itself. Scherr (1995) supplements their claim by highlighting the multiple environmental, social and economic factors that influence a farmer's adoption decision. He argues that farmers in the same environment may have different objectives and livelihood strategies, and so respond differently to a given technology. Thus, this linear approach to technology development met with considerable criticism. It was fundamentally assumed that it neither takes account of the poor farmers' needs nor explains adoption by wealthier farmers.

\subsubsection{Some Sub-Saharan African experiences in agricultural R\&D, extension and development}

In West Africa, for example, the 1970s marked a break between the exogenous research systems of the pre- and post-independence periods. After the 1970s, the constellation of many factors made countries of the region more aware of the need to build on and strengthen the existing research structures from colonial times (Pardey et al. 1996). The development and transformation of these structures eventually led to the emergence of the National Agricultural Research Systems (NARS) ${ }^{2}$. Yet, in the absence of certain preconditions, many problems arose. Constraints were identified such as the fragmentation of research, the lack of research policy, inadequacy and instability of national support, particularly at financial and institutional levels.

Other problems related to low investments for human resources development and the fragmentation and short duration of foreign aids, poorly conceived

\footnotetext{
2NARS is composed of agricultural research, educational and training, institutes/centres and extension services for agricultural technology generation, diffusion and adoption
} 
objectives, inadequate equipment facilities, and lack of institutional links. Consequently, despite efforts to promote agricultural research and substantial investment in the sector, the vast majority of West African countries have not been able to benefit fully from the enormous wealth of scientific knowledge in agriculture. To overcome the shortcomings (of the 1970s and 1980s) related to African agricultural research systems, the World Bank, the Special Programme for African Agricultural Research (SPAAR) working group and the International. Service for National Agricultural Research (ISNAR) jointly prepared a set of guidelines for strengthening the NARS in SSA. These were distribution widely during the 1980s (World Bank, 1988). The efforts to promote agricultural technologies included, among others, the networks linking national and international agricultural research institutes that were created (Ahmed and Ruttan, 1988).

In 1990, it was recognised that even the SPPAR efforts did not have the expected impact on agricultural research systems in Africa (World Bank, 1996). Simply, the failure was attributed to the poor performance of the agricultural research. The need for substantial technology-based growth to tap the immense potential of the agricultural sector pushed the Conference of Ministries of Agriculture of West and Central Africa (CMAWCA) and the SPARR group donors to initiate a new approach in 1991. This was based on tighter interactions among the NARS components, known as Framework for Actions (FFA). In terms of this new approach, the realisation of the agricultural potential requires, in addition to sound and appropriate policies and investments in infrastructure, an adequate rate of technology generation, diffusion and adoption. Assessment of the performances in the 1990s shows no sound improvements in crop yield as the result of the application of new agricultural technologies (Badiane, 1999).

If the economic significance of new knowledge to development processes is that it constitutes an important source of opportunities for economic growth, it can do so only if it is turned into innovations of diverse types. Yet, how the scientific and technological knowledge might be installed profitably in specific economic and social contexts still constitutes a big problem in least developed countries in general and in SSA in particular. Effective technological innovation implies the availability, access and the use of the technologies. Though not sufficiently, there is however, some stock of new knowledge (new methods and techniques of production, new improved seeds, new animal species and many other embodied technologies) that the research system has generated. But the farmers, the majority of which are smallholders (Omamo and Lynam, 2003), continue to rely on traditional knowledge inputs to agricultural production. This traditional 
knowledge, though ingenuous in many respects, suffers from low productivity while access to and the use of new technologies that meet the farmers' needs encounter constraints.

However, the history of agricultural technology development through research and extension services has been subjected to various successive dynamics and has also had stories of success in SSA. The earliest large programmes were on export crops (Pardey et al., 1996). Large programmes in food crops research in West Africa are more recent (maize, rice, cassava, root and tubers) where ITTA, WARDA and CIRAD are playing an important role in their development. Since the $1980 \mathrm{~s}$, there have been successes in improving technology development capacity (Pardey et al, 1996). The number of agricultural research scientists grew fourfold in Africa; their level of training also increased markedly and nationals rather than expatriates now staff the research systems (Pardey et al., 1996).

This accurate success has had limited effects. Resources-poor and small-scale farmers, most of which are rural dwellers (Omamo and Lynam, 2003), rest on low rates of adoption and utilisation of productivity-enhancing technologies and practices. They have not taken sufficient advantage of innovation possibilities. It is assumed that increases in the total production of major crop commodities resulted from area expansion and to a lesser extent from productivity increases (World Bank, 1996; McMillan et al., 1998). It appears obvious that the central problem facing agriculture in Africa today remains the same as it was, at least, four decades ago, namely, how to promote self-sustaining processes of growth fuelled by technological advances in small-scale agricultural production (Jones, 1965, quoted by Omamo and Lynam, 2003). Having said this, what is the main problem the whole story highlights?

The tradition of technological innovation, with its focus on production and technical efficiency, has predominated agricultural development agendas, probably due to the major production gains from the green revolution and introduction of input-intensive agriculture. Along this line, human resource development tradition focuses more on institution building, organisational work, and capacity building at research and extension levels. Many scientists, agricultural research institutions and policymakers in Africa have fundamentally conceptualised and treated the vital question of agricultural development as a technical or scientific issue. The focus concentrates essentially on agricultural technical innovations enhancing productivity and environmental conservation (Ochieng, 2002). One result of these technologically-biased conceptualisations has been a misguided top-down policy approach oriented towards the creation of 
modem agriculture. This produced irrelevant institutional settings that developed unsound framework, which undermined and marginalised the inputs of farmers and their needs (Kuyek, 2002). It also followed a proliferation of technologically-biased studies, with the replication of erroneous assumptions about how agricultural development might be achieved in SSA. In essence, they ignored the broader and complex processes through which successful agricultural innovations operate (Astone, 1998; Barrett et al, 2000).

Participatory research and extension approaches, which initially aimed to solve some major shortcomings related to the top-down approach and thus provide a starting point for the real takeoff of agriculture in SSA, are also very restricted in their focus. In fact, they are assumed to form a means of putting research capabilities in the hands of the deprived and the disenfranchised people so that they can identify themselves as knowing actors: defining their reality, shaping their new identity and transforming their lives for themselves (Sohng, 1995). These approaches however, fail to capture the full range of factors and relationships that would interact to affect successful agricultural innovations at the farmers level (in the context of agricultural development in SSA).

\section{Box 21. Summing up the problem}

The concem of the study is the everlasting problem of agricultural innovation processes defined as those allowing farmers to pick up innovations and apply them in their businesses. Simply, agricultural innovation processes are those through which farmers innovate Most of the existing approaches and the institutional settings in which they are embedded have done little or not enough to allow farmels to become inuovators. They conceptualised invovations in mere techucal terms. Such conceptualisation views farmers as passive reciplents of new technologies or information providers as they are required to participate in some stages of new technology development. The inistutional settings that recognise the need to develop capacily at farmers level have linuted the framework of their actions to issues such as Integrated Pest managenent (IMP) and new production technique skils alone. These approaches still are shorttern developnent strategies that confine farmers in the status guto of subsistence farming. Not surprisingly, the processes of agricultural innovation are weak and inefficient. Consequently agricultural innowations are not spread to the essential part of farmers in the counties of SSA. Stil, the question of how to enhance agricultural innovation for all categories of famers renains unanswered. 


\subsection{Research Hypothesis}

For decades, SSA has been facing numerous problems leading to, among others, incapacity to produce enough food to meet population demand. In a crosscountry comparison of food production, Africa dominates the list of individual countries whose agriculture has increased the least since 1970 (Pasour, 1985). Analyses show that poverty and hunger are widespread and getting worse. Low per capita agricultural income is directly linked to high rates of poverty and hunger, forming a vicious, recurring cycle that leads to a low-growth trap (USAID, 2003).

It is assumed that because of insufficient quantity and quality of food and profound poverty, an estimated 200 million people on the continent are undernourished, and their numbers have increased by almost 20 percent since the early 1990s, while about 33 million children go to sleep malnourished and hungry every night (Inter Academy Council, 2004). The continuing human costs of inadequate food and nutrition are enormous, and the aggregate costs of food and nutrition insecurity at the country level impose a heavy burden on efforts to foster sustained economic growth and improved general welfare. Feresu (2002, p.1) summed up the problems as follows:

\footnotetext{
"Africa is a continent in dire need of sustainable development. It is a continent currenly characterised by poverty, food insecurity, poor economics and poor health status. The worsening sisuation in agriculture is a result of declining soil fertility, low yield potential of crops, pests, plant diseases, storage losses, land pressure due to a rapidly growing population, poor managenent practices and frequent droughts accompanied by hunger, mass staroation and deaths."
}

Given these constraints, the primary objective of the actors involved has been to increase agricultural growth and rural incomes rapidly. The primary problem diagnosed is that most African farmers continue to practice traditional methods of cultivation instead of using the power of science and technology. Indeed, accumulation of scientific knowledge and its technological applications play an important role in the process of economic development. Therefore, the main objective has most often been to rapidly harness the best of science and technology to help Africa increase its agricultural productivity and improve food security. Agricultural research and development investments were essentially emphasised as the most crucial determinants of agricultural productivity. It is the acuteness and everlasting character of the problems that put SSA in a sort of endless emergency that propelled people and made of them "fire men". The need to find urgent and short-term solutions is permanently felt while it seems to deny 
the search for long-term solutions. Knowledge-intensive and technology-driven approaches and methods (the linear model) were integrated into indigenous knowledge and farmers' needs (participatory approaches) to ensure the appropriateness and adoption of technologies. The belief rested on evidence that it is possible to increase food production in SSA this way.

Large increases in output by peasants in India, China, and other countries show that a boost in agricultural output does not require big farms, big dams; big irrigation systems or an agricultural plan (Pasour, 1985). It was thought that the most important step is to increase the application of science in agricultural production. In this respect, Avery(1985) contends that even in Africa, technology is now available to double yields and drought-proof its food supplies (Pasour, (1985). As evidence, he mentions the availability of a new, more drought-resistant sorghum hybrid developed in the Sudan that appears to have the potential to triple yields in much of East Africa. Avery (1985) also assumes that, in West Africa, there is the potential to become self-sufficient in rice production by shifting from upland to swamp rice production. Nigeria, for example, has a new corn variety that yielded nine tons per hectare, even during a period of soft drought (the current average yield is one ton). Other countries like Senegal, Mozambique, Zambia, and Zimbabwe have new peanut varieties with yields several times those of current use. Improved pest control and new varieties helped bring about a seven-fold increase in yields of cow-peas in West Africa. If available technologies have not been more widely applied in Africa it is primarily because of reductionist conceptual definitions that equate hunger and poverty to a mere lack of food. From this misreading emerged institutions that did not take account of farmers in the settings for more knowledge acquisition. They were based on an assumption of rapid social transformation, which is, in essence, utopic. The need for farmers to acquire knowledge was ignored.

\subsubsection{Changes will not occur spontaneously}

Advanced countries have come to identify that the most precious resource of a country is its human capital, given the knowledge that people may generate and, in particular, their ability to use it (Inter Academy Council, 2004). This is often not the case in SSA. In the region, the urgency to overcome social malaise in the here-and-now led to insufficient emphasis on longer-term needs. Leaders and development actors often undertake numerous actions and generate many projects for curing the ills that faces SSA and improving the welfare of people but, little is said and lesser (of that little) is done about the necessary human resources for turning these noble goals into reality. In addition, leaving all of the 
technical knowledge to agricultural science researchers and extension agents, and expecting farmers to benefit from the results, is an illusory and unproductive institutional setting.

The diverse African situation implies that no single magic 'technological bullet' is available for radically improving African agriculture. A comprehensive set of strategies is thus required in Africa for the effective harnessing of scientific, technological and socio-economic opportunities to meet human needs. As a consequence, more investments in a wider range of agricultural research and development, in collaboration with extension agents while farmers are associated, are not enough. The fact that high-yield crop varieties and animal species are available is not sufficient reason enough for farmers to adopt them. The promises of increasing agricultural productivity are, however, the starting point. Adopting new technologies means expanding production beyond subsistence level. It places farmers in a market-led productivity improvement situation, which requires a strategy in order to strengthen the competitive ability of the smallholder farmers. In effect, when farmers are able to grow more than they eat, conservation, processing, packaging and marketing of the excess will be required. Increased agricultural production therefore has a wider impact and requires more competence from the part of the farmers. Thus increasing productivity is not enough.

There is no quick or easy solution for what is being defined as 'poverty'. Available resources limit production of food and other products, and the only effective way of increasing incomes is to raise productivity. The logic is as follows: broad-based economic development is necessary to address the multifaceted problems. Economic growth can be achieved primarily through enhanced economic productivity, which depends on broad improvements in the technical capacity of the population. There is no short-cut to economic development. The solution to economic development in poor countries lies primarily within the countries themselves (Inter Academy Council, 2004). Analogically, the development of a community, a region or a society and of any economic sector depends foremost on the capacities of people involved. If, given the predominance of agriculture in the livelihood of most Africans, strategies aiming at economic development could begin and continue with agricultural development, it thus appears indispensable to upgrade, develop and build new capacities of farmers. Unfortunately, many actors concerned with development misread the scope of the issue. 
According to Eicher (2001), the development and diffusion of agricuttural technologies critically depend upon the joint performance of the three pillars of the knowledge triangle constituted by research, extension, and higher education. He asserts that this concept of the knowledge triangle is equivalent to the concepts of agricultural knowledge system (AKS) and the agricultural knowledge and information system (AKIS) developed by Roling (1994) and the World Bank (2001). "Many donor specialists and academics have encouraged African nations to build national agricultural knowledge triangles - systems'" (Eicher, 2001, p. 7). Against this concept of the knowledge triangle Clark (2001) asserts that knowledge flowis are also a function of related actions on the part of the recipients (farmers). He argues that the capacity to understand the full potential of external knowledge depends, in a large extent, on the recipient knowledge.

Harnessing and refining these ideas, the study sets its fundamental hypothesis. It contends that providing an incentive framework (such as the knowledge triangle, or AKS/AKIS), aiming to favour agricultural innovations, will be of little assistance if the technology users, mostly smallholder farmers, are not adequately involved in the system. The research underlines that some determinants of successful innovations fall under the sphere of influence of the farmers. Technology adoption is certainly a question of availability and adequacy of technology, but there is more to it. Decisions to adopt new technologies are typically investment decisions, involving the acquisition of new capital goods. Such decisions are therefore subject to the same sort of economic calculus that attends all investment decisions. The present study espouses the perspective advanced by Hall and Yoganand (2003) who advocate for the need to concentrate on capacity development in an innovation system sense. It argues that because farmers have been so far neglected within the system regarding effective capacity development, the agricultural innovation system as whole is weak. Strengthening the system and making it more proficient implies the reconsideration, the inclusion and the more effective involvement of farmers in capacity development processes. What is emphasised is that farmers must have a variety of skills to access and transform new ideas, new technologies or market opportunities into innovations. The following paragraphs begin with a clear definition of how to understand adequate and effective involvement of small farmers in the process of agricultural innovations.

\subsubsection{Involving farmers}

The analysis of economic and technical change in agriculture as in other sectors shows that innovation is a complex social phenomenon. It implies that 
development depends on a country's ability to understand, interpret, select, adapt, use, transmit, diffuse, produce and commercialise scientific and technological knowledge in ways appropriate to its culture, aspirations and level of development (World Bank, 2003). Understanding agricultural innovation processes needs also the perception of people who make the final decisions about adoption of new technologies - the farmers. Including farmers goes beyond a mere consideration of their needs and/or programmes promoting their participation in some research activities. It means allowing them to actively participate in the technology development process by allowing their needs to be heard and giving them the ability to provide input into the development itself. Involving farmers means acting on the perception that higher-skilled farmers would open up markets created by new technology and more sophisticated consumers. The combination of skills, attitudes and behaviours is not optional in an economy. Everyone's commitment is needed to drive innovation, as it depends on people having the right mix of skills (CBC, 2001).

Research outputs, efficient extension services and quality of education depend primarily on, the qualification and skills of the researchers, the extension agents and the teachers, among other factors. Their profession results from their deliberate choice to go through training processes that have been purposely designed. Apart from individual abilities to learn, a research or teaching competence is gained in different areas through specific training models. While some people enter such training programmes without any previous background in the field, others enter in order to strengthen their current but insufficient capacities to face the emerging tasks.

Like researchers, teachers and extension agents, farmers need to gain the ability to perform functions, solve problems and set and achieve objectives. The conditions that determine this increased ability call for improved farmer capabilities in order to keep abreast of the process of emerging or upgrading technologies and economic opportunities. This requirement encompasses training on how to more effectively perform well-defined technologicallyoriented tasks, and master a greater variety of new tasks. The challenge is to take a more strategic approach towards supporting agricultural technology flows and ensuring that farmers can use them. To guarantee survival and continued prosperity, agriculture must meet the challenges. Innovation as a culture must pervade the agricultural sector as a whole. In this respect, providing training to farmers goes beyond a mere formality of equal treatment. 


\subsubsection{Developing new capacities}

In fact, new technologies and practices are unfamiliar by definition. In considering whether and how to use them, farmers may face, among others, conditions that require that they imagine situations that have never occurred in their past and thus require of them abilities and attributes that they likely have never had cause to build up (Omamo and Lynam, 2003). Adoption of new technologies is not the terminal stage in a multi-step process. Generally speaking, this process includes formulating a problem itself, identifying the relevant information, applying pre-existing abilities or developing new ones better suited to the solution and, finally, identifying alternative courses of action, only one of which is selected. The ability to complete this multi-step process is key and cannot be assumed present. It has not only a technical dimension, but also an organisational one (Dosi and Egidi, 1991, quoted by Omamo and Lynam, 2003, p.1685). In many cases, adopting new technologies calls also for investment capability including investment feasibility analysis and project execution. The former involves the ability to undertake the initial analysis of its profitability, detailled specifications of the project, and ability to ascertain prospects for viability (Kim, 1997).

Successful diffusion, adoption and effective use of these potentials (Foray, 1997) for the dismantling of obsolete activities and for the start-up of more efficient new ones (Kim, 1997), constitute, among others, a fundamental factor for a transition from a peasant subsistence to more productive and commercial agriculture in West Africa. This requires a skilled and entrepreneurial farmer population that can adopt and exploit the new technologies. Thus, instead of forming a "knowledge triangle", an agricultural innovation system in which farmers are effectively involved is required:

a) What is argued is that economic activity is driven by a more complex interplay between different factors, with, at its core, innovation.

b) What is stressed is that low skills affect farmer's innovative capacity to take full advantages of new technologies and participate in commercial agriculture.

c) What is suggested is that building entrepreneurial skills for farmers would trigger their innovative capacity.

What will maintain perpetual productivity increases or cost reductions over years is the farmers' ability to constantly try out new ideas and technologies, 
adapt them to their own needs, and then share them with each other. However, the development process will not be sustained just because farmers learn and apply a lot of production techniques and technologies, which positively affect their gross outputs (yields). The development process will continue over time as farmers become involved in social, economic and technical processes of constant innovations, in which they seize production prospects while supported by input and output market opportunities. Neither the production prospects nor market opportunities are always given or static. They are dynamic and need to be sought and fought for; in many cases they also need to be created. And that is not all. In addition, permanent and new behavioral actions are required to maintain and continue what has been is attained. For the process to sustain over time farmers have to be able to innovate.

Innovation literature does not provide extensive coverage of the concept of innovative capacity. There is an issue of inconsistent semantics in relation to the concept. The terms innovative ability, innovative capability, innovative competence and absorptive capacity all seem to relate to the same concept of innovative capacity (Neely and Hii, 2001). Yet, when the literature focuses on the ability of a firm to innovate, innovative capability is often cited. It is defined as "the ability of a firm to recognise the value of new external information, assimilate it and apply it to commercial ends" (Cohen and Levinthal, 1990). According to Neely and Hii (2001), innovative capacity is the potential of an innovative unit to generate innovative outputs. In statistical terms, innovative capacity is a latent variable. We cannot see it all thus cannot directly measure it. 


\section{Box 22. Summing up the hypothesis}

If agricultural inmovation processes are conceptualised in system terms then there is a need to address the concerns in system lhinking: streng then all the systems components and linkages between them. Within this, the regunement is to concentrate efforts on the ( 50 far) biased and weakest links: the farmers. The focus should emphasise on capacity development at farmers' level 11 has 10 go beyond production and fechnical capacities. Successful agricultural innovation processes iequire that farmers acquire innovative capacities. They must engage lin processes Whereby they can leam to innovate. A farmer's innovative capacily is his ablity to innovate and we can also think of it as including entrepreneurial capacites (als defined in the chapter four) I lere we retain that innovative capacity includes:

$\Rightarrow$ The ability to adopt new ready nade' agricultural technologies and handle the resulted outputs:

$\rightarrow$ The ability to carry our new combinations of existing farming production inputs or the ability to combine new agricull tural inputs (lechnical knowledge, and other resources) in the prodiction of some goods or services (whether these are new or not)

$\Rightarrow$ The ability to master new input resonices (new or not) needed for the new agricultural business the farmer ains to establish;

$\Rightarrow$ The ability to produce competitively the farmer should be able to sell the agricultural products and services she produces. This can be achieved either as a result of product quality, newly created distribution channels, or new marketing tools (techniques and nethods) being used,

$\Rightarrow$ The ability to connect to some networks of information at various levels being a member of various farmer organisations, having telationships with peer farmers, connecting to research and extensions agencies or agents, interacting with input suppliers and also with exporlers of agricullural products, if necessary. 


\subsection{Research Objective and Questions}

Knowing what is wrong forms the basis for knowing what to do (Liebenberg and Theron, 1997). However, making the analytical connection sometimes seems to be the source of a new problem. As stated earlier, it is disturbing for me to acknowledge the context in which development issues are tackled. In SSA, the urgency to overcome social malaise in the here-and-now led to insufficient emphasis on longer-term needs. Donors are just funding concepts and many researchers simplly follow. Indeed, for a research project to be funded, all it needed was to subtly insert a notion such as "Community based", "Rural community", "Small farmers", "Poverty reduction", "Gender", "Empowerment", "Participatory", "Poorest of the poor"... Everyone wants to empower women and the poorest farmers; everybody wants to involve the poor or whole communities in research. Everybody wants to find the best and quickest solutions for the problems of the poor. Yet, problems are diverse, interrelated and may vary over time as they are also a concern of mental attitudes. They develop, squeeze or take other forms and may have a multiplying effect. In fact, while some problems arise as a consequence of many factors, others may seem spontaneous. Problems are endless and inherent to individuals as well as society as a whole; this will never change. Thus, instead of trying to end an endless, let's allow people to gain the ability and power enabling them to deal with undesirable situations.

All economic actions are embedded in social relationships and institutions (Jessop, 1999). Agricultural production also links actions of farmers to economic relationships and social structures while governed by institutions at both the micro and macro levels. The objective of the research is to determine how a training/learning model can become a major contributor motivating and enhancing farmers' innovative capacity. The focus is on identifying the attributes of such training model while primarily concerned with agricultural innovation processes. Fundamentally, the study seeks to suggest ways of addressing institutional settings in which agricultural development is embedded, and the underpinning principles that support them. Acknowledging the effects of historical, biophysical, socio-economic and politico-institutional factors and their interactions, the study is supported by the concept of systems of innovations.

The system approach to innovations puts emphasis on innovations and the processes through which they occur as the core determinants of performance improvements of economic activities. Linkages, institutions and learning from their interplay constitute the underlying thoughts of the system approach to 
imnovations. Literature review shows that, unlike other concepts, learning is highly weighted and consequently stressed within the system approach to innovations. Approaches to new knowledge acquisition at the tarmer level have for decades been based on "learning-by-doing", "on-fam dewnonstrations" and "farmer field schools" (Tripp, 2001). All have proven their limits in providing sustained basic know-how (new methods, techniques and practices), mostly in staple crop and livestock production to farmers. They also failed to grant farmers capacities to grasp the "know-who" knowledge, which is information about who knows what and who knows how to do what (Malecki, 1997). In effect, agricultural innovation processes cannot be sustained in a framework that does not provide a background for upgrading and adding to the knowledge stock of farmers. Individual farmers must know how to acquire the knowledge they need, when, how and at the right time they need it. Finally, farmers require basic technical knowledge to help them manage new techniques.

Much of the basic knowledge that farmers need could be imparted in a special training programme that prepares them to operate in increasingly sophisticated input and output markets (Tripp, 2001). It may include "know-how" (new agricultural methods and techniques and other best practices) in crop production, animal husbandry, fish farming, processing, marketing and farm management. Innovation is the process of turning ideas and knowledge into products and services that create a consumer demand within the marketplace. The innovation process is a cycle in which ideas, skills, investments and management expertise come together to create commercially viable products and services. The world is swept away by change. New technologies emerge constantly; new markets are opening up while others are shutting down. These circumstances challenge all economic agents to be innovative and creative, so as to improve performance continuously. Success depends on how well the most valuable assets such as knowledge, skills, and creativity are exploited. Farming is a production activity that relates to input and output markets (of services and products); as such it also requires entrepreneurial skills.

In a dynamic economy, market conditions regullarly change due to the invention and introduction of new products, changes in production technology, changes in consumer preferences, and so on (Pasour, 1985). Consequently, there are always profit opportunities available for alert individuals with innovative ideas. According to Pasour, (1985), entrepreneurship may be rightly defined as an alertness to profit opportunities which have not been grasped and acted upon by others. Entrepreneurs thus sense opportunities and take risks in the face of uncertainty to open and exploit new markets. Schumpeter (1934) defines an 
entrepreneur as one who reorganises economic activity in an innovative and valuable way. That is, an entrepreneur is one who engages in a new economic activity that was previously unknown for the sake of profit. This definition has great application to agricultural development in SSA, in particular, as producers are searching for news ways to increase their incomes. The training programme on farming can do little more to foster entrepreneurial spirit, equip farmers for the long term, and prepare them to seize opportunities and commit to constant innovation that enhances performance. The study investigates how training transforms the learner farmers into relevant "node" in the agricultural innovation system.

\section{Box 2,3: Research Questions}

1) Conceptualising agricultural innovation in system terms, how can continuous innovation processes that ensure the development of agriculture be enhanced?

2) Conceptualising farmers as components of an agricultural innovation system, what new forms of training and capacity development would be needed to allow continuous innovation processes at the farmers' level?

3) Using the Songhail traimng framework as an example, how does it build the innovative capacity of farmers rather than just training them in new production techniques?

4) How are the attributes of the Songhai training different from the current models of extension or farmer training?

5) Conceptualising (agricultural) innovation system in developing countries' context, what sorts of skills, attributes, habits and practices would be predicted to be involved in building the innowative capacity of farmers? 


\section{Research Methodology}

\subsection{Introduction}

This chapter describes the empirical research design, which follows the case study method. Yin (2003, p.20) defines the research design as "the logic that links the data to be collected and the conclusions to be drawn to the initial questions of a study". In essence the research design is "the action plan" that enables the researcher to move from research questions to valid conclusions through the collection and analysis of data (Yin, 2003). The case study is one of several methods of doing social science research. It can be used to explain the causeeffect relationships; to describe a person, programme, or event in its natural context; to illustrate how or why an intervention worked as it did; to explore situations in which there has been no clear discernible outcome and to evaluate the evaluation process itself. Further, Yin (2003, p. 13-15) explains that case studies examine a "phenomenon within its real-life context" and often look at several possible points of interest, rather than looking at one particular result or variable. As such, they are used in various types of research including social science dissertations. Moreover, the case study as a research method has a unique strength, which lies in its ability to deal with a full variety of evidence: documents, artefacts, interviews and observations ( $Y$ in, 2003). Given the fact that this research seeks the causal effects of a training programme on the capacities of farmers to innovate, the case study research design seemed the most appropriate approach to take. 
The first step towards this accomplishment consisted in identifying an appropriate educational organisation that provides formal training to farmers. An exploratory field research revealed that the "Songhaï Centre" stands out to match this expectation, given its activities. In this research, the case study will focus on the Songhai Centre as a training/learning institute. The case study is descriptive, illustrative and explanatory in that it intends to understand Songhai as an institute; it illustrates the training programme and identifies its effects on farmers" ability to innovate. The case study presents an interesting challenge as it also looks at sub-cases within the larger case. The research methodology (design) uses an embedded case study method: while I investigate the innovative capacity of Songhai farmers (the targeted case) as a result of their full-time enrolment in the training programme, I first describe and present the Songhai Centre as a subcase followed by the training programme as a second sub-case. In fact, an embedded case study design has a primary focus of study (primary unit), but multiple sub-units are studied to help understand the primary case more fully (Yin, 2003). This design allows me to use the innovative capacity of graduate farmers who set up their own agricultural business to identify how the training was a major factor enhancing farmers' innovative capacity.

This chapter describes the process followed to achieve the research objectives and follows the five components of case study research design. These include the case study's question, the propositions, the units of analysis, the logic linking data to the propositions, and criteria for interpreting the findings (Yin, 2003, p. 21-28). Because units of analysis define the fundanental concern of what the case is (Yin 2003), in this research they are first articulated and then, used as the general guide, around which other components are built. As mentioned earlier, the primary unit of analysis is the Songhaï farmers. However, the potential power of the knowledge they have acquired cannot be properly grasped without exploring and understanding why, what and how they have learned. This implies the necessity of considering the training framework as a second unit of analysis. Likewise, the research perspective demands that the institute providing the training be investigated. The Songhaï Centre thus becomes the third unit of analysis. In practice however, the entry point of the study is the Songhaii Centre itself. The training framework and the farmers' cases then follow. More concretely, empirical results are presented in the form of an embedded case study comprising three units of analysis. In such a framework, the study of each unit of analysis can be done as a separate case study, and is then referred to as sub-case
study. 


\subsection{Sub-Case ONE: Discovering the Songhai Centre}

\subsubsection{The Songhaï Centre as a unit of analysis}

Using the Songhail Centre as a unit of analysis establishes an illustrative case study. Yin (2003) instructs that all case studies have either an explicit or implicit theoretical framework, which guides the design of the study. By stating a study"s propositions, he argues, a researcher makes his focus explicit and identifies the research"s "conceptual framework". The case study's proposition, which is the underlying assumptions I brought to the study, is developed from insights gained in the literature review. It relates to the rationale behind development institutional settings. The literature review distinguishes between long-term and short-term developmental goals, as they constitute the fundamental principles underlying them. The rationale for setting up the Songhai Centre is rather a longterm vision for African development primarily based on Africans themselves and motivated along agricultural development. The founder of the Songhai Centre believes that global economic development in SSA should be based on the development of agriculture. As a starting point, he understands that agriculture develops best when appropriate institutional settings allow agents involved in the sector to acquire more knowledge in order to upgrade and build-up general purpose farming skills (Nzamujo, 2002).

The conceptual framework then leads to the third component of the research design, the study's research question and sub-questions. The primary research questions for this study are stated as follows: "Conceptualising agricultural innovation in system terms, how can continuous innovation processes that ensure the development of agriculture be enhanced? This primary question is then broken into sub-questions in order to respond to each sub-case. The research sub-questions reflect the insights on which the sub-case study focuses. Here, the questions are:

a) Wry was the Songhai Centre created?

b) How does it conceptualise the process of economic development in reition to agriculfure?

The fourth component of the research design is an articulation of the logic linking the data to the propositions. In this study I followed the four-component analysis process of data collection, data reduction, data display and verification. For the purposes of this sub-case, a less structured interview guide was developed and used to interview the key management staff of the Songhai Centre. The process, as described under the following heading, involved conducting, taping and transcribing the interviews. 


\subsubsection{Sources of evidence, nature of the data and collection procedure}

Given the sub-case study question, a compact research questionnaire was designed. Upon my arrival and after making first contact with the informant, I came to realise that I needed to change the course of the issues. I broke down the questionnaire into two parts. The first includes questions for the founding director and the second part comprises those for the management team. I reviewed my research abstract and added it to the questions.

The Songhai founding director seemed busy all the time and suggested three stages through which I could get answers to the questions related to the rationale for founding the Songhail Centre. Firstly, he advised me to read the book he wrote about Songhai as it could answer most questions. Secondly, he instructed the technical director to check the list of questions and find out if he could answer some of them. In the third stage, we should meet to discuss more deeply about matters neither the book nor his team members could answer satisfactorily.

The second part of the research questions on Songhail followed roughly the same process. The deputy director noticed that the questions related to the Songhail training, production, partnership and follow-up. He advised me to separate the questions according to the four topics and then he would direct me to the appropriate managers for discussions. The nature of the research topic, though exciting and may present some interest for Songhaï, needed to be carefully reviewed and be translated into French. At the same time the technical director acknowledged that people might not have the answers to some of the questions and some official statistical data might not be available. Consequently, he advised to read the Songhaï quarterly bulletin, "L'AIGLE DE SONGHAI", which could be found in the Songhail library and centre for documentation. And then the process of data collection at Songhaï and about Songhaï began.

The month of January 2004 seemed extremely busy for the Songhaï managers. They were absorbed by the work of daily activites, finalisation of annual reports added to the idea of new prospects for the following years. And that was not the whole story. Apparently the managers deal with many things spontaneously and simultaneously. Not only are they in charge of the site of Porto-Novo, but they are also accountable for the managers of other sites. Many times my appointments with them had to be cancelled, despite their willingness; sometimes an event cut the course of discussions. Any time this situation occurred, I went to library for secondary data. L'AIGLE DE SONGHAI published in 50 issues, with the last edition in the first quarter of 2003, contains the bulk of 
information relative to Songhai partnership. In investigating the Songhaï Centre as unit of analysis, the data collected relate to four main issues:

a) The genesis of Songhaï (rationale, the perceived problems and objectives)

b) The development of Songhai (Songhai sites)

c) The Songhai production and research frameworks

d) The Songhai philosophy of partnership building and Songhai partners

\subsubsection{Data analysis}

Given the historical, philosophical and system foundations that have influenced the creation of the Songhai Centre ${ }_{\mu}$ an in-depth study that naturally lends itself to qualitative research appeared the most appropriate. Qualitative research methods are better employed when there is little known about a phenomenon (Hoepfl, 1997), and indeed very little is known about the Songhai Centre and the framework of its training programme. According to Hoepfl (1997), qualitative research has an interpretive character, aims at discovering the meaning events have for the individuals who experience them and the interpretations of those meanings by the researcher. It thus has an emergent design, and researchers focus on this emerging process as well as the outcomes or product of the research. Qualitative research attempts to view the 'big picture'. It also tries to discover causal events contributing to the phenomenon, descriptive details of the phenomenon itself $f_{r}$ and the ramifications of the phenomenon under study (Hoepfl, 1997). Johnson (1995) argues that qualitative research probes for deeper understanding rather than examining surface features. As such it produces richer understanding and insights as it looks at people and events holistically and not just at what happens, but also why it happens.

Qualitative data analysis goes beyond organising, storing, reproducing and retrieving data. It entails creative and interpretive tasks requiring human reflection and understanding. As such, it is complex and time consuming and there is a lack of specific guidance on how to carry it out (Dawson, 2002). Yin (2003) acknowledges that the analysis of case study evidence is one of the least developed and most difficult aspects of doing case studies. A qualitative researcher cannot be satisfied merely with 'telling convincing stories', but instead must be able to generate theoretical explanations. This puts a strong emphasis on ensuring the validity, reliability and generalisation of results in order to ensure the true causes of the effects (Gibbs et al., 2002). 
Yin (2003) distinguishes three analytical strategies for case study data analysis, which rely on theoretical propositions, setting up a framework based on rival explanations and developing case descriptions. Within this study, the data analysis is qualitative and built on the strategy of theoretical propositions. As it is common in qualitative researches, I ran data analysis in parallel with data collection, and the two became integrated, systematic and comprehensive. In practice, the handwritten reports that emerged from interviews were typed in the computer. By so doing, I divided the data into relevant and meaningful topics, as a result of reading and examining the data and linkages that were made between them. I then printed and submitted them to the informants to whom I gave the opportunity to confirm that my interpretations were consistent with what they said. This created a climate of confidence with the Songhail managers while enhancing the credibility of the research.

Indeed, it was imperative that I send a three-month research report to my promoter and supervisor for comments in order to direct further research. This report would not be possible without such constant interim analysis. However, the analysis process begins by reading all of the data to achieve a sense of the whole. Data interpretation and analysis involves making sense out of what people have said, looking for patterns, putting together what is said in one place with what is said in another place, and integrating what different people have said (Patton, 1990). Analysis involves working with data: organising and breaking it into manageable units, synthesising it, searching for patterns, discovering what is important and what is to be learned, and deciding what to tell others (Bogdan and Biklen, 1992). Performing such analysis requires appropriate case study techniques.

Yin (2003) distinguishes five techniques in case study research design at the level of data analysis. They include pattern matching, explanation building, time-series analysis, logic models and cross-case synthesis. While there are very few fixed formulas regarding the choice of a technique, the researcher is better guided by his own style of rigorous thinking, along with sufficient presentation of evidence and careful consideration of alternative interpretation (Dawson, 2002). My exploratory fieldwork, which enabled the choice of Songhaï, provided also logic model deliberately stipulates a complex chain of events over time with the goal of matching empirically observed events to theoretically predicted events (Yin, 2003). Subsequently, the study traces and analyses the data following the chronology of changes and events that warranted the changes. The principle of simultaneous data analysis and data collection corroborates with this technique 
and facilitates the whole process. In fact, Songhai has been and continues to be a dynamic entity that can be captured only as such.

\subsection{Sub-Case TWO: The Songhai Training Framework}

\subsubsection{The training programme as a unit of analysis}

This sub-case about the Songhair training framework traces the dymamics that have occurred since the creation of the Songhai Centre. Emphasis is put on the changes that have been occurring and the factors that stand behind these changes. It presents the rationale for the training programme, the main objectives it aims to achieve and its contents. Further, this sub-case discusses issues regarding prospective regular students in terms of admission conditions, admission tests, and the training process added to student evaluation process. The specificity of the training programme also includes the uniqueness of the teachers with explicit profile. Other institutional settings concern the relationships between the students and their educators. The training case also informs about the existence of other specific (shorter) training curricula. The "After-Graduation" issues are also examined. The assumption supporting this sub-case study is that, when system approach to innovation underlies the foundation of the training programme, its content and the framework for its delivery to the learners, there are promises that the graduate farmers become successful innovators.

What a graduate may know from a training organisation is mostly what is taught. A first set of data being collected relates to the training or learning model. Students are trained to build up and strengthen their technical skills and capacities by acquiring more in-depth knowledge in techniques of agricultural production, in agro-industry and in management of agricultural enterprises. They take theoretical courses but practical issues predominate in the curriculum. By informing on the attributes of the training issues and how they can grant farmers the ability to act on multidimensional grounds, this sub-case study will show the importance of capacity building at farmers' level and within an agricultural innovation system. It will also show how agricultural innovations remain a continuous process that goes beyond the development and the adoption of appropriate and high yielding technologies resulting in higher productivities and improved outputs. Based on this, three case study questions are set.

a) Why does Songhai provide specific training to young people in agriculture? 
b) What are the man attributes of the Songhai training programme and how are wey different from the current models of extension or farmer trainitg?

c) How does the training trigger innowative capacities?

\subsubsection{Sources of evidence, nature of the data and collection procedure}

To answer these questions, I used the second part of the research questions I initially broke down. It was rather an unstructured interview guide that served to discuss with 18 staff members, all of which are managers. The technical director (also acting as deputy director - this function does not officially exist), was the reference person, the facilitator and also, due to other functions, the main informant; with him the process started. I sought information about training because activities are built around it. In other words, a clear understanding of the training issues provides better insights into other topics. This led me to depend heavily on two managers. The first was the technical director of all Songhaï training programmes. He masters the history of Songhai, the genesis and evolution of the training issues. During several meetings which lasted many hours, discussions with him provided, more specifically, understandings on:

a) The purposes the training programmes are to serve

b) The contents of the training programmes, their evolution in terms of changes and the rationale that stands behind the changes

c) Admission requirements for training and their evolution

d) The processes of the training, their evolutions in terms of changes and the rationale supporting the changes

e) The methods of evaluation of the students and their evolution

f) The profite and evolution of Songhaii trainers

Appointments with the managers had to be very flexible. Whille consulting with the technical director, I was trying to get quantitative data from the manager in charge of regular students at Songhai. The data related to the evolution in number of applications, admissions and graduates. The objective was not only a "mechanical" understanding of the trends, but rather the factors that engender and warrant them. The manager shed light on general and gender-specific 
student performances. It was only after I partially finished with training issues that I turned to production, research and partnership.

Previously and successively in charge of international relations, Songhai research, human resource management, the production manager is another busy and powerful manager who retains an abundance of information. From the Songhaï concept of good partnership, to research findings through financial and technical collaborations, he highlighted some of the main activities, accomplishments, and future goals. As the human resource manager and production co-manager, he elucidated the context of production choice, the relationships between production and training and provided an overview of the recruitment process and a breakdown of staff data.

Another resource person was the manager in charge of the follow-up programme, the Songhair representative before the RENAFERS (Reseaw National des Fermiers Songhai - National Network of Songhai Farmers) and co-manager of the Songhai farmer credit fund. He masters the follow-up processes, knows the history and the evolution of the Songhai financial assistance to farmers and he is the man of the field. He knows the approximate number of students that set up farming businesses after graduation, their contacts and the exact itinerary to their farms or homes. This manager constitutes a sort of bridge between Songhaï as and the farmers. Very mobile and unpredictable, he was the second person, on which $I$ relied the most concerning the information I needed.

Numerous meetings of several hours were needed to cover the research questions at stake. In between meetings I could make neat copies of my notes, add new questions if necessary, then submitted them to the manager at the end of a current meeting for verification. This method had three aclvantages. First, the managers could correct my misunderstandings. Second it gave them confidence that I would faithfully report what they told me and not what I might have pre-conceived before coming to them. Indeed, it happened that some researchers (students) came to Songhaï and conducted interviews, but their report did not reflect the position of Songhair. Third, it allowed the managers to add or eventually correct some information they gave during a past meeting section. We then fixed the approximate term for the following meeting. This process continued throughout three months. During this period I also questioned the managers about information I found in "L'AIGLE DE SONGHAI". In addition, I was given a guided tour through the various production and training units where $I$ had the opportunity to talk with other staff members. 


\subsection{Sub-Case Study THREE: Farmers' Innovative Capacity}

\subsubsection{The Songhaï farmers as units of analysis}

In many low-income countries, the innovation potential does not translate into an active demand for technology, even under conditions suggesting economic benefits that applying new technology might bring (Springer-Heinze, et al. 2001). The rationale for using Songhai farmers as units of analysis is to discover how farmers can more effectively participate in agricultural innovation processes when they have access to training that supplements their initial knowledge. Finally, the case study will show why farmers' innovative capacities, the processes through which they occur and institutions supporting them, are all requisite and deserve adequate treatment like other components of a national agricultural innovation system. Evidence on innovative behaviours of the Songhail farmers is required to validate the above statements. The subsequent case study question is: how have the Songhai farmers innovated? This exciting question is broken into two study questions.

a) Why did the young people enter the Songhai training programme?

b) How have Songhail farmers innovated? Is there empirical evidence of their innovative capacities?

The research assumes that the conditions in which the graduate farmers set up their agricultural businesses (the means and how these means are acquired), the types of activities they have undertaken and the evolution of these activities will provide the base to ascertain the innovative behaviour of the farmers.

Before moving toward the nature of data I collected, it would be useful to define the general meaning of innovation or what it means for someone to innovate. Innovation is the process of turning ideas and knowledge into products and services that create a consumer demand within the marketplace (Verpagen, 2001). The innovation process is a cycle in which resources and management expertise come together to create commercially viable products and services. It is the new way of economic exploitation of existing things, given new opportunities or circumstances. The rationale for innovation is to create goods and services of better quality or more value added. As such, it is also a factor of competitiveness. The innovator gains more benefits from the innovation if it is widely accepted (Kline and Rosenberg, 1986). For Branson (1998), true innovation is not just about changing a product, a service or even a marketplace. It is also about recognising and relishing the need to change oneself. Thus, new attitudes and ways of 
bargaining, searching and mastering resources, creating or tapping into new opportunities are also innovative behaviours. Indeed, the system approach postulates that it is rather the combination and interactions of different factors that make innovations successful.

\subsubsection{Sources of evidence of the data and collection procedure}

\subsubsection{The interview guide - research questionnaire}

Once the research design had been created, the interview guide needed to be developed. Generally, there exist three types of interviews including structured interviews, unstructured interviews, and semi-structured interviews (Oka and Shaw, 2000). For this study I used structured interviews. I asked the same set of questions, in the same order, using the same words, to different interviewees. Structured interviews are convenient for comparing different interviewees answers to the same questions. Hence ${ }_{r} \mathrm{I}$ first developed a standardised interview guide in the form of a questionnaire at farmers' level. Compared to the interview guide I used at Songhai level, this one was more structured, following a specific order, with a certain degree of detail. I used the three basic types of questions including multiple choice, numeric open-ended and text open-ended. Some questions could also be qualified as rating scales and agreement scales types of questions that some researchers treat as multiple choice questions and others treat as numeric open-ended questions (Oka and Shaw, 2000). The questions were flexible enough to account for the flow of the conversation. In my attempt to investigate farmers' innovative behaviours, I started with background and demographic questions that helped me to understand the context from which the farmers' responses emerged. Indeed, while trying to respect the KISS (Keep it Short and Simple) principle (Oka and Shaw, 2000), I also found it necessary and useful to include all six kinds of interview questions as Patton (1990) identifies:

a) Descriptions of respondents' experiences, behaviours, and events.

b) Opinion or value questions, which aim at the interpretations that individuals have of the events and behaviours they describe

c) Feeling-oriented questions, which seek to understand the emotional responses individuals, have to the events and experiences they have had.

d) Knowledge questions, which elicit the factual information the respondent knows. 
e) Questions, which ask the respondent to reconstruct a situation by describing the situation, as if it were happening in the present.

f) Demographic and background questions.

In an interview guide, great care is also given to the choice of words used in the questions. The words used should be in language and terms familiar to respondents so that they can clearly understand what is being asked (Patton, 1990). As part of the process of developing the interview guides, 1 found it extremely helpful to consult a sociologist, a researcher at INRAB (Institut National des Recherches Agricoles du Béwin - National Institute of Agricultural Research of Benin). Indeed, my interview guide (questionnaire) was in English, and I had to conduct the interviews myself in French. With him, I seriously discussed about appropriate terminologies, and the terms that would be easily comprehensible to the farmers. I learnt much from him, as I was not familiar with French terminology in the field. Further, he advised me to behave in the simplest way while trying to identify myself with the farmers. I had to let them know that I originate from a remote village where I grew up and my parents live. In addition, I should try to show them that I was familiar with farming activities, he emphasised.

He also advised me to be very careful in order to avoid leading questions thereby unwittingly prompting a certain response from farmers. He also stressed the need to consider certain ethical matters in conducting the interviews. In this respect, he advised, for example, not to ask the farmers directly about how old they are. He explained that, in general, that question is not welcome in many milieus in the country. Instead, it would be preferable to ask them the age at which they went to Songhain for training. A key issue was the need to create and establish a sort of confidence at the outset of the interview process. The farmers should know who I am and how the information was going to be used. In my introduction I should let them know that they also have the opportunity to ask any questions they might have. This would enable them to share any additional pertinent information not already covered in the interview.

\subsubsection{Farmer population and sampling}

This case is less qualitative than quantitative involving the use of statistics. There are two major branches of statistics, each with specific goals and specific formulas (Trochim, 2002). The first, descriptive statistics refers to the analysis of data of a known population (the sample population). In other words, descriptive 
statistics uses numbers, graphs or charts to describe what is currently happening within the sample population or a data set. The second, inferential statistics are to estimate or predict. Both statistical branches rest on a sample population. Sampling is the process of selecting units from a population of interest so that by studying the sample it may be possible to fairly generalise the results back to the population from which they were withdrawn. In principle this sample only provides information about the selected elements of the population. Making inference about the population as a wholle is possible only if the sample is selected using a proper sampling design (Trochim, 2002). The sampling model that is applied in the current study usually goes through three stages. It starts with the identification of the population to which it is to be generalised. A fair sample is then drawn from that population and research is conducted with the sample. Finally, because the sample is supposed to be representative of the population, results can automatically be generalised back to the population.

\section{The study's population}

Since the definition of research issues and the choice of the Songhaï Centre to illustrate them, it was evident that the Songhaï farmers constitute the study population. In sampling, a major question relates to whom the research results should be generalised. Indeed, according to Trochim (2002), social researches are usually interested in more than just the people who directly participate in the studies. A most desirable goal is to be able to generalise almost universally. But while psychologists, for example, are often interested in developing theories in their research that would hold for all humans, most applied social researchers are concerned with generalising to specific groups called a study population. A population consists of an entire set of people or objects that have something in common or anything one might be interested in studying (Trochim, 2002). This study researches the Songhaii graduates that have created their own farming business and then seeks to make inference to all the graduate farmers. Yet, Trochim (2002) advises to distinguish between theoretical population and accessible population.

\section{Theoretical population}

When I had to take a sample from the Songhai graduate farmers, I faced the dilemma of the population to be considered. Two types of populations appeared. The first population represents the set of all graduates, whether they have established their own business or not. I could also draw from the population constituted of those who set up their own farming businesses. Songhaï revealed 
that at least $64 \%$ of the prospective farmers create own business after graduation. The rest are employed in other social and economic structures. The problem was that I couldn't deny that those working for other people are not innovating. At the same time it was evident that I would not be able to identify the share of innovations that would be attributable to a Songhail farmer within the entity in which he works.

Therefore, I chose to consider the subset of those owning an agricultural business. However, Songhail does not have the actual addresses of all of those who own farming businesses. Songhai explained that it is only after a certain period of time that the graduates themselves come back to Songhaï or send a latter to inform about their current activities and addresses. Many times Songhail could not even find the former students on the initially indicated locations. While it would be possible to estimate the number of those who set up their own business ( $548=856 * 64 \%$ ), it would not be however, easy to guess their addresses and get to them. It is this population of 548 farmers to whom it would be appropriate to generalise research results. In the framework of this study, innovative capacities are to be investigated only at the level of those who have their own farms. Trochim (2002) denotes it as the theoretical population.

\section{Accessible population and sample frame}

The accessible population is part of the theoretical population. It consists of those farmers who have declared themselves as farm owners to Songhail some time ago. Songhai had the opportunity to visit them and knows the actual itinerary to their farms. These farmers form the set called the accessible population. However, the Songhaï follow-up team has acknowledged that many times it happened that they were not able to locate some farmers after certain period of time. When some farmers found other business or job opportunities they moved to other places. In addition, they have the contact addresses of some newly settled farmers but they have not yet visited them to have the precise itinerary of how to get to their places. This limited the number of farmers whose actual addresses Songhai knew at the time I was there. This gave birth to another subset within the accessible population. The listing of the accessible population from which I drew my sample was then more restricted. It was the set of those farmers whose address itineraries Songhai claimed to know well and possessed at the time of my stay. This part of the accessible population is called the sampling frame, and in this case was composed of 195 farmers. The sample is defined as the set or the list of farmers I selected to interview. 


\section{Sample size}

This study aims to research Songhaï graduates who were involved in some kind of agricultural business (enterprise, activities) and are the only owner or coowner. In case of co-ownership, all co-proprietors must be Songhaï graduates. As I was trying to determine the sample population, I moved from theoretical to sample frame through the accessible population. This exercise gave me the opportunity to have an idea about the importance of the farmers in different regions. I then selected the farmers according to their importance in the defined geographical regions, denoted zones. Indeed, Songhaï distinguishes eight: zones from where the farmers can be found. These include (from the south to the north and from east to west of Benin) Ouémé, Mono \& Couffo, Southern Atlantique, North-Atlantique \& Southern Zou, South-Eastern Zou, Northern Zou, Borgou and Atacora. The farmers are not evenly distributed across the various zones. I set the probable number of farmers I intended to interview within each zone. The objective was, simply, to have enough to ensure that all agro-ecological zones and socio-economic conditions in which the farmers live are covered. This method is analogous to stratified random sampling in that it is typically used to assure that smaller groups are adequately represented in a sample (Trochim, 2002). I set to interview at least 60 farmers. Because I had no prior knowledge of the farmers, there was no way to prefer one over another. Because there was no way to inform the farmers before visiting them, I counted on a high risk of missing some randomly selected farmers. Because I. had a list of 195 farmers, I randomly targeted each other farmer beginning from the first one. Table 3.1 displays the randomly selected farmers across the zones.

Table 3.1: Distribution of farmers across their zones of settlement

Zones
Targeted sample size Real sannple size

Zone 1: Ouémé

Zone 2: Southern Atlantique

Zone 3: Mono \& Couffo

Zone 4: Northern Atlantique \& Southern Zou

Zone 5: Northern Zou

$20 \quad 17$

Zone 6: South Eastern Zou

Zone 7: Borgou

Zone 8* Atacora

Total

$20 \quad 15$

$5 \quad 5$

$22 \quad 18$

1210

64

$8 \quad 6$

$5 \quad 0$

98

75




\subsubsection{Nature of the data}

The issue at stake is to examine, by the means of appropriate data, the extent to which the trained farmers have been able to acquire other resources, to combine and apply them in their production activities, and if they have also exploited market opportunities. The study thus investigates issues reflecting the innovative behaviours of the farmers. The data then relates to:

a) The mode of access to land

b) Access to initial investment capital

c) Access to other forms of financing

d) Adoption of new crop varieties

e) Adoption of new animal species

f) Adoption of new equipment (types of tools or machines used as means of production)

g) The use of new methods and techniques in handling daily farming activities

h) Adopted farming management techniques

i) Integrated system of production

j) Job creation

k) Access to existing markets

1) Seizing and exploiting new market opportunities

m) Connection to networks of information involving other agricultural innovation system components (farmers' associations, organisations, researchers or research institutes, government bodies, etc.)

n) Upgrading initial knowledge

o) Overall performance in terms of the trend of incomes 


\subsubsection{Conducting the interviews}

I conducted in-depth personal interviews. A personal in-depth interview describes the case when the interviewer asks the questions face-to-face with individual respondents rather than groups. I always travelled to meet the farmers at their places (homes or farming enterprises). No interview took place outside their working environment, where in many cases the farmers have adequate infrastructure to dwell on their farms. The farmers are located in various city suburbs, small cities and villages, throughout the country. Face-toface interviews require a substantial amount of means in terms of money and time. Given the resource, the costs and the requirement to consider the agroclimatic conditions, I faced the need to define the most appropriate itinerary before I could start. I had to define a network representation in which it was required to find the shortest critical path length to the different regions and various places where the farmers live. I found it helpful to use, in a very simple way, the most famous combinatorial optimisation problem method: the Travelling Salesman Problem (TSP).

\section{The travelling salesman problem}

The TSP is one which has commanded much attention of mathematicians and computer scientists specifically because it is so easy to describe and so difficult to solve (Hoffman and Wolfe, 1985). The problem is simply stated as: if a travelling salesman wishes to visit exactly once each of a list of $n$ cities along with the cost of travel between each pair of them, and then return to the home city, what is the least costly route the travelling salesman can take? The travelling salesman problem naturally arises as a sub-problem in many transportation and logistics applications. Most importantly, it often comes up as a sub-problem in more complex combinatorial problems, the best known and important one of which is the vehicle routing problem (Hoffman and Wolfe, 1985). It is the problem of determining for a fleet of vehicles, which customers should be served by each vehicle and in what order each vehicle should visit the customers assigned to it. More recent applications involve (Hoffman and Padberg) ${ }^{2}$ the scheduling of service calls at cable firms, the delivery of meals to homebound persons, the scheduling of stacker cranes in warehouses, the routing of trucks for parcel post pickup and a host of others. Besides these transportation applications, the simplicity of the model has led to many interesting applications in other areas.

\footnotetext{
"Market, Social and Opinion Research Glossary: Available http:/www.mrsorguk/mrindustry/glossary.hm

2 Available: http://www.tsp.gatech.edu/apps/index.html
} 
Variations on the travelling salesman problem include the resource constrained travelling problems. Kubo and Fujisawa (1997, p.10) developed the Life Span Method (LSM), which is a generic for combinatorial optimisation problems, and applied it to the travelling salesman problem as follows:

Given at set $\mathrm{V}=\{1,2,3, \ldots, \mathrm{n}\}$ and $\mathrm{n} \times \mathrm{n}$ symmetric matrix $\mathrm{D}=\left(\mathrm{d}_{i j}\right)$, find a cyclic permutation $p: V \rightarrow\{1,2,3, \ldots, n\}$ which maximises the cost function:

$C(p)=\sum_{i=1}^{H-1} d p(i) p(i+1)+d p(n) p(1)$

Kubo and Fujisawa (1997) argue that to minimise travelling cost is to minimise travelling distances. Hence, the problem lends itself for the following interpretation. A salesman wants to visit $n$ cities, and the distance $d_{i f}$ is the intertravel distance between cities $i$ and $j$. The $i$-th element of the cyclic permutation $p$ represents the $i$-th visiting city of the salesman. The cost $C(p)$ is the total travel distance of the salesman. The objective of TSP is to find a tour for the salesman which minimises the total travel distance. Using $0-1$ variable $x_{i j}$ which is set to 1 if the salesman visits city $j$ immediately after city $i$, the TSP is stated as the following integer programming problem:

$\operatorname{Min} \sum_{i} \sum_{j} c i j x i j$

Subject to:

$$
\begin{aligned}
& \sum_{j} x i j=1 \quad i \in V \\
& \sum_{j} x j i=1 \quad i \in V
\end{aligned}
$$

In practice I did not need many computations. Hoffman and Padberg argue that the first step to solve instances of large TSP is to find a good mathematical formulation of the problem. In simple cases, this would consist of a mathematical structure, which is a graph where each city is denoted by a point (or node) and lines are drawn connecting every two nodes (called arcs or edges). Associated with every line is a distance (or cost). A round-trip of the cities corresponds to some subset of the lines, and is called a tour or a Hamiltonian cycle in graph theory. The length of a tour is the sum of the lengths of the lines in the round- 
trip. In conducting the interviews, I used graphs as mathematical structure. I needed a set of three different graphs of which two where adjustable. It is important to note that my model (graphs) was just an adaptation of the TSP methods. In effect, while the TSP models are concerned with getting from an initial place and return back to the same place, the ending points of my graphs were the exit to the nearest zones, cities or village.

On the first and fixed graph each zone or region is denoted by a point and lines are drawn connecting every two nodes. Associated with every line is a distance. I could get from one zone to another directly, then this graph is said to be complete. But what counted more was the graph of the cities and villages within the various zones. Because there were so many cities and villages I didn't know, I worked together with the manager of the Songhail follow-up group to draw the second graph. However, other factors such as new or better routes, and the suppression of others, sometimes led to the modification of a graph structure. The third and last TSP graph related to getting from one farmer to another. Upon my arrival at the place of the first farmer in a city or a village, I drew a new TSP graph connecting the farmers I intended to visit and some other farmers it would be possible to find. When I could not find a farmer at his place I either skipped him definitively or I went to others (even those I hadn't initially included in my sample) and came back. Simply put, I could not find and interview some of the farmers that I had randomly selected. At the same time I had to interview others I randomly found at home or in their business on the recommendation of a previously interviewed farmer. In total, I interviewed 75 farmers (Table 2.1) overall.

Following my schedule I started the interviews from the region of Ouémé and tried to meet at least three farmers from the suburbs of Porto-Novo. The telephone contacts I got from Songhaï were no longer in use. From one place to another, and from morning until the evening, I could not find any of the targeted farmers on the first day. The second day, 1 decided to increase the probability off meeting the first one by leaving very early to arrive at his place by $7 \mathrm{a} . \mathrm{m}$. This tactic worked, but I had to wait until 8.30 a.m., which is when he finished his preliminary daily tasks with his fowls. While waiting, I could observe and I even helped him with minor tasks. At the outset of the interview, he asked me to introduce myself once more. Indeed, he was amazed at the helping hand I gave him and it set the foundation for a friendly discussion that took much more time (three hours) than I planned. II used the last minutes with him to adjust the second and third TSP mathematical graphs. It even happened in many circumstances that a farmer became my guide for more than a half day. Not only 
do the farmers know their own villages and neighbourhoods well but they also know each other's places well, thanks to their involvement in the local coordinations of the network of Songhail farmers (RENAFERS).

After I introduced myself to the farmers and outlined the aim of my visit, I always let them know that the interview is more a framework for experience exchanges than "an investigatory time". This means that I always allowed the farmers to ask me any question they may have. I found that while I generally followed the sequence of questions, at times I altered the sequence for each respondent as it seemed appropriate. This was especially in cases of where in the course of answering some questions the farmer addressed the concerns I was planning to explore in a later question. As the interviewer, I found myself experiencing a range of emotions. Each farmer brought his unique personality and perspective into the interview. One of the hardest challenges came with the longer talkers who would take several minutes to respond to each question. Yet, to allow the opportunity for new insights to emerge, I didn't interrupt them. Instead, I carefully followed to allow them to relate their experiences as much as they could. In addition, what amplified this issue was the friendly question at the end, which invited each farmer to share any additional pertinent information not already covered in the interview.

\subsubsection{Data analysis}

According to Yin (2003), data anallysis consists of examining, categorising, tabulating and testing or recombining both quantitative and qualitative evidence to address the initial propositions of a study. The analytical strategy for data analysis relies on theoretical propositions of the case study while thinking about alternative explanations. Such theoretical propositions are those upon which the original objectives are based; they reflect the research questions, hypothesis and would have shaped the data collection (Yin, 2003). In the frame of this research, the more general theoretical proposition from which others are derived, is that "agriculture could have a better takeoff and impacts its bearing on the overall economic development if the institutional settings, in which agricultural innovation processes are enbedded, are conceptualised in system terms and if they allow farmers to acquire innovatize capacities through adequate formal training processes.

Like in most social research, data analysis is drawn in two major steps preceded by cleaning and organising the data for analysis. This consisted of checking the data for accuracy. Indeed, after each interview I gave myself a few minutes, during which I read each question with the corresponding answer. This 
immediate checking was necessary because it has been very difficult to reach many farmers and getting back to a farmer in case of missing data would be very problematic. Once the fieldwork research ended, I entered the date into my computer according to the specific documentation structure I developed, which integrated various variables and their measures. The phase of data description followed this first step.

\subsubsection{Descriptive statistics}

Descriptive statistics is used to outline the basic features of the data in a study (Trochim, 2002). Descriptive Statistics are used to present quantitative descriptions in a manageable form. These include frequency distributions, central tendency and dispersion referred to as the spread of the values around the central tendency. They provide simple summaries about the sample and measures (Heffner, 2004). Together with simple graphics analysis, they form the basis of virtually every quantitative analysis of data. I used descriptive statistics to illustrate what is occurring in the data and what the data shows. In a write-up, I carefully selected and organised into summary tables and graphs the statistics that only show the most relevant or important information. That is not to say that all questions were not relevant. Instead, many questions have an indirect effect of helping to understand more clearly other issues (questions). It was after the data description that I could go on to inferential statistics.

\subsubsection{Inferential statistics}

Taking what is known to make assumptions about the unknown is the concern (Heffner, 2004). Inferential statistics are used to draw inferences about a population from a sample. There are specific procedures used to make inferences about an unknown population, which vary depending on the type of data used and the purpose of making the inference. Inferential statistics refer to the use of current information (descriptive statistics) in order to make assumptions about what might be happening in a population based on a sample of the population and/or to determine what might happen in the future (Trochim, 2002). They are thus concerned about generalising beyond actual observations. With inferential statistics it can be inferred that what was true for a few hundred people is also true for a very large population of hundreds of thousands of people. Usually, the researcher links each of the inferential analyses to specific research questions or hypotheses that were raised earlier in the study (Heffner, 2004). Within the frame of this study, two inferential methods are used: hypothesis testing and estimation. 


\section{Hypothesis testing}

This study is concerned with testing the hypothesis of how the knowledge gained through the Songhai training framework enhances the innovative capacities of farmers. In the most common use of hypothesis testing, a null hypothesis is put forward and it is determined if the data is strong enough to reject it. Statistical procedures consider two hypotheses while the results are always stated in regard to the null hypothesis (Heffner, 2004). In the framework of this study, if the results indicate that the researched Songhaï farmers have demonstrated outstanding innovative behaviours, then the null hypothesis would be rejected and, by definition, the alternative accepted. In effect, the null hypothesis states that there is no change or difference as a result of the independent variable: the Songhaï training. In this study, the null hypothesis is put as follows:

H0: "The farmers have not demonstrated innovative patterns attributable to the Songhaï entrepreneurial training, in which they have participated..

H1: "There is evidence that the farmers have demonstrated innovative patterns as the result of the innovative capacities they have acquired through the Songhail entrepreneurial training process.

\section{Regression analysis}

In estimation, the sample is used to approximate a parameter, and a confidence interval about the estimate is constructed. A confidence interval is a range of values with a specified probability of containing the parameter being estimated. While there are many specific procedures available for estimation, the nature of the data implies that this study uses regression analysis. Regression estimates relationships between independent (explanatory) variables and a dependent (outcome) variable. It is a statistical technique used to find relationships between variables for the purpose of predicting future values. This study uses a multiple regression, which helps determine the relationship between the continuous process of innovations or, more precisely, innovative behaviours $(Y)$ of farmers and the occurrence of different types of innovations as explanatory variables. Specifically, it enlightens factors that most influence agricultural entrepreneurship among the farmers and the extent to which they do so. 


\subsection{Conclusion}

I have described the principles and processes I followed in developing the research design, interview guides and questionnaire used in this study. I have attempted to flesh out the process by describing my own experience. The prospect of conducting these in-depth personal interviews required that I engaged in a significant amount of pre-planning and forethought. Overall, I gained a renewed sense of the farming activities as they are actually handled at present. The diversity of perspectives and experiences made the fieldwork exciting and challenging and I expect it to be rewarding. Thanks to my farming background, I could gain sounder significant insights into what farmers said and what $\mathbb{I}$ saw in their farms. Through the vehicle of in-depth interviews, I was able to explore the richness and complexities of farming activities across the different agro-ecological regions of my country. I discovered many farming activities and systems of which I had not previously been aware. I cannot escape the truth that each person and each relationship had a special uniqueness and I made many new acquaintances. 
a

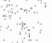

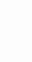

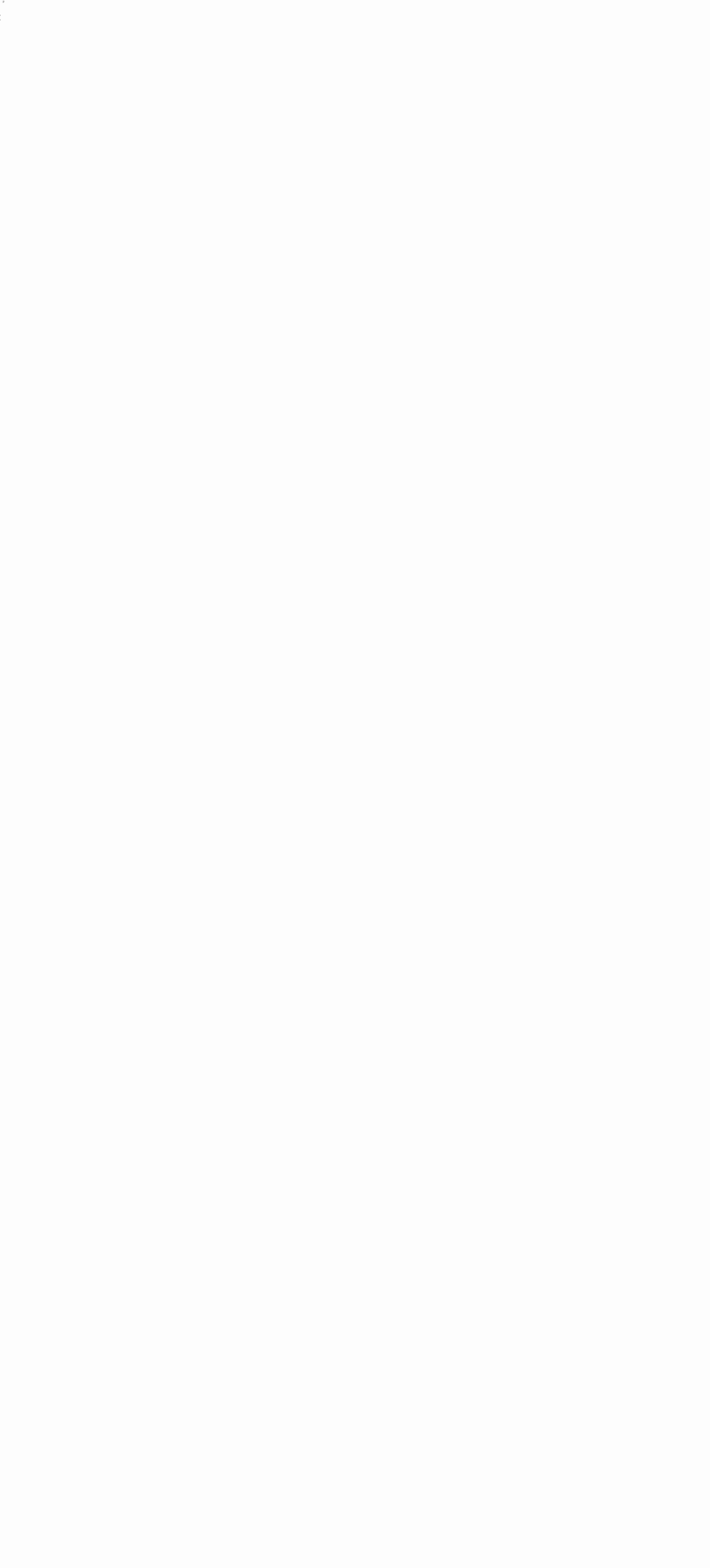




\section{Innovation and Entrepreneurship Theories}

\subsection{Introduction}

Stein (2003) describes Africa as a continent mired in a profound developmental crisis, which is basically structural in nature. He points out that structural adjustment has exacerbated the deteriorating African economies, already unable to recover from colonial and post-independence inadequacies. The corollary is a pervasive developmental crisis defined as "the generalised incapacity of the economies to generate the conditions necessary to a sustained improvement in the standard of living" (Stein, 2003, p.153). According to Nzamujo (2002), this crisis resulted in the bad development equation that was written for the continent. For Stein (2003), rewriting this equation bears at its core a variety of issues such as state transformation, agricultural development, industrial and export diversification and resources mobilisation. The main concern in this study is innovation and development in SSA. Because agricultural activities constitute the foundation of SSA economies (Olomola, 2002) in the sense that they occupy the bulk of the active population (Jalloh, 2002), the research is directed toward agriculture: it tackles the issues of economic development from some aspects of agricultural development.

Innovation, 'the servant of many masters', is of special interest as it constitutes a key factor motivating productivity growth and development. Indeed, according 
to Johnson et al., (2003), development depends on technical and organisational changes brought about by a continuous process of innovation. That is, innovation introduces technical and organisational knowledge in the economy. In SSA where agriculture employs the bulk of the work force, enhancing agricultural production capacity through productivity increases should be a vital policy goal in a region where hunger constitutes an everyday threat. While there is a growing dissatisfaction with current patterns and processes of globalisation (UNRISD, 2001), Kaudia (2002) points out, in particular, that efforts to attain sustainability in African agriculture have been an illusion. Nzamujo (2002) refuses the status quo and asserts that to development, agriculture, as any economic sector, requires the development of the capacities of involved people; only working force can introduce innovations.

This chapter discusses the theoretical framework that supports the study. It is composed of two sections. The first section reviews innovation theories with particular reference to agricultural innovation processes. It begins with Schultz's (1964) theory, which argues that agriculture develops when research and extension agencies produce and provide farmers with productivity-increasing lechnical inputs. It debates the definitions of innovations, their functions and theories relative to their diffusion and adoption. Further, this section addresses the sources and determinants of innovations. The limits of the linear models and participatory approaches in explaining successful agricultural innovations at farmers' level, led to the consideration of the much broader and more appropriate concept of innovation systems. In discussing the national dimension of an innovation system the study highlights its main pillars including institutions, linkages and learning and poses the question of how they: apply in developing countries' agricultural context: the national agricultural innovation system (NAIS). It follows that institutional arrangements that favour learning for innovative capacities building at farmers' level are required.

The second section follows on and assumes that to ensure smooth agricultural innovation processes and enhance innovations at the level of all categories of farmers is the link to agricultural entrepreneurship. It provides a historical review of entrepreneurship with an attempt to understand how it relates to innovation. The section thus sets out a framework for identifying the skills, capacities and competencies that characterise an entrepreneur innovator. The question of whether entrepreneurs are "born" or "made" is discussed, leading to the argument that training can constitute a major determinant for the supply of entrepreneurs. Finally, it briefs some pedagogical models and contents of entrepreneurial training programmes. 


\subsection{Innovation theories}

\subsubsection{The role of agriculture in the development process}

Hirschman (1958) highlighted the role of agriculture in the definition of the concept of production linkages as an inducement for stimulating economic activities through backward and forward linkage effects. Sayigh (1959) argued that agricultural development is a prerequisite condition and advocated for its prioritisation over industrial development objectives. Nurkse (1961) also emphasised the basic principle of linked progress in farming and industrial sectors. Johnston and Mellor (1961) espoused these views and identified five market linkages through which agriculture impacts on the process of economic development. The starting point is that for the development of other economic sectors, the critical mass of the labour force needs to move from agriculture, which concurrently bears the responsibility of providing them with food and raw materials. During this process, it is also expected that agriculture generates, by the means of exports of cash crops, the foreign exchange needed for imports and necessary domestic savings required for the industry development. At the same time agriculture broadens the size of the market for industrial output. Johnston and Mellor have articulated that all five roles are equally important.

According to Timmer (2001), models of economic development widely applied in the developing countries of Africa and Latin America in the 1950s and 1960s, and up until the 1980s, neglected the potentials of agriculture as the key to integrating diverse objectives. He noticed that, by placing agriculture at the centre of the development strategy, as in the case of Japan, South. Korea and Taiwan it is possible to address the problems of rapid economic growth, economic and political stability all at the same time (Timmer, 2001). In the early stages of development, the role of agriculture is to stimulate economic grow th through the establishment of linkages to the rest of the economy. Timmer (2001) asserts that a key lesson from the sustaining rapid economic growth in Japan, South Korea and Taiwan is to use the agriculture sector to pursue simultaneously with other sectors growth and development objectives.

In its interdependent relationships with other sectors, agriculture plays a dynamic role. It is required to provide the resources ever more importantly. In the process of development, the agricultural sector is to increase the food supply for the workers of other sectors. It has also to provide higher rural incomes to enlarge the markets for urban outputs, as well as provide resources to expand urban outputs (Hwa, 1989; Timmer, 2001). This implies that, in order to play this 
role, agriculture itself has to develop. Thus, assuming that growth is the basic foundation of economic development and, in a poor country or region, agriculture is the comerstone of the economy, only strategies that include agricultural development can establish strong links for overall development (Timmer, 2001). In other words, agriculture requires going through mechanisms that increase outputs and productivity. This calls for the critical question of how agriculture develops.

\subsubsection{Theories of agricultural development in poor countries}

Schultz (1964) was one of the pioneers of agricultural development theories in low-income countries. In his famous book "Transforming Traditional Agriculture", he made it clear that farmers in low-income countries are rational and make effective use of their resources. He asserted that they are poor because the resources they have at hand are very limited and knowledge that would permit them to produce the same output with fewer resources or a larger output with the same resources is not available to them. There is little scope for the expansion of traditional resources (land, labour) beyond the amounts that exist. Since the accessible resources are being used efficiently, there are no likely productivity gains to be expected within the traditional agricultural methods. At the same time, the model assumes that peasants respond to prices and other economic incentives if any arise. The concern is not that traditional farmers are inefficient or irrational but rather that they have fewer resources.

The notion of peasant rationality as defined by Schultz (1964) implies that peasants are using the resources they have in an efficient manner and maximise profit. There is no other way the resources they have can be rearranged to obtain greater output. They are efficient producers although they have low productivity. They are using all known technology within the traditional agricultural system. Output can increase for individual households if they are able to obtain more resources. Given more land and labour, peasants will expand output. The new level of output will be greater and will be produced efficiently; but productivity will not have increased. Schultz assumed that it is technical change that causes productivity to increase. Therefore, he stressed the need to provide farmers with new technical inputs to production. 


\subsubsection{The role of agricultural research}

Addressing developing countries" agriculture, Johnston and Mellor (1961) asserted that the low productivity of farm labour, land and other resources is largely due to the lack of certain complementary inputs of a technical and institutional nature. In a study, Peterson (1978) brings evidence that while in 1978 , only about $5 \%$ of U.S. population work in agriculture, though in the 1770 s it took about $85 \%$ of the US population to produce its food. He attributes this improvement to the performance and effectiveness of an agricultural research system that has allowed increases in agricultural productivity while it became essential in the process of economic development. He viewed agricultural research as a production activity having both input and output. The output is new knowledge that comes in several forms. This knowledge is, in its turn, utilised in a variety of ways to produce or to facilitate the production of new and more efficient inputs to agriculture.

Mellor (1986) also demonstrated that even higher prices and profits have a limited impact on developing countries' farmers in increasing the quantity supplied. He asserts that to increase output, emphasis must be placed on new technology generation. Schuh (1988) documented that increases in productivity over the past 100 years in advanced countries have come largely from the application of science-based farm technology and from changes in management and inputs developed through organised research. Pardey et al, (1996) share this view and assert that although factors affecting growth and productivity in agriculture are manifold, there is particularly convincing evidence that investing in a functioning agricultural research system is a requisite component of a successful development strategy. In this respect, Schuh (1997) and Tribe (1997) also view agricultural research as the core of technological improvement. However, while Schuh stresses the need for capacity development in research and extension, Tribe emphasises the need for appropriate policies and supportive institutions aiming at promoting the generation of the new technologies. Thus, the role of agricultural research, as part of development strategies, is to generate new production technologies (Pardey and Beintema, 2001). In fact, prior to them, Hayami and Ruttan (1991) combined these views and claimed that central to the theories of agricultural development is the concept of technological and institutional innovation. 


\subsubsection{Definition and domains of innovation}

Innovation cuts across a broad range of activities, institutions and time spans (Botkin et al., 1983) implying a wide range of definitions for innovation. Though there are commonalties in the definitions of innovation among the different disciplines, it appears that the definition of innovation is not identical in all domains. Also, depending on the level of economic development, on region or culture and many other factors, conceptualising such concrete things as innovations may have different connotations, thus denying any universality. In this study innovation will be viewed in a context of backward agriculture in a developing country. Before approaching the contextual definition, let us explore some other general definitions.

Innovation denotes an activity and describes a process that embraces theoretical conception, technical invention and commercial exploitation (Hamilton-Howard and Howard, 2000). It should be understood as the work of developing an invented element for practical and commercial use and of ensuring that the introduction of the element is accepted (Adjebeng-Asem, 1995; Verspagen, 2001). This definition emphasises innovation as a process but views it as antecedent of invention. The innovation process conveys the idea that new products or services are the result of the innovation process, which goes through all phases of a business and implies creativity, marketing, research and development, design, production and distribution (European Commission, 1995). The distinction between invention and innovation is that invention is the creation of a new idea or concept, and innovation is turning the new concept into commercial success or widespread use. In my view however, successful introduction of new goods or services into the marketplace may be an antecedent of an innovative behaviour. Innovation can be thought of in terms of a new and better product even at a higher price, a new convenience or the creation of a new want and finding new uses for old products (Drucker, 1986).

Also defined as a process (process innovation), innovation implies changing the way individual economic agents or production units perform tasks in order to carry them out in a better and more efficient way but without necessarily changing the product. It may be innovation in design, product, process and marketing techniques (Treloar, 1999). It may be innovation in management organisation or management methods and an improvement of the instruments or methods of doing innovation itself (Kline and Rosenberg, 1986, Lundvall, 1992; Sundbo, 1998; Vesrpagen, 2001). It may be innovation in the price or service offered to a customer (Drucker, 1986). Indeed, innovation is also an economic and social, rather than exclusively a technological issue. 
Whitehead (1925), as cited by Mowery (1990), incorporates another dimension to innovation: institutional. Without making a differentiation between invention and innovation, he argues that the greatest invention of the $19^{\text {th }}$ Century was the invention of the method of invention. Mowery (1990) refer's to this method as the institutionalised processes of transforming intellectual and physical capital into new knowledge and technology. These processes take the form of industrial research laboratories, agricultural experiment stations, and research universities (Ruttan, 2001). In the sense of this definition, institutions denote organisations or institutes or bodies. But for Ruttan (2001, p. 119), institutions are also :

\footnotetext{
${ }^{*}$ Social rules that facilitate co-ordination anong people by helping them form expectations to deal with each other. They reflect the conventions that have evolved in different societies regarding the" behaviours of individuals and groups".
}

Like technology, argues Ruttan, institutions must also change if development is to occur. This is because their past potential of generating growth can be revealed as being obsolete, thus becoming an obstacle for further economic development. Meyer-Krahmer (1998) also has argued that as far as innovation is concerned, institutions may exert negative influence. Static, they may lead society to miss opportunities and act inappropriately when circumstances change. Institutional innovation is clearly viewed as induced by technological innovation with which it co-evolves (Ruttan, 2002).

Other characteristics of innovation brought to supplement discussions distinguish between radical and incremental innovations. While radical innovations are defined as qualitatively new and different elements that change a whole field, incremental innovations concern small improvements that occur continually through the introduction of smaller new elements (Kline and Rosenberg, 1986; Sundbo, 1998; Verspagen, 2001). The generation of radical innovations may require substantial $R \& D$ inputs, whereas other categories are based on various types of activities such as purchasing machinery, engineering or design, organisational and institutional changes, collaboration and interactions between different agents. Innovation may be defined by its identification mechanism, better than in general. The objective of the innovation concept is to help identify the important and worthy phenomena. This can probably be shown in that a meaningful conceptualisation of any innovation related issue is often given in a complementary form. 


\subsubsection{Contextual definition of innovation}

In the frame of this study innovations are conceptualised, primarily, based on Schumpeter (1934, p.51-52) who viewed entreprenetrrship as innovative activity. The definition of Niosi et al. (1993) summarises the major points: "Innovations are net and improved products and processes, new organisational forms, the application of existing technology to new fields, the discovery of new resources, and the opening of new markets". Moreover, specific to the field of agriculture, is also equating innovation to the adoption of innovation. When agricultural production units in developing countries, for example, have access to developed countries' markets, they usually need to undergo new institutional (norms), technological (new machinery) and organisational (management with respect to new technologies and norms) arrangements (Hall et al., 2003).

The research results of Ryan and Gross (1943), for example, support this idea when they characterise early adopters of hybrid seed as innovators. They are pioneers who adopt innovations very early in the diffusion process. The concepts of multiple innovations (Rogers, 1995) and innovation cluster (Treloar, 1999) support this view. They assert that sometimes the introduction of an innovation requires simultaneous use of other innovations. Anderson (1992), for example, highlights that it is more likely that, adopters of an innovation will adopt other innovations. In this connection, he made the case of the IITA breeding programme that has developed new cowpea varieties, which were found to be more productive in almost every sense than the varieties they were intended to replace. Anderson (1992) explains that introduction of these new cowpea varieties implies the availability and use of other technologies. This means that the adopters would have to reorganise their production activities, which may require new techniques or methods of handling the usual tasks (soils preparation, sowing, harvesting or conservation). A definition linking innovations to their causes is the one proposed by Wheatley (1992. p113):

"Innowation is fostered by information gathered from new connections: from insights gained by jowrueys into other disciplines or places; from active, collegial networks and fluid, open bonndaries. Innowation arises frown ongoing circles of exchange, where information is not just accumulated or stored, but created. Knowledge is generated anew from connections that weren't Nere before."

However, field specialists fail to explicitly put at the heart of their definitions the role of individual economic agents. Innovations do not occur at random and/or without human action. No matter how innovations emerge, they are purposive outcomes of economic agents struggling to establish and defend competitive 
positions in various markets. In effect, as Summers (1974) argues, understanding how the economic system produces what society wants in the manner it deems most efficient requires focusing one's attention on the actions of individuals. When one understands these actions, then one understands the actions of society, for society moves only as its individual members move (Summers, 1974). Thus, in the framework of this study, innovation as human action will denote one or several of the following:

a) Farmer(s) introducing and successfully commercialising new or improved products.

b) Farmer(s) introducing and using new methods or techniques of production.

c) Farmer(s) introducing new forms of agricultural enterprises and managing them.

d) Farmer(s) making new use of existing products or defining new production functions based on existing production factors and obtaining better results.

e) Farmer(s) creates new markets for existing products or accessing existing markets with new products; farmers creating new distribution channels.

f) Farmer(s) discovering new resource sources or new ways of accessing existing resources or discovering new resources. Embodied in this notion of discovery is the farmers" ability for successful exploitation of the resources.

g) The process of farmers bringing any new problem-solving idea into use or new ways of doing ordinary things for new purposes.

h) Farmer(s) acquiring, imitating and adapting technology developed elsewhere to their socio-economic and agro-ecological environments.

i) Farmer(s) exploring for commercial purpose, through formal (organised) or informal search, new ideas, products and process, methods and techniques with their effective translation into economic value.

\subsubsection{Functions of innovation}

Fundamentally, the role technological innovations could play in developing countries' agriculture has been elaborated by Schultz (1964), followed by others such as Peterson (1978), Johnson and Mellor (1961), Hayami and Ruttan (1985), among others. And still, there is more to innovations. According to Sundbo (1998), innovations are tools that create more value added with qualitative 
change. As such, it appears obvious that innovations are vital for growth and the maintenance of competitiveness at individual, firm and national levels (Clark, 1987; Johnson et al., 2003; Nelson, 2004). At the macro level, the most widely used indicators relate to international trade with an attempt to determine the significance of innovations for export performances (Soete, 1987; Fagerberg, 1987). At individual or firm levels, competitiveness is defined as the ability to increase in size, market share and profitability. It also is determined by comparative cost of production in traditional economic theory (Clark and Guy, 1997). In evolutionary approach, even though the need to innovate is not an imperative for the survival of individual firms, innovations are treated as a collective necessity for economic well-being (Nelson and Winter, 1977).

\subsubsection{Diffusilon and adoption theory}

Ishikawa (1981) and Kline and Rosenberg (1986) assert that innovation is a process involving not only a mere generation of something new. The new must be associated with its diffusion and adoption and is affected by the existing knowledge under sociall and economic constraints. Along the same lines, Dodgson and Bessant (1996) argue that innovation is not an instantaneous event, but a time-based process involving several stages. These include initial recognition of opportunities or needs, search, comparison, selection, acquisition, implementation, and long-term use. Rogers (1995) defines diffusion as the process by which an innovation is adopted and gains acceptance by members of a certain community. Following this definition, four major factors interact to influence the diffusion of an innovation. They include the innovation itself, how information about the innovation is communicated, time, and the nature of the social system into which the innovation is being introduced. Diffusion research investigates how these major factors interact to affect the adoption of a specific innovation among members of a particular adopter group (Surry, 1997). In general, four basic concepts dominate diffusion theories (Rogers, 995).

Inwovation decision process concept states that diffusion is a process that occurs over time and can be seen as having five distinct stages. The stages in the process are knowledge, persuasion, decision, implementation, and confirmation. It implies that potential adopters of an innovation must learn about the innovation, be persuaded as to the merits of the innovation, decide to adopt and implement the innovation, and confirm (reaffirm or reject) the decision to adopt the innovation (Rogers, 1995). 
Individual innowativeness implies that individuals who are predisposed to being innovative will adopt an innovation earlier than those who are less predisposed (Rogers, 1995). Those who have been found as predisposed and who adopt an innovation very early in the diffusion process are called innovators. Rogers (1995) characterised them as risk takers, as the entrepreneurs in the sense of Knight (1921) and, pioneers or leaders as Schumpeter (1934) defined entrepreneurs.

The concept of perceived attributes states that potential adopters judge an innovation based on their perceptions in regard to its relative advantage, compatibility, complexity, trialability and observability. An innovation will experience a higher increased rate of diffusion if potential adopters perceive it as having these characteristics (Rogers, 1995).

The causes underlying the poor diffusion of agricultural technologies to all categories of farmers in the least developed countries remain a sort of mystery to the field. Diffusion theories investigate how these major factors, and a multitude of others, interact to facilitate or impede the adoption of a specific product or practice among members of a particular adopter group (Surry, 1997). By better understanding these factors, actors concerned with agricultural production and development are supposed to be better able to develop approaches that enhance smoother agricultural innovation processes. Rogers' theory thus provides one valuable "hook" on which research and practice can be hung: the analysis of innovation adoption behaviours from the perspective of factors that fall under the sphere of control of the adopters. Given an innovation, it is the personal capacities (skills and competencies) of the potential, adopters that most determine the pace and rate of its adoption.

Rogers distinguishes between five categories of adopters, ranging from "innovators" to "laggards" as derived from their time of adoption. This offers the generalisation that, given the technical characteristics of an innovation, it is the socio-economic status of the adopters, their personality characteristics, and communication behaviours that determine how quickly they adopt innovations. Assuming that socio-economic status is the result of successful application of one's outstanding or progressively developed skills and competencies throughout some years of endeavours, then what really counts is the adopters' personal ability. Assuming that communication behaviours are not innate to people, but are developed through mechanisms of purposive search, they also pertain to personal characteristics of the adopters. 
Indeed, most agricultural technologies, either embodied or disembodied, typically, constitute production factors for their users. Adopting them results in increased production capacities or quality and productivity improvements. A knowledgeable farmer would not adopt them just because of their technical characteristics, their relative advantages over the exiting ones or just because of their technical performance or economic importance. All must couple with the farmer's ability to use them and with his/her ability to predict and handle the subsequent outcomes. Adoption depends also on the farmer's ability to set clear production objectives and then seeks innovation paths leading to their achievement. As Andersen (1992) argues, the adoption of certain agricultural innovations often requires the adoption of some complementary technologies. To gather together all resources needed to meet the innovation's requirements, the farmer must have versatile knowledge, skills and competencies.

\subsubsection{Channel for agricultural innovation diffusion}

Rogers (1995) defines the social system as a set of interrelated units that are engaged in joint problem solving in order to accomplish a common goal, and forms a boundary within which an innovation diffuses. The members or units of a social system may be individuals, informal groups, organisations, and/or subsystems. If communication is the process by which participants create and share information in order to reach a mutual understanding, a communication channel is the means by which messages get from one individual to another (Rogers, 1995). Emphasised here is the idea that the means and medium through which information is received affect potential adopter's decisions (Rogers, 1995). Agricultural extension has been an important channel for the diffusion of agricultural innovations.

Agricultural extension services can be traced back to the 1860 s when James Stuart gave lectures to women's associations and working men's clubs in the north of England. In 1871 he appealed to the authorities at the University of Cambridge to organise centres for extension lectures through the university (van den Ban and Hawkins, 1996). Drawing on this example, many researchers realised later on that simply reading or hearing about new findings would not in itself change farmers' practices, On one side, efficient and rational farmers with old practices (Schultz, 1964) would welcome any new methods enabling productivity increases; on the other side stand university researchers whose findings are waiting to be proven in the fields. It is reported that in the 1950s, universities in the US developed a large number of high-yielding technologies (such as hybrid corn) that were deemed beneficial for farmers (van den Ban and Hawkins, 1996). 
However, the major concern was how to bridge the two groups of agents. If researchers were aware of farmers problems, farmers had no idea about university research results that could solve some of their problems. Logically, researchers sought a way and the means to enhance the application of their findings by farmers. Agricultural extension agents were to disseminate university agricultural research through demonstrations on farmers' own land (Rasmussen, 1989).

Extension workers must be able to understand and work with both academic professionals and farmers. Their role is twofold. Extension agents seek, either to educate farmers so that they may make their own informed decisions, or they inform farmers of new practices and innovations and try to persuade farmers to adapt and adopt them. Extension workers need to keep in mind the characteristics of the innovations they intend to disseminate (Clarke, 1999). Extension as the main channel for agricultural imnovation diffusion has not been static but dynamic. It has evolved over time and diversified to various approaches as described in chapter 2 , section 2.1.3.

Summing up, this study argues that an important contribution of the innovation diffusion theory, and which has not been properly grasped, is the characteristics of the different categories of innovation adopters. In this categorisation, Rogers (1995) defines innovators as being venturesome, mobile and daring. They are risk takers and have the financial resources to absorb innovations; they understand and apply complex technical knowledge to cope with a high degree of uncertainty. The innovators are visionaries with higher aspirations. Innovators have interest in new ideas, leading them out of local circle of peer networks and into wider social relationships.

Unfortunately researchers and other development actors had not tried to grasp how to "produce" such innovators, as Rogers (1995) describes. They ignore that it is the individuals who make the decision about adoption. More concretely, it was neglected that individuals themselves must have the abilities to perceive (Clark, 2001) the attributes of innovations based on their knowledge, skills and their objectives. To understand how this happened, there needs to be a review of the models that have shaped innovation processes.

\subsubsection{Linear models of innovation: An overview}

How innovation occurs, what forces are at play and how they interact are the questions, which underpin innovation theories (Sundbo, 1998). They aim at developing a theoreticall understanding of why and how innovations arise and 
tend to shed light on the factors that generate innovations, how innovation processes arise, organised and supervised both at micro and macro levels (Sundbo, 1998). Bringing these issues into discussion is of great importance because the way innovations are understood and the sources of innovations are conceptualised affect research and innovation policies in the economy (Sundbo, 1998). Literature review distinguishes a number of models that attempt to explain the mechanism through which innovations occur. The linear models and the system approaches account for the main models. Between the two, Rothwell (1994) identified the coupling and integrated models.

Fundamental to this concept is a one-way source of innovation. According to Basalla (1988), of all determinants of innovations, two have predominantly emerged and retained particular applications. The "science and technology push" model represents innovation as resulting from new ideas in basic science recognised to have commercial potential. The other, "demand pull", portrays the process as stemming from a market need detected and exploited by the innovator (Clark and Guy, 1997). They both emphasise the role of market. Innovations are stimulated by the push of growing supply of knowledge or by the pull of increasing demands of the marketplace. Unlike in industrial sector, where other market forces account for the determinants of innovations, and in the case of developing countries' agriculture in particularly, only technology push theory has for long dominated issues (Clark, 2001).

\subsubsection{The linear model of agricultural innovation}

Agricultural research is believed to be the only active force pushing the innovation process and major emphasis was put on the transfer of knowledge and technology from research centres, while farmers were rather passive receivers of a preconceived solution (Clark, 2001). In this model new technology development goes through three stages (Clark, 2001). First, widely adaptable technologies in the form of materials, management packages, blueprints, research methods and institutional forms are generated at international agricultural research institutes such as those members of the Consultative Group on International Agricultural Research (CGIAR) and the Overseas Development Natural Resources Institute, London (Biggs, 1990). Second, these technologies are transferred to national research institutes for adaptive research. At the third stage, national extension systems transfer the new technologies from national research institutes to farmers. 
For Rogers and Bozeman (2001) however, innovation and knowledge flows cannot be assessed independentiy from the collective arrangement of skilled people, their laboratories and instruments, their institutions, and their social networks of communication and collaboration. Indeed, observation shows that there are, in fact, several sources of technology that research itself is being driven by economic and political forces, and that every innovation process is bound to specific economic and institutional circumstances (Kline and Rosenberg, 1986). Thus the innovation process is recognised as a continuous learning process that evolves in cycles, in feedback loops between technology users and the providers of technological services. This process can start at any point, be it a research idea, a practical farming problem, a market opportunity or a development project supporting local initiatives (Kline and Rosenberg, 1986).

\subsubsection{Participatory approaches in agricultural innovation processes}

Science and technology affect agriculture only if $R \& D$ results translate into innovations (Chambers et al., 1989). In the 1980s however, it was noticed that the majority of farmers, most of whom were smallholders, had not adopted the new technologies generated through R\&D mechanisms (Chambers et al., 1989). According to practitioners, these technologies did not meet the needs of farming under precarious conditions (Asiabaka, 2002). Scientists developed and recommend poorly-suited technologies that many poor farmers rejected (Norman et al. 1995). In effect, under the prevailing institutional setting, researchers usually misjudged the complex priorities that farmers must balance. As Chambers et al. (1989, p.55) put it,

"Mast professionals assume thy know what farmers want and need but are often wrong. Not knowing farmers priorities and not putting farmers' agendas first mean that professionals are likely to address the wrong problems in their research. Conversely, identifying farwers "priorities and helping farviers met them leads to innowations which are adopted."

The conventional research paradigm needed to be modified drastically and replaced by one that would involve farmers as stakeholders from the beginning of the technology design process (Farrington and Martin, 1988). The prescription aimed to change the model with emphasis put on the so-called "farmer participation". This approach would encourage analysis by farmers and enthances changes in the attitudes of researchers and farmers (Asiabaka, 2002).

To make sure that research takes account of the needs of technology users, local resource constraints and risks, farmers need to be involved in the planning, implementation and evaluation of research activities. For Okali, et al. (1994), the original idea stemmed from the recognition of the value of local knowledge that 
warrants the interest in farmers' involvement. However, Agrawal (1995) and Sillotoe (2000) admit that involving farmers became more than a simple recognition of the contributing effect of their knowledge. They assert that it was compelling and that there was no other way ahead. Okali et al. (1994) stressed that farmer participatory research aims to operate at the interface between knowledge systems. It can be described as a people-centred process of purposeful and creative interplay between local individuals or communities on the one hand, and outsiders with formal agricultural and research knowledge on the other. A wide range of approaches and methods to achieve this exist. In the present study, we will refer to some of those used in agricultural research and extension.

\subsubsection{Farming Systems Research (FSR)}

Experiences during the 1960 s and early 1970s revealed that farmers are rational in the methods they use. They are natural experimenters and understand the environment in which they operate rather complex farming systems (Norman, 1993). Associating them with researchers would help in identifying the appropriate path for agricultural technology development. Farming sysitems research was then introduced into many national and international agricultural research institutes in poor countries with the purpose of improving the relevance of research for small-scale farmers (Petheram and Clark, 1998). It is a process of "research" and "co-learning" involving iterative stages of observation, analysis, action and evaluation, carried out jointly by farmers, researchers and extension agents (Norman, 2002). For Gibbon (2002), farming systems research is an active partnership of farmers and other stakeholders in the process of designing. planning, implementing, monitoring and evaluating research.

However, despite its echo during the early years of implementation, this approach was criticised for been too scientific and technologically oriented (Norman, 2002). It required communicating the results to those not directly involved in the process and usually requires further extension activities (Norman et al., 1995). From there, other methods such as farming systems to development (FSD) and participatory technology development arose with the objective of taking account of social and economic aspects of farming life (Norman, 2002). 


\subsubsection{Participatory Technology Development (PTD) and On-Farm Resench (OFR)}

PTD, OFR, and Client-Oriented Research (COR) are all generic forms of participatory approach to agricultural R\&D. While PTD describes a general methodology, OFR is a set of techniques for conducting research in close cooperation with farmers and under real-life conditions. The aim is to rapidly identify factors limiting production, and test potential solutions for their economic and social acceptability by way of on-farm experiments. A common characteristic they share is that research is done in cooperation with researchers involving farmers, farmers' organisations and extension agents.

\subsubsection{Participatory Action Research (PAR)}

Deshler (1995) views participatory action research as just a process of systematic information inquiry that brings researchers and members of a community together to work and apply that information to the benefit of the community. For Dick (1999) however, the process goes beyond mere information gathering. It is about knowledge, which stimulates changes. He defines participatory action research as a flexible spiral process, which allows action (change, improvement) and research (understanding, knowledge) to be achieved at the same time. This framework sees research as being embedded in the social world and attempts to remove the distinction between the researcher and the subjects by engaging scientists and community members in the process of inquiry (Dick, 1999). For Brown (1985), the approach transcends research. It engages non-scientists into the inquiry by incorporating education and action directed toward social or institutional change. It focuses on local problems and builds coalitions among researchers, community members, government agencies, and non-prolit organisations and brings them together in collaborative action (Browm, 1985).

\subsubsection{Extension approaches}

Historically built on the linear agricultural R\&D model, extension services serve as a vehicle to transfer agricultural technologies from researchers to farmers. Logically, the objective is to enable farmers to increase the quantity and quality of agricultural production through the introduction of innovations (Röling, 1995). A number of participatory approaches and methods also arose ir extension. They include Training and Visit System (T\&V): Contract Farming; Strategic Extension Campaign; Farmer-to-farmer extension; Partner-centred Extension; Farmer-first; Beyond farmer-first; farmers field schools (Chambers et al., 1989; Wilson, 1992; 
Foster et al., 1995; Hunter and Hayes, 1996; Röth, 2001). Here we just brief the farmer field school approach.

\subsubsection{Famer field schools}

The Food and Agriculture Organisation (FAO) was the first to initiate (1978) and promote farmer field schools as a practical way of diffusing knowledge-intensive integrated pest management (IPM) concepts and practices for East Asian ricebased systems (Kenmore 1991). According to Pontius et al. (2000), the farmer field school approach to extension emerged from the need to address some negative effects of the Green Revolution. It is a group learning approach intended to build knowledge and capacity (analytical skills, critical thinking and creativity) among farmers to enable them diagnose their problems, identify solutions, develop plans and implement them with or without external support (Asiabaka, 2002). Farmer field schools are also expected to bring about costeffective knowledge diffusion and financial sustainability (Feder et al., 2003). They have evolved from integrated and pest management issues to include a much broader coverage of other farm-relevant topics (Pontius et al., 2000; Asiabaka, 2002). Training sessions in the Philippines and China (FARM) ${ }^{1}$, Kenya (Mureithi and Njue, 2001) and in West Africa (Benin, Cameroon, Ghana and Nigeria) also encompass integrated soil management techniques and plant protection (Asiabaka, 2002).

\subsubsection{Impacts of participatory research and extension approaches}

Participatory research and extension methods have emerged since the 1970 s to create a framework enhancing new institutional relationships among researchers, extensionists and farmers (Wilson, 1992). Farmer participatory research and extension approaches aim to empower farmers to develop their own solutions to agricultural problems and to develop and disseminate technologies more appropriate to their own farming systems. More concretely, research and extension participatory approaches are supposed to boost the process of agricultural development by improving the effectiveness of technology development, raising adoption rates, and increasing the payoff to agricultural research. What have been the achievements of these methods to date?

Assessment reports are contradictory on the potentials of participatory methods. Van den Berg (2004) remarks that impact studies published in official literature

\footnotetext{
1 FARM - Farmer lield School Bulletin. hotp://dbtindia, nic.in/farm/intro.htm
} 
tend to focus on specific aspects of impact. They varied in focus, approach, methodology and robustness. Pilot projects often compared pesticide use and yields or profits of field plots grown with IPM practices and those under regular farmer practice, to demonstrate the merit of the approach. Bunch (2002) for example reflects the enthusiastic view:

"I have been very jupressed with the results that FHS hate achieved. Because of its very positive results (tremendous decreases in the use of pesticides, by hudreds of thousmads of furmers, oter a relatively short period), Ifeel FFS is one of the most important, even most exciting and certainhy one of the" most successful, agricultural extension efforts in the worlat foday" (Bwnch, 2002, pr.1)

In their book "From Farmer Field Schools To Community IPM - Ten Years of IPM Training in Asia", Pontius et al., (2000) reported interviews with some women farmers who had participated in farmer field schools:

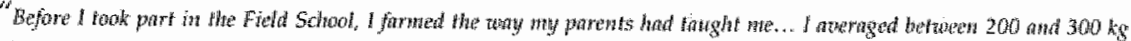

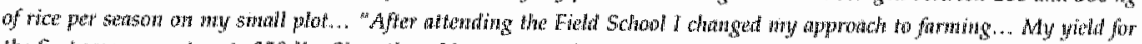

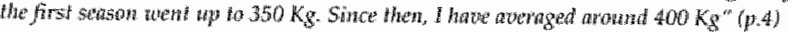

Yet, impact assessment studies by Feder et al. (2003), focusing on economic benefits, do not indicate that farmer field schools in Indonesia have induced significant improvements in yields or a reduction in pesticide use by graduates relative to other farmers. Also, secondary diffusion effect on those exposed to graduates is neither significant. Astone (1998) demonstrated that researchers employ participatory methods to gather background information, after which local people have little or no role in influencing the flow or interpreting the research content. Seldom are they even informed of the outcomes of the research or its conclusions. In the absence of objective and conclusive impact assessments of participatory agricultural $R \& D$ and extension approaches, the study raises a number of questions regarding their potential in affecting agricultural innovations processes.

\subsubsection{Questioning participatory research and extension approaches}

a) Assuming that poverty was the main cause of the farmers' inability to adopt the promoted technologies, a number of questions are posed. The first concern relates to the price of the new technologies that may appear too high for the farmers to bear. Also, high prices may result from high production and delivery costs. Under such simple facts, the question is how does participation reverse the situation or by which mechanisms participation affects these costs 
and consequently allows prices to become affordable to all farmers (including those who have not participated in the research and extension)?

The second issue addresses the farmers' incomes. Assuming that the prices of the new innowations are normal and that it was the insufficient level of the farmers" incomes that mattered then, follows the question: is there any mechanism through which participation allows increases in farmers' incomes? In effect, while researchers and extension agents are paid salaries for the work they do, what do the participating farmers gain as a reward for their active involvement? If they are paid some money, that leads to income improvement, what about those who have not participated in the projects?

Finally, if the non-adoption of new technologies is just attributable to farmers' lack of money, can we thus, ascertain that providing financial assistance to the farmers will result into automatic adoption of these technologies? Suppose that the participatory research and extension managers grant for free to the participant farmers the new appropriate technologies as a reward for their participation. Even in this case, adoption rates may not increase since the bulk of resource-poor farmers cannot participate.

b) If we simply accept the argument (of proponents of participatory approaches) that holding small land surfaces was the reason of non-adoption of innovations (under the liner model institutional settings), which mechanisms are available through participation and which allow farmers to increase their farmlands? Even if participation was a means for farmers to have access to more land, what is the evidence that granting more land will lead to the adoption of new technologies? In effect, agricultural production requires a set of diverse inputs. How can one ensure that having more land necessarily enhances the flow of other farming production factors? When promoters of participatory research and extension mention large-scale farmers or wealthy farmers as the adopters of technologies generated and disseminated under the linear model institutions, they however do not provide any other characteristics of these farmers. Is there any evidence that these two factors alone suffice to explain the adoption?

c) Assuming, as the proponents of participatory methods, that the lack of a comprehensive knowledge about farmers' problems and the neglect of farmers' knowledge (indigenous) was the main cause of inappropriate technologies that farmers did not adopt, how can one ensure that knowing the real needs of poor farmers will necessarily lead to the generation of 
technologies appropriate to their farming systems? Indeed, it was argued that what to outsiders (researchers and extensionists) may seem to be the most obvious problem, does not necessarily have to be experienced by the inhabitants of a given area as being the most important problem (Liebenberg and Theron, 1997). Therefore, allowing the farmers to shed light on the issues the community perceives as reall problems, will help generate technologies responsive to the farming communities ${ }^{t}$ needs.

Yet, the finding of Kline and Rosenberg (1986) challenges the hypothesis and contends that there exist many technologies that would have important advantages in the marketplace. However, they cannot be realised because of current natural issues or technical infrastructure barriers. Advocates of participatory methods found a way to increase their scientific and technical knowledge by adding to the participating farmers' indigenous knowledge. Still, this study maintains that there is no way to ensure that this mixture of knowledge will necessarily engender a better solution to farmer's complex problem. The problems farmers face are not only of a scientific and technical character. They also transcend natural hazards and some of them are socially embedded. How does then a mere participation contribute to finding solutions that would increase the rate of adoption of new technologies?

d) Without questioning the non-discriminatory methods that apply in the selection of participant farmers, this study raises a number of important issues related to the promises of participatory agricultural $R \& D$ and extension approaches. What is the status of the participant farmers? What underlines or motivates their participation? Is it the expected empowerment based on additional skills of carrying out certain technical tasks? R\&D undertakings are often costly, financially risky and their results are uncertain (Kline and Rosenberg, 1986). Because of the high costs associated with agricultural research and extension services, developing countries usually rely on donors' assistance. In particular, participatory research and extension are donorfunded projects with limited duration while restricted in subject focus. In addition, there is a certain gap between research and research results testable and effectively applicable as innovations on farms. It is also known that research does not always lead to technology development. In case the project fails to generate the expected innovations, what compensates for the hope and the work of the farmers while researchers have already been paid for the work that becomes unfruitful? 
e) The skills a farmer can gain through participation, if he/she is not just an information provider, are mostly technical in nature thus confined to production. Therefore, put in the general context of successful agricultural innovations, the so exalted empowerment is just illusory. Indeed, new technologies generated and/or disseminated through participatory channels may not be the sole inputs to farming activities of a farmer. Under the assumption that the farmer has been able to acquire the new technologies in which he/she participated, how then does the participation in one or few projects, allow him/her to master other production factors? Moreover, one does not adopt a new technology (as a factor of production) just because the technical characteristics of the new technology allow him/her to perform tasks. aimed at. Also, producers do not buy new technologies just because they have enough money. New innovation adopters think mostly about the additional payoff the new technology is to enhance. Someone may object and argue that not all new technologies are associated with high cost and, some new crop varieties or animal races and or new practices may be available at very low cost. If such an argument holds, why then is the focus on resource-poor farmers?

f) Troublesome for me, when reading about the different approaches and methods, is the extent to which researchers believe in concepts: the concept, the approach, the methods... allows, permits, enhances... I do not believe that concepts, approaches, methods or models allow something. The power to change things is not even at the side of concepts. Instead, I view the approaches or concepts as a set of tools and try to understand the real circumstances, under which I can apply any of them to serve a well-defined purpose. A tool may not be a ready-made food or drink. It is to be used and, even the use may require certain skills, competences or prior experience though minor. Finally, should it be fair to think about these various approaches, methods and concepts as Rosenberg has since 1994 written about the linear model of innovations?

\footnotetext{
"Exeryone knows that the linear model of innovation is dead. That model represented the inwowation process as one in which technological change was dosely dependent upown, and generated by, prior scientific research. It was a wodel that, however flattering it may have been to the scientist and the acadewnic ans econonically nate and simplistic in the extreme. It has been accorded numerows decent burials" (Rasenberg, 1994).
} 


\subsubsection{Systems approach to innovations}

According to Freeman (1995), as cited by Johnson et al. (2003), some basic ideas behind the concept of system of innovations go back to Friedrich List (1841) whose analysis focuses on development of productive forces rather than resources allocation issues. In terms of national production systems, List pointed to the need to promote the accumulation of mental capital and use it to spur economic development rather than sitting and waiting for the invisible hand to solve all problems (Johnson et al., 2003). This should be done by including a wider range of institutions such as those engaged in education and training, as well as transport infrastructures (Johnson et al., 2003). A system approach to innovation thus put on the ground of discussions the salient determinants of innovation processes. These include economic factors as well as institutional, organisational $_{x}$ social and political factors influencing innovation processes. When defined as a system whose objective is to produce, diffuse and use new and economically useful knowledge (Lundvall, 1992) and a system of interconnected institutions to create, store and transfer the knowledge, skills and artefacts which define new technologies (Metcalfe, 1995), the concept of systems of innovations emphasises three main components. These include linkages, institutions and learning.

\subsubsection{Linkages}

A system approach to innovation emphasises the role of interactions and resulting linkages as important as innovation system components (Foray, 1997). Information and knowledge requirements in an innovation process are often unpredictable and unknown and thus uncertain. Further, it may not be known whether the required information exists at all. Foray (1997) argues that the more complex the task to perform, the more one may be forced to rely on the expertise of others. Also expressed in terms of networks, the essential function of interactions is the exchange of information (Carlsson and Stankiewicz, 1991). Innovation system components interact with each other and with other economic agents in order to gain, develop and exchange various kinds of knowledge, information and other resources. Thus, a central assumption behind the innovation system perspective is the focus on interactions and relationships. While relationships are seen as carriers of knowledge, interactions are defined as the process by which new knowledge is produced and learned Johnson et al., 2003). Consequently, this study argues that two main groups of factors explain interactions among system components: 
a) Input requirements in terms of knowledge, information and other resources of the undertaken innovative activities.

b) The actual state of knowledge, information and resources of the actor engaged in the unowation process and its economic competence.

\subsubsection{Institutions}

Many authors (Freeman, 1987; Nelson and Rosenberg, 1993; Edquist and Lundvall, 1993; Niosi et al., 1993; Patel and Pavitt, 1994; Metcalfe, 1995) have put institutions at the heart of their definition of system of innovations. Universities, research institutes, R\&D laboratories, schools, patent systems, consulting agencies, labour market organisations, banking systems, various governments agencies, property rights, norms, habits, practices and routines are differently referred to as institutions. Lundvall (1992) explains the rise and the weight given to institutions in the analysis of the innovation processes by the need to establish innovation-related linkages between the component parts of the systems, which can be defined at national, sectoral or regional level. Indeed, Edquist and Johnson (1997) argued that an economy's ability to generate growth depends on its ability to generate technical change and simultaneously adapt and renew its institutions to support growth and innovation. To this end, institutions have to be dynamic.

Freeman (1992) asserted that institutional innovations, in terms of formal sciencetechnological systems, constitute one of the most important factors that affect technological development. The loss of British technological leadership provides a sound framework of understanding. Freeman (1992) argued that, with the new technologies that emerged in the first half of the $19^{\text {th }}$ century, it was not possible to train good engineers by a combination of practical on-the-job experience and night school. Full-time professional formation was required (Pavitt, 1991; Freeman, 1992). For Johnson (1992) and Lundvall (1992) innovation depends on learning and learning is interactive, implying that innovation is rooted in the institutional set-up of the economy and in the prevailing economic structure. As such, institutions create the basis for social interactions that help individuals to form a conceptual foundation to understand and act in a complex society by learning (Johnson, 1992). 


\subsubsection{Learning}

The starting point is the recognition of the fundamental role knowledge plays in the processes of innovation and production. Lundvall (1992) asserts that innovation systems work through the introduction of knowledge into the economy and requires active learning by individuals and organisations taking part in processes of innovation of different kinds. Johnson (1992) defines learning processes as those that lead to new knowledge or new combinations of alreadyexisting knowledge, or put existing knowledge into new heads. Consequently, the stock of knowledge that affects innovation processes is a function of learning (Lundvall, 1992). The causation confers the right for conceptualising learning as a source of technical innovation (Johnson, 1992). Freeman (2000) explains that learning which propelled ahead and allowed Germany to catch up and later advanced Britain was specified and purposely oriented: reverse engineering. The same idea was expressed by List who wanted to stress the need and fundamental role of learning in the process of innovation and development (List, 1841 as cited by Freeman, 2000).

\footnotetext{
"The present state of the nations is the result of accumulation of all discoveries, inventions, improvements, perfection and exertions of all generations, which have lived before us. They form the intellectual capital of the present human race and every separation sation is productioe only in the proportion in which is has known hou to appropriate those attainnents of former generations and to increase them by its own acquirewsents ${ }^{\text {" }}$
}

Evolutionary theorists put forwards that technical change is a process of evolutionary change that builds on diversity, the generation of diversity and competitive selection. Technical diversity conveys the idea that various kinds of knowledge exist in the economy, which constitutes the knowledge base of the economy, and therefore affects innovations because it affects technical, organisational and institutional learning. Johnson (1992) thus, logically contends that a system with a lower degree of diversity has a lower capacity to generate innovations. Economic processes that generate diversity rely on the functioning of learning mechanisms within organisations that participate in the process of innovation. (Cohendet and Llerena, 1997). Indeed, successful innovation requires learning about markets and user needs as well as learning about technologies. All these raise the question: how do we learn?

Literature review distinguishes two main types of systematic and organised searching for new knowledge. The first, including different types of research and specialised training institutes and R\&D departments, relates to the search organised in close connection with production and influenced by the commodity 
logic of the enterprise sector. It is called learning by searching. The second is denoted learning by exploring and concerns universities and other educational institutions. Johnson (1992) argues that the two kinds of organised searching institutions are strongly interdependent. A third but non-organised type of new knowledge generation is the learning process associated with economic activities. It is termed learning-by-producing which is composed of learning-by-doing, learning-by-using and learning-by-interacting (Johnson, 1992).

\subsubsection{Applying the National System of Innovation (NSI) Approach in developing countries}

Before the consideration the of NSI approach in developing countries agricultural context, other thoughts of systemic character have emerged. These include the multiple sources of agricultural innovation (Biggs, 1990), the participatory research and extension approaches (and their derivatives as discussed earlier); the indigenous knowledge system (IKS); the concept of national agricultural research system (NARS); agricultural knowledge and information system (AKIS). The NARS focuses on the generation of knowledge and comprises agricultural research, extension, and education agencies. Formulated and developed by (Röling, 1990), AKIS is defined a set of agricultural organisations and/or individuals and the links and interactions between them, engaged in processes as the generation, transformation, transmission, storage, retrieval, integration, diffusion and utilisation of knowledge and information. The system integrates farmers, agricultural educator's, researchers and extensionists to harness knowledge and information from various sources for better farming and improved livelihood (Röling, 1990). Finally, while each of these perspectives has its own strengths, they can all be seen as interlinked and cumulative. Nevertheless, they have proven a weakness in emphasising the specific role of farmers within the agricultural innovation system and how to enhance their effective participation as full system components.

\subsubsection{National agricultural innovation systems (NAIS)}

While the NIS concept looks at innovation throughout the whole economy, the basic ideas of an innovation system approach can without any problem be applied to a specific sector of a national economy (Roseboom, 2004). Agricultural innovation processes involve a diverse set of factors and are shaped by a complex historically-defined social, political, economic agro-climatic and institutional context (Biggs, 1990). Indeed, the responsibility of agricultural innovation system actors does not end with the conception, development or production of new 
knowledge or technologies. Satisfaction comes only when the new technologies are successfully diffused, adopted and used by farmers (Roseboom, 2004). The NAIS thus comprises a broad set of actors and considers innovation as taking place throughout the whole economy with diverse sources of origins. Temel et al., (2002, p.6) defines an agricultural innovation system as:

\begin{abstract}
"A set of agents farmers or farm organizations; input supply. processing and mankting enterprises; reseatch and education instikutions; credit institutions, axtension and mformation units, prizate consultancy firms, international dewelopment ngencies, and the gonermwent that contribute, jointly andtor individually, to the developwent, affusion, and use of new agricultural technologies, and that influence, directly andlor indirectly, the process of technological change in agriculture."
\end{abstract}

Breaking away from the traditional one-way source model of innovation, the system approach is expected to be more consistent with the sector's realities. The innovation system framework asserts that the way these actors relate to each other in the wider political, social, economical and cultural environment determines the outcomes of the whole system. In this respect, Hall and Yoganand (2003, p.8-9) highlighted the following features as characteristics for a NAIS in developing countries:

a) It focuses on innovation (rather than research) as its organising principle. The concept of innovation is used in its broad sense, i.e., the activities and processes associated with the generation, production, distribution, adaptation, and use of new technical, institutional, organisational, or managerial knowledge.

b) By conceptualising research as part of the wider process of innovation, it helps identify the scope of the actors involved and the wider set of relationships in which research is embedded.

c) By recognising the importance of both technology producers and technology users, and by acknowledging that their roles are both context specific and dynamic, it escapes the polarized debate between proponents of the theories of technology "push" versus demand "pull."

d) It recognises that the institutional context of the organisations involved (and particularly the wider environment that governs the nature of relationships) promotes dominant interests and determines the outcomes of the system as a whole.

e) It recognises that innovation systems are social systems. In other words, it focuses not only on the degree of connectivity between the different elements, but also on the learning and adaptive processes that make such systems dynamic and evolutionary. 


\subsubsection{Innovation systems and development}

Concern about the relevance of the NIS concept for developing countries has been raised (Johnson et al. 2003). It is mainly argued that just transplanting the insights from innovation studies in developed countries to developing countries would be a terrible mistake. However, this would be very much against the evolutionary character of the NTS approach, which argues that innovation processes and systems are context specific and historically determined (Roseboon, 2004). Arocena and Sutz (2000) point out that innovation system building and promotion stand out as far more important issues in developing countries than in developed countries. Arguing for its suitability for developing countries, Johnson and Segura-Bonilla (2001) assert that the NSI concept helps to concentrate on what we believe is important in development. It takes a departure from learning capabilities and focuses on innovation processes and their role in development.

McKelvey (1997) follows the evolutionary view and asserts that the production and diffusion of diversity is shaped by the learning capacities of the economic agents. In his studies on sectoral systems of innovations, Malerba (2002) argues that a sector's ability to generate and exploit opportunity conditions largely depends, among other factors, on the level of educational and training systems. Smith (1997) also justifies the use of NSI in the developing countries context by its roots in learning as the base for technological competence through the educational, training and capacity building systems. For Johnson et al. (2003), innovation systems put emphasis on learning processes, meaning that innovation is a matter of producing new knowledge or combining existing elements of knowledge in new ways as well as diffusing and utilising them. They argue that, beside science and technology, innovation reflects interactive learning taking place in connection with on-going activities in procurement, production and sales. There exists some historically empirical evidence.

Luu (1988) stresses the importance of education and training for improving the level of science and technology as well as the receptivity of cadres and peasants in Vietnam. He notifies that the North Vietnamese leaders have been fully aware that successful agricultural innovation processes depend heavily on the skills and competences of all actors (scientists, technicians and farmers) concerned with agricultural development. In this respect, they have endeavoured efforts to develop the country's human resources for technological innovation. The Project Impact Evaluation No.27 of the Agricultural Research Project of 1973, which successfully transformed and helped to develop the Korean agricultural sector 
and rural life, stresses the tremendous positive impact of training and learning on its success (Steinberg et al. 1982, p.5).

"...There was universal agreement among Korean academicians and the U.S. Agency for" International Development administrators and with the ADD evaluation team that the most successful aspect of the project was [thel training component... Both the groups of researchers and farmers are trained..."

In his focus on the Japanese experience of technological changes in agricultural production and changes in agrarian structure in the late $19^{\text {th }}$ century, Ishikawa (1981) mentions that the major problem related to the diffusion of new techniques to groups of small-scale farmers lies in their low level of technical knowledge (Ishikawa, 1981, p.164-170):

\footnotetext{
"... The governments at that time ever used compulsory methods to raise such insufficient level of technical knowledge by training farmers on farming better practices... The technical knowledge depended not only on education level but also on how strong the learning process was carried on..."
}

The bulk of contemporary development theories, approaches or concepts over the past four decades are critically flawed (Liebenberg and Theron, 1997). The prevailing paradigms encompass some mythical baggage that shifted attention from the real needs of developing countries' farmers. The study has shed light on some major flaws of the approaches and concepts that have governed agricultural innovation processes. Agricultural development concerns should be conceptualised in terms of challenges to be surmounted instead of problems to be solved. It argues for the "unplugging" of development processes. This means "getting back to basics", which implies examining knowledge and its application as the comerstone for innowation processes.

Within this context, the study contends that what is required is that farmers acquire abilities to innovate. The ability to innovate is what underlies advancement either at individual, firm or national level. Participation in research and extension activities does not make farmers into innovators. Listening to farmers or giving them voice is not what enables them to pick up new knowledge and apply them to their businesses. What counts is what the farmers can do individually or collectively. Farmers need institutions that embed them in training processes whereby they learn and gain skills and competencies defined as innovative capacities. These capacities are dynamic, meaning that the skills and competencies should be perpetually updated to cope with the dynamics of the overall social and economic changes. Why doe s no one bother or dare to ask: 
a) What skills and competencies do farmers in the least developed countries need to be good at innovation?

b) How can capacities for the farmers be built, developed and sustained?

The study thus firmly holds the argument that only an approach that provides a framework for training where farmers can learn and gain, develop and sustain capacities to innovate is required for successful agricultural innovation processes. The innovation system approach offers such a framework. It puts emphasis on capabilities, knowledge and institutions as the roots of development (Gregersen et al., 2004). A system approach to innovation advocates the need for institutions influencing learning and innovation capabilities as well as the interconnections between them. Here, institutions represent the sets of common habits, routines, established practices, rules or laws that regulate the relations and interactions between individuals and groups (Gregersen et al., 2004). They also represent diverse organisations in which these norms, behaviours and regulations are embedded. This is not to say that the innowation system approach will replace people and do their jobs. It is not enough to say that the approach allows something. People have to deliberately act. They need to create, develop and sustain the institutions, which have to be dynamic and managed by knowledgeable people. This is to say that concepts and approaches are tools to be used by people to achieve their developmental goals.

\subsection{Innovation and Entrepreneurship}

The different historical views of economists offer a broad perspective on the concept of entrepreneurship as well as on the intermediate variables that form the connection between entrepreneurship and economic growth (Filion, 1997). Entrepreneurship is at the heart of national advantage (Porter, 1990) because of the eminent importance of carrying out innovations (Schumpeter, 1934). For Wennekers and Thurik (1999), newness through start-ups and innovations are key factors linking entrepreneurship to economic performances. Neo-classical economists stress the role of the entrepreneur in leading markets to equilibrium (Filion, 1997). In the Austrian tradition, the alertness for profit opportunities and the importance of competition are emphasised. Baumol (1993) and Kirchhoff (1994) summarised the main economic trends of thought on entrepreneurship and proposed two categories of entrepreneurs: the entrepreneur-business organisers and the entrepreneur-innovators in economic life. 
For Liebenstein (1968, p. 74) the most striking characteristics of entrepreneurs lie in their ability to "search and discover economic opportunities". Demsetz (1983) argues that the entrepreneurial discovery is a process that is associated with the actor's interpretation framework, or his stock of knowledge. Discovery in this context means that the actor interprets incoming information in a way different from perceptions of the general public. The challenge is to synthesise the insights and provide a picture of the interdependence between innovation processes and entrepreneurship and how to supply agricultural entrepreneur innovators. Assuming that entrepreneurship affects economic growth through a functioning and strong innovation system, the study tries to investigate the mechanisms through which entrepreneurs develop.

Baumol (1993b) states that the main shortcoming of Schumpeter's theory is that it does not formulate any policy of how governments should stimulate innovative entrepreneurship. Indeed, there are institutional arrangements that affect the quantity and quality of entrepreneurial efforts. Investment in entrepreneurial ability is a means by excellence to enhance entrepreneurship (Schultz, (1980; Wennekers and Thurik, 1999). Walstad (2004) highlights how more entrepreneurship education throughout a society can lead to more improvements. Educating people on entrepreneurship should include all aspects of their life, which is about new and better ways of communicating, seeing and feeling about things. It should also include new and better ways of doing, organising and mostly of learning about things (Kolshorn, 1999). Blawatt (1995) observed that entrepreneurs work in an evolving context where activities and roles change gradually. Entrepreneurs learn from what they do (Filion, 1997), and because the nature of what they do changes, they too must change. Therefore, they have to learn to play different roles as their business evolves (Filion, 1997).

This section draws on the previous one and assumes that a way to ensure smooth agricultural innovation processes and enhance innovations at the level of all categories of farmers is the link to agricultural entrepreneurship. The second subsection provides a historical review of entrepreneurship while an attempt is made to understand how it relates to innovation. The third subsection sets out a framework for identifying the skills, capacities and competencies that characterise an entrepreneur innovator. Subsection four answers the question of whether entrepreneurs are "born" or "made". The fifth subsection draws from the answer that training can constitute a major determinant for the supply of entrepreneurs. Finally, it briefs some pedagogical models and contents of entrepreneurial training programmes. 


\subsubsection{Entrepreneurship/Entrepreneur Defined}

Richard Cantillon (1680-1734), a French economist, is credited with coining and giving the concept of entrepreneur a central role in economics (Filion, 1997; Lynskey, 2002). Cantillon (1931) distinguished entrepreneurs from landowners (capitalists) and wage-workers and perceived the market as a self-regulating network of reciprocal exchange arrangements, in which entrepreneurs play the pivotal role as the contributor's to a society's economic value (Lynskey, 2002). The term entrepreneurship has evolved with numerous variations. Definitions have emphasised a broad range of activities including:

a) Entrepreneurship as a risk taking activity and the bearing of uncertainty,

b) Entrepreneurship as the creation of business organisations,

c) Entrepreneurship as the bringing together of factors of production and as management of production and distribution activities. Finally

d) Innovation underlies entrepreneurship. In discussing these different aspects, the research intends to shed some light on their complementarities and how they relate to innovation processes.

\subsubsection{Entrepreneurship involves risks and uncertainty}

(Cantillon, 1931) describes the entrepreneur as someone who exercises business judgement in the face of uncertainty, engages in arbitrage and bears risks. His definition acknowledges the existence of an entrepreneurial function at farmers' level within the economic system (Lynskey, 2002).

"The farmer is an undertaker (entrepreneur) who pronises to poy the landowner, for his farm or land, a faxed sum of money without assurance of the profit he will derive from this enterpriser (Cantillon, 1931 , p.47 quoted in Lynsikey, 2002).

Entrepreneurship as a risk-bearing activity is also found in the definition of Say (Lynskey, 2002). He referred to entrepreneurs as merchant wholesalers who bear the risk of selling agricultural and manufactured produce. Entrepreneurs were therefore people who seized opportunities with a view to making profits, and assumed the inherent risks (Filion, 1997). For Knight (1921), entrepreneurs attempt to predict and act upon change within markets. He emphasises the entrepreneur's role in bearing the uncertainty of market dynamics. Mill (1848) also describes entrepreneurs as risk takers, decision makers, and individuals who 
desire wealth by managing limited resources to create new business ventures. Hence, entrepreneurship involves the founding of a private enterprise.

\subsubsection{Entrepreneurship as a new business venture creation}

Entrepreneurship as the creation of business organisations is found in the work of Smith (1776). In Smith's view, entrepreneurs react to economic change and undertake the formation of an organisation for commercial purposes thereby becoming the economic agents who transformed demand into supply (Chan, 2004). Following Smith (1776) and drawing on the physiocrates, Say (1830) regarded economic development as the result of venture creation and hoped the English Industrial Revolution would spread to France and help serve as a means of developing farming through entrepreneurship (Filion, 1997). He described an entrepreneur as one who possesses certain arts and skills of creating new economic enterprises; a person who has exceptional insight into society"s needs and is able to fulfil them (Lynskey, 2002; Chan, 2004.). In this connection, the function of an entrepreneur relates to the activity of combining factors of production and managing the production and distribution of goods and services.

\subsubsection{Entrepreneurship implies production and distribution management activities}

Say (1971) defined production as the activity leading to giving existing materials (capital and nature) the utility they have not possessed previously (Lynskey, 2002). In the process of wealth (utility) creation, Say (1971) saw the entrepreneur as the one who applies knowledge to the creation of a product of human consumption (Lynskey, 2002). The entrepreneur must possess managerial and administration skills (Knight, 1921) and be able to provide the necessary fund:

\footnotetext{
"Not that he should be alyeady wich; for he may work upon borrowed capital; he" must at feast be solvent, and have the reputation of intelligence, prudence, probity and regularity; and must be able by the nature of his connexions, to procure the loan of capital he may happen hiviself not to possess" (Say, 1971, quotes in Lynskey, 2002, p. 5).
}

In Marshall's (1930) view, entrepreneurs drive the production and distribution process; they coordinate supply and demand on the market, and capital and labour within the firm. In this respect, Kirzner (1982) argued that it is alertness to profit opportunities that drives and motivates the actions of entrepreneurs as decision-takers who bear the risks associated with production. According to Linskey (2002), Baudeau (1730-1792) thought of an entrepreneur as one who invents and applies new techniques in order to reduce his costs and thereby 
increases his profit. As such, he introduced the sense of the entrepreneur as an innovator whose development was left to Schumpeter.

\subsubsection{Entrepreneurship as innovation}

Becoming an entrepreneur means more than just getting an idea and finding the financing to run it. For Schumpeter (1934), it is innovation with all its effects that drives economic evolution. By making new combinations of already existing production factors entrepreneurs make an economy move. Entrepreneurship thus consists of making innowations that cause disequilibria in the economic system and allow it to grow. However, Schumpeter pointed out that when entrepreneurs complete their entrepreneurial function (innovation), their task is complete. This means that no one is an entrepreneur in one activity for ever. It also implies that one can be called a professional entrepreneur only when he is actually and constantly performing innovative activities.

Hayek (1959) showed that the role of entrepreneurs is to inform the market of new elements while the basic concept in Kirzner's (1973) theory of entrepreneurship is alertness that leads individuals to make discoveries. Through alertness, entrepreneurs discover and exploit economic opportunities. For him, "entrepreneurship is at all times on the lookout for hitherto unnoticed features of the environment, which might inspire new activities". Like Schumpeter, other economists (Knight, 1921; Baumol, 1968; Kirzner, 1976; Sexton et al., 1982...) who took an interest in entrepreneurship also associated it with innovation and viewed entrepreneurs as detectors of business opportunities (Filion, 1997).

Summing up, we see a strong link between entrepreneurship and innovation being applied in a business context. In entrepreneurship, creativity and innovation are key elements. By adding innovative features to products or services and setting up a business, new entrants become entrepreneurs. Like creating new products for the market, someone who starts a business by providing a totally new way of serving his clients is an entrepreneur too. If an individual starts selling a product that is already common in lhis area or country, he will not be seen as demonstrating entrepreneurial behaviour. However, if he is the first to sell the same product in a virgin locale or to an untouched market segment, he will be seen as an entrepreneur innovator in his own right (Chan, 2004). Banking and lending money activities are not new. But Yunus was the first to provide such facilities in a rural part of Bangladesh, and that is definitely innovation and risk-bearing on his part as an entrepreneur (Chan, 2004). An individual can also become an entrepreneur if he sells a product or service using 
new systems or mediums of marketing, distribution or production methods as a basis for a new business venture (Chan, 2004). Finally, to become an entrepreneur is to innovate.

\subsubsection{Entrepreneurial Process}

Bygrave and Hofer (1991) define the entrepreneurial process as the involvement of all functions, activities, and actions associated with the perceiving of opportunities and the creation of organisations to pursue them. It is a holistic, dynamic process initiated by an act of human volition and occurs at the level of the individual firm. Management literature identifies the following as elements of an entrepreneurial process (Bull et al., 1995):

a) Creating (recognising) and developing an opportunity

b) Evaluating the opportunity's desirability:

$\Rightarrow$ Its economic potential

$\Rightarrow$ The financial risks involved.

$\Rightarrow$ The personal risk involved

c) Marshalling the resources to exploit it:

$\Rightarrow$ Financial

$\Rightarrow$ Managerial

$\Rightarrow$ Technical

$\Rightarrow$ Physical

d) Possessing the will or tenacity to do it

e) Managing the launch:

$\Rightarrow$ Competitive and cooperation relationships

$\Rightarrow$ Networks

f) Managing the downstream opportunity capture and realisation

$\Rightarrow$ Creation of value for the entrepreneur and society

$\Rightarrow$ Realisation of value for the entrepreneur and his family 


\subsubsection{Characteristics of entrepreneurs}

Several definitions of entrepreneurship encompass elements of personality traits common to most successful entrepreneurs. By defining entrepreneurs as individuals who recognise opportunities where others see chaos or confusion, Ferrel and Gresham (1985) characterise them as aggressive catalysts for change within the marketplace. Entrepreneurship is the symbol of business tenacity and achievement as entrepreneurs must be able to face failure and learn from it (Summers (1974). Entrepreneurship involves creativity and the ability to generate and build a vision from practically nothing (Timmons, 1994; Mitton, 1997; Fawkner, 2002). While Leibenstein (1968) views the entrepreneur as one who marshals all resources necessary to produce and market a product that answers a market deficiency, Kirzner (1982) notes that to be able to fill the gaps that market deficiency creates, it is necessary to be alert to new opportunities (Lynskey, 2002). He argues that much of the entrepreneur's decision-making process is beyond systematic calculations and proceeds based on alertness to possible newly worthwhile goals and available resources:

"The entreprenewrial profits exist where "people do not know what [it] is that they do not know, and do not know that they do not know it". The entrepreneurial function is to motice what preople have overlooked" (Kurzner, 1982, p.273 as quoted by Lynskey, 2002, p.20).

However, from Schumpeter's view it not enough to have such alertness if it does not lead to carrying out new combinations (innovations). If market deficiencies exist or occur, they do only in the mind and can be perceived only by those capable of carrying out new combinations. Indeed, as a wise old African man observed (Ferrell and Gresham, 1985), "Anybody can see a seed in an apple; the wise person can see an apple in a seed". By analogy, it can be inferred that "to see an apple in a seed" is also to become an entrepreneur. Given all these attitudinal and behavioural traits that characterise an entrepreneur, and the skills, competencies or capacities required to perform entrepreneurial functions, the study poses the following questions: how should entrepreneurship be promoted or how should entrepreneurs be supplied? Are entrepreneurs "born or made"?

\subsubsection{Promoting entrepreneurship}

\subsubsection{Entrepreneurs are "born"}

Entrepreneurs need to have the capacity for developing business ideas, working alone or as a member of a team, and the ability to do multi-level production, management and marketing tasks. They have to be self-confident, independent, 
flexible, creative, knowledgeable, versatile, and diligent in order to create a successful business. While these qualities are especially important for starting up a business, the striking question is whether individuals are born with these characteristics that predispose them or whether one can be taught or learn to become entrepreneur.

Many people believe that entrepreneurs possess innate, genetic talents and hold the view that entrepreneurs are born, not made (Mair, 2002). Hetherington (1994) shares with Kiyosaki and Bennett (1993) the provocative assertion that "if you want [to] be rich and happy don't go to school. For a business owner John Simpson in Business Day (1987, p.12), a degree is probably the most inhibiting factor in starting a business ${ }^{\prime \prime}$. Mair (2002) reports that, according to an article in Leadership (2001, p.54), "degrees do inspire their holders with confidence to face the world, but it is not the kind of confidence that can transform intellectuals into intuitive business people. Bolton and Thompson (2000) argue that entrepreneurs seem to turn the importance of education upside down. De Bono, the world's most foremost advocate of lateral thinking has advanced that thinking is by no mean the prerogative of school trained graduates. People with very little education or even without schooling can be brilliant thinkers if the frames are used (Mair, 2002, p.7).

\subsubsection{Entrepreneurs are "made"}

Against the "born-side" of entrepreneurs, Kirzner (1979) argued that an individual's expectation, belief and awareness are largely the result of learning experiences that neither occurred entirely without having been planned nor are they deliberately searched for. Opportunity discovery, like all human actions, involves knowledge and ignorance problems. It is through a deliberate search that the entrepreneur can gain knowledge enabling him to discover "hidden" economic opportunities. Brazeal and Krueger (2004) developed a model in which entrepreneurial behaviour is a planned and intentional act based on the interactions between personal characteristics, perceptions, values, believes, background and environment. Machaba and Lazenby (2003) assert that "if you cannot teach an individual how to take risks, you can however, teach him how to spot opportunities". For them the proliferation of college and university courses on the subject supports the point that entrepreneurship can be successfully learned or taught.

Kolshorn (1999) clearly put it that without competence, not even the most hospitable environment or the best of motives is likely to generate a successful business. The successful American entrepreneur Henry Ford was once quoted as 
saying, "If money is your hope for independence, you will never have it. The only real security that a man can have in this world is a reserve of knowledge, experience and ability". At the end of the day it is the competent individual who manages the process and produces the result. Creating a company is a matter of knowing customers, suppliers, partners, and sources of capital. It is a matter of discovering and knowing the marketplace well enough to notice tiny fault lines of change. For Machaba and Lazenby (2003) the need to "make" entrepreneurs relates to today's market that becomes so competitive that a substantial amount of knowledge is necessary to run a successful business. Thus, confirm Lambing and Kuehl (1997), education becomes an important requirement for entrepreneurship.

\subsubsection{Entrepreneurial training}

Following Dunkin (1987) the words learn and teach come from the same source, the Middle English word learnen implying that they both mean the same. He asserts that the word teach expands to additionally mean show a person how to do something. The Random House dictionary of the English language (2001) defines learwing as the act or process of acquiring knowledge or skill, the modification of behaviour through practice, training or experience (quoted in Kruger, 2004). For Miner et al. (2001), learning is a systematic change in behaviour or knowledge that could be brought about via one's own experience, experimentation, trial-and-error, refinement, exploration and sharing of knowledge. In corollary, teaching as a success signifies that learning is implicated in the teaching process (Kruger, 2004). Eggen and Kauchak (2001) view instruction at the centre of teaching and advocate that teachers must understand different ways of involving students in learning activities and techniques for checking their understanding. Training (education) should thus provide an opportunity for students to learn, explore and implement new ideas (Antonites, 2003). The question at stake is how to teach entrepreneurship.

\subsubsection{The pedagogical process of entrepreneurial training}

For Antonites (2003), entrepreneurial training is to act as a facilitator for entrepreneurial activities with the goal of stimulating performance. Wambui (2002) points to the innovative and versatile characters it requires and stresses that training should encourage to look for creative and innovative ideas that provide multiple solutions to problems. Entrepreneurship education is the process of providing individuals with the concepts and skills to recognise opportunities that others have overlooked and to have the insight, self-esteem and knowledge to act where others have hesitated. It includes instruction in 
opportunity recognition, marshalling resources in the face of risk, and initiating business ventures. It also involves instruction in business management processes such as business planning, capital development, marketing, and cash flow analysis. In this connection, Fayolle (1997) suggests specifying pedagogy objectives before making explicit the approach to be adopted. Pedagogical content is an understanding of ways of representing the subject and that make it comprehensible to others. It is also an understanding way of what makes the learning of a specific topic easy or difficult (Eggen and Kauchak, 2001).

Models are used as frameworks or paradigms to serve as guidelines for the compilation of entrepreneurship education programmes. To be effective, an entrepreneurial training approach must balance conceptual ${ }_{r}$ instrumental and experimental dimensions. Students must be fully involved, either individually or collectively in all phases of exploration, experimentation, and application (Fayolle, 1997). Further, Pretorius (2000b) insists that an entrepreneurial training takes account of the contexts in which future graduates will operate. Further, he includes the facilitator (teacher, trainer, or educator) as a key element, whose skills, knowledge and experience affect the whole training process and its performance.

Traditional pedagogy is frequently in contrast to the needs of entrepreneurial education (Mitton, 1997). An alternative to it is the method that requires the instructor to become a learning process facilitator. Through problem-posing methods teachers inspire students to meaningfully learn. Teachers trigger motivating problem situations through which the students discover relationships by collecting data as well as reasoning and hypothesis stating. Through processes of comparison, contrasting and classification, the students consequently acquire new knowledge. The experiential learning style starts with carrying out an action in a particular instance and seeing the effects of the action and then trying to understand these effects. The following step consists of understanding the general principle under which the particular instance falls, and applying the concept through action in a new circumstance within the range of generalisation (Avenant, 1990).

Following Veblen (1899) and Audretsch (2001), Hull (2003) asserts that an argument for linking and incorporating behaviour to entrepreneurial activity is the claim that the level of entrepreneurial activity is tied to the "demonstration effect":

"Entrepreneurial actioity inwalves not just the firm or individual responsible. Rather, others will observe this activity and the results of entrepreneurship. Other people learn that entreprenewrship 
is a viable alternative to the sitatus grwo. As a result of this demonstration effect. others will be induced to also develop entrepreneurial strategies. Thus, there is a compeling positive extermality associated with entrepreneursinp, particularly, in areas with no strong entreprenewial traditions" (Audretsch, 2001, quoted in Hull, 2003).

In support of this idea, Hjorth and Johannisson (1997) stress that entrepreneurship and learning have overlapping features, and therefore training for entrepreneurship cannot be separated from entrepreneurship itself. Such training, in turn, has to be related to the personal strategies being used to adopt an entrepreneurial mode. Informal apprenticeship is an example of experiential learning. It is a form of proprietary training common in countries that have a large informal sector, both rural and urban. Many training programmes expand apprenticeship type programmes by integrating school-based education with workplace-based learning in enterprises (ILO, 2001). These are often run by independent organisations while entry requirements and the duration of training vary considerably. The widespread acceptance that entrepreneurship should be taught, and how it should be taught, raises the question of what the curriculum should look like.

\subsubsection{Pedagogical content of entrepreneurial training}

Bentszen-Bilkvist et al. (2003) remark that of the fundamental changes in business education curriculum, the most striking change relates to the reorientation from a technique-based to competence-based curriculum. Individuals learn by experiencing small failures in order to build-up resilience in the face of future organisational conditions. The striking insight is that overall success of entrepreneurial efforts depends on people discovering for themselves what goals to set and what to do to achieve them (Matta and Ashkenas, 2003). With this approach they can learn what entrepreneurship truly is, to understand its competitive challenges, and its behaviour and strategic requirements (Honig, 2004). Fundamentally, entrepreneurs are in acute need to make things happen rather than wait on the activities and initiative of others (Gibb, 1998). Therefore, Streeter (2003) recommends the identification of learning goals and those of the institution in offering entrepreneurial training with the stages of readiness of the potential learners.

Following Carlsson et al., (2002), entrepreneurial training curricula should include elements of innovative capacities and economic competence development such as: 
a) Selective (or strategic) capability - This relates to the ability to make innovative choices of markets, products, technologies and organisational structure; to engage in entrepreneurial activity; and to select key personnel and acquire key resources, including new competence. An important part of this capability is the notion of receiver competence or absorptive capacity: the ability to scan and monitor relevant techmological and economic information, to identify technical and ruarket opportunities, and to acquire knowledge, information, and skills needed to run and develop agricultural enterprises.

b) Organisational (integrative or co-ordinating) ability - The task is how to organise and coordinate the resources and economic activities within the business so that the overall entrepreneurial objectives are met.

c) Functional ability - It involves the efficient execution of various functions within the system to implement technologies and utilise them effectively in the market. The key question here is that of efficiency: are we doing things right?

d) Learning (or adaptive) ability - It concerns the ability to learn from success as well as failure, to identify and correct mistakes, to perceive the needs of markets and take appropriate actions leading to turning demands into supply.

e) Economic conpetence denotes the total sum of abilities to generate and take adwantage of business opportunities. It includes the ability to perceive new opportunities, read. and interpret economic signals, co-ordinate activities such as production, marketing, service and general administration. It is the channel through which innovations lead to economic change. Economic competence affects the degree to which successful innovation will take place. The main argument is that economic agents differ in their knowledge base, and in how and the extent to which they use their knowledge, in the ability to perceive opportunities.

Hindle and Angehrn (1998) introduced a theory to guide in the development, selection, and evaluation of entrepreneurship activities. They categorised relevant factors into four skill areas: communication, control, human resource, and technical skills. Fayolle (1997) stresses indispensable core content: the development of an entrepreneurial way of being. Gibb (1998) makes the reflection that a training programme focusing on an entrepreneurial way of being should address, at least, the development of commitment, strong sense of responsibility and learning to learn capacity; persuasion, negotiating skills and leadership.

In practice, entrepreneurial course content varies widely, including the use of case material, simulations, and various "hands-on" approaches (Gorman et al., 1997). One of the most popular curricula formats consists of teaching and 
monitoring the production of a business plan (Honig, 2004). In considering entrepreneurship education, the pedagogical implications of business plans are paramount and in a study of leading entrepreneurship educators, the development of a business plan was identified as being the most important course (Honig, 2004). Yet, Mitton (1997) deplores the importance of a business plan in entrepreneurial training programmes. He asserts that "doing" is what entrepreneurship is but entrepreneurial training programmes do not encompass enough practical issues. Comparing entrepreneurship students to baseball players he laments: If students in entrepreneurship training were baseball players! Actually, in universities, baseball players get far better teaching than entrepreneurship students. They have a practice field where they learn the fundamentals and do them over and over.

\subsection{Discussion and concluding remarks}

The study has adopted the system approach to innovations for the analysis of the potential, incentives and the interaction of the multiple social actors involved in technical change because innovation processes are deeply embedded in social systems (Rogers, 1995). The approach builds on institution and learning theories, all of which are consistent with the new trends in rethinking development. Institutions are viewed as the main root of development (Johnson et al., 2003). They favour interactions among system components and allow a smooth occurrence of linkages as channells for innovation input resources. Among these inputs knowledge is seen as the most crucial resource driving innovations and development (Ruttan, 1998; Johnson et al., 2003). Acquiring new or more knowledge for capacity development at system level (Hall and Yoganand, 2003) is thus required for achieving developmental goals.

A system performance is determined by both the performance of each element (individuals, organisations or institutions) and how they interact between themselves within the system. Evidence from literature reveals that the means whereby to develop the system's capacity remains underemphasised. The innovation system approach lacks clarity about the notions of interactions and relationships. Interactions are purposive and needs-based. They may be defined as the search for additional resources (of all kinds) required within given innovation processes. Within an innovation system, all elements may not necessarily need to interact with each other even if one admits the existence of indirect relationships. It is economic agents going about their own production and innovative activities who find themselves in the position to involve 
themselves in relationships if they are to succeed. Thus, engaging in relationships becomes a matter of deliberate choice. In our view, the following main attributes characterise them.

Interactions and relationships are innowation activities dependent -Their occurrence and intensity depend on the area, complexity and scope of the innovation activities at stake. Domains of activities, their complexity and their size determine the nature, focus and importance of innovation relationships among system components and direct towards potential partners. This applies even in the case of internal interactions within various units of firms, institutions or organisations.

Interactions and relationships are resources dependent - The state (quantity and quality) of knowledge and other resources that agents involved in innovative activities possess compared with those required to perform these activities, determines whether or not and with whom to interact (more concretely). Another side of the issue is that the more an innovative individual or organisation possesses resources, the more it is solicited by other system components for interactions.

Interactions and relationships are time dependent - Relationships between given elements of a system may relate to specific innovation tasks and thus, may not last forever. They may end with the innovative activities but may rise again with new emerging activities.

Interactions and relationships are capacity dependent - They also imply the capacity of the partners to understanding each other: more concretely, the capability on the part of the recipient to handle and do something useful with new resources.

In terms of learning, the system approach to innovations overvalues institutions (organisations) at the expense of individuals. Edquist and Johnson (1997) define institutions in the sense of patterned behaviour. "Institutions are a set of common habits, routines, established practices, rules or laws that regulate the relations and interactions between individuals and groups." Like North (1995), they stress the need for a clear distinction between institutions and organisations. For them, organisations and institutions play different roles in innovation processes. Organisations are formal structures with an explicit purpose. They stand for the players or the actors while institutions are viewed as the rules that define how the game is played. If organisations are consciously created, institutions may develop spontaneously as self-grown; institutions may be also created by political or economic agents (Edquist and Johnson, 1997). This study reveals that 
neither institutions nor organisations exist outside of people. From an innovation system perspective, even if institutions emerge spontaneously as self-grown, they stern from system components and cannot survive if they do not promote innovations and are not desired by the elements of the system.

Values and contexts defining institutions or organisations are embedded in people. Thus any attempt to differentiate institutions from people, taken individually or collectively, would miss the target. That new institutional arrangements in agricultural development in poor countries put emphasis on capacity development in system terms, foremost, implies the development of individual capacities with respect to the desired innovations. Collectively or not, individuals are the first movers of innovations. Only through such a lens it is possible to account for all actors involved in agricultural innovation systems. The work of ISNAR aiming to help developing countries build their agricultural capacity (ISNAR, 2000) missed this golden lens and then overlooked farmers within the system. Innovations, process of innovations and systems of innovation concepts have to be redefined with individuals at their core. Thus, to adjust capacity building in NAIS, the focus should be seized towards farmers with the specific question, what capacity or capacity for what? To answer this question, the study builds upon the entrepreneurship theory.

Schumpeter (1934) is credited with many significant developments in economic theory (Outcalt, 2000). Essential to the current topic is his theory linking economic development to entrepreneurship. Through entrepreneurial activities, individuals innovate and allow economic systems to avoid repetition and to progress to more advanced states. Schumpeter has associated innovation with entrepreneurship. What makes an individual an entrepreneur is his innovative activities. For Schumpeter, without innovation there is no entrepreneur; becoming an entrepreneur is to perpetually innovate. Thus, entrepreneuriall endeavours are, by definition, innovative. Becoming an agricultural entrepreneur is to become a farming innovator. I believe that adopting an entrepreneurship theoretical framework, would help promote agricultural innovations at the farmer level. The emerging concern is how to promote agricultural entrepreneurship.

Many factors affect entrepreneurship. They are not all easily controllable. Based on characteristics of entrepreneurs, it is demonstrated that entrepreneurship educational programmes constitute a key determinant for successful entrepreneurship. New education initiatives should be created for teaching and learning entrepreneurship. By equipping more people with the skills to become entrepreneurs, a country can effectively increase its supply of competent 
innovators. I believe that entrepreneurial dynamics at farmers' level will revitalise interactions among NAIS components while contributing to strengthening linkages. With entrepreneurial skills, farmers gain innovation capacities, and economic competencies allowing them to know how to make innovations work. Further, agricultural entrepreneurial training brings more benefits.

Earlier we demonstrated that backward economies of Sub-Saharan Africa can take off allong agricultural development, which basically rests, among others, on innovations (technological, institutional or organisational). Many new people want to get into farming as into new businesses. But traditional sources of information and learning based on inter-generational transfer of farming knowledge and skills do not meet this need. Many people who are considering a farming career may not come from farm families, and thus lack the tools or experience to make effective decisions about farm entry. The challenge of agricultural entrepreneurial training is to rebuild and strengthen NAIS so that all or at least the majority of farmers can access the technical, informational, natural, and capital resources they need to innovate and to succeed.

The desired agricultural entrepreneurship training should focus on both theoretical and practical aspects of entrepreneurial behaviour but with greater emphasis on practical issues in real environment. In effect, as Mitton (1997) put it:

\footnotetext{
"In entrepreneurship, knowing is not enough.. Entrepreneurial prowess is not in what you know, but in what you can do with what you know ... No annownt of simulation in the classroom will fully prepare someone for the hardiships and personal anguish that a business is bound to calsse... No amount of positize reinforcement of feedback in a training course is likely to come close to the thrill of achievement affer a difficult struggle..."
}

Finally, what this study aims at and stresses is that, in addition to the technical "know-how" farmers may already possess, they need "know-who", "know-where", "know-what", and know-when. When farmer entrepreneurs spot and seize their opportunities, they know-why. Agricultural entrepreneurship is expected to motivate innovations so that the sector can advance and have its bearing on the process of economic development. 


\section{Discovering the Songhaï Centre}

\subsection{Introduction}

Capabilities, knowledge and institutions play a central role in economic development process thinking and their importance is increasingly being emphasised (Gregersen et al., 2004). That is, rather than resource endowments, human capabilities form the main contributing factors to development. Thus, action toward effective development should create an environment in which all people can expand their capabilities (UNDP, 1994). The importance of knowledge to development lies in the recognition that different forms of knowledge constitute the backbone inputs to all human actions and social changes. Institutions constitute the vital rules of economic behaviours and as such, they have the potentials to foster or hinder all other development factors (Gregersen et al. 2004). The Songhai framework of actions builds upon these three dimensions. It is an illustration of a broader approach to economic development.

For Songhaï, a viable economic society encompasses two main components, which allow surmounting ecollogical, biophysical, social, religious, technical and economic constraints. They imply a correct choice of strategies and incentives under a coherent approach at all levels. The first component aims at the emergence of new human capacities such as knowledge, know-how and skills. 
The second component ensures the development of the institutional framework that helps build-up appropriate behaviours required for change and progress (Nzamujo, 2002, p.60 - the founder of Songhai). Institutions create conditions for learning that affect knowledge enabling the development of human capacities, which bear their impact on innovation processes. These interactions between changes of capabilities, institutions and knowledge are therefore at the core of the development process.

\section{The sub-case study}

This sub-case study is descriptive but revelatory. It is about the Songhai Centre, whose founding director viewed African society under the permanent threats of many crises, and felt the need to advance his people. In engaging in the practice of development processes, he understands that the best way to help the "poor" is to transform the poor into dynamic producers struggling for permanent effectivertess. The basic assumption is that raising the standards of living of people cons go alongside agricultural development. To develop, agriculture itself requires embedding people involved in processes, which ensure the development of their innoration capabilities. Fundamentally, it is thought that sustainable economic growth will not occur unless the institutional set-ups provide an environment that favours the generation of creative capacities. This also cannot be the result of spontaneous or instinctive actions. It requires clear vision from which sound objectives derive. In esserce, the case lends itself to the system of innovation conceptual framework and tries to answer the simple question of Why Songhai?

For an efficient development of productive forces, it is important to place technology issues in a systems framework (Nzamujo, 2002). Father Nzamujo, the Founding Director of Songhaï, contends that it is the absence of this consideration, which led to the emphasis on "ready made" technology transfer. The frame ignored the exploitation of local potentials. Songhaï thus proposes "technological grafting" defined as "technological combination that makes use of the world applicable technologies while taking into account the complexity of the environment in which activities are taking place". This means that Africa, though rooted in its values, must be open to absorb, for its own sake, and according to its needs, the most advanced techniques, no matter where they originate from. What is stressed is the consideration and the exploitation of local resources and the uniqueness of the environments where development is needed and consequent activities undertaken. The right mixture of both traditional and ultra modern technologies is required to obtain better results, given local constraints (Nzamujo, 2002).

For Farther Nzamujo, institutional settings should trigger the appropriate imnovations in Africa. The kind of innovations required in an African agricultural 
context may concern the improvement of diverse tools applicable in crop production, animal husbandry, fish farming, simple techniques for the conservation and the transformation of diverse fruits and the diversification of products etc. Such simple but structured attitudes toward innovation imply that innovations are not only the privilege of experts. Africa has to develop innovation capacities from the local realities analysed and thought by skilled people burning for economic and social dynamics of the continent (Nzamujo, 2002, p.99). Diffusion is an unbreakable part of an innovation process. Songhaï has developed a diffusion process that allows farmers, particularly Songhaï farmers, to acquire the new agricultural technologies, embodied or disembodied, and to possibly adapt them to their specific environments. In the process, different forms of assistance have been necessary, and still are.

This chapter is organised into five sections covering all issues related to the Songhaï centre, which is a socioeconomic and rural development actor specialised in training, production and research activities. The chapter traces the institution from its creation, meaning that the study has tried to capture the dynamics of the issues it is presenting. The chapter draws its contents from interviews with the founder and 18 other staff members, of which many head goods or service production units. It also draws on the basic information from the memory book the founder wrote in 2002. The first section introduces the whole story about why and how Songhaï was created. It informs about the fundamental purpose the institute is to serve and documents the development and expansion of the centre in terms of sites and scope of activities. The second section focuses on the requisite issue: production. This has evolved from crop and animal productions to services through the production of agricultural machinery and processing activities. It is an innovative production organisation based on minimal inputs, local resource use, no waste and profitability (cost-effectiveness). It has also evolved from the basic integrated system to a complete integrated production system. In addition, this section depicts the staff and the organisational and managerial structure that supports the production. In a third section, the chapter concentrates on the research framework pointing out research policy, partnership and research results. The fourth section argues that successful human activities require collaboration with other social and economic actors. It defines the context of good partnership, as Songhai has conceived, and shares Songhai experiences on the issue. 


\subsection{Genesis of Songhai and its expansion}

While not short on detail and finer logical points, this section provides an account of the history of the essence and evolution of the institute. It links five fundamental points. The first exposes the rationale for creating the centre. It describes the general socio-economic state of SSA as unsustainable. To contribute to changing this deplorable state of affairs, Father Nzamujo took the initiative to create the Songhai Centre. The second point reports the problems the founder aims to address. He argues that a bad development equation was written for Africa. The Songhai founder argues that the African crisis is, to some extent, more moral and spiritual than economical: it relates to some mental attitudes, behaviours and beliefs. The third issue relates to how, in concrete terms, the centre addresses the problems. It presents a sort of defined road map to longterm solutions compiled as objectives. The last two subsections record the startup and the development of the centre with its current state.

\subsubsection{Rationale for founding Songhaï}

Despite the importance of the active population (70 to $80 \%$ ) that agriculture employs in SSA, it contributes in a slighter proportion (about $30 \%$ ) to the wealth of the countries with many farmers starving everyday (Nzamujo, 2002, RCA, 2005). The sector appears incapable of achieving the fundamental rolle it is supposed to play in the process of economic development. The production framework is typically unsustainable with unprecedented environmental concerns such as deforestation and soil degradation added to erosion. Struggling with unproductive and inappropriate technologies and farming practices, just for survival, the peasants run towards heavy risks. For Father Nzamujo, there is a need to question the development path that has been followed. The great development theories have been inadequate; they have been rather mythical than a stimulus for real development actions. A direct corollary is also the failure of educational and training policies due to their inappropriateness. Other concerns relate to the cost of social and economic actions such as corruption, bad political decisions and management practices. With no real search for efficiency, advantages are wasted and destroyed. There is a need to highlight the main roots of the concerns. To break this circle, one needs to bring to light its starting point, the essence of the matters.

\footnotetext{
This first section is essentially drawn from the book "Quand l'Afrique Relève la Tête" written by Fathen Godfrey Nzamujo (2002), the Dinector and Founder of Songhai, and the interviews made with him.
} 


\subsubsection{The perceived problems}

Agriculture may be viewed as a point of departure for the development process. The situation as described above is the consequence of many factors, of which those affecting the agricultural sector appear more life-threatening in SSA. To perceive the real problem, one needs cleamess. For Father Nzamujo, lucidity means the recogmition of what goes well and what does not. As opposed to optimistic and pessimistic views, it is a reallistic attitude that begins with sound observation of the surrounding world with a loving heart and with the intention of struggling for its transformation. He explained that lucidity leads to an objective analysis of events, no matter whether it hurts or not. It impels to measure the challenges, prepare oneself to affront them, and enter the dynamism of change. And then it comes into sight that it is no longer possible to believe that development will result just from the injection of Western money or know-how and that it is not necessary to take into account the specificities of local conditions namely, natural and human resources.

In the development process, the capacity to observe and identify things that would impinge on success is thus essential, but not all. It must lead to the production of new ideas, goods and services. Lucid observation perceives the complexity of phenomena and the effects of the many parameters that compose them, the Father stressed. It constitutes a systemic approach that combines the social, economic and spiritual dimensions, and which stand to be the basis for individual and societal life. The development of a society requires the interactions of all these dimensions, affirms Nzamujo (2002).

Father Nzamujo also shed light on the importance of mental values. He argued that the belief in oneself and in the ability of one's fellow Africans to innovate is the principal root of concerns. Anyone, any group or human community is capable of creativity, new ideas and innovations that generate opportunities and wealth leading to development. Accepting mediocrity and blaming others for things that go wrong is the attitude of those who have lost confidence in themselves: "It is the fault of my parents, my friends, the history, the political environment and the socio-economic context". To some extent, each individuall is the driver of his/her own life. Others can do whatever to affect him/her on his way of life; they can help, or hinder him/her to progress. The individual has to make more of an effort to reach his goals. Nobody has the right for failure if just and only others are to be blamed, stresses the founder of Songhaii. Thus, the problem Songhai wants to address is a profound multidimensional crisis resulting from the crisis of identity of the African who has lost confidence and no longer 
believes in him/herself. To tackle this crisis, Songhaï built a track, a sort of clear road map compiled as objectives.

\subsubsection{The objectives}

Farther Nzamujo argues that there is no fatality for the flawed development of Africa. A sustainable economic growth will not occur until a social economy provides an environment that favours the generation of creative capacities. This also cannot be the result of spontaneous or instinctive actions. It requires clear vision from which sound objectives will derive. A vision is an ideal, a mental image of a situation projected in the future, and which must become real through a progressive process of communication and actions (Nzamujo, 2002, p.60). Such a vision commits to a process, the search for real freedom that can be realised only in a well-defined environment conducive to free up productive potentials. Reciprocal encouragement, demonstration of mutual confidence, responsiveness and forgiveness are essential to such an environment. Further, openness for change, the recognition of obsolete practices, ideas and the motivation to learn and grow are required elements of the environment, the Father adds.

Songhaï has a vision. To the vision, Father Nzamujo gave the name Songhail. Songhaï was a powerful economic, commercial, political and military empire in the $15^{\text {th }}$ Century in part of what is today West Africa. For the founder, this name is a symbol of pride and excellence not only from the past but also in present Africa. The motto of Songhaï is "Commitment to Excellence". Songhaï does also have an emblem: the eagle, which symbolises eyesight, courage, determination and rapidity. These characteristics constitute the basis of the system of values of Songhaii.

The objectives of Songhaï rest on this vision and are compiled in its charter (Nzamujo, 2002, p.9-10). The ambition of Songhai is to advance the emergence of a new African society based on a sustainable socio-economic entrepreneurship that can efficiently exploit locall resources (natural and human), and find its place in the global economy. To start, Songhai seeks to create viable socio-economic environments through the development of human cultural, social, spiritual, technical, organisational, and economic potentials. Such potentialls empower individuals and groups as active members of the society and embed them in a sustainable integrated production that links agriculture with industry and trade. Songhaï aims to trigger an entrepreneurial spirit by being itself an "entrepreneurial space", sharing the risk and reflex of entrepreneurs. The movement (Songhai) aspires to promote a competitive, leadership spirit and a 
sense of creativity and innovation by developing training programmes in agriculture.

The main objective of Songhail is to train young agricultural entrepreneurs who, once established, become pillars of success. They must be capable of commanding respect and attracting the surrounding populations to the entrepreneurial way of being. Indeed, Songhai wants to fight one of the fundamental constraints to development of Africa: mediocre work ethic. Principles, values and behaviours that form the basis of a good work ethic constitute the foundation of an economically and socially viable society. Father Nzamujo argues that these values cannot be a subject of laws but an integral part of the conscience of the citizens. The values do not always develop spontaneously. They have to be integrated by means of a deliberate process of socialisation: training/learning and a follow up. Songhai aims to become a centre for the emergence of culture of entrepreneurship and where people learn to change their mentality, where the youth is put before its responsibilities, and young people are taught to become actors of their own development. Finally, Songhail intends to transform the poor into active producers using local resources while the expected result is the re-establishment of a stable African society. Nevertheless, achieving these objectives could not be an act of spontaneity.

\subsubsection{Setting up Songhaï}

Changes occur beginning from the heart, with love that progressively transforms into an obsession, a radical commitment and a concern of every point in time, asserts the founder of Songhaï, the Dominican priest Father Godfrey Nzamujo. Father Nzamujo (2002) explains that his engagement for daily struggle driving and bringing others into motion, was not instantaneous; it is rooted in Africa and its history. Indeed, he reports that he was born in Nigeria and raised in the light of lbo culture characterised by courage, vigour, communitarian spirit of life and individual accountability. Considering one-self, searching and daring to pursue original objectives despite fear and doubt, were the basic values taught. He reveals that his great-grandfathers settled in the lbo region after slavery and did not really know the country and region they originally came from. Therefore, he has acquired a larger vision that does not confine him in neither ethnic nor nationalistic behaviours. Instead, it grants him some kind of freedom to act on a continental dimension.

Father Nzamujo, who is a computer scientist as well as a microbiologist, was Professor of Engineering at the University of California-Irvine. In the mid-1980s, the crisis in Ethiopia, characterised by severe droughts, famine and starvation, 
became the decisive event that propelled him to a new commitment. In effect, he saw a series of ads on TV to "help the starving children of Ethiopia". The ads struck him so deeply and he continually began to ask himself "What can I do for my continent of origin?" He returned to Africa, visited several countries and realised that Africa is endowed with tremendous natural resources, but now is very poor because a wrong economic equation had been written for Africa. For Father Nzamujo, an economy for Africa must rest on its own realities, be they cultural, environmental, or geographical. Logically, he deduced that the best way to draw Africans out of poverty is to transform them into active producers using local. resources. Father Nzamujo acknowledged the existence of constraints but argued that they can be removed if, together with others, he commits to a success.

\subsubsection{Sources of inspiration}

For the founder, the birth of Songhaï is, foremost, an act of faith in the values of agriculture. Father Nzamujo argues that there is no dichotomy between human spiritual and socio-economic life. Both these aspects of life need to be mutually fertilised, and each individual needs to develop this double dimension of his life. He testifies that it was faith in God that has been the powerful stimulus, which pushed him to where he would not necessary need to be. He added (Nzamujo, 2002, p. 41):

\footnotetext{
"Two complementary poles support my evangelical spirifuality and conwitment: fhic| resurrection of Jesus Christ and divine energy. It is in this perspective that I becane [a] priest and [am] still happy to remaim priest. Resurrection offers multiple possibilities of understanding and dizerse interpretations of events of life. For me, resurrection means that tomorrow can be different and lthel constraints will not last forewer and considered as fatal outcownes."
}

Further, he shares two other sources of inspiration and claims (Nzamujo, 2002, p.43):

"Furdamentally, Songhat would not brave existed, if I didn't initially follow the exanvple of Dominique, the fourder of Dominican Preacher Order (in the eighteen century)."

Indeed, Dominique de Guzman distinguished himself from the then religious movements. He saw the society in a crisis and the church as corrupted. He viewed ignorance as an essential factor of this decadence and searched for the values that could help the world change. He therefore sent his brothers to undertake university degree studies. Dominique de Guzman however, did not consider knowledge gained from education/training as an end in itself $f^{\prime}$ but as a tool to respond to the needs and the challenges of the emerging society from feudalism. Yet, this was not all. The Dominican Father Louis-Joseph Lebret, the 
Founder of Economy and Humanism, was the second source of inspiration. He discovered poverty in the maritime region of France in the 1930s. Instead of researching and literary focusing on poverty, he engaged in training people in economics and in the development of the conscience of solidarity. He trained leaders that transformed the world of fishermen. Lebret introduced new methods of investigations such as systemic analysis of social and economic situations in their real aspects and spiritual thinking that is open toward the realities of the world.

\subsubsection{Beginning from Benin}

What is the rationale for setting up the Songhaï movement in Benin when the chronic food crisis in Ethiopia propelled him into action? Logically, addressing the issue should begin from Ethiopia. Father Nzamujo argues that by comparing the situation to a house on fire. He advocates two kinds of actions. The first and immediate would consist of saving people and stopping the fire. The second action would consist of investigating the causes of the fire and searching for ways to prevent future fires. When in the 1980s, Ethiopia was facing a severe food crisis the international community mobilised to express solidarity by sending food with other social assistances. After the fire has been stopped, there was a need to take preventive actions: the Songhai project for example. During one of the interviews with him, the founder brought to light a number of reasons that explain the rationale for starting the Songhai movement from Benin.

a) "During the 1970s, West Africa has also been severely affected by droughts and famine. This means that food insecurity became a threat for most of SSA countries. Thus, any substantial vision translated into [a] project and which aims to address long-term food concerns can start from anywhere in the sub-region..."

b) "As mentioned earlier, I have acquired a larger vision that does not confine me in neither ethnic nor nationalistic behaviours. I acknowledge the historical fact of the division of Africa into the so many countries with their consequent national borders. However, I do not see any difference between Africans..."

c) "I acknowledge colonisation as a historical fact and it was an act of random that Africans have adopted English, French or Portuguese as official languages. Why did I start the project from a francophone country? For me, speaking English, French or Portuguese does not make difference between Africans. In other words, having English in Nigeria, as [an] official language, has not made me different from a 
Togolese just because he speaks French. Whatever the official language we use wherever in Africa, we have common values to share "."

d) "As common negative values, all Africans share economic crisis that results from a crisis of identity, the lack of confidence in oneself and in one's brothers. An institutional enviromment of creativity and innovation, and which would enable adequate training production, research and development of sustainable agricultural practices, matters in mostly all countries. Solving these problems requires restoring self-confidence, the ethic of good work and following methods for the creation of viable agricultural (to begin) enterprises. The basic leitmotiv is "let [us] count on our own skills and on our own means". Use what you have to get what you need. Improve on your skills to "innovate". Seek, wherever, whatever complementary knowledge and know-how so as to provide yourself with missing resources required to sustain an efficient production. And all these elements were found in the development programme of the Benin Government of the 1980s."

\subsubsection{Getting started}

In 1985, after the decision to set up the project in Benin was definitive; he requested land from the Government of Benin. The Ministry of Agriculture and Rural Development granted him ten hectares of fallow land located in Ouando, al suburb of Porto-Novo (capital of Benin). Father Nzamujo associated a set of six dropouts from school, and together they launched clearing activities. Then they built six basins for fish farming. After these basic tasks, only a small amount of money was left from the initial capital the founder had. In effect, it was just enough to acquire 32 quail eggs, 12 ducks, 100 hens, 10 sows, 20 sheep, goats, etc, and the project kicked off. Friends of whom Father Nzamujo had associated with in a support group at the time of his studies and work in the USA ensured the initial investment capital. The project was officially inaugurated on 5 October 1985. The fish, quails and sheep proliferated. By the end of 1986, the representatives of the African Foundation for Development (AFD) visited Songhaï. The project's achievements within a year amazed them so that they decided to contribute. The AFD signed an agreement ensuring Songhai substantial financing for the construction of 84 aquaculture basins and pigsties. The sale of some products on the site started (Nzamujo, 2002). From this starting point, Songhaï grew. 


\subsubsection{Songhaï sites}

When Father Nzamujo was setting up the Songhaï centre, he already had in mind the continental dimension of the project. Pushed by the Ethiopian food crisis he came to challenge the phenomenon beginning from Benin. The development project issues should first spread through the whole country and then cross its borders. The achievement of such an ambition requires an effective participation and sound interactions between many actors concerned with development. Individuals, associations and organisations (public, private, national or international) have been sharing the Songhaï vision. Benin and Nigerian government bodies also rank among Songhaï partners. All together, they have supported many investment projects leading to the expansion of Songhai throughout Benin. By the means of the diverse partnerships with these actors, Songhaï has developed its headquarters in Porto-Novo and created other sites in Savalou, Parakou, Lokossa, Kinwédji and Kpomasse. A close collaboration of Songhaï with Nigerian authorities has also enabled the creation of Songhaï in Delta Amukpe (Nigeria).

\subsubsection{The Songhaï site of Porto-Novo}

The centre is situated in a suburb of Porto-Novo (in the Ouémé region, in the south-eastern part of Benin) on an area of 15 hectares with no possibility for extension. The main activities conducted on the Songhaï Porto-Novo site include:

a) Training in biological agriculture

b) Crop, animal and Biogas productions, mushroom and fish farming

c) Workshops for agricultural machines and tools and for processing of agriculturial products such as butchery of animals, delicatessen, production of fruit juices, jams, syrups, smoked chicken, yogurt, cheese and soymilk

d) A feed mill production centre that grinds well-balanced animal feeds for different species and mixes plant products grown on the farm

e) Two restaurants, one "European" and the other "African"

f) A Community Networking Service Centre(CNSC)

g) A centre for documentation and information(library)

b) Workshops for rice hulling, cashew nut processing and for soybean processing 


\subsubsection{The Songhaï site of Savalou}

Operational since January 1999, the Savalou site is located in the Zou region (the centre of Benin). In addition to the activities carried out in Porto-Novo (with the exception of certain workshop activities), this site offers greater opportunities for large-scale vegetal production using agricultural machinery, cow-driven ploughing (yoking), and irrigation system. The main crops produced include maize, ground-nut, soybeans, cassava, cowpea, yam and fruit trees (mostly ail palm, mango, papaya and coconut). Songhai Savalou comprises three detached locations with a total surface area of 214 hectares, which can be expandled. Like Porto-Novo, the site of Savalou accepts students into a similar training programme each semester. The number of admission varies and with it, the number of graduates.

\subsubsection{The Songhaï site of Parakou}

Parakou is the third city of Benin and is located in the northern part. Like the Savalou site, it was created in 1999 but covers a surface area of 126 hectares, with a possibility for extension. About 41 hectares comprise a manmade lake used for rice production and fush farming. The Borgou region stands for the northern Benin, which is climatically very different from the southern regions with some differences in farming systems. Its population density is very low with possibilities for larger arable land per capita allowing the use of cow-driven plough techniques. Training northern people at the site of Parakou allows them to remain in contact with the realities of their environment. Songhai is currently trying to develop an integrated, sustainable agricultural system based upon cowdriven farming, irrigation, and the use of agricultural machines. Crops such as yam, sorghum, groundnuts and soybeans are produced on the site with larger fish farming. In addition, the site develops a mechanical workshop for the maintenance and repair of agricultural machinery.

\subsubsection{The Songhät site of Lokossa and Kinwédji}

The Songhai Centre of Lokossa was established in 1994 and covers only 0.3 ha. The centre manages the Kinwédji site, and monitors and assists the established farmers and villagers through continuous training. It basically commercialises Kinwédji productions and assists students in the application phase and Songhai farmers in the Mono region. Kinwédji covers an area of 19 hectares and the soil is 
exceptionally fertile. It is located $12 \mathrm{~km}$ from Lokossa in the south-western region of Benin. At the beginning, Kinwédji was a farm that Songhai set up for a village group. Efforts were made in 1999 to transform the farm into a place where the students could have direct experiences in rural settings. In other words, Kinwédji is the application site accommodating students trained in Porto-Novo. Indeed, the Porto-Novo site is a semi-urban environment, which does not correspond to the real rural environments in every respect. Two facilitators and a manager, supervise the students and manage the various production activities. These include market gardening, rice, banana production and the rearing of layer hens and pigs. In May 2004, 12 students were in their phase of application on this site.

\subsubsection{The Songhai site of Kpomasse}

The Songhai centre of Kpomasse was created on the initiative of the United Nations High Commission for Refugees (UNHCR) in 1999. The objective was to increase self-sufficiency and encourage socio-economic integration of refugees through social orientation and assistance in the areas relating to community development. It is also a training-production centre housing infrastructures for crop production, animal husbandry (mammals and poultry) and fish farming. Processing activities are also developed. The training put particular emphasis on managerial and technical capacities in the various sectors of crop, animal, and craft productions and, is organised accordingly. Each field of training lasts two and a half months, of which half a month is committed to intensive training in Porto-Novo. Two months are spent on further training on the site at Kpomassè. Graduates wishing to start a small family business are eligible for a micro-credit loan, during which time Songhaï continues to assist them technically. Local populations also receive training that equips them with skills in techniques of production and management in the different domains of vegetal and livestock productions, fish farming and small-scale processing.

\subsubsection{The Songhai site of Delta Amukpe (Nigeria)}

Fundamentally, the centre aims to train young high school graduates in the Delta State to enable them to manage the Centre and consequently train the local populations. The site builds the culture of the sense of responsibility, discipline, creativity and courage. The training model and production activities are similar to those on the site of Porto-Novo (Benin). 


\subsection{Production ${ }^{2}$}

Vis-ä-vis then afflicting situations, Father Nzamujo advocated that it was pressing to think differently and search for essential strategies that apply for sustainable development in Africa. Development of agriculture should be a starting point while real mechanisms based on sound policies have to be introduced. From this point of view, Father Nzamujo $(1993)^{3}$ has conceived and proposed an "Africant definition of development": Setting up production systems based on the relative advantage of Africa. The African heat, humidity, biological lives (bacteria, insects and flies), African cultural heritage and conceptual framework should be at the basis of African new economic order, clarified the priest.

This section deals with the production framework, which constitutes the background and one of the nodes of the activity system of Songhail (production, research and training). It points out the fundamental characteristic of the Songhail production context known as 'integrated production system'. It comprises six interlinked key issues tackled and presented in a dynamic way. The tirst subsection presents the basic integrated production system articulated around three key poles: crop production, animal production and fish farming with, at their intersection, biogas production. In the second subsection, the focus is on the activities of processing and mechanical production, viewed as pure manufacturing. The third subsection combines the issues defined in the first and the second subsection and describes the complete integrated production system. Within the production framework, the institute provides ICT services, as well as restaurant, hotel and conference services and catering. These are the subject of the subsection four. In the fifth subsection, human resource components are analysed. Finally, in the sixth and last stage, the section concentrates on the evolution of the managerial and organisational structure of Songhaii.

\subsubsection{The basic integrated production system}

For almost 20 years, Songhai has been trying to integrate available natural resources and means of production. The model is based on minimal inputs and the use of local resources. It is also based on no soil degradation, no pesticides, no pollution and no waste. This system, in which nothing is lost, makes it possible to

\footnotetext{
2 Apart from specific indications, data from this section is obtained from Songhai production department.

${ }^{3}$ Rev. Dr. Godfrey Nzamujo, Director of the Songhai Project, Benin. On the Occasion of Receiving the 1993 (4 October) Africa Prize for Leadership, Tokyo.
} 
recycle and to constantly revalorise lost energies. The "waste" produced by a sector, thus constitutes raw materialls, whatever their level of degradation, for another activity. Initially, it is a modest organic farm, an integrated production system articulated around only three key poles: crop production, animal production and fish farming as illustrate in Diagram 5.1.

Crop production comprises market gardening, major staple crops and perennial plants. Instead of using chemical fertilisers that are often very expensive, Songhai produces compost from plant wastes and animal dejections, so that the restructuring of impoverished soils is done by organic fertilisation. Waters from ponds where fish is raised are rich in minerals and serve to water vegetable gardens.

a) Market gardening includes cabbage, lettuce, carrots, vegetables, sweet maize, French beans, onions, etc.

b) Major staple crops are maize, yams, soybeans, cassava, rice, beans, groundnut, etc.

c) Perennial plants involve coconut, papaya, banana and mango.

According to Songhaï, it is very difficult to specify the varieties of maize cultivated because of the fast crossing between the various varieties in the fields. Taken together, the average yields per hectare on the Songhai sites, vary between 1.7 and 2 tons, which largely exceed the national average approximating 1 ton per hectare. Soybean varieties belong to the TGX family with outputs reaching 2 tons per hectare. As for manioc, Songhaï does not cultivate improved varieties yet. Average yields of local varieties vary between 15 and 20 tons per hectare.

Livestock production includes mammals, poultry and fish, all of which are fed with fodder and composed feed rations. The main mammals consist of pigs, rabbits, grass-cutters (African giant bush-rat), cattle and bovines. The poultry is essentially made up of broiler and layer hens, turkey, geese, ducks, quails, guinea fowls, etc. Tilapias and catfish form fish farming.

a) Pigs - The species raised come from the interbreeding between the local species (of Benin) and some European ones. This new species is larger than the local but smaller and more resistant to the tropical conditions than the European species. The farrowing capacity of the pigs is of 10 to 12 piglets twice a year.

b) Grass-cutters - For three births in two years, they have farrowing capacity of 5 to 7 young, which are consumable in 8 months. 
c) Broiler hens - Songhail raises two main species including ANNACK Titan and ANNACK 2000. They grow fast and become consumable (1.4-1.5 kg) after 6 weeks.

d) Layers hens - Songhail raises the species known as HARCOT and SHAVER and has about 40,000 on all its sites. Their average laying rate ranges from 70 to $80 \%$.

e) Fish farming - Tilapias and catfish - Whereas the tilapias reach $200-300 \mathrm{~g}$ after six months, each of the two species of the catfish makes easily $2 \mathrm{~kg}$ within a year.

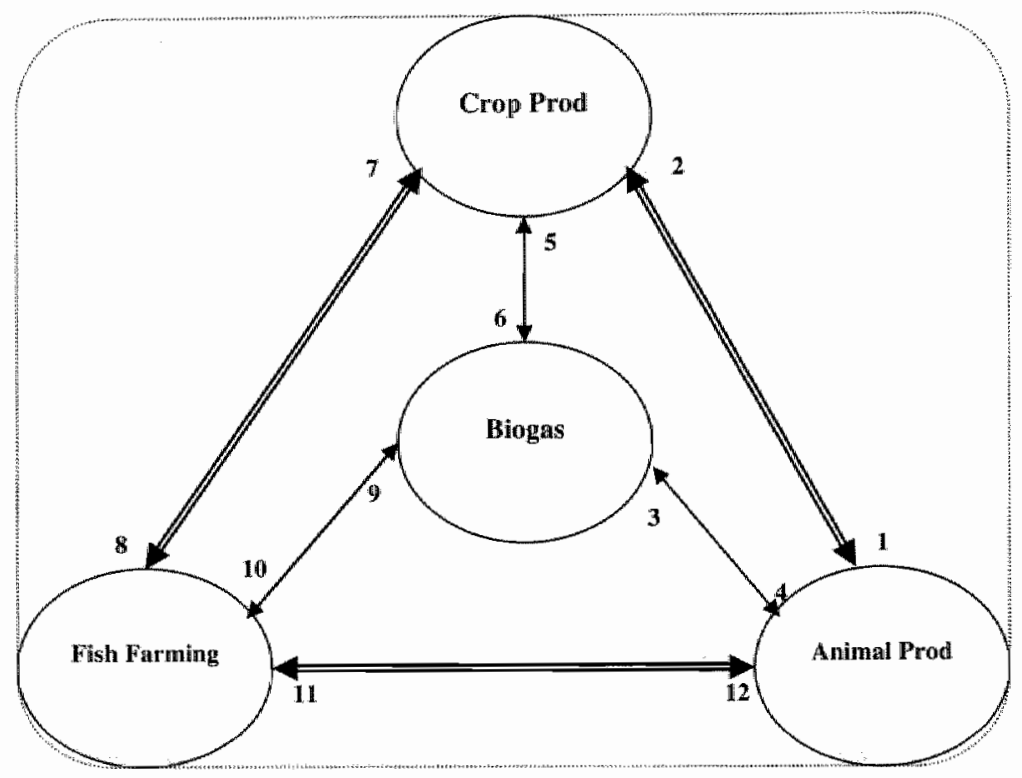

Diagram 5.1: The Basic Integrated Production System

Source: Songhai Websitet

\section{Interpretation of the diagram ${ }^{5}$}

1. Animal production benefits from crop production: Maize, soybeans, maize stems and groundnut haulms are elements of animal feeds. Farmers produce them to feed mammals and poultry. Other plants (for example vernonia and papaw) are intentionally cultivated to feed animals.

\footnotetext{
4http//www songhai.org

${ }^{5}$ Based on an explanation given by the training department
} 
2. Crop production benefits from animal production: Compost is produced mixing dejections of mammals, and poultry droppings with plant wastes for the fertilisation of poor soils. In addition, pig liquid manure is an excellent fertiliser.

3. Biogas production benefits from animal production: The dejections of pigs are also used for biogas production.

4. Animal production benefits from biogas production: Energy produced from biogas provides electricity for pigsties and fowl houses.

5. Crop production benefits from biogas production: Effluents (composts rich in nitrogen and organic elements) produced as waste from the biogas digester, serve to irrigate fields where certain crops are cultivated.

6. Biogas production benefits from crop production: Wastes from certain plants (mostly, market gardening products) are also associated with animal excrements in the production of biogas.

7. Crop production benefits from fish farming: Water wastes from fishpond are very rich in minerals and serve for the irrigation of vegetable gardens.

8. Fish farming benefits from crop production: cassava roots and maize stalks are excellent feed for fish.

9. Biogas production benefits from fish farming: Wastewaters from fishponds, when associated with other wastes, produce biogas.

10. Fish farming benefits from biogas production: Feeds for fish is made of dried granulated ingredients. The drying process uses energy that is supplied by the biogas.

11. Fish farming benefits from animal production: Fish appreciate eating fowl droppings.

12. Animal production benefits from fish farming: When some fish are underweight after a normal period of production, they constitute wastes to be recycled. They are then dried and used as ingredients in the composition of animal feed. 


\subsubsection{Processing and mechanical production}

Processing activities comprise both traditional and semi-industrial techniques, which match the social and economic environment of the country. The techniques are those Songhail trainees will have access to and will be able to deal with in their enterprise settings. The main production units of food processing include the department of crop products and the department processing animals. The crop-processing unit supplies a variety of products such as soymilk, yogurt, biscuits, jams, cakes, fruit juices, and syrups. It also supplies sandwich bread, birthday cakes, canned tomatoes, and other catered products. The animal processing unit concentrates on the techniques of butchering and smoking of animal products, especially, pigs, quails, grass-cutters, chickens, ducks, turkey meats, and fish. Songhail advocates that processing activities help reduce waste, which is often important in agricultural production processes in Africa. Processing makes it possible to have agricultural products throughout the year. It also contributes to the improvement of their value added. For Songhaï, the introduction of processing units has favoured the diversification of agricultural products with an increased demand for other production equipment.

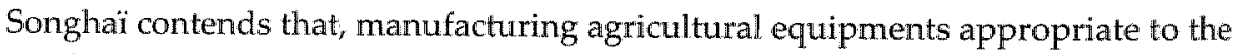
production environment has a positive impact in strengthening and increasing the production of many crops. A higher stage of agricultural development necessarily encompasses mechanisation. Yoking equipments, pedals or motorized threshing machines, pedal pumps, decorticators, graters, presses, and even watering cans and wheelbarrows are tools that contribute to trigger agricultural production. As the activities grow, the integrated production framework develops. That is, Songhail manufactures such appropriate equipments.

\subsubsection{The complete integrated production system}

With the development of the existing activities and the creation of new ones, the Songhai production system became more complex. Linkages have been established with food processing units, mechanical workshop and with the marketing of the various outputs. The integrated production system, as illustrates diagram 5.2, aims to increase productivity possibilities. Each production and training unit is managed like an autonomous agricultural enterprise capable of self-financing. Songhai handle every unit for profitability for it has to serve as a model for the prospective farmers (trainees). Links are created between different production units, which taken separately would not be 
cost-effective. Thus, a given production activity may not be necessarily profitable by its own. It becomes cost-effective through the process of reciprocal interaction with the others: what it gives to the other production units and or it receives from them. For Songhaï, the integrated production system induces more profitability and allows an effective exploitation of the advantages and opportumities that offer production environment (locality). It leaves no room for waste. As examples, Songhaï explained that

a) The dejections of pigs, hens, turkeys and the by-products from processing crop and animal units go to another unit for compost. Two to four months later, these wastes, completely broken up, serve for biological manure in market gardening or for the fertilisation of orchard.

b) Dejections of pigs serve as raw materials for the production of biogas, which is used by generators to create electricity for cooking and processing.

c) Maize stems and groundnut haulms enter feeds for grass-cutters whose dejections serve directly to fertilise banana, papaw and manioc fields. These same grass-cutter or rabbit dejections create favourable environment for the production of earthworms that geese, ducks and other fowls highly appreciate.

d) Crop production and processing units supply the two restaurants of Songhaï (Porto-Novo) with their products. Finally, Songhaï uses the marketing unit and even the Community Networking Service Centres to commercialise the remaining or other produces of the processing, mechanical, and crop production units. Songhaï offers two restaurants, as well as hotel and conference services and catering at all convenience. 


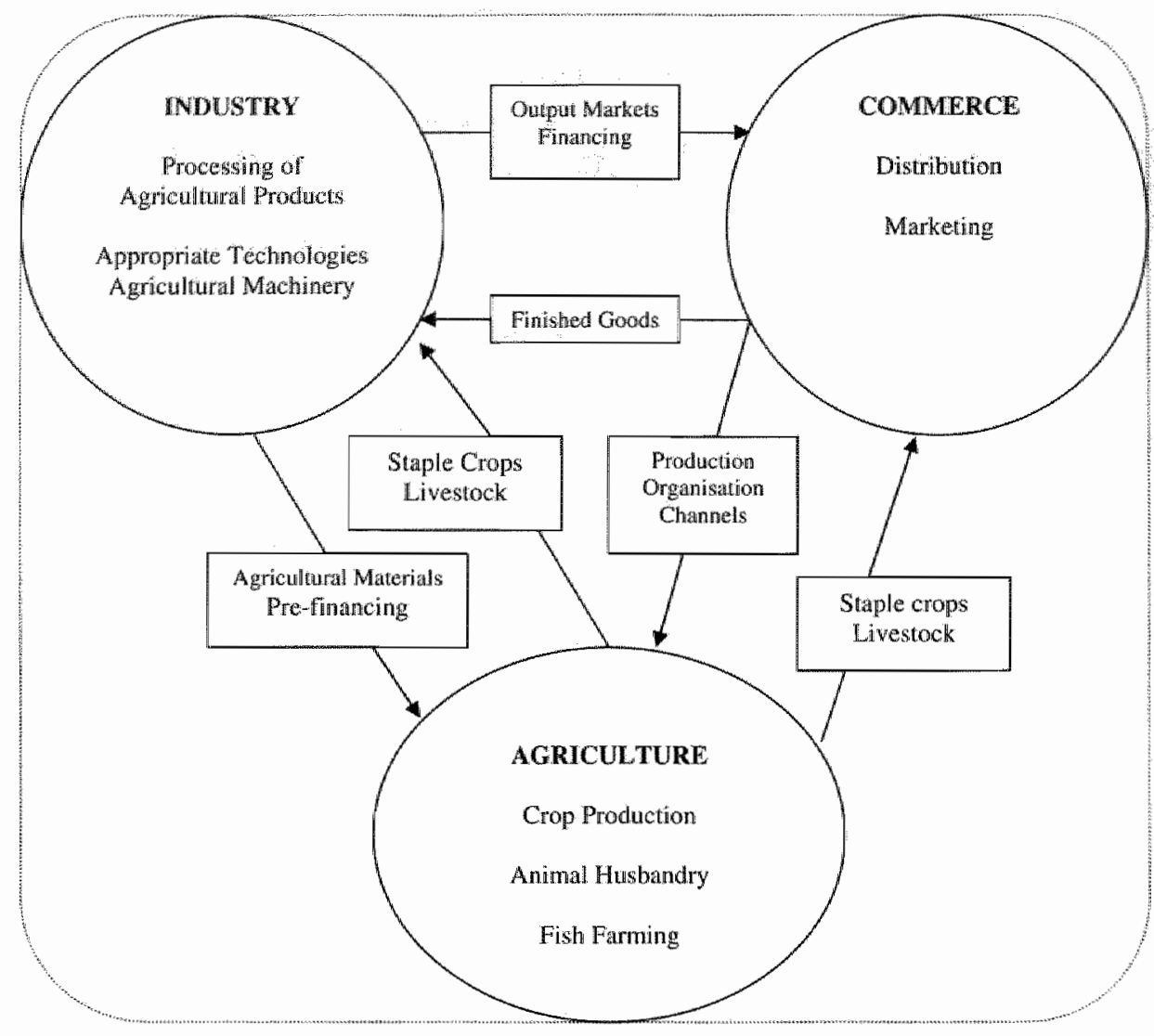

Diagram 5.2: Complete Integrated Production System

Source: Adapted from Aigle Songhail No 45, 3 rd and 4th quarter, 2001

\subsubsection{Services}

A larger approach to development that Songhai has been trying to promote is the careful integration of selected methods, processes, techniques, inventions and ideas from the modem era to traditional economic, cultural and environmental systems. ICT's also constitute a wital element in the development process. The need to improve production, organisation, and productivity lled Songhai to create Community Networking Service Centres (CNSC) in the larger cities where Songhaï sites exist: Porto-Novo (south-east), Savalou (centre) and Parakou (north). The CNSCs are expected to provide communication, education and lifelong learning opportunities within Benin and help build internet access. Songhai Centre has built a vast network of development partners within Benin and 
internationally with whom it maintains contact, exchanges information, provides services and implements collaborative projects.

The U.S. Agency for International Development (USAID) supported the CNSC project while LearnLink ${ }^{6}$ implemented it. To compensate for the poor electricity and telecommunications, the CNSCs use solar power and high frequency microwave links to run the computers and high frequency digital radio technology to ensure reliable and fast communication links. It is also expected to significantly reduce operating costs. Connecting individuals and communities with the resources they need to accomplish development objectives are fundamental to LearnLink"s work. It has developed and implemented a realistic self-sustainability plan for each of the Centres. It has also provided training and technical assistance for Centre staff and other Songhaï staff in the use, maintenance and development of internet and distance learning pedagogy. Further, LearnLink has developed and implemented a monitoring and evaluation system for the CNSCs. This is not however ${ }_{r}$ the whole story.

a) The activities of the CNSC are integrated into the overall activities of Songhai and have the following objectives:

$\Rightarrow$ Create within the Songhaï community a culture of information and experiences sharing both internally and externally.

$\Rightarrow$ Training staff at each of the three centres on basic notions of ICT.

$\Rightarrow$ Facilitate the acquisition and exchange of experiences among farmers and other members of the rural community.

$\Rightarrow$ Share technical results and experience gained by Songhaï with other development actors in Africa.

b) The CNSC offer special services such as:

$\Rightarrow$ Photocopying, telephone and fax, typing and printing, word-processing, database and spreadsheet, graphics.

$\Rightarrow$ Design and production of badges, business cards, greeting cards, postcards, letter-headed paper, logos.

$\Rightarrow$ Image scanning and production of digital photo albums.

$\Rightarrow$ Internet connection (electronic mailing and internet telephone).

\footnotetext{
15. LearnLink is a five-year, Indefinite Quantities Contract of USAID. It is funded by the Human Capacity Development Center in the USAID Global Buread, the African Bureau, and other USAID Bureaus, offices and nissions. It is operated by the Academy for Educational Development (AED) - LearnLink, 1999. Benin, available at: www aed.org/learnlink.).
} 
Thanks to the partnership with the International Development Research Centre (IDRC), Songhaï has also been able to implement a network titled "Network of Information and Communication for Sustainable Agriculture in West Africa". Its first mission is to develop and test the contents of distance learning. The second mission is to identify and adopt technologies appropriate for networking with different key actors (students, entrepreneurs, teachers, etc.) within the framework of the promotion of sustainable agriculture in West Africa. The project resulted in the development of distance learning, forums and discussion groups, development of multimedia courses on CD-ROM as well as on the internet provision of services accessible via the web.

\subsubsection{Human resources}

Since its creation Songhaï has been employing workers from different fields of specialisation, levels of qualification and from various countries. At the beginning, Songhail staff comprised a group of people that shared the Songhai vision and philosophy of development. While some staff members are "ready made products", others result from Songhaï internal training and learning process. Highly advanced experts, junior specialists, average qualified and many practitioners from Africa, America, Asia and Europe have been able and continue to share their experiences at the Songhai Centre. Working terms openly varied from few days to many years. Father Nzamujo explained that, unlike many development projects designed just for few years, Songhai is a long-term vision for development where one can harvest only what he has sown. Therefore, working at Songhai is rather viewed as a long-term investment for future generations. Despite this atypical philosophy, the Songhaï Centre has provided permanent jobs for many people who are proud of producing and sharing their knowledge, expertise or experiences.

By January 2004, Songhai had an employment level of 146 permanent workers on all its sites put together. This number excludes workers under short-term contracts (equal or less than six months), those in their trial (probation) period and occasional labourers. The analysis however, comprises workers holding university degrees, Baccalaureate $(\mathrm{BAC})^{7}$ and those who are qualified under baccalaureate, either local or foreign. The proportion of the staff with university education represents $22 \%$ of the employment size. In the context of Benin, this is definitely a highly regarded share mainly when one considers that Songhaï is thoroughlly managed as a pure business enterprise. Medium-level qualified

\footnotetext{
In the educational system of Benin, BAC (BACCALAUREAT) is the diploma one gets when he passes the secondary leaving school examinations. It gives access to university level education.
} 
workers constitute the highest proportion ( $45 \%$ ) of the permanent staff. They are mostly involved in production under the governance of university graduates. A top management member asserted that this category of workers could be considered as university graduates. He explained that upon their arrival at Songhai, employees go through learning processes allowing them to build and develop new skills or strengthen their competences in many fields. He stressed that after few years, they are rooted in the integrated production system and become general-purpose workers and capable of carrying out and managing different production activities. The lowest qualified class forms $33 \%$ of the employment size. The proportion may seem insignificant in the eyes of many observers for Songhai is an agricultural enterprise. The majority of these workers are those trained at Songhaii. The chart below (Figure 5.1) is the graphical representation of the staff according to the level of education of the workers before entering Songhaï.

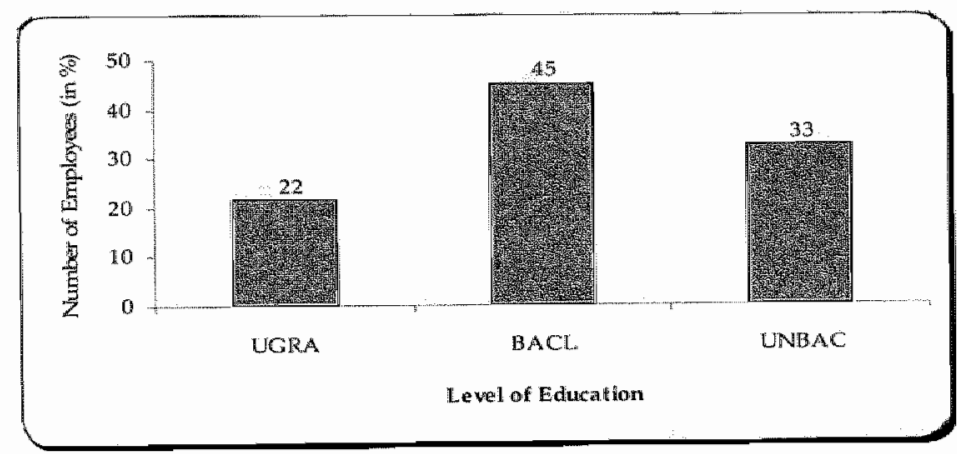

Source: Songhaï Human Resource Department: January 2004

Figure 5.1: Relative distribution of the stafl according to educational level

Legend:

UGRA: University graduates

BACL: BAC Level

UNBAC: Under BAC Lewel

Whatever their origins and qualifications the various staff members participate in the activities carried out in the different production units. Table 5.1 below shows that, alone, animal production employs almost quarter (34) of the total permanent staff. This production department employs $12.5 \%$ of university graduates and almost half of the average-level qualified workers $(45.5 \%)$ as displayed in Figure 5.2. In effect, at Songhaï livestock production includes many production units and sub-units such as poultry (layer hens, broiler hens, local improved hens, turkey, gees, quails, etc.) and mammals (pigs, cattle, rabbits, grass-cutters, etc.). It does not however employ any staff of the lowest category (UNBAC). 
The departments of ICT and vegetal production (VP) are on equal footing regarding the number of total employed workers (18). The department of HotelRestaurant-Bar works with 17 employees. In terms of the qualification of the staff, they diverge. ICT ranks first (25\%) in terms of university graduate employed and shares the same third place with Hotel-Restaurant-Bar (6.1\%) regarding the average qualified, while Vegetal Production ranks second $(22.7 \%)$ after the Animal Husbandry department. Like Accounting \&Finance and Animal Husbandry, Vegetal Production employs none of the lowest qualified workers. It however disputes the same fifth place $(9.4 \%)$ with the Department of Administration \& Management as to university graduates. Concerning the under BAC level employees Hotel-Restaurant-Bar takes the lion share (25\%) followed by General Service $(20.8 \%$ ) with ICT and Sales \&Marketing (SM) on equal footing $(12.5 \%)$.

The training department seemingly employs eight of the total (146) staff, $6.3 \%$ of the university graduates and the lowest category and $4.5 \%$ of the average qualified workers. In this department, the university graduates design, orientate and manage the training. They are only two in absolute value. In practical terms, staff with $B A C$ conducts training activities in the different production units. This explains the reason why their majority (77.2\%) work in Animal Husbandry, Vegetal Production and Mechanical Workshop.

Table 5.1: Distribution of workers according to level of education and across production units

\begin{tabular}{|c|c|c|c|c|c|c|c|}
\hline \multirow[t]{2}{*}{ Production Unit } & \multicolumn{2}{|c|}{$\begin{array}{c}\text { University } \\
\text { Graduate: UGRA }\end{array}$} & \multicolumn{2}{|c|}{$\begin{array}{l}\text { Baccalaureate } \\
\text { Level: BACL }\end{array}$} & \multicolumn{2}{|c|}{$\begin{array}{l}\text { Level Under BAC: } \\
\text { UNBAC }\end{array}$} & \multirow[t]{2}{*}{ Total } \\
\hline & UGRAB & UGRAF: & $\mathrm{BBACL}$ & FBACL & BUNBAC & FUNBAC & \\
\hline Animal Husbandry: AH & 2 & 2 & 29 & $\mathbb{1}$ & 0 & 0 & 34 \\
\hline Vegetal Production: VP & 3 & 0 & 14 & 1 & 0 & 0 & 18 \\
\hline Admin. \& Manage.: AM & 3 & 0 & 0 & 0 & 3 & 0 & 6 \\
\hline Training Depart: TID & 2 & 0 & 3 & 0 & 2 & 1 & 8 \\
\hline Food Processing: FP & 0 & 0 & 2 & 0 & 5 & 0 & 7 \\
\hline Mechanic Works : MW & 1 & 0 & 6 & 0 & 3 & 0 & 10 \\
\hline Accounting \& Fin: AF & 6 & 0 & 1 & 0 & 0 & 0 & 7 \\
\hline ICI \& Services: ICT & 8 & 0 & 4 & 0 & 6 & 0 & 18 \\
\hline Sales \& Marketing: SM & 2 & 0 & 0 & 0 & 6 & 0 & 8 \\
\hline Hotel-Restaurant: HRB & 1 & 0 & 4 & 0 & 12 & 0 & 17 \\
\hline General Services: GS & 2 & $a$ & 1 & 0 & 10 & 0 & 13 \\
\hline Total & 30 & 2 & 64 & 02 & 47 & 1 & 146 \\
\hline TOTAL & 3 & & 6 & & & & 146 \\
\hline
\end{tabular}

Source: Songhaï Human Resource Department: January 2004 


\section{Legend}

$\begin{array}{ll}\text { UGRA } & \text { University Graduates } \\ \text { UGRAB } & \text { University Graduates - Benin citizens } \\ \text { UGRAE } & \text { University Graduates - Foreigners } \\ \text { BACL } & \text { BAC Level } \\ \text { BBACL } & \text { BAC Level - Benin citizens } \\ \text { FBACL } & \text { BAC Level - foreigners } \\ \text { UNBAC } & \text { Under BAC Level } \\ \text { BUNBAC } & \text { Under BAC Level. - Benin citizens } \\ \text { FUNBAC } & \text { Under BAC Level - Foreigners }\end{array}$

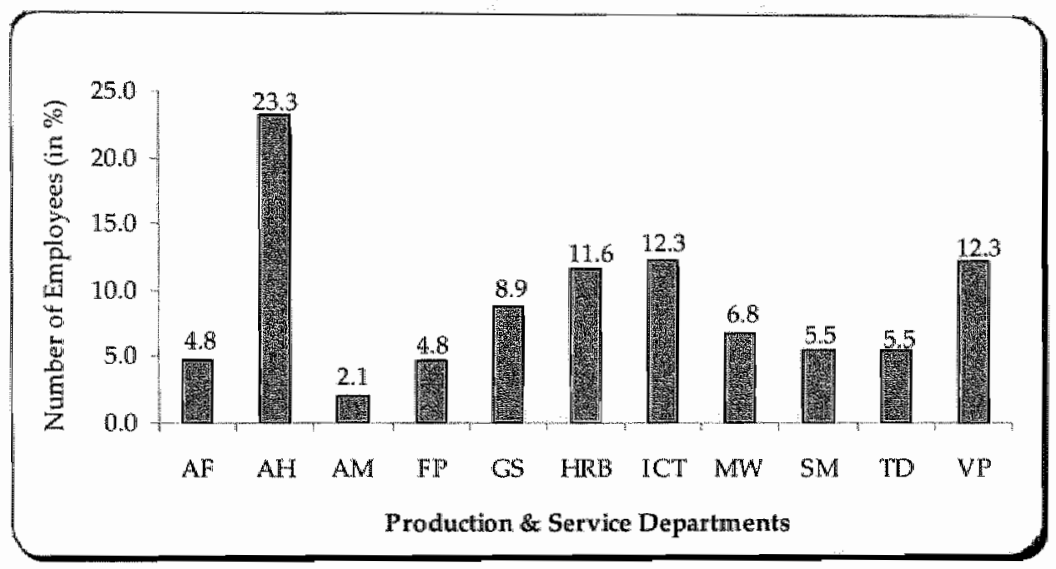

Source: Songhai, Human resources, 2004

Figure 5.2* Relative distribution of the Songhai staff across different production departments

Legend:

AF Accounting and Financial Division

AH Animal Husbandry

AM Administration and Management

FP Food Processing Unit

GS General and other Serwices

HRB Hotel - Restaurant - Bar

ICT Information and Communication Technologies and Service automation

MW Mechanic Workshop

SM Sales and Marketing

TD Training Department

VP Vegetal Production 


\subsubsection{Organisation and managerial structure}

Investigation of the administrative and managerial organisation of the Songhai Centre may be done with respect to two fundamental periods. The first period begins with the birth of the centre in 1985 to the year 1999 when other sites were created. The second period covers the years from the enlargement of Songhail activities with the emergence of new sites. This means that the adjustments in the administrative and managerial organisation of Songhait were subjected to the changes that have been occurring. More specifically, it is the permanent search for profitability and the motto of Songhaï: "commitment to excellence", which endorse and motivate the adaptations.

Three decision poles or managerial organisations composed the Songhaï centre at the beginning. They include an executive committee, a technical committee and the administration board. The executive committee was made up of the technical chiefs heading secretariat \& administration, finance \& accounting, training, production, hotel-restaurant-bar and supplying (stocking). The technical committee was restricted to only the different chiefs heading the departments of production, training and hotel-restaurant-bar. The founder is the executive director of Songhai and headed each of the two committees. He is also member of the administration board, which comprised essentially people outside the centre. The board continues to have a validating and assistance role. The members of the board used to control the executive committee (and now the management council). They can help in fund raising and provide technical advice to the council management members. Diagram 5.3 illustrates the organisational structure.

At their creation and functioning from 1999, there was a manager at the head of each site. The site managers were directly attached to the director and were truthfully accountable to him. They had decision-making power, and were responsible for all production, training and research activities that took place on the sites. They used to prepare the annual or periodical budgets of the sites and, straightforwardly, submit them to the director for examination and approval. It was a real decentralised management. The past managerial structure may be simply pictured as displayed in Diagram 5.4. Songhaï argued that some site managers began to behave too independently in detriment of strengthening linkages with other sites. They took unfair advantages of their position with a danger of drifting into indecent and non-ethical practices. Inadequate production and financial management, unsatisfactory training or care of students, in short a 
pure abuse of power was progressively leading to tarnish the image of the centre. Quickly, Songhai took steps toward the normalisation of the situation.

The first attempt to deal with the problem was the reduction of the autonomy of the site managers. The management council appointed two representatives, and to them the site managers were accountable. They became intermediaries between the sites managers and the director or management council. The site managers were no longer members of the management council; they lost all decision-making powers in favour of the representatives. They became simple observers at the council. They were subjected to new rules that constrained them to consult the representatives and have their agreement before they could take any important decisions. A site manager argued that it became very difficult to handle the site operations because the new organisation seemed more centralised, and many activities were often delayed. He recognised the need for such step necessary to solve the problems at stake. However competence of the representatives in carrying out their tasks. Finally, the new managerial organisation did not survive through the criticism due to inefficacy. 


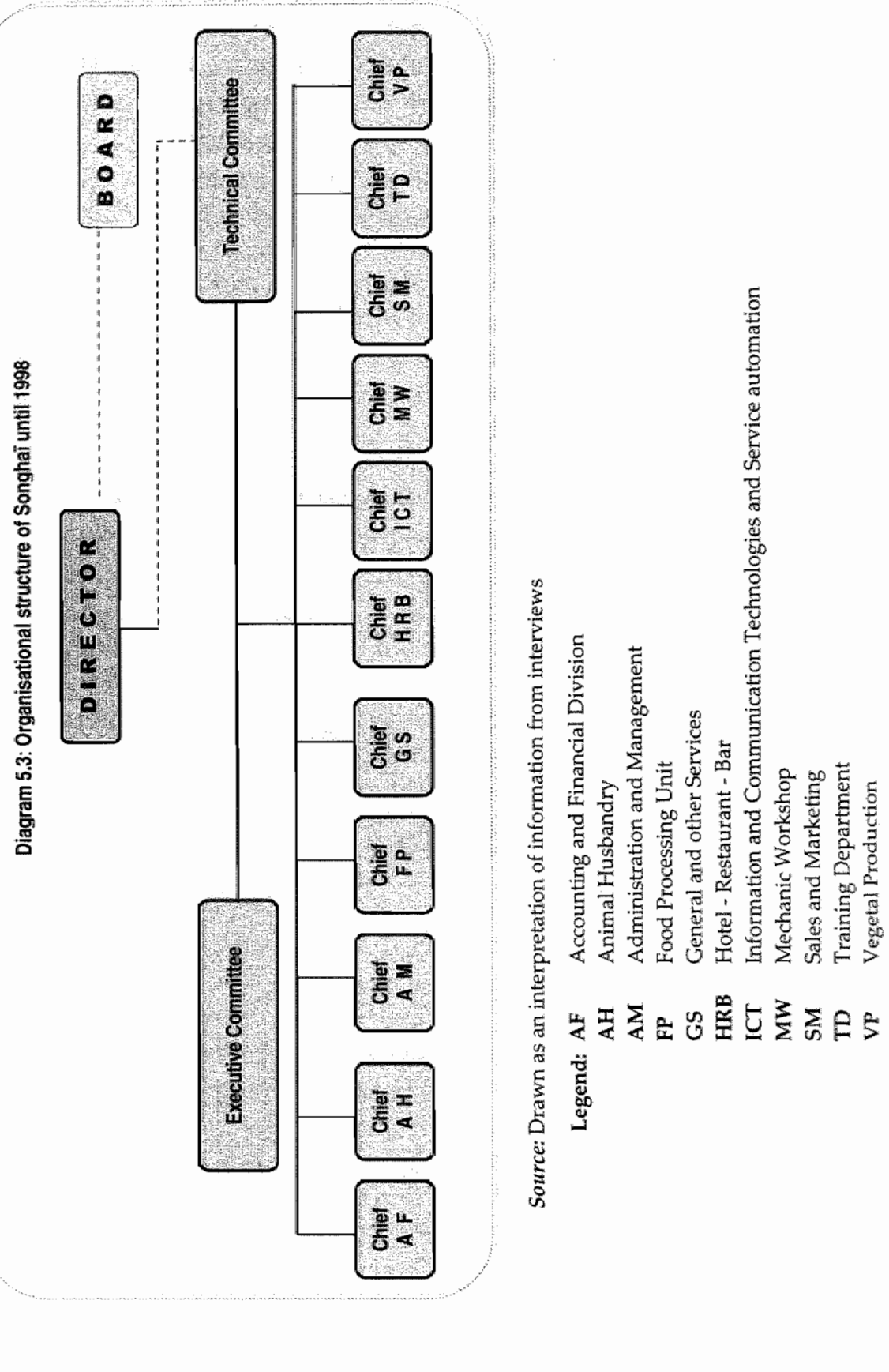




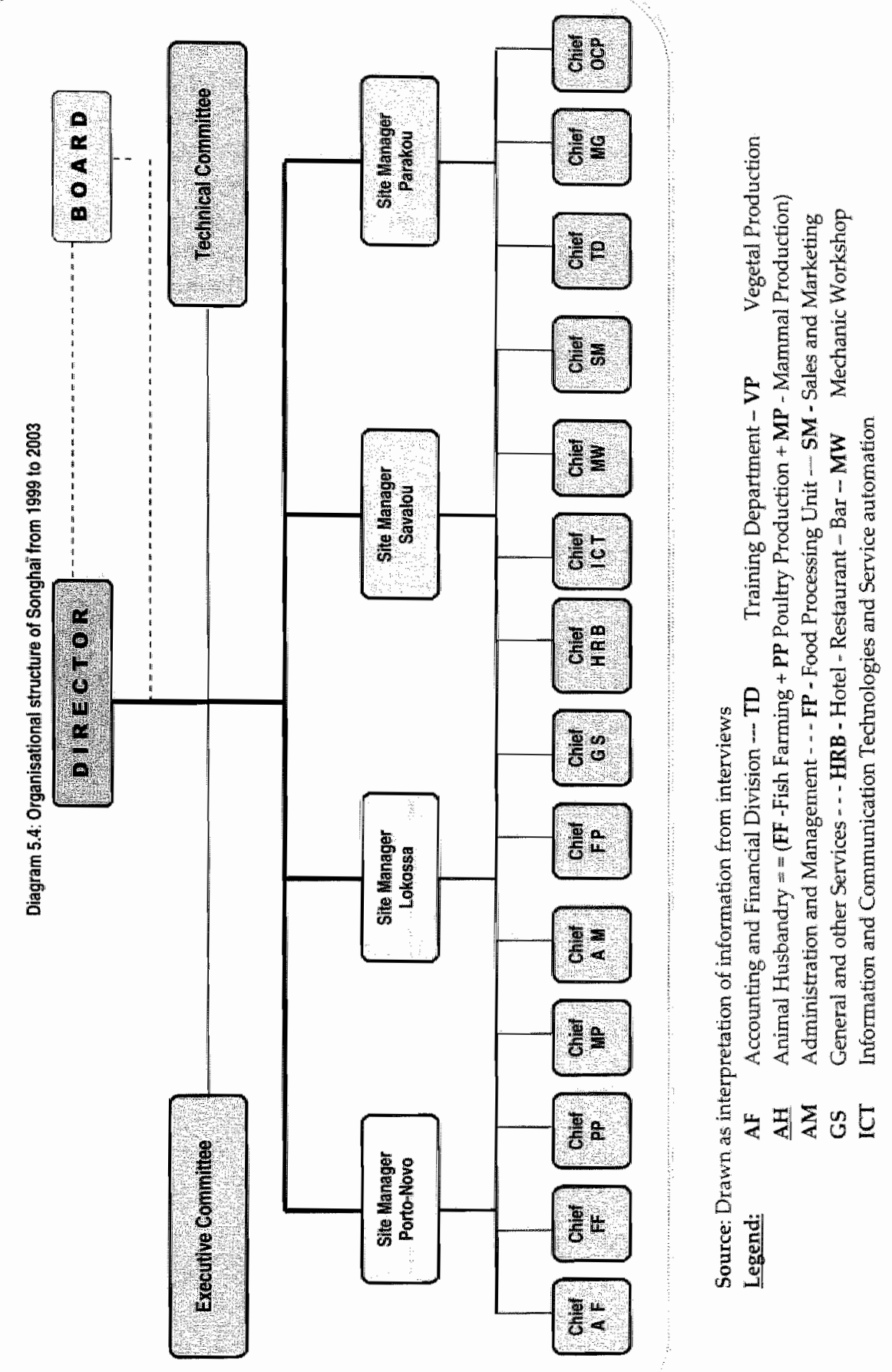


From 2003 onward, another managerial and organisational structure was put under trial as illustrates Diagram 5.5. The founder of the institute continues to have his position as Songhai executive director, the head of the management council and member of the administrative board. The management council is composed of all technical dinectors heading the different production or service departments on the site of Porto-Novo, the headquarters of Songhai. The position of site manager was cancelled. There is a technical manager at the head of each production or service department on the site. These technical managers interact with one another, but without any subordinating relationship. Each of them is accountable to a technical director at the headquarters. For example, a technical director from the headquarters centrally manages poultry production. The managers in charge of poultry production on the other sites are accountable to him. Thus, instead of site managers, only coordinators of site activities are nominated. A coordinator is, first, a technical manager. His mission is the follow up the activities of the site in order to ensure that linkages between the different production and service departments flow conveniently. He is a simple observer at the management council. He can participate in the debates of the council but does not have voting rights. The current tendency is to transform many of the current production and service departments into mini-enterprises, with autonomous status. The following are under consideration:
a) Porcine enterprise
b) Poulltry enterprise
c) Market gardening enterprise
d) Food processing enterprise
e) Soybean processing enterprise
f) Rice processing enterprise
g) Mechanical or machinery enterprise
h) Hotel-restaurant bar enterprise
i) $I \mathrm{CT}$ enterprise 
$\infty$

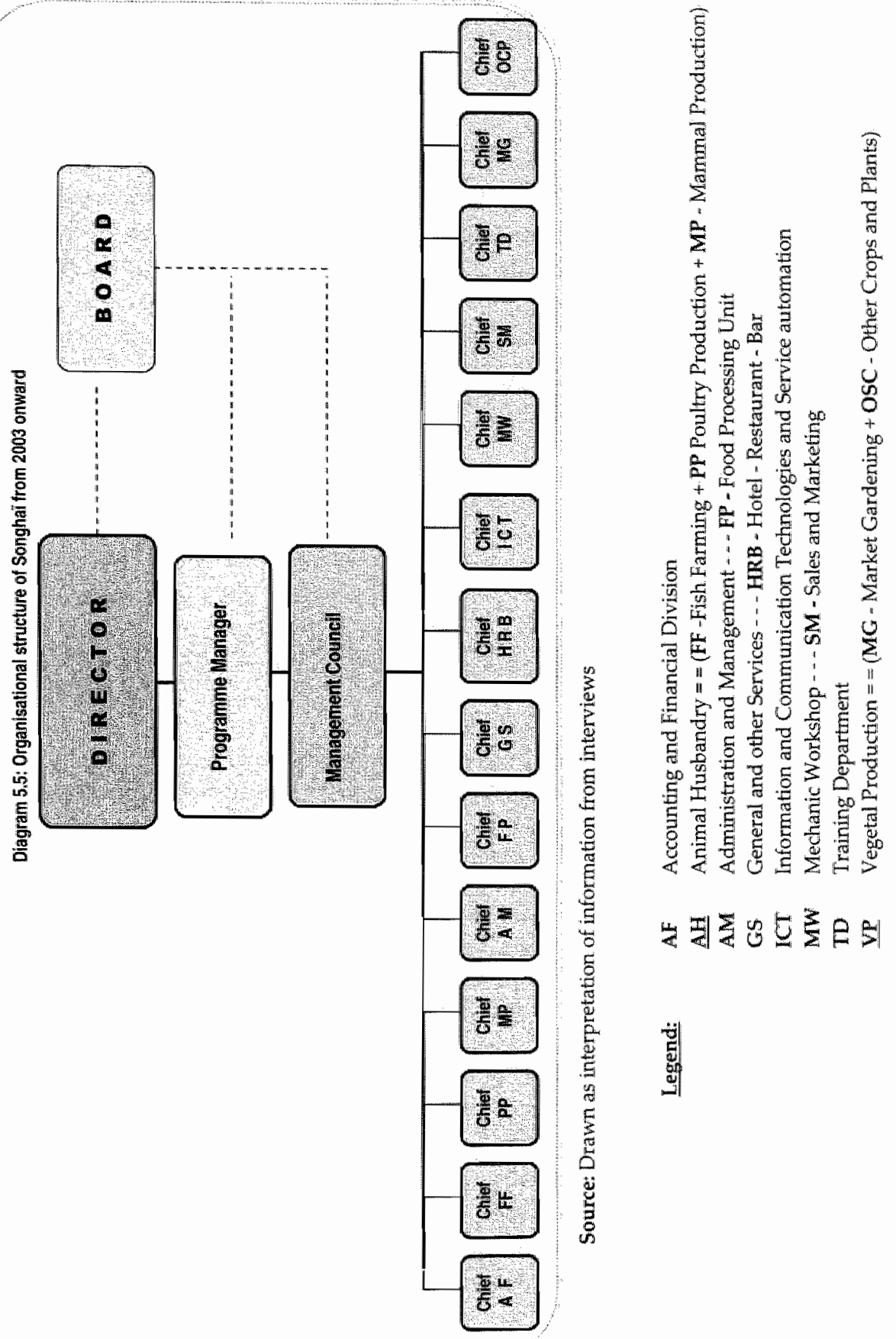




\subsection{Research}

\subsubsection{Research policy}

The definition of research topics begins from the observation of the production environment, and the analysis of the constraints to determine the problems for which it is necessary to find solutions. Once the problems are identified, the researchers explore whether existing solutions (in terms of tangible or intangible technologies) can solve them. First, the question of their appropriateness to the social, economic and environmental context is posed and answered. Songhai calls it selective absorption. Here is an example. The palm oil press contains a component part called reducer, which is very expensive and has always been imported. Concerning this matter, the Songhai research consists of finding a solution that will help avoid importing the reducer. To this end, the technologists are currently working to adapt to the palm oil press, in lieu and place of the reducer, the gear (speed) of old abandoned Peugeot cars.

\section{Research areas}

To strengthen the linkages between its different units of production, Songhai conducts permanent research articulated around the following issues:

a) Quality improvement and cost reduction of animal feed

b) Waste recycling: biogas production, green used water purification by means of specific plants, composting, etc.

c) Improvement, adaptation and production of tools and machines

d) Improvement and or introduction of new crop varieties and animal species

e) Diversification of income sources through production diversification. For example, Songhai has initiated the production of soybeans, mushrooms and snails.

\section{The researchers}

At the beginning, some staff members were basically, specialised in research activities. Today, it is no more the case. Educators, producers and trainees face a permanent search for improvement, adaptation, imitation and the introduction of something new. However, one can note the presence of a specialist on the site of Kinwédji. His job consists of testing nearly 300 varieties of rice that the director brought from diverse Asian countries. 


\subsubsection{Research partnership}

Songhaï has developed research partnerships with both domestic and foreign institutes. In Benin, the technical cooperation involves INRAB (National Institute for Agricultural Research of Benin), FSA (Faculty of Agricultural Sciences) and IITA (International Institute for Tropical Agriculture). Windhoek University of Namibia and the NGO ZERI (Zero Emission Research Initiative) of Switzerland constitute the main foreign research collaborators.

a) Collaboration with the FSA relates to organic manure production, water control, quality improvement of mushroom production and the improvement of soybean seeds and yields. FSA students conduct their thesis research in the fields of Songhaï in order to formalise the innovations.

b) IITA-Benin, IITA-NVigeria and the Windhoek University use Songhail farms to test some of their laboratory research results in terms of producer-user relationships. New varieties of soybeans and cassava have been tested. Songhai tests the seeds and reports on the behaviours of the crops and the yields they have provided compared to those of research stations. The Songhai report contains information on the resistance of the crops to diseases. and other circumstances of fields.

c) ZERI Songhai co-operation applies essentially to the improvement of the Songhaï integrated production system, in which wastes from a given unit of production can be used as raw materials in the others.

d) Concrete benefits from technical co-operation with IITA-BENIN include, plant genetics diversification and the exploitation of by-products from crop production in the preparation of animal feed. Many varieties of manioc, maize, cowpea and soybeans were developed and have been adopted by Songhaï farmers and their surrounding colleagues. IITA-Benin helps Songhaï to improve the processing of some derivatives of soybeans (milk, biscuits and flour) and a small-scale processing chain allowing the transformation of manioc into gari and maize into fermented flour. 


\subsubsection{Research Attainments}

\subsubsection{Research results in terns of technologies and innovations}

a) Broiler hets raised or pile: The technique Songhai has adopted in the growing phase of these birds is very different from that usually practised elsewhere. The hens are very sensitive to infections especially in the tropical countries, where the climatic conditions favour the proliferation of many germs. For about a decade, Songhai has been using hen houses suspended on piles allowing a direct flow of the droppings to the ground. This device avoids the direct contact of the birds with their dejections and contributes to a healthier and sanitary environment. The droppings then serve for composts production. Songhail admitted to have imitated the Thai method of rearing ducks on piles under which are water basins where fish is raised.

b) Plants for a sharper yolk: In poultry production, several experiments were initiated and others are still in hand. Experiments like the introduction of fresh and dried amaranth and papaw leaves in food for poultry have already proven efficacy. Instead of using artificial dyes, Songhail has preferred these plants, which have the virtue of giving yolk the normal bright yellow colour.

c) Feeding fish with rraggots: In fish farming, Songhai has developed at the beginning of the 1990 s a technique of maggot (larvae of domestic flies - Musa domestica) production using wastes from the brewery, animals, crops or processing. The maggots feed fowls. According to Songhai, these maggots, not only contribute to the reduction of the production cost, but they also constitute genuine concentrated proteins $(45-50 \%)$, which definitely enthance faster growth of the birds.

d) New hen species: The importance of demand for chickens known as improved race or pedigrese sire led Songhaï to set up a programme called "Operation Coq" in 1997 . whereby species Rhodes Island Red were set for multiplication. In 2000, Songhai introduced species such as Naked Necks, Kabir, and Sussex with a double effect expectation: faster growth and bigger chickens that produce greater quantity and quality of eggs.

a) New crop varieties: Songhaï has introduced several early varieties of maize, rice, soybeans, banana, tomato, papaw etc. Still, Songhai has not yet been able to multiply the seeds to the arnount that would satisfy farmers' needs. This is a problem.

f) Neen lotion: It serves for controlling insects on cowpea, maize, millet, sorghum and groundnut farms. Neem potwder serves for crop conservation.

g) Blood nueal flour: it is incorporated in animal feed; flour made of lenves of cassam associated with water hyacinths enter animal and fish feeds.

h) Dried hen droppings: They enter pig rations up to $20 \%$. 


\subsubsection{Simple machines and tools: socio-economic context friendly}

In the framework of integrated farming, Songhai has developed and adapted, improved, produced and introduced a number of agricultural machines and tools in the market place. The machinery includes, foremost, post-harvest processing equipment, incubator $(60,150,200 \mathrm{egg}$ model), cooker $(300,450,1000 \mathrm{~kg}$ of nuts) and various tools for market gardening (watering cans, buckets).

\subsection{Partnership}

Development calls also for partnership (Nzamujo, 2002). Generally speaking, "A partnership is a strategic alliance or relationship between troo or more people. Successful partnerships are often based on trust, equality, and mutual understanding and obligations" ${ }^{\prime \prime}$. For Songhaï, partnership does not mean equality. Instead, it means parity in the relationships, complementary differences, and long-term collaboration. Partnership needs care and adjustment to occurring realities of the fields. It means network and implies experience sharing with one another, argues the founder of Songhaii. Development is a complex mechanism that does not rely on money alone (Nzamujo, 2002). Injections of funds, the ineffectiveness of projects, technical assistance, and other forms of international supports have created in people in the South a mentality of dependence to such an extent that they have lost confidence and no longer believe in themselves. Northern public opinions also lost confidence in the engine capacity of their actions of solidarity (Nzamujo, 2002). Ineffectiveness of their financial and technical assistances and failures disappointed them.

\subsubsection{The context of good partnership}

Partnership has long-been considered under its material and financial aspects with on one side, a powerful backer (the donor) and, on the other, assisted people receiving the gift. North-South and South-South collaborations should develop in the form where one gives openly and does not intend to impose their will onto the other. The beneficiary should also be able to help determine the 'gift' based on needs on the ground. For Songhaii, partnership means sharing a common vision, common objectives and common risks. Real partnership begins when several people or groups of individuals, despite cultural, social, geographical, historical or religious differences, decide to work together in order to face a common

Anttp://www.seasiteniu edu/lao/undp 
challenge, which becomes an objective set in everyone. That then becomes the common adventure where everyone agrees to risk, to share in successes, or be frustrated, worried or revolted by failure. It is rather a commitment to a mutual fecundation of ideas, means and forces, contends the founder of Songhai.

In the South, many recipient organisations are too often born in a burst of enthusiasm or as a reaction to a problem. In such circumstances, they live on a drip, ready to take all the aid they can find (Nzamujo, 2002). In a constant state of dependency with the sole concern of survival, they ignore any long-term strategy. For Songhaï, conditionality is not a bad thing, as long as it rests on an ethic and favours human development. Problems emerge when donors set domineering and poor conditions that ignore the social, economic and even the cultural environment of the beneficiaries. The conditions put the donors in the position of experts, the only or best "knower", while the recipients are viewed as ignorant. In the past, Songhaï also encountered such cases whereby it preferred to return funding already paid into its account, notably to two religious groups and to a multilateral aid agency. The reason was that their goals and conditions were no longer in line with the vision and strategies Songhaï tried in vain to share with them.

Before engaging in partnership, one needs to check out the supporting vision. Each partner will consider the issues from his specific position but will endeavour to harmonise his objectives and approach with those of others. Without agreements on these principles, it does not stand worthy to accept any proposed funds (Aigle Songhaï, 2000). In partnership, credibility that is based on financial transparency, regular communication, follow-up and evaluation reports, is essential. For Songhaï, the value of partnership should not be equated with the importance of financial contribution. Financial capital plays a vital role, but alone it does not ensure development if other forms of capital are not mobilised to create a favourable environment. The approach must be systemic (Nzamujo, 2002). In the perception of Songhaï, financial capital constitutes a substantial adjuvant, when the community or individual receiving the funds is motivated and trained, and has a vision.

Entering partnership requires following the rules and principles and not the deliberate will of having a domineering position. Under such a framework of understanding, Songhai has worked and is currently working with many domestic, foreign and international individuals, government bodies, organisations and institutions. They contributed to targeted Songhail activities in different periods, and include diverse types of support. From deliberate 
voluntary acts to the willingness to help development in Africa through the personal endeavours of the director, added to amazements before the performance of the institute, there is a little story behind each partnership.

\subsubsection{The partners}

\section{The African Foundation for Development (AFD)}

By the end of 1986, Songhaï signed a partnership agreement with the AFD after some of its representatives had visited the farm on several occasions. It was the first foreign organisation that recognised the originality of the Songhai project and its importance for development. The AFD granted financial assistance, which served to construct infrastructures for livestock production (basins for fish farming and pigsties), acquisition of cultivators, electric generator and well drilling equipments.

\section{The Catholic Commission against Hunger and for Development (CCFD) ${ }^{9}$}

Since 1987 the CCFD has engaged in a partnership aiming at strengthening Songhaï in its institutional setting as a training centre for agricultural entrepreneurship. This partnership has evolved in different forms. Concrete training projects, support to graduate farmers, strengthening production units, experience and knowledge-sharing through organised conferences have been achieved thanks to the CCFD and its allies. In 1989/1990, Songhaï launched its activities of Tchi-Ahomadégbe (in Mono region) with the joint financial support of the CCFD and the European Funds for Development (EFD). Today, though there is no formal project to be carried out, the two partners continue their collaborations in other forms. Songhai participates through experience sharing in any action the CCFD initiates. The CCFD advises many of its partners to visit Songhai in order to draw inspiration from Songhaï paths of development.

\section{The Rabobank Foundation (RF)}

The RF offers financial assistance to any community engaged in a development process and has reached a certain stage. It helps people in unfavourable socioeconomic conditions to achieve relative management autonomy of their economy, wealth and social environment. Above simple financial assistance, the

' CCFD-Commission Catholique contre la Faim et pour le Développement 
goal of the foundation is to help marginalised people to develop their economic potentials to create a framework for decent employments and life. The Rabobank Foundation intervenes to support initiatives undertaken in the field of agriculture, craft, trade and financial infrastructures. In general, the micro projects are evaluated based on their feasibility and durability. Finally, groups of individuals wishing to join their efforts, and who are looking for appropriate working environment, are eligible to request the Rabobank Foundation assistance (Aigle Songhai, 1999).

In partnership with the Rabobank Foundation, Songhä sought to suppout agricultural entrepreneurship activities of its farmers. This support took various forms from one farm to another but had two components. A large part (70\%) of the funds served for subsidies to enable the acquisition of farmlands and agricultural equipments. The remaining $30 \%$ was granted as refundable credit at an annual interest rate of $5 \%$. This project aimed to ensure technical and financial assistance to young agricultural entrepreneurs (Aigle Songhai, 1999).

\section{Association Solidarité Songhai - France}

At the beginning, the Dominican priest Jean-Pierre Lintanf introduced M. Andre Coquemont to his colleague Godfrey Nzamujo. That was in 1992. In the same year, André Coquemont, pork butcher in Jugon Les Lacs (Côte d"Amor, France) offered his professional competences and experiences to Songhai without remuneration. He noticed that Songhai lacked the required technical means to perform this activity. To assist Songhai he activated the network of his relationships and created "Solidarité Songhai". This association has supported. Songhai, concretely, in the processing and marketing of animal products. It also provided financial assistance and permanent technical support to the porkbutchery workers by means of regular follow-up through telephone, facsimile, cassettes and electronic mails (Aigle Songhaii, 2000).

\section{United States Agency for International Development (USAID)}

Parthership between the US and Benin has three fundamental aims relating to health, democracy and basic education. Partnership between Songhaï and USAID precisely built upon the last objective. By the end of 1991, Benin had established the structure for an ambitious education reform programme. Based upon recommendations from a wide range of stakeholders, the programme was launched during the Education Conference (Etats Géneraux de l'Education) in the wake of a political transition. USAID was approached to assist with funding for this education reform programme. The programme consisted of one 
institutional contract and four grant instruments implemented by a number of educational or education-related institutes, among which is the Songhail Centre (Lightfoot, 2001)

Cooperation between USAID and the Centre Songhai in this respect goes back to 1995, when a first experience was undertaken with admission of about 20 young people. Songhai arranged a special one-year training programme to the students. while financed by USAID. During the time this experience was being carried out, the Benin Government was interested in facilitating the expansion of Songhai activities throughout the whole country. Thus, in July 1995, the US and Benin governments signed an overall agreement, the main objective of which was the creation of centres capable of ensuring adequate training in agricultural entrepreneurship. The Government of Benin guaranteed land capital, USAID subscribed to bring technical, organisational, material and financial capital, and Songhaii was to ensure the achievement of the project through the training.

The initially idea was to create in each of the six departments a training centre at the image of the one in Porto-Novo. Later on, a more realistic solution was found. The training centres just have to corroborate with the major agro-ecological realities of the country. The existing centre of Porto-Novo represents an agroecological environment of most southern regions. Savalou and Parakou were selected to represent respectively central and northern regions. Thanks to its geographical position, Savalou occupies an incontestable strategic place and gives access to north-western areas of Benin and Togo. On its side, Parakou is the most significant agglomeration of North-Benin and occupies a strategic place of economic importance for the country. The agreement signed on 12 September 1996 also aimed at strengthening the institutional capacity of the Songhail Centre of Porto-Novo, which was to be used as technical direction and headquarters. The agreements also encompassed the support to the network of Songhai farmers.

\section{CODEV Toulouse (France)}

The first contact with CODEV Toulouse (France) goes back to March 1997 when Didier Burg, a member of CODEV Toulouse, visited Songhai. Discussions between the Songhaï director and Burg were constructive, and both representatives found a common ground for partnership: tangible and intangible technology transfer for energy supply (electricity). This consisted of training Songhai members on installation and maintenance techniques and the supply of energy power and mechanical equipments. CODEV Toulouse has also trained 
many master artisans through Songhai. It was thought that Songhai could become the relay of CODEV Toulouse in Benin (Aigle Songhai, 2001).

\section{Society for International Development (SID): Experience sharing partnership ${ }^{10}$}

The SID constitutes a vast network of actors from both the North and the South as well. It sets up programmes throughout the word at the national, regional and intermational levels. The fundamental mission of the SID is to lead development actors (state leaders, economic agents and NGOs) to think about means which would allow the whole of humanity, without exception, and in particular marginalised populations, to live and maintain their living conditions without real threats for their wellbeing and their environment. Songhai has adhered to the network of the SID since 1996 and takes part in the programmes of Sustainable Livelihoods, whose first phase has been completed in 1997. During this phase, both partners carried out several actions.

In 1996, a sociological research drawn from "Gender approach" was carried out under the topic: "Relations between social categories and places of the woman in her" community". Also within the framework of capitalisation of successful stories, Songhaï presented its experience entitled "Songhaï and Kinwédji, an integrated sustanable development". Upon the $40^{\text {th }}$ anniversary of the SID, Songhai was asked to organise a national conference on "process of development". In 1998, Songhai shared with other members its vision of sustainable development through articles and reflections published in the specialised reviews of the SID. In 1999. Songhai was requested to participate in the second phase of the Sustainable Livelihood project and a food security project.

\section{United Nations, Office of the High Commission of the Refugees (UNHCR)}

On the request of the authorities of Geneva, the representative of the Office of the UNHCR in Benin asked Songhail in June 1998 to ensure the construction of a lodging centre for refugees in Kpomasse (South of Benin). The UNHCR chose Songhai to carry out these activities for its transparency in management. In the pursuit of this partnership, Songhai trained many of the 1,300 refugees.

10 Aigle Songhai, 1999 


\section{Colorado State University (CSU) $)^{x}$}

The CSU is an Institute of Technology with rich experience in ICT (Internet and electronics), mechanical design with a particular predilection for two-stroke engines. In 2000, the CSU received a grant from the American Educational Department to set up a study programme in "International Development" including a component related to practical training courses in West Africa. Songhaii serves as the base for their research on air pollution reduction (in the developing countries). Within the framework of this partnership, Songhai has welcomed many undergraduate and graduate students and a number of the CSU professors. In February 2003, both parties signed an agreement to create a "High Institute of Technology for Employment Development in Benin". The institute offers specialised training in moulding and foundry techniques.

\section{Research Centre for International Development (CRDI) and the Renewable Energies and Environment Group(GERES)}

Gilles Forget, the CRDI Regional Manager for West Africa, visited Songhai in January 2002 to lay down the partnership between the two institutes. The focus was on ICT and concerns building information and communication network for sustainable agriculture in West Africa. The project aims to develop and test the use of multimedia for distance learning. It also tries to identify and adopt appropriate technologies to set up the network of the various actors involved in agriculture in West Africa. To strengthen linkages between specific activities and increase their socio-economic impacts, the NGO GERES, which has an action framework that lies in the promotion of research on alternative energy technologies, and Songhai decided to formalise their partnership through a global programme in 2002-2004. This partnership built upon the promotion of the small-scale food processing enterprise in Benin.

\section{Songhaï-Chasselay ${ }^{12}$}

This association is located on the hills of the Mounts d'Or in the suburbs of Lyon (France) and is today an integral part of Songhaï. This partnership started in 1993 with biogas production technologies transfer. Collaborations also include the provision of a complete mechanical production unit to Songhaï. The Chasselay

\footnotetext{
10 Agigle Songhaii, 2003

12 Aigle Songhaï, 1998
} 
Association helped Songhail to acquire many agricultural machines and tools from France.

\section{The Chalendars ${ }^{13}$}

In January 1996, Alain and Christiane Chalendar and their daughter visited Songhai. At the time of their stay, which lasted about 15 days, they had the opportunity to discover Songhaï sites in Porto-Novo, Lokossa and Tchi. They also visited smalll farms belonging to Songhaï farmers. These discoveries amazed them, and they manifested their will about how and in what ways they could support Songhaï. From that, Songhaï released the idea of financial support enabling new graduates to establish their agricultural business. Indeed, to create their farms, these young farmers must acquire land and build shelters for themselves and their livestock. They also need many other inputs. The Chalendars then committed to fund-raising for the benefit of the farmers. They created an operation called "Collecte pour Jeunes Installés - Collect for Young established". From June to December 1997, they collected and sent to Songhaï about 5516 euros $(5,516 €)$.

\section{Programme d'Insertion des Sans Emploi dans l'Agriculture (PISEA)}

The freezing of recruitment in the public sector since 1986 has reduced new graduates to being jobless. At the beginning of $1990 \mathrm{~s}$, the government initiated a National Programme for the Insertion of Young people in Agriculture. After three years of experience, and to support the existing programme, the government set up a new one denoted "Programme for the Insertion of jobless in Agriculture - PISEA". This programme should encourage agricultural entrepreneurship, boost agricultural production through the mechanism of financial and technical assistance.

Generally, the amount of credit granted to the young farmers varies between $500,000 \mathrm{~F} \mathrm{CFA}$ and $4,500,000 \mathrm{~F} \mathrm{CFA}(762 €$ to $6,860 €)$ depending on whether the applicant has experience or training in agriculture. A per annum interest rate of $5 \%$ is charged and the term of the credit depends on the nature of the project and the expected results, but cannot exceed five years. Further, a subsidy of $10 \%$ is granted if the estimated profit rate is equal or higher than 50\%. Many Songhai farmers benefited from this credit. In this deal, Songhai and PISEA act together as

13 Aigle Songhaii, 1998 
facilitators encouraging Songhail farmers to share their experiences with other recipients by helping them built their business plan and providing them with technical assistance. It is credited with a successful partnership between public and private institutions.

\section{Appropriate Technology International (ATI) ${ }^{\mathrm{14}}$}

Songhai was the second institution the ATI association had chosen to train young people in the construction of pumps NAGUEZE (with pedals). ATI transfers technology and technological knowledge to local artisans. ATI has trained six mechanical technologists for Songhaii. The pump NAGUEZE allows the improvement of irrigation conditions in zones where a lot of people are involved in market gardening. This pump was initially introduced in Bangladesh in 1984 and more than 500,000 units are currently being used. In Africa, farmers in Senegal, Mali and Burkina Faso have already tested it.

\section{India 15}

The Songhai director nourished the ambition of South-South partnership. He visited several countries of the South, of which Vietnam, Thailand, Kampuchea and India share certain commonalities with countries of tropical Africa. A few Thai farmers visited Songhai in 1995 for experience-sharing in rice production. Thereafter, Songhai accelerated collaboration with India, which has outstanding expertise in green revolution technologies and processing of agricultural products. The Songhaï director believes that India offers enormous opportunities, from which his institute can draw inspirations and exploit them to expand its activities while developing a broader framework for agricultural training. His trip to India confirmed his belief that innovations are neither a simple copy without adaptation of the Western technologies or technological autarky that ignores progress achieved by others. India has adapted and developed many technologies, which meet her socio-economic structures and production objectives. For the Indians, he asserted, what counts is not "a mass production" but "a production for the masses".

During his trip to India, the Songhaï director met one of his fellow-members, Father Johnson Kottaram, director of Bosco Institute of Electronics, specialised in

\footnotetext{
it Aigle Songhai, 1998

s. Aigle Songhaï, 2003
} 
training the young poor in electronics. In January 1998, Father Johnson Kottaram visited Songhai to set the ground for their partnership. He helped Songhai in finding suppliers according to its expressed needs and endeavoured for the transfer of two technicians respectively specialised in mechanical engineering and computer science. The partnership built mostly upon the transfer of agricultural technologies and other machinery adaptable to the socio-economic contexts in which Songhail operates. Through this partnership, Songhai has acquilred several machines and factories with the financial support of USAID. A team of six Songhai staff members made a working trip to India for 17 days. The Indian experiences inspired a foundry project in Porto-Novo. It will be possible to locally manufacture spare parts of two-stroke engines. Other partners participating in this project include CODEV Toulouse, Chasselay, and the CSU.

\subsection{Conclusion}

Songhai is an innovative centre in many respects. The problem it aims to address may be not new, but its approach is uncommon. When it comes to development issues, many actors concerned with development of Africa do not often attack the "illness" from its roots (the causes). Instead, the global tendency is to treat the seeming symptoms. The founder of Songhaï noticed that SSA lagged behind the other regions of the world; it was really in a bad shape (no significant improvement to date). He realised that the power to restore bad things, and create new ones and wealth lies in the capacity of the society to command her surrounding environment. Africans have not been trained enough to be able to keep pace with the changes of their own society and with global changes that also affect their world. Poverty may be defined with reference to many and any other parameters. In the African context, it is still rooted in lack of adequate skills of its victims. In effect, as List (1.841) asserts, what counts most is the capacity of individuals, then of the whole society to renew, through production activities, the consumption to a level that equals, at least, the value of consumption.

Father Nzamujo shares this outstanding analysis of List (1885) and advances further. He stresses that the power of producing wealth goes beyond technical competencies. It also includes social, cultural and institutional values such as work ethics, confidence in oneself and in others, courage and perseverance, passion and love for one's world. It is in this mindset that he found out that "a bad development equation" was written for Africa. Passion and love for the continent propelled him to write "an equation" embodied in the Songhail Centre 
he created. The centre specialises in production, research and training in agricultural entrepreneurship. For the founder, Songhai is an open dynamic institute that combines indigenous and modern knowledge based on social and cultural, economic and natural environmental realities.

The Songhai Centre initially seems to be a modest farm built around three components to the development: crop production, animal husbandry and fish farming where everything is organically grown and in a simple way. The integrated production system is based on minimal inputs and use of local resources. It is also based on no soil degradation, no pesticides, no pollution and no waste. Wastes from one production unit become inputs for other components. Hence, production activities become more profitable because they belong to the system, in which the different components strengthen each other by means of what they provide to the others or receive from them. However, the main goal of Songhaii was not production per se. It lies in the conviction of the founder that the only way to fight poverty in Africa is to transform the poor person into an active producer using local resources. The social process through which this happens is central to Songhaï undertakings. 


\section{The Songhai Entrepreneurial Training Process}

\subsection{Introduction}

The Songhaï Centre is a development actor specialised in training for agricultural entrepreneurship. According to the founding director, it is training to acquire values of leadership in African society and not only training for agricultural technical knowledge. The intention is to produce graduates who reject weakness, powerlessness and hopelessness. After graduation, the Songhai trainees are expected to be capable of creating and managing agricultural enterprises in a highlly professional and efficient manner, and in the spirit of an integrated development. These leaders are those committing themselves of becoming agents of change and the pioneers of the development of their regions. Songhaĩ expects them to become the drivers of youth. Finally, the educational project of Songhai can be summarised as follows: to help each individual to become a driver responding to the development dynamics of his region through his own entrepreneurial activities.

For Songhai, entrepreneurs are not born; they are made. Entrepreneurial capacities can be nurtured hopefully through education and they are amenable to personal choice and decision. Entrepreneurs seek opportunities, and innovations often provide the instrument for them to succeed. The function of these 
entrepreneurs is to innovate or to carry out new symergic combinations of all forms of capital needed to drive a dynamic development. Training generalpurpose farmers capable of carrying out multiple production activities would allow them to become entrepreneurs, as they will be able to select among activities and invest in those promising higher profitability. When the farmers acquire knowledge, not only in carrying out pure production activities but also in marketing, they can become entrepreneurs in the sense of Say (1971). Entrepreneurs discover, often in an existing knowledge pool, ideas untried in commercial reality and introduce them into economic life. They overcome barriers in place from existing customs and institutions. In addition, Songhail believes that entrepreneurship requires entrepreneurial skills that are not yet present in SSA. The founding director of Songhai stresses that Africa has to develop such innovative capacities from the local realities analysed and thought by skilled people burning for economic and social dynamics of the continent.

Songhaii has created a framework for proactive training and learning aiming primarily at promoting agricultural entrepreneurship. The training/learning process prepares young people for diverse activities in agriculture. It breaks down gender stereotypes and develops their capacity to improvise and be creative. The training Songhaï provides aims to equip students to deal with the complexities of agricultural production and marketing. By providing general core entrepreneurship skills, the training also helps to develop further competencies and the underpinning professional knowledge. With the training focus specified, Songhaï needed to chose among several possibilities of training forms. Thus, by choosing to integrate school-based education with apprenticeship training and learning in agricultural entrepreneurship, Songhai has to become an entrepreneur. The main objective, according to Songhaï, is to be able to form entrepreneur farmers whose function is to reform or revolutionise the patterns of production by exploiting untried technological possibilities for producing new goods or services while relying on their own social and economic environments.

\section{The sub-case case study}

This subrase stady takes its roots in entrepreneurship theory. It describes the illustration of how social and economic development objectives centred on agriculture are ranslated into actions. Entrepreneurial training/learving is seen as a key factor for building agriculturat entreprenewhal skills and enterprise culture, as much as within an uppropriate pedagogical framework adequate tools are used. More specifically, it is assumed that entrepreneurial behawowrs are innovative, by definition, and the primary objectioe is to develop the trainee's capacities to innowate. This subcase study concentrates on the Songhai entrepreneurial training/leaming model as a whit of 
andysis and exposes its attributes. It is admitted that to properly grasp the essential is wes, one requtres an understanding of the underlying philosophy. Thus emerge the questions:

a) Why has Songhai comnntted to training in agriculture?

b) What are the attributes of this training and how are they different from the existing models of extevision or farmer training?

c) How does the training frametwork conslitute a promise for agricultural innowation capacities?

This chapter traces the training model from the creation of the institute to the present state. It emphasises the changes that have been occurring. It contends that farming is a professional commitment, agricultural development is a longer and complex process and that, an effective development of agriculture is a system work. The second section introduces the main objectives the training is to achieve while the third describes the content of the training process. Initially based on only three poles (crop production, animal husbandry and fish framing). the training curriculum has evolved together with the production system. It also includes processing activities, agricultural machinery mechanics and elements of accounting and management. The fourth section discusses issues regarding prospective regular students. These include the admission conditions, admission tests, and the training process.

In the fifth section, the focus rests on the process of evaluation of the students as potential farmers. The specificity of the training programme defines the uniqueness of the teachers, whose explicit profile is the focus of the sixth section. Section seven presents and explains the evolution of relationship between the students and their educators while in the following, the study briefs the analysis of relative importance of factors such as level of education, age, sex and initial occupation on the performance of the students. Section nine informs about the existence of other specific (shorter) training curricula. Songhai training and learning do not end with the graduation of the students. Successful agricultural entrepreneurs need regular follow-up or continuous leaming; there is a permanent need for upgrading and updating the stock of knowledge. The tenth section conveys this important message. Then follow two sections focusing respectively on technical partnership and the new prospects for the training process since January 2004. An integral part of the training is the financial assistance that Songhai provides; this section closes the chapter before the conclusion. 


\subsection{Rationale for the training}

For Songhai, the development of African agriculture requires a broader view, a system approach that makes it possible to touch all parameters likely to affect productivity. Father Nzamujo argues that the way a society thinks, the social organisation it has set up, the technologies it uses and the agro-ecological environment it has inherited are all elements to be interwoven. There is a need to find the right means, which will make it possible to create and motivate new mentalities willing to move and remove the constraints (Nzamujo, 2002). Training young people in farming techniques with emphasis on entrepreneurship may be a motivating and a vital starting point. It is the spirtt and culture of entrepreneurship that will make it possible to feel the needs of the populations, to take assessed risks, and render agriculture a profitable production activity. Since its existence, Songhai has been trying to develop this fibre of entrepreneurship throughout the process of its multidisciplinary training programme, which includes theoretical and practical farming techniques, processing, marketing and management. The backdrop of these settings consists of three main arguments.

\subsubsection{Farming is a professional commitment}

Becoming an agricultural entrepreneur means making farming one's profession. Songhai believes that a professional is one who is committed, has a conviction and passion to transform the environmental capital for greater economic and social well-being. A professional requires a broad range of technical information and appropriate technologies in a creative manner to ensure an efficient exploitation of available resources. Developing agriculture requires professionalisation, which is the creation of a real class of farmers as it is with other professional bodies. Farming is a complete economic activity, which is, like other sectors, subjected to the dynamics of environmental (local, national, regional and international) factors. Farmers must thus demonstrate capacities in reading the enwironment in which they operate. They also need to demonstrate skills in production planning, production organisation and in marketing. However, such competences are not necessarily instinctive; people acquire them through training and learning processes.

Various organisations in the field have tackled the issue from diverse angles. They are all running towards the objective of helping rural populations reach a balanced self-determination. For Songhaii, what counts is the development of appropriate values leading to self-promotion, work ethics and rational use of available resources. Training to form professionals in agriculture should be general-purpose. It should allow skills in general organisation of production at all levels. Songhaii argues that only through approaches such as an integrated 
production system and training on agricultural production techniques based on agricultural entrepreneurship that farmers can become real professionals. For Songhaï agricultural: development is a process, which also implies the direct or indirect involvement of many other socio-economic agents and organisations.

\subsubsection{Agricultural development is a complex process}

For farmers, having just technical knowledge is not sufficient to ensure successful agricultural entrepreneurship. For Songhaï as well, few and isolated individual farmers are not likely to drive the process of agricultural development. Songhai believes that trained farmers can easily involve the surrounding communities through their performances and their openness. It appears vital to help the farmers forming real and broad socio-economic dynamics and who are the driving force in rural development. It is a motivating process because onlly a strong interest and concrete solutions to their problems would propel them into knowledge sharing. The recognition that farmers are the primary actors of their own development implies for supporting organisations to provide them with opportunities enabling the acquisition of necessary competences. The farmers must gain communication and knowledge-sharing capacities. Yet, whatever the skills and the organisation of farmers, agriculture alone cannot ensure its own development.

\subsubsection{An effective development of agriculture is a system work}

For Songhaï, making agriculture the driving force of development also assumes its relation to the other sectors of the economy: industry (processing; appropriate technology) and trade (input and output markets). This requires some preconditions like professionalism of actors and the removal of other major constraints (soil management, water control, financing, technical. knowledge, etc.). Interactions between agriculture, food processing industry and commercialisation reduce the losses and advance the devellopment of the primary sector. The diagram 6.1 below explains the appropriate linkages and fully describes the Songhail approach to the agricultural development process. It pictures the complete integrated production system. A vertical production system where losses are recorded throughout the chain is over. In this integrated system of production, sectors provide to and exploit inputs from each other. The porcine production case is an illustration. 
In effect, Songhaï argues that the enormous losses and the non-organisation of commercialisation channels do not encourage the farmers to produce in larger quantity, as the question of conservation and marketing arises. Developing agriculture does not simply mean the modernisation or the mechanisation of the production operations. It rather means the upstream and downstream sector strengthening of production activities for a much better exploitation of the potentialities and their greater value added. To this end, the strategy to adopt concerns the real integrated management of input markets, production, processing and output markets. This needs setting up a pedagogy, which implies multidimensional integration of production to training. This constitutes the paradigm Songhai is trying to put forth.

\subsection{The objective of the training}

The Songhai training aims at human and economic development. Human development includes mental attitudes such as self-confidence, sense of accountability, creativity and openness to others. It also comprises technical and managerial capabilities. Human development is a process that does not evolve alone and separate from the production environment. Economic and human developments will affect each other within the framework of an integrated production system. At the heart of this production system lies a vision for an Africa that moves, creates and exploits its potentials. For Songhaï, there is also a strong willingness to succeed in fighting fate and help African youth to take off. Four points summarise the objectives of training (Nzamujo, 2002):

a) Being an alternative to the numerous educational centres that provide training just on project management skills: Songhaï wants to be a place where a culture of entrepreneurship can emerge. It wants to become a place of inspiration where each individual can find confidence in oneself and in others and realise that something is possible.

b) Fight a poor work ethic: This is one of the major constraints harming development of Africa. The principles, values and behaviours at work constitute the basis for an economically and socially viable society. These values do not fall under the governance of laws. They must progressively from an integral part of the conscience of the citizens; they never develop spontaneously. Only by means of a deliberate social process (training and 
follow-up) can communities integrate them into their socio-economic behaviours.

c) Creating real agricultural technicians and professionals: Those are farmers who master the techniques of agricultural production and related activities by the means of tangible technologies (machines and tools) and intangible technologies (knowledge and know-how).

d) Producing capable women and men: Educating people to create and manage enterprises in a very professional and effective way and in the spirit of integrated development and of economic and social profitability.

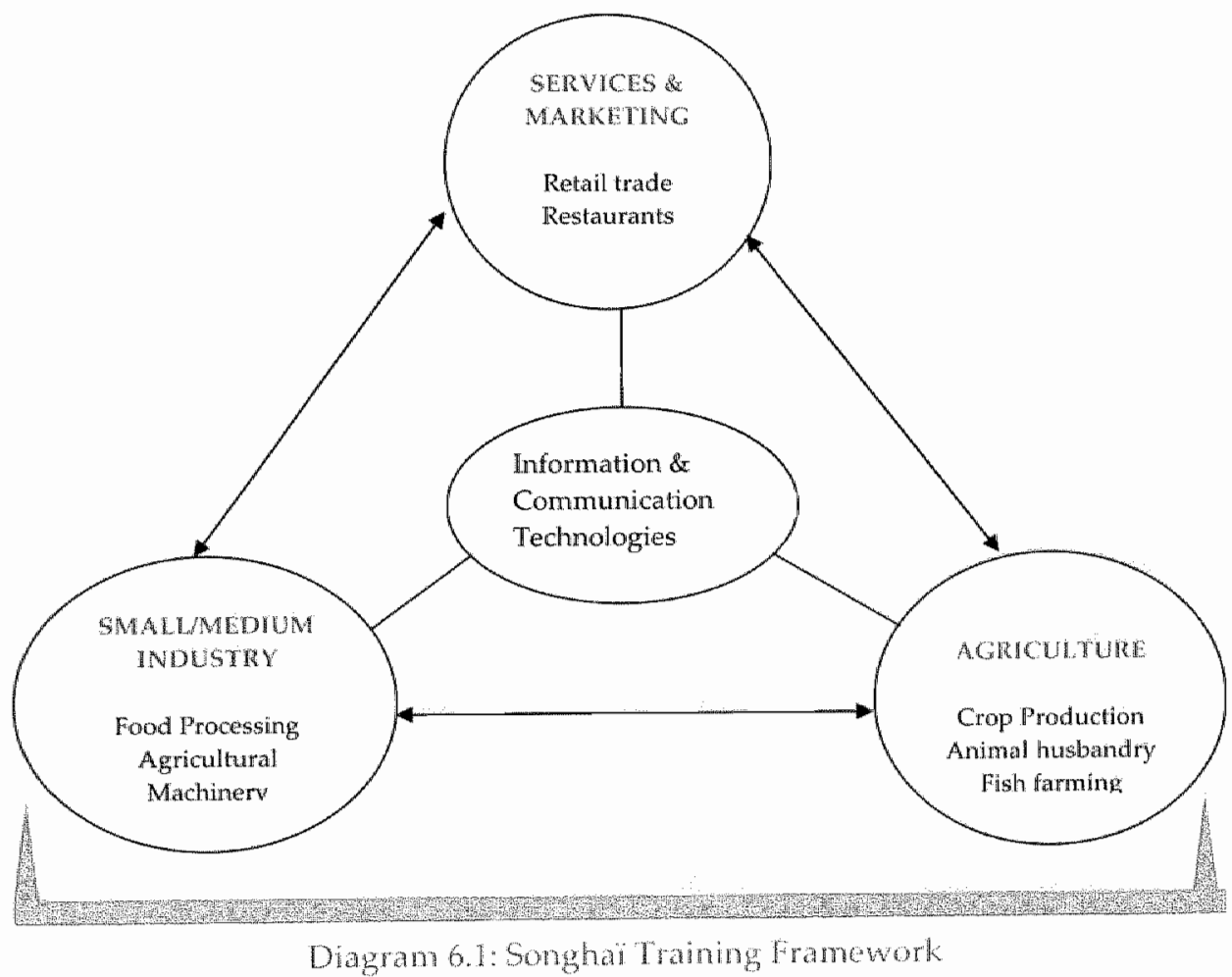

Source: Songhai

" http://www.songhai.org 


\subsection{The contents of the training/learning programme}

Af the beginning, the training at Songhaï can be perceived as a sort of apprenticeship where the students ${ }^{2}$ learned quite simply and primarily by practising. There was no formal course. However, practical exercise did not stand for the whole. The educators were to explain the "why" of the new knowledge being taught and that the students have to acquire. The conditions and circumstances that warranted the use of one or other technology needed clear explanation so that the learners could understand them. Indeed, after graduation, the prospective farmers were to work in various natural environments and face different constraints. Songhaii aimed at training general-purpose farmers to be able to answer questions such as:

a) Which technology is the most appropriate in meeting given recuirements or reaching prospective defined results?

b) How does the technology apply?

c) Why is the aforementioned technology the most appropriate for the current case?

d) When or in which other circumstances is the same technology applicable?

e) How can one modify this technology and adapt it to other circumstances?

For Songhaï, this versatility embraces knowledge and know-how related to the integrated production system. The concepts of socio-economic and ecological factors regarding specific environments are included. One also seeks, for example, to know the crops, trees and the animals that are more advantageous to produce in the various agro-ecological localities of the country or a particular region. At the beginning, the tendency was to train general-purpose farmers in the above-mentioned fields of production; but these fields developed only very recently, from 2001. With the expansion of Songhaii activities, other fields such as processing, mechanics, project design and management were open to students. More specifically, a prospective Songhaï farmer can master diverse new or improved techniques and methods of production in the following fields:

2 The terms student, trainee, and learners are alternatively used and means the same. They designate the young admitted to the Songhai training programme. 
a) Vegetal production: Includes market gardening, perennial crops, fruit trees and other staple crops. In this broad field, the trainees are taught on agrobiological growing techniques (for market gardening) and management (regarding major tropical plants, staple crops and fruit trees farming). They learn the effective order of operations for each plant and the different techniques of ploughing and planting (making beds and nurseries, applying manure, sub-culturing or direct planting, upkeep after planting, and subculturing). Soil fertility management is also taught and it concerns the different forms of organic fertilisation (composting, organic fertilisers, green manure, etc.), techniques of mulching, rotation, plant mixing and grafting. Upon a manifest interest, a student can also learn cow-driven ploughing techniques and farm mechanisation. Under vegetal production fields, the different methods of integrated protection of tropical plants against pests and parasites are not the least.

b) Animal husbandry: Comprises swine (pigs), grass-cutters, rabbits, cattle, sheep, layer hens, boiler hens, local hens, pigeons, quails, ducks, turkeys, others fowls, snails and earthworms. In this field, the training focuses on production and reproduction cycles and the management (feed requirement, diseases control and other cares and vaccinations) of each type of various animals and their associated species. Animal farming management begins with the definition of the production objectives. Students learn how to determine the investments, record and analyse the results, and make the appropriate decisions. The training includes techniques related to the choice of different breeds, shelter building and animal feeds production.

c) Fish farming: The main species are tilapias and catfish. Training in fish farming involves a chain of activities related to technical and business management of fish production units. They pertain to pre-production, production and post-production issues. Upon the completion of this field, students have a good command of how to define production objectives and activities; design, build or acquire the appropriate infrastructures and estimate production results. They master the basic principles of nutrition including the nutritive values of raw materials and their transformation into feeds for the fish. Finally, they learn raw material, feed and fish stock management and marketing techniques.

d) Renewable energy production: Consists of the mechanism by which animal and human manures are transformed into biological gas to produce energy needs. 
e) Processing: The trainees learn to identify and handle various equipments. They, also learn small-scale and semi-industrial processing techniques and methods related to the production of yoghurt, ice cream, juice, jant, syrup, oil, soymilk, drying and smoking of meats, soap dyeing and weaving bags. Further, they learn how to manage raw materials and supply the products in proper packaging. To recall, one of the basic goals of this training is to build awareness of the students about the new fields of opportunities and innovations. Thus, a sort of symbiosis between traditional and semi-industrial methods of production develops, showing students the various possibilities they could exploit, given their financial means and the specific advantages of the environment in which they will set up their business. The importance of training on processing techniques is better understood when the advantages it gives are well grasped (Nzamujo, 2002).

$\Rightarrow$ Reduction of losses - In Benin as in other tropical countries, excessive heat and/or humidity accelerates the rot of many products. Thousands tons of agricultural products are lost each year because processing techniquies, either traditional or semi-industrial, are not adequately mastered. For the producers, this fact results directly in enormous losses in earnings. Solving this problem implies training and informing people to recognise and seize economic opportunities in order to conquer new markets. Moreover, processing makes available many agricultural products throughout the year, and even longer.

$\Rightarrow$ Increase of benefit - according to Songhaï, an agricultural entrepreneur would gain more if he could process his products and commercialise them in various forms. Processing is then viewed as a normal continuation of the production and, may be the best way for a farmer of making more profits from his activities.

$\Rightarrow$ Creation of new markets - Implementation and the existence of processing units, either small-scale or large scale, create market opportunities for other producers, which could increase their production to respond to the new demands.

f) Mechanics: agricultural machinery: The use of physical human force alone limits cultivated surfaces with a very low level of arable land exploitation. In addition, the labour force becomes increasingly rare and expensive with respect to the painfulness of the agricultural tasks. Yoking systems and 
agricultural machines associated with other tools can replace part of human physical force. Agricultural mechanisation can then allow output improvement through better tillage, rationalisation of sowing times, facilitation of harvest and even an improvement in the processing of agricultural produces.

There are, however, multiple levels of mechanisation beginning from the use of simple machines to the most powerful through the intermediate. Machines can be used at any stage of agricultural production and in the tasks like the preparation of soils, ploughing, maintenance, sowing, and harvests. The most important is to know the types of machines fitting specific production needs and environment. For Songhaï, adaptation, conception, design, manufacture and effective diffusion of such machines that are market and environment friendly are preferred to exclusively imported ones. Farmers need to be associated with this process. Thus the training curricula incorporate not only how to use the machinery but also how to maintain and diffuse it in one's locality.

g) Initiation to design and the formulation of agricultural business plans: This is obligatory for all students. It begins with mini-projects on which the learners work once per month. Entrepreneurship requires decisions and initiatives, which are, by definition, risky. Becoming an entrepreneur is also a question of accountability. The training scheme puts a particular emphasis on scrutinizing the potentialities. The business plan is indeed a document prepared by the entrepreneur, which describes the purposes and the pathway necessary to achieve the goals. It is a referential document serving not only to inform about the entrepreneurial activities, but also to establish the estimated bases of feasibility and viability of the activities (Berry, 2004). This exercise leads the students to think strategically about the resources available (in their localities), the existing opportunities, those they can create and how they can exploit them.

The mini-project remains a practical exercise of design, planning, programming and impact analysis of the technical choices to carry out. For example, the choice of a student (a prospective farmer) to involve in the production of crop, poultry or processing can depend on factors such as quality and quantity of available land and the consumption behaviours of the targeted populations. Layer hen production, for example, can constitute a subject for an agricultural business plan, which must provide the full details of its feasibility and the economic consequences of the choices. In these 
respects, a farmer launching the project should count where and how to get the chicks, how to feed them and where to sell the eggs (outputs). Apart from that, the promoter must define his technical choices in terms of livestock production:

$\Rightarrow$ The type of the shelter (building), its dimensions and when to build it.

$\Rightarrow$ Which plan of disease prevention and food rationing to use with respect to the selected species in order to control the death rate and harmonious growth?

From these technical objectives, a cost-benefit analysis can be made. The exercise thus makes it possible to know what to expect if one wishes to be involved in this business.

h) Accounting and Management: Commonly called "Compta-Gestion ", the training essentially consists of basic elements of investment conception, planning and costing. Indeed, this exploratory study allows students to connect the technical data of their activities to the economic and management requirements. Here, the concept of management implies the ability to:

$\Rightarrow$ exploit quantified data

$\Rightarrow$ deal with various factors of production

$\Rightarrow$ set a production organisation necessary to maximise outputs

$\Rightarrow$ to mobilise and use means necessary to carry out, control and analyse activities

$\Rightarrow$ proceed to corrective actions

The "Comta-Gestion"' is carried out everyday in the various units of production where the students take part in the forecasts and book-keeping such as: stock sheets, delivery books, cash and bank vouchers and the ledger. The training emphasises cost management with basic elements of the follow-up techniques of completed activities and their appraisal with respect to the forecasts. 


\subsection{The students - trainees - apprentices - learners}

\subsubsection{Evolution of admission conditions and rationale for the changes}

At the beginning, the prospective candidates were young school dropouts. They constituted a somewhat marginalised group of the social system, as their majority originate from rural areas or from parents having very few resources and information to direct them towards other activities. Songhaï believes that anyone has the capacity to overcome constraints. However, there is a need to commit oneself, together with others, to a movement, which would enable the development of intern forces in all cultural, social, technical, organisational and economic dimensions. The candidates needed to have absolute and strong motivation for farming. For Songhaï, personal motivation was a decisive factor. It means a very deep aspiration to the practise and life of agriculture. It is also the personally expressed determination to commit oneself to play a social role in a rural community. These initial criteria will evolve following the flexibility and the willingness of the institute to satisfy the needs of populations toward development.

Songhaï argues that development is the concern of the whole society and denies exclusion. It endeavours to give each an individual opportunity for participation. To respond to the need of the populations, the institute revised and modified admission criteria. Songhaï welcomes everyone who believes in the value of work, individual and collective work, and work based on knowledge not necessarily instinctive to human beings (Nzamujo, 2002). It enlarged the base of prospective candidates in order to give the opportunity to anyone who was motivated to learn.

Initially, the training was open only to school dropouts from rural areas. However, other categories of young manifested their interest and Songhai has to adjust its initial criteria. From 1998/1999 onward, urban dwellers, illiterates, socio-economic or development actors involved in continuous learning processes can upgrade their capacities and knowledge stock at Songhaï. They can either opt for the regular 18-month training or define their duration aim. Further, students and researchers from other institutes based either in Benin or in other countries, can conduct studies of diverse purposes using Songhaï as reference. 


\subsubsection{Evolution of the tests and methods of selection of the candidates}

Because of limited training capacities, Songhai has introduced some criteria of selection. Selection tests have evolved together with admission criteria. Though recruited based on their rural background, it was important to measure the endurance at work, which is only the direct and convincing consequence of the passion students may have. The candidates have to demonstrate a particular endeavour and ambition for agriculture. In practice, specific tasks were assigned to the candidates divided in small groups under the inspection of a jury of three members. The practical test consisted in working in the field using a hoe and machete. The objective was also to show the young candidates the real aspects and likely dimensions of what training at Songhaï will look like. Personal interviews relating to the past or current occupation of the candidates followed. The interview results shed light on what the candidates knew about Songhai and what their expectations from the training institute were.

With the removal of rural background from admission criteria, written tests were introduced in order to determine the real educational level of the candidates. This test encompasses logical thinking, and calculus. Though the candidates take the same test, they have equitable chance despite their different levels of education. The test had two main goals. First, it intended to show the prospective students that mastering practical tasks is not enough; an entrepreneur needs also to think. In addition, it makes it possible to divide the students in different groups for theoretical courses.

As from December 2003, the candidates have been selected on files according to a rigorous sorting. This file must comprise an official certificate of attendance that shows the educational level of the candidate. Songhaï must be able to make an adequate distribution of the students into groups according to their educational level and, mainly for a better follow-up during the training process. To allow a better pedagogical follow-up the candidates are required to provide the certificate of criminal record, which would make it possible to establish a relation of cause and effect between the past and the current moral behaviours of the students. Songhaï appeals parents for collaboration to support their children, and makes clear to them that they are trainees and not employees. Since January 2004, there has no longer been a written test examination. A six months trial period replaces the practical tests, which lasted few hours. The objective is to remedy the many cases of those giving up for lack of effective will to become agricultural entrepreneurs. 
The most important is what the students are willing to do. The wisdom of the innovating pedagogue will evaluate the evidence of the will and passion of the prospect agricultural entrepreneurs by means of two analytical instruments. The first and most important method of evaluation rests on the system of mentorship. Any staff member of Songhai becomes a mentor of at most four trainees. The eligible students can turn to their mentor at any time and in any situation. The mentor frequently dialogues with the educators and with the trainee about the technical capabilities and morals of the latter. In the various training and production units, the eligible students are evaluated on a weekly basis. A special notebook, in which grades and remarks are reported, is assigned to each single individual student. The strengths and the weaknesses of the students are frequently discussed between the educators, the mentor and the students in an atmosphere of reciprocal confidence: a notion very precious to Songhaii. The second method of evaluation consists of daily observation of the behaviours of the eligible students. It puts emphasis on how the students have embedded themselves in the community at the training centre while obedience is highly valued.

\subsubsection{Evolution of the number of admitted candidates and factors determining the changes ${ }^{3}$}

Factors such as reorganisation of the training framework, the capacities of Songhaï (in terms of infrastructures, number of educators, and finances) and other changes desired by Songhaï have been affecting the evolution of the number of students admitted to the training programme. From October 1985 to July 1991 (from the first to the fifth batch), the average number of those recruited was 11 students per batch excluding those who gave up. During that period, Songhaï registered 24 cases of abandons including the disqualified ones leading to an average of five abandons per batch. It may be useful to specify that the fifth batch alone registered 15 abandons.

From August 1991 (sixth batch), the year of the first reorganisation of the training, the number of admissions progressively increased to reach a peak of 66 students in January 2003. Indeed, this number has evolved together with the diversification and the expansion of Songhai activities since 1996 thanks to the financial support of USAID. These two phenomena, in their turn, induced the birth of more research and training fields. The USAID support was enough to build two new sites (Savalou and Parakou) and expand the capacities of the existing site of Porto-Novo. Here, new production and training units, especially

3 This analysis takes account only of the site of Porto-Novo. For the data see section 7.26 
small-scale processing, other mammal (grass-cutter, sheep) and the break of poultry units into five different units with various birds appeared. Evolution in number of admitted students also affected the training process.

\subsection{The training process: How one teaches and how one learns at Songhai"}

The Songhaï method of training is simply "I do it with them and I let them do it". Training at Songhai is a form of apprenticeship where the trainee learns by observing the master in action. The master controls how to do things and knows why s/he does things in certain ways. Through vigilant observation, the learner tries to understand the actions of his master. The educator always gives the student many opportunities but under various conditions and cases to repeat the activities, s/he has previously observed. At the end of the day, the master asks the apprentices to describe in their own way the activities they have observed, how they understood them and what impressed them. Later, research topics replaced these syntheses. Both the synthesis and research topics represented the theoretical part of the training programme. The teacher used to propose a number of research topics with respect to the ongoing activities. Students chose, conducted research and prepared presentations. These constituted the first experiences of Songhail at a time when there were no formal training curricula.

Gradually, Songhaï transformed the aforementioned research topic framework into theoretical modules based on existing knowledge and not necessarily on the activities carried out in practice. This set the background for theoretical training with the introduction of course modules taught in a participatory way. Knowledge sharing between the teachers and the students led to the formalisation of the training subjects. Students were not passive observers but actors of research and production and therefore, actors of their own training. The teachers set the objectives and formulated the methods and pathway to reach them. The students knew in advance the share of the tasks that would fall to them and what would be the role of the teacher. Within this new framework, the teachers divided the students into small groups according to their levels of education. Indeed, such separation was necessary to avoid the superiority and inferiority complexes and to allow each student to acquire the knowledge in a more suitable way and in a manner most convenient to each. 


\subsubsection{The training process: Initial settings}

At the beginning, two levels composed the training process. The basic training, which allowed the students to acquire production techniques, master them and integrate them into their agricultural activities, pertained to level one. At this level, they learn vegetal production techniques, livestock production techniques, processing techniques, mechanics of agricultural machinery and marketing techniques (commercialisation) of agricultural products. The training also included human values such as decision-making and related accountability, fervour at work, courage, and family values in different socio-economic contexts. Successful students moved to the higher level.

At level two, the training related primarily to the creation and the management of agricultural enterprise. The students were not necessarily at Songhaii. In any case, educators visited them every month and provided them with technical, organisational, planning, management / accounting or moral support. Until 1993 , Songhaï used to grant a diploma to the successful students at the end of each level. As from 1994, the confusion and inadequate understanding of these diplomas pushed Songhaii to grant only one diploma at the end of level two.

The notion of specialisation came together with the reform of the training process in 2001. Within the new framework, each learner spends a total of nine months at the level of core courses; that is one month in each of the nine fields of specialisation. After this first period, the students choose sequentially three different fields for specialisation. The duration in each field is three months. When one considers that at the core course level, a student has already spent one month in each field, then in fact the duration of training in each of their specialised fields is four months. Indeed, this period was very transitory. The notion of phases came to improve it.

\subsubsection{The training process: Current settings}

\subsubsection{The phase of core training}

Core training evolved to last only six months instead of nine. During this period, the students start learning for a relatively short time and sequentially, in the various production units, the new production techniques. The production units include vegetal (crop) and animal production, fish farming, processing and mechanics. Each of these production units is subdivided into several sub-units or training fields of specialisation. Animal production includes, for example, 
mammals and poultry. Mammal production comprises pigs, grass-cutters, rabbit, sheet and bovine sub-units. Poultry comprises layer hens, broiler hens, quails, ducks, turkey and other fowls. Whereas this period does not allow the students to experience all activities available through the different production units, the field of the vegetal production is obligatory. After this period, the students continue their training within the phase of specialisation.

\subsubsection{The phase of specialisation}

Each student chooses to specialise in three different fields of production in sequences. There must be such a connection between the fields to allow an integrated production. The choice may also be subjected to natural or environmental criteria (the region of settlement) or economic and market opportunities the student intends to exploit after graduation. Training in each field of specialisation lasts three months. The students that successfully end the phase of specialisation get three months to prepare a mini-project or business plan to carry out during the phase of application. The three months are those cut off from the phase of core training. The students must however, successfully defend their proposals.

\subsubsection{The phase of application}

The phase of application constitutes the last stage of the training process and lasts 12 months. In groups of two, three or four, the students have to demonstrate some entrepreneurial behaviour and innovative abilities. Indeed, the farmers must be able to combine the new knowledge with indigenous knowledge, the whole subjected to local socio-economic and envirommental constraints. Through their activities, the prospective entrepreneur farmers seek to achieve the goals (not necessarily simultaneously) of better outputs, cost effective production and a better adaptation to rural environments. According to certain students, the phase of application constitutes the most important period of the training process. The application phase is, to some extent, an individual leaning level where entrepreneurship demand the exercise of a range of personal capacities or qualities as mentioned earlier. The following issues govern the phase.

a) Group formation and choice of sites for application: The students form groups from those within their batch. Songhaï has imposed the size of two to four students for each group. Concerning the choice of the sites for application, the students go preferably to the areas that present similar agro-ecological characteristics with their training centres (sites). Students 
trained in Porto-Novo carry out their activities on the site of Kinwédji situated in a southern part of the country.

b) Access to investment capital (land, production infrastructures and credits): The first condition for admission to the phase of application is to pass the final examinations of the phase of specialisation. Then, the students present business projects to carry out within 12 months using the available infrastructures. Such projects exclude, for example, layer hen production because it lasts, at least, 1.8 months. Songhai always grants refundable credits to the students to finance their activities. The amounts vary with the projects and are free of charge; the students repay the capital without any additional interest.

c) Follow-up (forms, means and agents): There are three mechanisms of follow-up during the application phase:

$\Rightarrow$ The internal follow-up: Relates to the organisation within the students themselves. A first committee is in charge of activity programming within the group. Every other week it meets to assess the group's activities. A second committee is responsible for inputs and output markets. The financial manager of the group takes care of the budget, centralises the receipts and carries out periodic refunding to Songhai.

$\Rightarrow$ The open/exchange follow-up with a reference group: This role pertains to certain educators (at Songhai) who examine the activities of the prospective farmers and take care of an adequate application of production techniques. They are to draw inspirations from the potential innovations the students may introduce. They do not exert any power over them because master-learner relationships have ended. It is just a "farmer to farmer visits" relationship.

$\Rightarrow$ Organisational and logistic assistance: Through this form of follow-up, Songhai seeks to ensure that the students have appropriately organised, planned and undertaken the completion of their projects. It serves as an intermediary between Songhail and the students. It determines and updates the needs of the students and achieves periodic evaluations.

d) Innovation results and their diffusion: The application phase is the first time for students to question the practices of Songhaii. It is the time of 
decision-making and management autonomy. The need to purchase certain inputs, for example, leads the students to raise the question about the existence of alternatives or substitutes to those Songhair recommends. Further, the necessity to repay the credits forces them to seek new methods, which would reduce the production costs. It was in the attempt to reduce the costs related to pig production that some students tested and walidated the use of a given papaw variety in the feed of these animals. Indeed, these prospective farmers hold weekly meetings during which they share information, experiences, and seek solutions to emerging problems.

e) Ending the application phase: Evaluation, refunding of the credits, handing-over the diploma: The organisational and logistic group of Songhail evaluates, once within four months, the farmers" activities with respect to their abilities to apply required production techniques while taking account of the socio-economic environment and innovations. The students have to demonstrate outstanding competitive skills by means of good results, which make possible credit refunding. They have to repay entirely the credit amount before they get their diploma. In case of deficit leading to non-repayment, an analysis is made to determine the causes and to locate the responsibilities because Songhaï itself can constitute the cause of some bad results. At the end of the application, members of the same group are granted a common grade. Those who succeed in the application phase obtain their diplomas and are directly eligible for Songhai credit. In case of failure at this phase, the completion of the project can be extended for six more months, depending on the report of the evaluation group. However, students who failed can go directly to set their farms if, they can prove that the failure does not relate to their abilities to carry out the project. Floods, droughts, swine diseases and lack of adequate infrastructure on the site, can each constitute a factor of failure. Irregardless, a student gets his diploma only if he repays the total amount of the credit. Nevertheless, the diploma is not what makes him an agricultural entrepreneur.

f) Since the introduction of the application phase, 17 students have been successful in the experience. In May 2004, there were respectively 12, six and nine students on the application sites of Kinwédji, Savalou and Parakou. 


\subsubsection{The application sites}

The primary assignment of the application phase is to ensure a transition between the end of the phase of specialisation and the settlement of the farmers. Experiences thave shown that many graduates failed in the first year of their farming activities just because of the lack of some types of experience. Songhai wants to reduce this risk of failure. The objective is to increase the economic leadership competences of the students through their capacities to plan, make decisions, and exploit commercial market opportunities. After graduation, the students must be able to set their own agricultural enterprises. A site for application is a geographically autonomous centre connected to a specific training centre. An application site offers the basic infrastructures such as dormitory, animal shelters, store, equipments and many other tools required in farming.

\subsection{Evolution of methods of assessment during the training process}

The exams and evaluation methods constitute an integral part of the training process. As such, they have also been subjected to the dynamics of the complete training framework. The exams have evolved from practical and theoretical forms to include discipline. At the same time, the methods have evolved form the evaluation by type of activities to phase evaluation. From there they have evolved from evaluation by section, sequence and module to evaluation by follow-up book.

a) Evaluation by type of activities combines practical and theoretical tests held at the end of the training period. At the practical examination, a given task is assigned to the student under the inspection of the examiner who observes and grades him/her according to the way the task is being completed, the duration and the quality of the result. In theory, the questions relate to the practical task the candidate has achieved. Indeed, if the candidate can, for example, vaccinate animals; it is not obvious that he knows the timing and frequency of the vaccinations. The examiner asks him to explain the "how" and the "why" of the job. The examiner also seeks to assess adaptability capacities of the student. In an environment more hostile or less favourable than the one of Songhaï, how shall the student manage to get better or similar results? Because the students are supposed to become general-purpose farmers, the evaluation subjects include all fields of production at Songhaï (animal production, vegetal production and fish farming). The examiner is a jury made up of two training specialists and one management staff. 
b) Phase evaluation does not exclude the theoretical and practical subject examinations. What changed is the period of examinations. It was not necessary to wait until the end of the training process to start the exams. There is a written exam at the end of each theoretical module. A module is a digest of theories relating to a given activity, for example, animal vaccination, conservation of market-gardening products, provender, etc. From 1999. sequential evaluation or evaluation by section was introduced. A section is defined as the set of activities related to a production unit. Pigs, layer hen, broiler hen or quail rearing, are examples of different sections. The examination consists of determining the capacities of the student to conduct alone all the activities related to a section. Discipline or behavioural attitude of the students at the production units, play an important role in setting the final grade. Here, the examiner is just the head of the section.

c) Evaluation by follow-up book has replaced sequential or evaluation by section from 2001 onward. With the preceding methods of evaluation, some students used to contest their grades arguing that they resulted from the subjective appreciation of the master. Others claimed that their grades were punitive and reflected moral attitudes more than technical skills. To avoid such disputes, Songhai introduced a system of a follow-up book. It allows more frequent assessments (often by fortnight) and in a more detailed way, the morals attitudes (behaviours) and technical capacities of the students. By the means of this book, the mentor also follows the student, maintains regular dialogues with him/her, and encourages him/her to continue thus and more. When weaknesses appear, the mentor seeks to elucidate the causes and decides together with the student how to go about his/her improvement. The philosophy is to lead students to believe in their own capacities to perform better if they show more motivation, will or conscience. Relatives of the students can upon a request, consult the follow-up book. To this end, Songhail organises periodic meetings with the parents to make them aware of the performances their children have accumulated.

d) Theoretical ewaluntion - A theoretical examination (written test), in all subjects of the specialisation fields, is required. This examination method makes it possible to know the extent to which the students understood the practical issues. The students get to defend the project to carry out during the application phase only after they have passed the written examinations. The student who fails can be constrained, or not, to repeat entirely certain specialisations, depending on his grade. 


\subsection{The educators - trainers - teachers - masters}

\subsubsection{The profile}

Apprenticeship, the traditional training system widespread in Africa, starts from production in workshops. Songhaï training framework seems to be an improvement of this system. Songhaï set up an apprenticeship system, which lies at the intersection of three actors: producer, trainer (teacher, educator or master) and learner (trainee or student). This new space is a training and pedagogical framework whose management shows that the profile of a Songhai educator is neither that of a mere producer, nor that of a mere master but of both; and this is not all. If the producer is entitled a right of result and error, he is also in the skin of a learner. He is a person in perpetual search for better performance. As such, the expectation is that he behaves in a way that allows him to give the trainees adequate knowledge while learning from them. In short, he must be open for continual valuable knowledge-sharing with all.

Songhai pedagogy is thus concretised in the concept of trainer/producer, who is far from being a dichotomy. The profile of the trainer sought here is a fusion of the trainer and the producer. In a processing unit where yoghourt is produced, for example ${ }_{r}$ a student also belongs to the production process. It is necessary to develop a practical frame, which integrates the student in the scheme. Thus, yoghourt and the trainee are treated like "two products" resulting from the same production process. It is a symbiosis of the two characteristics. However, the concern does not actually relate to training- production per se. The arising problem is how to bring the "trainer-producer" at the required level so that he can provide these "two simultaneous products". This general-purpose "master" does not confine himself just in showing. Instead, he also explains to the learners the "why" of the things he is doing. What is required is the ability of the mastert to transmit the knowledge and know-how to his trainees while trying to meet production requirements.

\subsubsection{Evolution of Procedures and Recruitment conditions}

At the beginning, only the top management staffs were qualified to be educators. They were indeed the executives of Songhai and were at the same time at the head of central production departments (crop production, mammal rearing, poultry and fish farming). The attached producers were their assistants in training. Before the reform of the training process, it was not possible to talk about a training department. With time, the administrative activities were more 
increasingly absorbing the educators who did not have enough time to meet the requirements of the training programme. Songhail then reinforced the technical skills of the assistants and qualified them as trainers. These new educators initially dealt with technical (more practical) aspects of the training. The former educators became responsible for training management while continuing to head the production departments. This new perspective did not grant senior trainers the right to loose contact with the students. In addition to the few hours they devoted to them, the senior trainers assisted the director in his weekly meetings with the students.

When new prospective people are recruited, they are taught about Songhail teaching issues during the first three months. This is called the period of insertion. They are then attached to the existing trainers, which allow them to participate in the training activities for six months duration. After the six months, pedagogical days (at least one week) are organised to initiate them on evaluation methods and on the various practical concerns that may occur during the training process. These prospective educators are always recruited based on technical need of Songhai. They must have the profiles of technicians and basic knowledge in a specific field. Moral values and the sense for communitarian life also have great importance in the process of qualification for trainer position. As well, any trainer must understand the history of Songhai. He/she must be able to tell and explain to students the "how" and the "whry" of the successes, difficulties and failures of Songhaï. A trainer must be able to lay down what a student can expect from the training. With these dynamics, the senior educators remain always central. They became the teachers of the trainers; they continue to play their role of training orientation, and guard the principles and the philosophical values of Songhaï.

\subsection{Evolution of the relations between trainers and trainees}

At the creation of Songhaii, the students were also considered as entire members of the Songhaï community. For this reason they had to participate in the construction and development of Songhaï. The relations between trainers and learners were those of fellow members and members of the same team of builders of Songhaï. Trainers and learners, worked hand in hand to create the sense of leadership, initiative taking and accountability. The feeling of being a member of the Songhaï community and the concept of knowledge sharing were very strong. With the structuring of the training, these initial relationships became more restricted. Songhaï is already built and the framework of 
construction does no more shape the new relationships. The new relations pertain to the spirit of participating in the production and training operations.

Today, it seems that there is a sort of division of functions or tasks between trainers and the learners while relations become more professional. To fill up this kind of vacuum created by evolution, Songhaï has introduced a mentorship system, which allows mentors to have close relationships with a number of students. Songhaï seeks to break the barrier, which make a learner "Learner"; someone inferior to the master. By so doing one aims to give the student confidence in him/herself and the trainer. In addition, Songhaii seeks to reassure the students that Songhai will always be recourse for them. Graduating does not imply the end of the relationship with the training institute. Today it is clear that it is no longer possible to reconsider old practices because of new and different realities. Songhaï thus continues to maintain the culture of mutual confidence through the follow-up system.

\subsection{Some performance assessment during the training process}

According to Songhaï, girls (whatever their age), older males and all those whose previous occupation and life did not relate to agriculture often perform better than the others do during the training period. They seem more accountable, conscious, and assiduous at work. They appear more devoted, curious and often even much more respectful. Indeed, it has been their personal choice to enter the training programme. They actually know what they miss, what they need and for which ends. On the other, hand, argues Songhaï, parents and other relatives influence the younger males to enter Songhai. The lack of personal goal makes them less conscious at work. Students with no background in agriculture perform better than those from rural areas. They find the work very difficult at the beginning and, especially, in the practical cases. Conscious of their weaknesses compared to their colleagues, they gradually try to adapt to fill up the gap. Hence, they manage to catch up and beat those who had had experience in the field and, who were ahead at the beginning of training process.

\subsection{Short term training programmes}

The objectives of Songhaï go beyond the long duration (18 months) training. Songhai also aims to empower people to become entrepreneurs in development besides their personal businesses. The challenge is to render them capable of 
encouraging and training their communities to develop creativity and innovative abilities. This training is open to the executive officers of Songhaï, other young farmers with experience, executives of NGOs, public sector officials, project managers, and private entrepreneurs. The setting distinguishes three domains of study.

a) Development entrepreneurship: This training programme is organised around three different sessions; each session lasts 15 days. Depending on his own ambitions and goals, a participant can choose more than one session. Prospective candidates may be those heading or managing projects, research bodies, cooperatives, associations, or training centres; and who seek to participate in development projects and initiatives at the grassroots. This training programme allows the participants to acquire, knowledge, devellop skills, and learn about appropriate behaviour in entrepreneurship to contribute in the development of rural communities. The thematic sessions include:

$\Rightarrow$ Becoming an entrepreneur - Upon the completion of this session, the participants know how to start a business, and have mastered the techniques of agricultural production and the marketing of agricultural products. They are also acquainted with how to run economic operations, organise, and execute various activities including the recruitment and management of human resources.

$\Rightarrow$ Becoming a programme manager - This session aims to build the participant skills in developing training programmes, evaluating and executing training activities and stimulating group activities.

$\Rightarrow$ Beconing an agent of development - After 15 days of enrolment in this thematic session, the prospective agents of development will be capable of thinking clearly about development and creating strategies for development. They will also be able to act as team leaders and developing their creativity.

b) Execution of agricultural and agricultural related activities: This programme is open to anyone who has achieved at least primary level of education (successful six years). There is no other requirement. The training programme covers six sequences, each lasting three months. Upon the completion of any sequence, the prospective farmer masters the mechanism of execution and management of agricultural and agricultural related activities with the ability 
of adapting them to diverse and specific environments. The training issues relate to crop production, animal husbandry, fish farming and processing activities.

c) Research and application: It is designed for students at all levels and other specialists seeking to do research work leading to write theses or essays and to test their theoretical knowledge against practical field activities. The duration ranges from a minimum of two weeks to three months maximum. Songhai supports students in developing their abilities to analyse the dynamics of an activity, theme, or operation within the agricultural sector.

\subsection{The follow-up or continuous training}

\subsubsection{Rationale ${ }^{4}$}

According to Songhaï, approximately $95 \%$ of the female graduates try to set up business. They do fail as massively as they undertook the activities. During this phase, they succeed less than men do. Two essential factors may explain their failures. In society, girls do not inherit arable lands from their parents. Thus, when they try to carry out a long-term project on the land the parents granted them, later on, the same parents remind them that the land does not belong to them. It belongs to the males (their brothers). The second fact, which negatively affects the development of the women enterprises, is marriage. After graduation, the girls evaluate themselves higher than they were before training. They find themselves superior to those young and illiterate peasants and artisans of their villages. The tendency becomes having a husband of higher or, at least, of the same social strata. Such men are, mostly, civil servants working in urban areas. The girls therefore stop their farming activities when the time comes for marriage. To remedy these alarming cases, Songhai encourages women to specialise in processing activities, which they can carry out anywhere. Moreover, processing activities are even much more suitable for urban dwellers. However, female students who married their Songhai male fellows became the type of female farmer Songhail always wishes; together with their husbands, they develop.

After the girls, the oldest with agricultural background are more successful as regards to successful farm setting. Very often, the younger return under the

* Songhail has provided no quantitative data that support the assessments in this subsection. 
authority of the parents and are usually less preoccupied with setting their own business. Those who come from rural areas develop much faster in their farming enterprises than the others. They were familiar to the environment and can readiapt very easily to it. On the other hand, farmers without previous experience in agriculture, count on only the knowledge they have acquired at Songhail. They scom peasants and their knowledge while ignoring the realities of the environment. Indeed, certain realities of rural areas frighten the uninitiated.

\subsubsection{The practical issues}

The objectives of Songhai exceed the only technical installation of the young farmers. Songhaï aims, as well, at a genuine society project touching all components, which may be social, political, economical and cultural. Indeed, the settlement of a farmer is expected to bring benefits beyond his personal autonomy. It allows wealth creation that benefits his neighbourhoods and motivates and increases production dynamics, especially, in rural areas. From these points of view, it is important for Songhai to create a favourable entrepreneurial environment, which covers a multitude factors that the new gracluates do not necessary control at the early stage of their activities. Thus, for the young agricultural entrepreneurs, the follow-up accounts for an essential success factor. Monthly or quarterly visits, depending on the cases, bring technical, managerial, organisational and financial support to the farmers. Other forms of assistance include distribution of technical publications, seeds and other inputs. Many other opportunities such as recycling stays on Songhaï farms, decentralised training at local level and diverse new courses are available to the farmers. The cases often vary and require that the follow-up agents adapt their visits to the individual needs of the different farmers.

Usually, an exploratory visit begins the process and allows the follow-up officer to assess the type and the importance of the assistance a farmer needs. During this visit, s/he discusses with the farmer the solutions that may fall under the control of each. S/he provides appropriate advice to the farmer and returns back to Songhai where s/he prepares for, following strategic steps, the next visit. Before leaving, the follow-up agent together with the farmer defines the date for the following visit. Upon his arrival at Songhai and before embarking to assist the farmer ${ }_{x}$ s/he arranges the different documents and tools needed for the visit and checks carefully to see that the farmer's orders are complete (seeds, other raw materials, veterinary products, photocopies). The documents usually allow the young farmers to have information on development issues in agriculture around the world. Back to the farmer with the complete orders, the follow-up officer, 
reviews and analyses the farm's management, and finds out whether or not the farmer has implemented the advice from the previous visit. S/he also ensures that the files and management tools (cashbook, daybook, stock file, etc) have been properly kept since his last visit. Finally, regarding ongoing situation, the officer provides new advice and makes suggestions that can help the farmer overcome the challenges.

Finally, for Songhai, the follow-up is an integral part of the training process. To be sustained and effective, agricultural promotion/advisory service must be conceived as a service that the recipient demands. In this connection, the followup also aims to allow the farmers to make a better reading of the various agricultural production opportunities in the country. Thus, the promotion of different production fields (various crops, trees, and livestock), the improvement of credit accessibility, the creation and management of an agricultural stock market and the practice of irrigation constitute the challenges and the current focus of the follow-up group.

\subsubsection{The Songhaï farmers' network}

Songhai graduates initiated in 1995, the National Network of Songhaï Farmers (RENAFERS- in French), because they were increasing in number and communication and interactions beyond their annual meetings at Songhaï became a challenge. The network is composed of individual Songhai graduates who have established their own farming business. Located all over the country, they are grouped into local co-ordination units based on geographical proximity. This network setting has a double purpose. The primarily objective is to create a framework for knowledge and information sharing among the members. Secondly, it constitutes the means by which Songhai follow-up mechanism works. There are eight regional co-ordination units within the network. Each coordination has its own management committee. At national level a committee has been set up to co-ordinate and harmonise the activities of the different regional co-ordinations. The committee is composed of seven members elected for a period of three years. Membership of the network is not obligatory for the farmers. A newsletter known as the "Fermes Actualites" is produced, and the farmers participate by sharing with their peers their expertise in various domains.

The network offers its members many advantages. Decentralised training allows them to take full advantage of any emerging innovation. It is a framework for mutual assistance with localised technical and agro- climatic problems. Members 
of the same regional co-ordination unit, for example, share experiences and information related to patterns or specific issues of climatic hazards. During the field research, it was amazing to acknowledge how the farmers tried to develop a local market system within the regional co-ordination units.

\subsection{Technical partnership in training}

Inside Songhai, there is a special institute in charge of continuing education of trainers and responsible for partnership with other institutes. It is denoted as the Training Institute of Development Entrepreneurs (TIDE or IFED - Institut de Formation des Entrepreneurs de Développement). It has built important relationships with many educational institutions in Benin, Cameroon, France, Nigeria and Togo. Within the framework of this partnership, the University of Abomey Calavi (the former National University of Benin) has provided important technical assistance in strengthening training capacities of Songhai educators. Indeed, any new staff willing to engage in training activities at Songhail was called to present a capacity strengthening plan for no more than three years. In case the TIDE does not have internal competence in the required field, it requests support from other educational institutes. In all cases, the TIDE funds the training project. Because of lack of adequate funds, the activities of the institute are currently reduced. It cannot sponsor the so many interested people. However, it continues to arrange training opportunities for the staff according to the expressed needs of Songhaii.

\subsection{New prospects for the training process since January 2004}

The prospective changes aim at cleansing much more the framework of the training process. They intend to affect Songhai itself and the training framework, which includes both trainers and learners.

a) Songhail has to become a genuine enterprise and, consequently, has to behave like a business corporation. It must struggle for self-sufficiency, economic profitability and large-scale production. With this intention, it must create more motivations among the educators and make them much more responsible. Songhai must avoid transforming the learners into human resources in the production units. A workshop master remains a trainer and must ensure that students learn effectively. The principle of "doing with them and allow them to learm while asking questions" remains fundamental. The phases of observations when the apprentice watches the master before undertaking 
any action are stressed. Songhai must continue to create in the mind of the youth the conviction that they are capable to produce expected results. In overall, Songhaï must hold on its motto: "commitment to excellence".

b) Concerning the educators, the technical framework would require:

i. More dialogues between the coordination of the production and the coordination of the training. This requires much more information exchanges in order to make of the training, an assessable activity.

ii. That equal weight for the quality of the training and the quality of production determine the performance of the educator. Currently, Songhail is in the phase of negotiations to determine new rules for such evaluation based on three quantifiable parameters not yet set.

iii. Selection of teachers through more rigorous criteria. It should be recalled that Songhaï is a training centre not only for students but, also for the executives of Songhaii. Then the concern is to improve the recruitment process. Songhai should anticipate its needs and should not leave room for randomness. To this end, the trainer must have adequate competences, passion to share knowledge with the others and passion to see others growing.

iv. More self-evaluation, self-questioning, searching for advancement and new solutions.

c) Managing students will require:

i. That the student knows in advance the various tasks to perform following, of course, a well-defined progressive teaching order.

ii. A well defined rate in the accomplishment of the different tasks so that the student may have an idea about the results.

iii. To consider the student as an interlocutor who has not come just to copy Songhaï, but who is able to understand and analyse factors that affect the failures and the successes of Songhaï. Student must share their useful experiences and propose solutions to the problems which can emerge.

iv. More regular evaluations in order to help the weaker become strong and to encourage the strong. 


\subsection{History and evolution of the subsidies and credits}

According to Songhai, to benefit from financial assistance, actors of the rural world must have ideas, realistic projects with rather modest objectives. They must be creative entrepreneurs capable of daring propositions. Credit is useful, when the borrower can demonstrate outstanding skills and competences enabling him/her to capitalise on it. It also implies that the donor has assurance of the entrepreneurial capacities of the beneficiaries. At this point, two major concerns lend themselves for critical thought: the borrowers' skills and the availability of the credit.

\subsubsection{Rationale of the subsidies and credits of Songhaï}

For Songhaï, financial assistance will contribute to socio-economic development only under a system approach that incorporates at its core training/learning processes supporting and encouraging innovation and entrepreneurship (Nzamujo, 1999). These processes are vital in the sense that they bring to the entrepreneurs the technical, organisational and managerial capacities they need for the conduct of their economic activities. Entrepreneurship is a reflex to acquire, and a capacity to develop continuously through innovation processes. Farmers must also acquire bargaining. Organisations should provide financial assistance based on innovative capacities and entrepreneurial skills of the farmers. However, many initiatives do not always return the expected echo.

In Benin, the traditional system of credits to agriculture does not offer favourable conditions that encourage agricultural entrepreneurship. When a young farmer gets loans to build the basic infrastructures (such animal shelters, and land), to acquire equipment (machines/tools), other inputs (seeds, veterinary products, provender) and to noturish himself while waiting for the first outputs, it not certain that he refunds integrally the money he borrowed (Nzamujo, 2002). Shortterm credits, high interest rates, loan conditionality very heavy to bear, all these make the access even more difficult for farmers. Against this situation, Songhai has been trying since its creation, to help the trainees after graduation, to have access to financial assistance. Songhaï grants them subsidies and credits at reasonable conditions for the development of their activities. Several forms of financial assistance have been experienced and have evolved following the training concerns, the needs for viable enterprise creation and the socio-economic context of Benin. 


\subsubsection{Objectives of the subsidies and credits}

The framework of subsidies has evolved over time. Subsidies were to serve the purpose of creating new chances for success and make farms, belonging to the Songhai farmers, model enterprises: the farmers must be able to demonstrate their entrepreneurial skills. It was a form of financial assistance intended to support the Songhai farmers in their efforts to become real innovators. Songhai expected its graduate farmers to play the role of diffusion agents of the knowledge and expertise they have acquired. Songhaï wants to encourage the farmers to share, by any means, their experiences with those who, despite the importance of their indigenous knowledge, continue to have mediocre results.

In its philosophy, Songhai wants to become not a model, but an alternative to the various development approaches. Financial assistance in the form of subsidies could indirectly allow Songhai to increase its training capacities through the alumni. Indeed, beside the limited training capacities of the Songhai Centre, the question of information about its existence is always posed. Further, whereas some informed people did not meet some of the admission conditions, circumstances such as family issues systematically excluded others. It is very hard for peasants, parents of at least three children, to leave their families for training of 18 months in duration (period during which they earn no money). Thus, during some dead periods, peasants can turn to their neighbouring Songhai farmers to gain some new agricultural knowledge. It is in this role of "training and diffusion agent of agricultural innovations within his community that the Songhaii farmer compensates the refunding of the subsidy. Songhail calls it social and economic refunding of credit.

\section{Financial assistance and pilot farms}

According to Songhaï, after having sold their production (cotton, maize, groundnuts, pineapple, citrus fruits, and livestock) peasants invest the money they gain in activities completely different from agricultural and related sectors, which do not contribute to the growth of their farming activities. Concretely, this does not ensure the generation of more incomes to improve their well-being. Songhaï affirms to have inculcate another culture, that of saving and investment into the trainees. Thus, instead of refunding the start-up capital immediately, they are encouraged to strengthen their production by reinvesting, continuously, their profits in the agricultural trail. The financial assistance thus aimed to give the young farmers more opportunities for development through the creation of viable agricultural enterprises called pillot farms. 
Outcomes of these pilot farmers attract many peasants who seek to imitate them, to believe in agricultural entrepreneurship for performance and success tor prompt changes. For Songhai it is an effective and persuasive means to touch the constantly increasing number of peasants. In addition, pilot farmers constitute true leaders in animation of the local coordination of the Songhai farmers" network. They use their means, farms and knowledge to accommodate and animate the various meetings of the zones where they share diverse information and knowledge. They nurture new graduate farmers during the process of farm setting.

\section{Types of financiall assistance: the subsidies}

Songhaii had proposed two kinds of non-exclusive subsidies to the farmers: specific support subsidies and integral support subsidies. In one or another case, the subsidies were available only to the graduates, who had created their own farming business or were in the process of setting them up. Subsidy-specific support helped farmers to solve particular problems requiring financial involvement. For example, circumstances can emerge and require urgent construction of infrastructures like animal shelter. In such case, the specific support subsidy applies. The amount of the subsidy was variable but could not exceed one million francs CFA $(1,525 €)$. More formal rules governed integral support subsidies. Songhaï invited each farmer to apply based on a clearly defined business plan applicable within two or three years. Songhai examined and analysed the previously mentioned files, and asked the farmers to defend their projects before a committee, which analysed, appreciated, and identified the likely projects that deserve subsidies. Integral support subsidies did not necessarily constrain Songhaï to finance all $(100 \%)$ submitted projects. The amount of this subsidy was limited and varied from 2,000,000 F CFA to 3,500,000 FCFA $(3,050-5,336 €)$.

\section{Types of financial assistance: the credits}

At the beginning, the credits were to help meet specific needs of the prospective beneficiaries. The credits were free of interest charges but unlike the subsidies, were refundable. No formal guarantee was required from the farmers. The disbursement of the credit was progressive to enable Songhai to get to the field and check the use of the funds. This role fell under the assignments of the followup team. Later, Songhaï combined subsidy and credit in the proportion of 7:3. Finally, with an increased number of graduates and to respond to the need of 
other agricultural production actors, Songhaï created an Agricultural Community Fund for Savings and Credits (ACFSC).

According to Songhaï, apart from PISEA (Programme d'Insertion des Sans Emplois dans l'Agriculture), no other credit setting matches the standards of the agricultural. sector. The lack of technical knowledge and know-how through training and learning processes, adequate technologies and regular follow-up may be part of the major obstacles preventing this sector to benefit from the existing credit setting. For Songhaï, only with farmers as innovators and entrepreneurs can institutional settings break this status quo. Songhai is thus setting up the present credit fund to provide funding to the rural world and impel the development of agriculture. The fund should also enable the existence of organisations of the type CUMA (Co-operative d' Utilisation de Materiels Agricoles - Cooperative for the Exploitation of Farm Equipments).

\subsubsection{First sources of financing}

It is not enough to recognise opportunities if nothing is done to exploit them (Nzamujo, 2002). From the knowledge acquisition to the exploitation of competences and opportunities, Songhaï has found, in its philosophy of development, the means of connecting and reinforcing all the chain links. This is an integrated or systemic approach to training. The culture of saving that Songhail has initiated supported this vision. It has been applicable to all farmers since the beginning of the training process. Songhai argues that the saving reflex is a state of mind, an action to acquire that belongs to entrepreneurial behaviour. The logic is saving-credit, credit-savings. The trainees are encouraged to save in a special fund at Songhai part of the monthly allocations they receive from their parents. Better still, they acquire savings behaviour, not from the point of view of a loan only, but also for the difficult times nobody can predict. These savings, though symbolic $(16,000 \mathrm{~F}$ CFA - 50,000 FCFA: $25.40 €-76.23 €$, within 18 months), play a fundamental role in the behaviour of the farmers toward credit capital, Songhaï asserts.

This vision of training aims allured and interested many partners. In 1989, the African Development Foundation (ADF), an American NGO, agreed to contribute to the process of building up a financing mechanism in favour of the graduate farmers. Called Revolving Fund (RF), it was refundable at annual interest rate of $4 \%$. From 1992, other partners/donors entered the game and brought their support to the financing system. These include DANIDA of 
Denmark, the CCFD (Catholic Committee against Hunger and for the Development) of France, and the RABOBANK of the Netherlands. Since 1997 , French partners (Christiane and Alain de Chalendar) have initiated an operation called "Collecting Funds for Young Established Farmers", always with the intention to support the system financially.

\subsection{The training results}

\subsubsection{Applicants}

This subsection brings to light the evolution of the number of people applying for admission to the Songhail training programme. It shows the trend of their interest for the training. Only the sites of Porto-Novo, Savalou and Parakou provide training. In Porto-Novo, the available data is restricted to 16 semesters out of 31 . However, only 12 recruitment semesters show the complete required data.

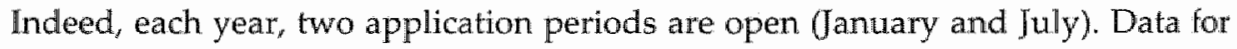
consecutive semesters distinguishing male and female applicants covers the period from January 1998 to July 2003. From January 2004, the admission settings were changed. The recruitment for the first semester of 2004 continued over the six months and the number of applicants was not known during the field research period. Savalou and Parakou display, respectively, complete required data covering the whole period beginning from their creation in January 1999 and August 1999 to July 2003. The analysis merges the numbers of applicants to all three sites. To have meaning, it considers only applicants from the same years and the same semesters: from July/August 1999 to July 2003.

Figure 6.1 below illustrates total application and male applicant trends only. The share of female applicants has been very low over time, ranging from a minimum of $8 \%$ to a maximum $15 \%$ of the total applications. Plotting it together with the total and male applicants, it appears very flat and its trend hardly visible. During the given period of nine semesters, the total application has evolved in waves with more of an inclination to decrease. It grew from July 1999 to July 2000 when it reached a peak with 212 applicants. The following semester, the number of applications fell to 187 and continually diminished to reach its lowest level with 130 applicants in July 2003. However, there was a break in January 2003 with 182 applicants before falling again, even under the levels of 2002 semesters. Actually, the numbers of applicants in each semester appears random. 


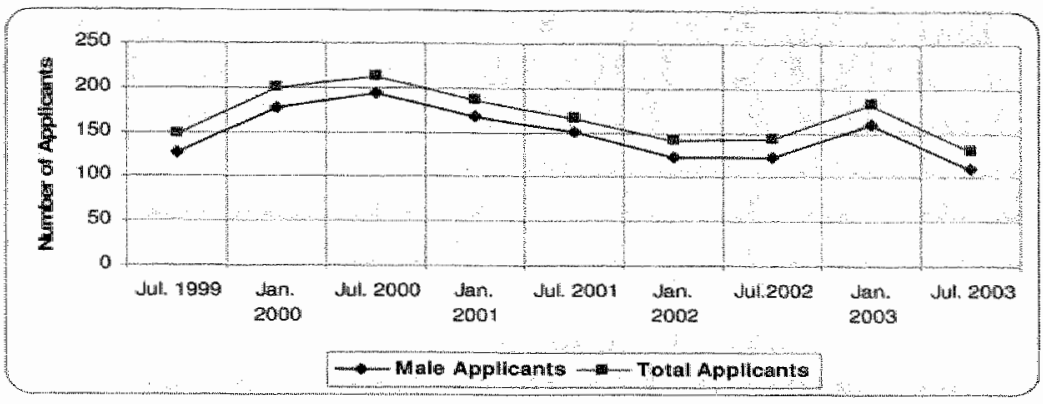

Figure 6.1: Exolution of Applications to the Songhä training programme Source: Based on Songhaî data, the training department

For the whole period under consideration, the average number of applicants per semester is roughly 167 with a standard deviation of 28.7 . These numbers may lead to ask what happened in July 2000 and three years later, in July 2003 with respectively 212 and 130 applications. Indeed, the number 212 is just slightly lower than the average plus the double of the standard deviation $(167+2 * 28.7=$ 224). At the same time, the lowest number of applications was 130 , which is 1.3 times standard deviation under the average. While the new sites of Savalou and Parakou opened their door for training in 1999, the site of Porto-Novo strengthened its training capacities. This might be an attracting event, which sparked the interest. Thus, to some extent, it may explain, the increases in number of applications from July 1999 to July 2000. Why is there less interest in the Songhaï training programme since January 2001? Does this relate to internal factors of Songhaï itself? Does it relate to external factors such as the opening up of similar training centres? Answering these questions may require a specific study aiming at assessing the Songhai centre.

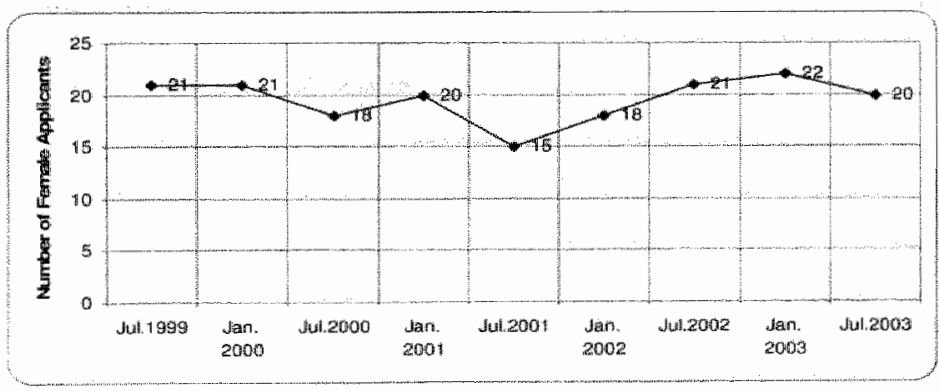

Figure 6.2: Evolution of the number of female Applicants

Source: Based on Songhaï data, the training department: 
This overall trend is due to the importance of male applicants. Relatively, they average approximately $88 \%$ against $12 \%$ for female applicants. The trend of female applicants is more noticeable when charted separately as shows Figure 6.2. A close observation of this chart shows that the women interested in the Songhai training follows another trend. With a steady state the first two semesters, it slightly declined in July 2000 and January 2001 before reaching its lowest level in July 2001. It grew the following three semesters to reach a peak in January 2003 with 22 applicants. Like the male applicants, the interest of the female rose in January 2003, but fell in the following semester even under the level of July 1999. The average number of female applications was approximately 20 with a 2.18 standard deviation value. One may think that something happened that shifted the interest of women from agricultural training. Indeed, the lowest level of the number of women applicants was 15 and is lower than the average minus the double of standard deviation $\left(19.55-2.18^{*} 2=15.64\right)$. In statistical analysis, we think of this as purely random numbers or issues which are affected by special events (these exceed the scope of this study). In sum, the youth interest in Songhai training has not had an overall growing trend as one would expect.

\subsubsection{Admission}

This subsection examines admission patterns. It mainlly compares the trends of total admission with application and presents some basic statistics contrasting male and female admissions. Table 6.1 presents the total numbers of accepted applicants to enter the training programme across the semesters while making a distinction between male and female successful applicants. It also provides a clear overview of the rates of admission. The rate of female admission, in a given semester is: the number of female applicants admitted to enter the training programme (NFA) divided by the number of female applicants (NFC) and the whole multiplied by 100: [NFA / NFC] * 100 .

Table 6.1: Admission patterns of all three sites together - period of July/August 1999 to July 2003

Jul199 Jano0 Jul00 Jano1 Jul01 Jano2 Jul02 Jano3 Jullos

\begin{tabular}{|c|c|c|c|c|c|c|c|c|c|}
\hline \multicolumn{10}{|l|}{ Admission } \\
\hline Total & 72 & 82 & 84 & 111 & 83 & 93 & 94 & 121 & 83 \\
\hline Male $(\%)$ & $62(86.1)$ & $67(81.7)$ & $68(81.0)$ & $96(86.5)$ & $70\{84.3\}$ & $79(84.9)$ & $80(85.1)$ & $101(83.5)$ & 68681.97 \\
\hline Femalue $(\%)$ & $10(13,9)$ & $15(1.8 .3)$ & $16(19.0)$ & $15(13.5)$ & $13(15.7)$ & 14. (15.1) & $14(14.9)$ & $20(16.5)$ & 15 (18.1) \\
\hline \multicolumn{10}{|l|}{ Adm, Rate $\%$} \\
\hline Total & 48.6 & 41.2 & 39.6 & 59.4 & 50.0 & 66.0 & 65.3 & 66.5 & 63.8 \\
\hline Male \% & 48.8 & 37.6 & 35.1 & 57.5 & 46.4 & 64.2 & 65.0 & 63.1 & 61.8 \\
\hline Female $\%$ & 47.6 & 71.4 & 88.9 & 75.0 & 86.7 & 77.8 & 66.7 & 90.9 & 75.0 \\
\hline
\end{tabular}

Sources: Based on Songhai data, the training department 
Since July 1999, Songhaï has recruited, each semester (all sites comprised), an average of 91 students of which 77 are boys and 14 are girls. If during the time of application, girls constituted roughly $12 \%$, with a higher rate of admission approximating $76.0 \%$ against $53.3 \%$ for boys, they form, on average, $\mathbb{1 1 6 \%}$ of the total students. People usually think that agricultural activities are very hard and are more relevant to men than women. Therefore, the girls choosing farming are those who have great motivation, as this constitutes the most important admission criterion. Contrary to many young boys, the girls go to Songhai on their own decision, which some times meet with the opposition of their parents as a woman farmer acknowledged during the field research.

\section{Bor 6. 1. Is farming gender specific?}

When I informed iny parents about ny decision to go for training at songhai. none of them agreed. My tather even put ont of sight the necessary documents needed to make my application file. After few days of searchung I found them stole them and made my application file to songhai, My parents argured that the profession of agicultural entrepreneur is not for women lin effect, when I entered the training programme, I found 1 too tifficult and I was aboult to give up. Bot my hissband, mathematic teacher at secondary schod and who was ny boyfriend at 1 at the, used to encourage me and support me in all respect After gradiation he provided ny initial investment capital $(500,000 \mathrm{FCFA}-76230 \mathrm{f})$ lowe hin wy suecess.

Figure 6.3 examines whether there is any relationship between admission and application. The charts show a common growing trend the first two semesters. In the third semester however, when the number of applications reached their peak, admission did not follow; it slightly decreased. Though evolving in waves with two peaks of 111 and 121 students respectively in January 2001 and January 2003, it shows a general growing trend over the whole period. However, it fell in July 2001 and July 2003 with the decrease in the number of applications. For Songhai the number of admitted students depends on the training capacities of the institute and the motivation of the applicants demonstrate during the admission tests. Indeed, the Songhai sites providing training, offers daily food, accommodation and other services to the regular students. In addition, in Savalou and Parakou, the training staff is also offered living infrastructure on the sites. 


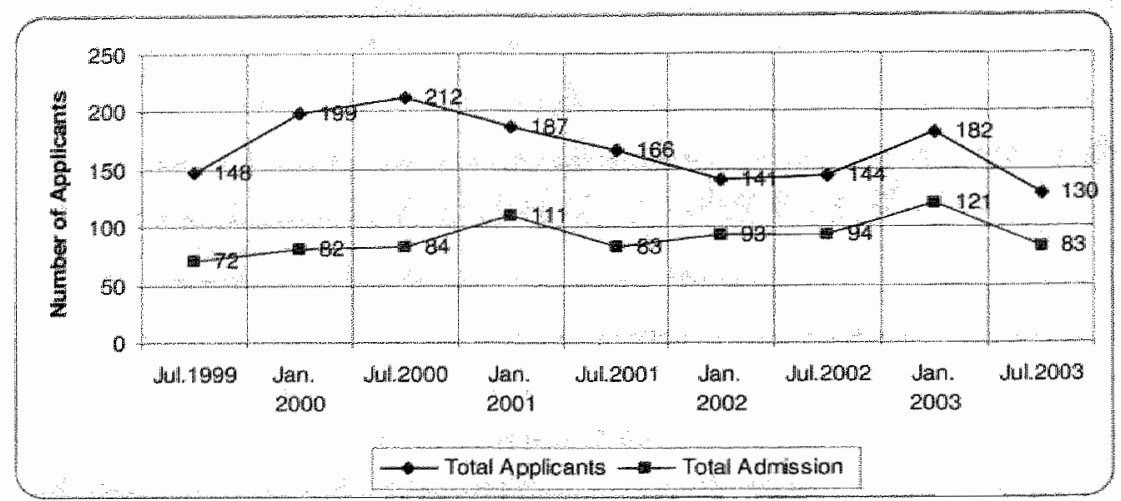

Figure 6.3: Comparison of Application and Admission Patterns

Source: Based on Songhaï data

\subsubsection{Graduation}

Songhai affirms to become an alternative to the current educational system that rejects so many students. During the educational process, many students fail (they do not pass their exams) several times, others are discouraged and for many other reasons they give up or the educational institutions exclude them. If, in the real world, things appear easier said than done, it would be interesting to examine closer how Songhai has been dealing with the admitted applicants. The main questions are how Songhail interacts with the students during the training process and what their performance is like. The major concerns thus relate to graduation of the students. The analysis first compares the evolution of the numbers of graduate students to the numbers of admitted students. Secondly, it contrasts the performance of female students to their male peers at the end of the training process. Third and finally, it examines the overall evolution of the graduation rates.

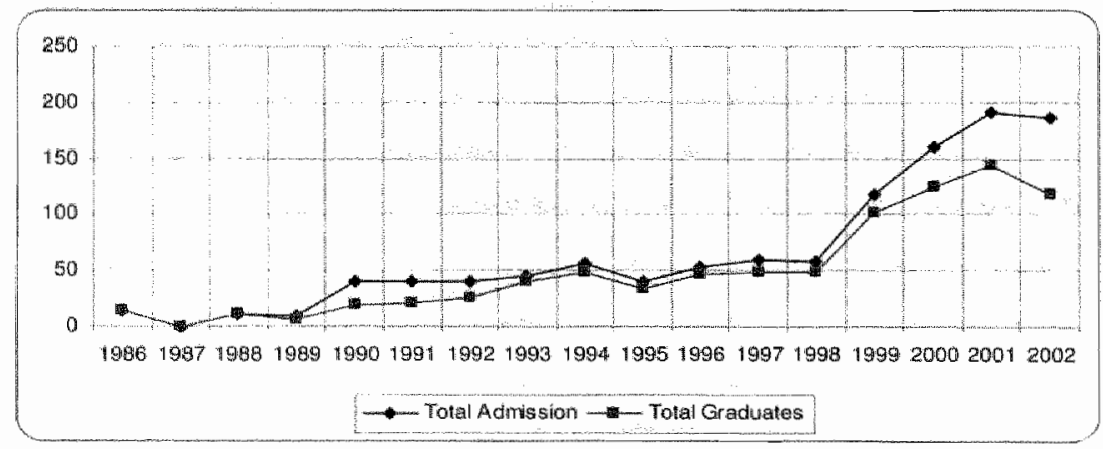

Figure 6.4: Comparison of the Trend of Admission and Graduation

Source: Computed and plotted based on Songhai data, the training department 
Putting everything together, admission and graduation from the three sites cover the period from 1986 to 2002 . It begins with the period when the site of PortoNovo was operating alone. It ends in 2002 because students recruited later (in 2003 and 2004) were still in the training process during the time of the field research; they had not yet finished. The charts of both the admission and graduation show the same development trend. Nevertheless, the gap between them seems big. The graduation rates, which amount to $78 \%$ on average, appear under all expectations. When Songhaï claimed to become a real alternative, it could be thought as an excellent system with almost $100 \%$ of success. Songhai advocates that many boys do present a sort of false motivation during the entry tests. They do so because of the pressure of their parents or relatives. However, by the time they realise that they cannot commit themselves to the profession of agriculture, they then purely abandon their studies and go home or perform some immorality so that the institute excludes them. Further, some students ignore the realities of farming and discover it as more arduous that they can manage; in such cases, they honestly give up. Figure 6.4 above shows that the gap between admitted and graduates students began to widen from 1999 with the enlargement of Songhaï training capacities. What concretely explains the gap? Can contrasting the male and female rates of success shed light on some more evidence?

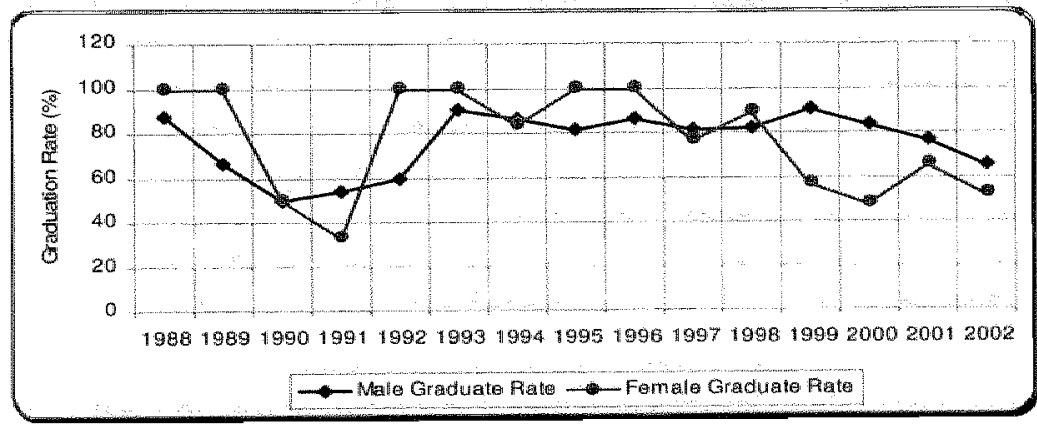

Figure 6.5: Comparison of the Evolution of Male and Female Farmer Graduation Rates Source: Computed and plotted based Songhail data, the training department

The rate of success of the first batch of students (1986) on the site of Porto-Novo was $100 \%$. The following year however, there was no admission. In the absence of admission, there is no way to compute a graduation rate. The analysis then leaves both years (1986 and 1987) and starts from 1988 (Figure 6.5). Except in the case of a few isolated years (1991, 1994 and 1997), the female students generally performed better than the males. Their rate of success exceeded the male rate until 1998. In six different years, it even reached 100\%. From 1999 to 2002, it falls under the level of male graduate rates. This period of poorer performance from. 
the side of women students coincides with the opening up of new sites. Indeed, the observed trends until 1998 relate exclusively to the site of Porto-Novo. Therefore, it impels one to examine separately the evolution of woman success rates on each site. Again, it is necessary to draw a graph (Figure 6.6).

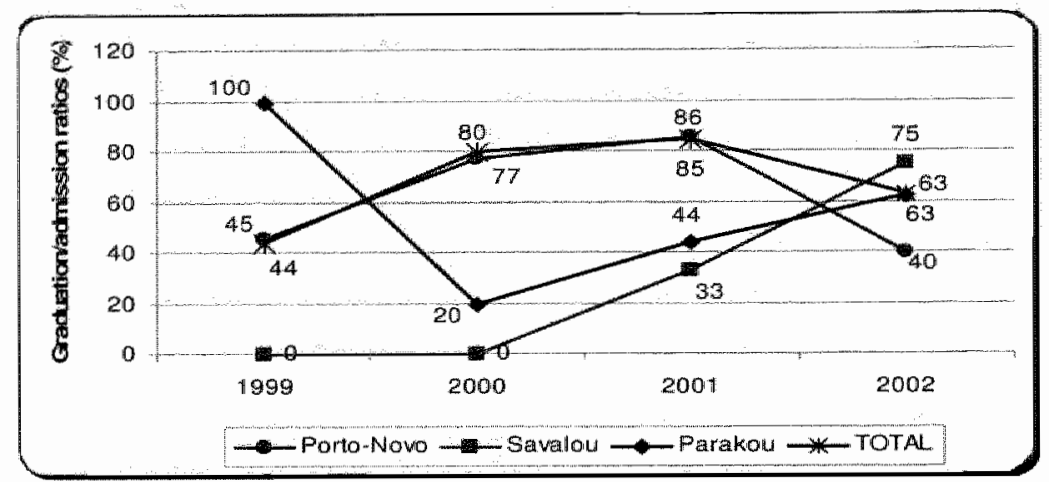

Figure 6.6: Trends of Female Graduation Rate on the Three Sites

Source: Computed and plotted based on Songhai data, the training department

From its creation in January 1999, the site of Savalou admitted six females to the training programme in the first two years. Statistics show that none was able to successfully complete the training in agricultural entrepreneurship. From 2001, the situation began to improve on the site with one out of the three admitted girls graduated. Later, three out of the four (75\%) girls recruited in 2002 graduated. When Savalou was stagnating with nil records, the three girls of the first batch on the site of Parakou demonstrated excellent performance with $100 \%$ rate of success. In 2000 however, none of the six recruited in January persevered to the end. Only two out of the four admitted the following semester were successful. Consequently, the rate of graduation fell from $100 \%$ in 1999 to $20 \%$ in 2000 . Growth in the rate of success of women was again observed from 2001. with four graduates for nine initially admitted students (44\%). The year 2002 also ended with a modest improvement in the rate of success on the site of Parakou. Graduation rate was $63 \%$. The mother site, Porto-Novo showed increases only in years (2000 and 2001) with respectively $77 \%$ and $86 \%$ rate of success. It reproduced, even worse, the observed weakness in 1999 with $45 \%$ rate of success, and recorded only $40 \%$ of success. What began to undermine the girls? Answering these questions may fall under the framework of another study.

Has Songhaï really demonstrated the uniqueness of it capacity to build an alternative training/educational framework? The previous paragraphs compared 
the evolution of admission and graduation in absolute numbers and tried to explain the widening gap through the differences between male and female student performances. It is also important to examine the trend of total graduates in order to be able to draw any acceptable conclusion. To have a real appreciation of the graduation rate trend the analysis skips the first two years and starts from 1988 as shows Figure 6.7.

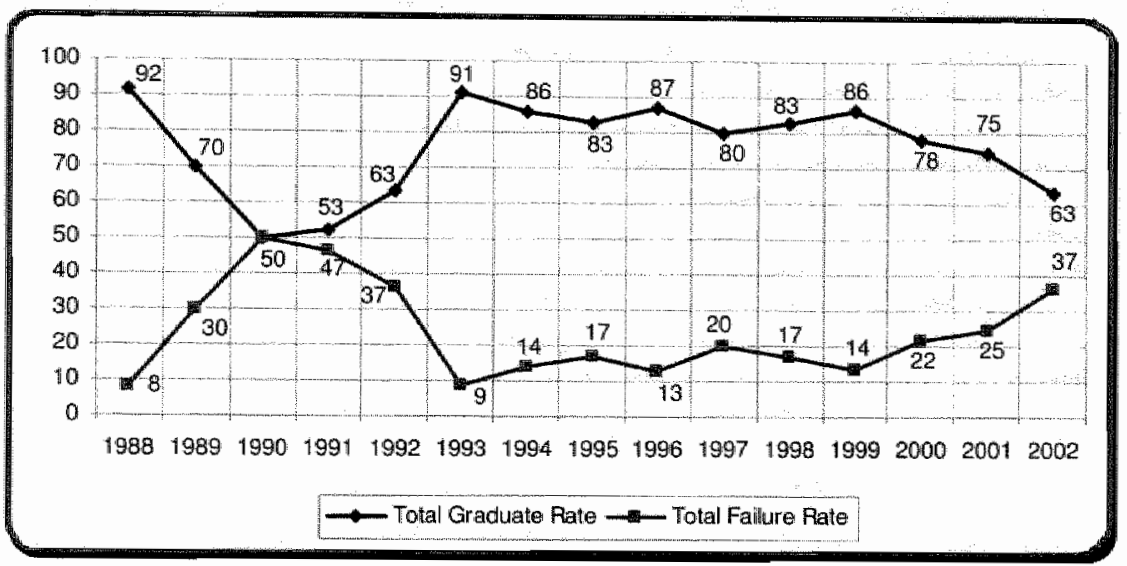

Figure 6.7: Trends of Success and Failure Rates

Source: Computed and plotted based Songhair data ${ }_{r}$ the training department

During the first six years (1988-1993), success rates show a V curve. From a very good performance of $92 \%$ in 1988 , the number of perspective farmers compared to admitted applicants fell rapidly to $70 \%$ and reached its lowest point with $50 \%$ in 1990. From there it slowly increased to $53 \%$ and $63 \%$ respectively in 1991 and 1992 , and reached $91 \%$ in 1993. Songhai explained that students recruited in January 1991 went on strike and only 11 boys out of the 26 students (of which two girls) had successfully finished their training. The study did not try to investigate what happened. However, it noticed that some deeds may have frustrated some students at that time. In fact, there is a special report showing that the 26 students were selected through a very high competitive process from 256 applicants (roughly $10 \%$ rate of admission). Moreover, statistics show that only seven students graduated from the previous batch (July 1990) composed initially of 22 students of which one was female. Including the female student, 15 students $(68 \%)$ did not succeed. Some of them deliberately gave up; others were excluded for some reasons while the cases for simple failure during exams were also acknowledged. 
The following period (of six years: 1993-1999) shows a waving curve. The high three points of $91 \%, 87 \%$ and $86 \%$ were reached respectively in 1993,1996 and 1999. The lows (logically two) appeared in 1995 and in 1997 with $83 \%$ and $80 \%$ rates of success. Since 1999, the total rate of graduate entrepreneur farmers has been decreasing. From $86 \%$ in 1.999 it reached $63 \%$ in 2002 through the records of $78 \%$ and $75 \%$ respectively in 2000 and 2001 . In general, the $100 \%$ of graduation rate as observed in 1986 and the $92 \%$ of 1988 have not since been registered at Songhai. Even, after the depression of the period of 1989 to 1992, the performance recorded in 1993 has not been able to take up the challenge. Neither has any other year demonstrated the level of 1993 from which an overall declining trend is obvious. Logically failure rates follow a contrary trend. They display fluctuations but prove a general rising movement.

\subsubsection{Other trainees}

In addition to regular training (18 months) students, Songhaï also provides shorter trainings for three other categories of people. The first category involves students from other educational and training institutes. In Benin, these include mainly the CETA (Colleges d'Enseignement Technique Agricole), FSA (Faculté des Sciences Agronomiques), and CPU (College Polytechnique Universitaire; all of which are secondary and university public educational institutions. The second category comprises those who come to Songhail for short-term training in specific fields. Moreover, Songhai acknowledged the experience of exchange visitors who fall into the third category of short-term trainees. These latter usually come from other organisations or government bodies in groups of several people. Their stay is very short ranging from one to a few days. The main objective of these visitors is to draws inspiration from the activities of Songhair and the way they are carried out. The statistics of Songhaï are not complete neither in the number of trainees in each category or in their fields of specialisations. Classification according to the duration of their stay at Songhaii does not exist. Statistics at disposal are gross data covering six years (1999-2004) as provides Table 6.2, and country of origins as displays Table 6.3. 
Table 6.2: Short-term trainees

\begin{tabular}{lllllll}
\hline Years & 1999 & 2000 & 2001 & 2002 & 2003 & 2004 \\
\hline $\begin{array}{l}\text { Number } \\
\text { of } \\
\text { trainees }\end{array}$ & 153 & 120 & 74 & 553 & 296 & 55 \\
\hline
\end{tabular}

Source: Songhaï, the training department

Table 6.3: Countries of origin of the short-term trainees

\begin{tabular}{|l|l|}
\hline Country of origin & Country of origin \\
\hline Belgium & Italia \\
\hline Benin & Ivory Cost \\
\hline Burkina Faso & Jamaica \\
\hline Cameroon & Liberia \\
\hline Central African Republic & Mali \\
\hline Chad & Niger \\
\hline Comoros & Nigeria \\
\hline Congo & Senegal \\
\hline Cuba & Togo \\
\hline Democratic Republic of Congo & Uganda \\
\hline France & UK \\
\hline Gabon & USA \\
\hline Gambia & Zambia \\
\hline Ghana & Zimbabwe \\
\hline
\end{tabular}

Source: Songhä, the training department 


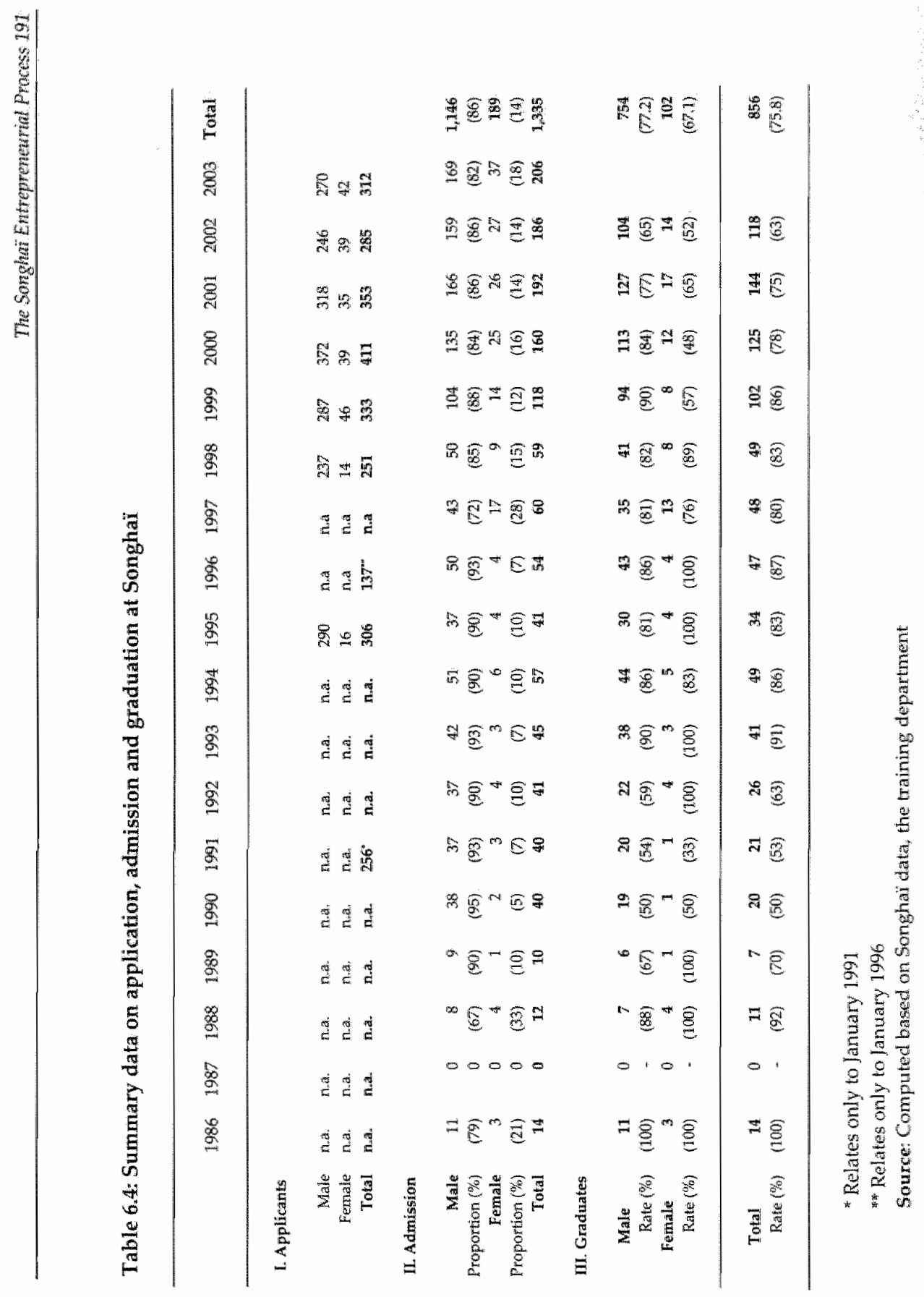




\subsection{Conclusion}

From its vision, Songhai wants to bring an alternative answer to the social, economic and cultural crisis that has been threatening SSA. Songhaï admits that agriculture will inevitably play a vital role in the process of the overall development of Africa. It also acknowledges that agriculture itself cannot be carried out without qualified human resources. This recognition has led the institute to embark on training/leaning processes aiming at promoting agricultural entrepreneurs and professionals. The professionals are technically prepared in agricultural and related activities while strongly equipped with moral values. They are general-purpose managers having capacities of leadership and are willing to transmit their knowledge to others. The main idea is to transform the learners into real actors of development. The requirement is to build human resources of a new standard, capable of seizing a culture of entrepreneurship that is a better guarantee for self-promotion of the populations at the grassroots level.

The principal merit of the Songhail training system consists of setting up a framework of apprenticeship and pedagogical follow-up based on traditional systems, and which combines new knowledge, know-how and know-being. It is also important to stress that the peculiarities and efficacy of the training lie in the fact that it is truly based on the realities of a business organisation. The various activities carried out in the different production units constitute the framework and the support for the teaching. It is a system of follow-up, which privileges a handy relationship between the learners and their educators. The strong point of this follow-up lies in the complicity, which exists between learners and their educator. This educator is, at the same time, the master of the workshop where the various productions take place. The culture of success fascinates the students and impels them to become like the master. In spite of recorded progress, the Songhail training has some limits.

There is a fear that the students can put themselves in a sort of automatism: imitate and build an enterprise in the image of Songhaï. To avoid this, the training frame foresees to stimulate the premises and the capacities of the students to innovate. They must be able to make an adequate reading of their environment in order to adapt to it using the knowledge they have acquired. Obviously, Songhaï wants to be "an open book", a source of inspiration where each one can swamp as much as he wants and needs. Even this reality hides another risk some learners may run: only the smartest and most curious will be able to 
benefit from the system. To avert this threat, the tutoring foresees, at the level of each production and training unit, some minimal requirements of knowledge and know-how, and through which the educators have to lead the learners: Further, the training process in the workshops or production units is not a simple teaching demonstration, but the participation in the life of the enterprise. It often happens that some important management decisions are only the responsibility of the masters who must have strong managerial capacities and the will to share with the learners the issues of their decision.

In addition, the training system is based on the principle of "nothing worthies action". In this respect, spaces known as application sites have been arranged to allow the prospective farmers to apply and experience real entrepreneurial behaviours. These relate to alertness on economic or market opportunities, decision-making about what activities, how to start them and with which means, management and administration of an enterprise in real environment. The sites of application are then the places of practice of entrepreneurship. However, such training policy produces the anticipated results only under the condition that the teaching framework is dynamic. The follow-up of the activities, the organisation of teaching weeks and other seminars aiming at upgrading and updating knowledge of the farmers answer this requirement. If Songhai shines by the uniqueness of its production framework and its training programme, what about the Songhai trainees (farmers) after graduation: how are they demonstrating innovation abilities? 


\section{Exploring Farmers ${ }^{r}$ Innovative Patterns}

\subsection{Introduction}

This study has made the argument that to enhance smooth agricultural innovations farmers need to embed in institutional settings enabling them to acquire capacities to innovate. It builds on the assumption that entrepreneurship implies innovative behaviours. A way to then equip farmers with innovative capacities is to train them on entrepreneurship.

This sub-case analyses how the type of training/learning process mafters in ensuring continuous fows of innovations at farners' level. It uses Songhai farmers as units of analysis and discusses evidence of these farmers" innovative behaviours as the results of their participation at the Songhai entrepreneurial training programme. The case answers the question of how have the Songhai farmers innovated. It assumes that the conditions under which the farmers set up agricultural businesses (the means and how these means are acquired), the types of the activities they have been undertaking provide the ground for the identification of their innovation capacities.

In addition to the introduction, four sections compose this central chapter. The second section briefs the regional distribution of the study sample and discusses the level of education of the interviewed farmers. Before they applied to the 
Songhail centre for training, the farmers needed to hear about it. Upon admission and before getting started, they built a sort of mindset regarding the accommodating institute. When the training process started, they began to question the appropriateness of the choice they have made. At the end of the process, they stood before some important questions: what have we learned? How is it, compared to others? How can we get a return on the new knowledge we have acquired? The third section thus, brings answers to these questions and traces some elements of the new cultural values, ethics at work and changes in mentality that Songhail challenges to inculcate to the students. Further, the section shares and discusses the views of the farmers about the evidences that make them agricultural entrepreneurs. The fourth section is about how the farmers set up their enterprises. In the most common way, innovation studies on agriculture investigate factors that affect the adoption of specific technologies by farmers. Contrary to this traditional approach, this research examines the whole process of agricultural business setting. This include access to input markets, building viable production function and production management, access to output markets and the network of information and knowledge sharing. A summary of the findings ends the chapter.

\subsection{Background analysis}

\subsubsection{Regional distribution of the sample farmers}

In the previous chapter, the analysis has given insights into the specific gender issue at the levels of application, admission and graduation of the students. The study does not consider treating separately male and female farmers. However, it would appear incomplete if it did not inform about their occurrence in the sample. As mentioned in the methodological chapter, the exact size of the population, from which the sample is drawn, is not known. Table 7.I below shows that three regions together (out of the seven) constitute $66.7 \%$ of the total sample with each accounting for at least $20 \%$. The arising question may not be why the study sample is so unevenly distributed but rather, why the trained farmers are unevenly spread out in the various regions of the country. 
Table 7.1: Regional and Gender Distribution of the sampled Farmers

\begin{tabular}{|c|c|c|c|c|c|}
\hline Zone/Region & Designation & $\begin{array}{l}\text { Male } \\
\text { farm. }\end{array}$ & $\begin{array}{l}\text { Female } \\
\text { farm. }\end{array}$ & Total & $\begin{array}{l}\text { Total in } \\
9\end{array}$ \\
\hline $\mathbb{1}$ & Ouémé & 15 & 2 & 17 & 22,7 \\
\hline 2 & South-Atlantique & 13 & 2 & 15 & 20.0 \\
\hline 3 & Mono & 5 & 0 & 5 & 6.7 \\
\hline 4 & $\begin{array}{l}\text { Northern Atlantique-Southern } \\
\text { Zou }\end{array}$ & 16 & 2 & 18 & 24.0 \\
\hline 5 & Northern Zou & 10 & 0 & 10 & 13.3 \\
\hline 6 & Eastern South Zou & 4 & 0 & 4 & 5.3 \\
\hline 7 & Borgou & 3 & 3 & 6 & 8.0 \\
\hline & Total & 66 & 9 & 75 & 100.0 \\
\hline
\end{tabular}

Source: Empirical/field research data

The most surprising is the number of established Songhaï farmers in the Mono region, which like the aforementioned three regions lies in the southern Benin and is ranked third in the department in population density (about 210 inhabitants per square kilometre). Songhaï affirms that, regarding admission of students and their graduation, the region is not biased against the others. In addition, the Mono region is the fourth in terms of its participation in the total population (about $14 \%$ ) and is not more or less rural than other departments. The region may not be a victim of its geographical location vis-à-vis the headquarters of the Songhaï Centre. It is close to it and could easily get information about the training programme. What may be interesting for those who know the country very well is that the farmers are more concentrated around urban areas of Cotonou (the biggest city and economic capital of Benin) and Porto-Novo (the capital and second urban city of Benin). In the southern region of Zou, the farmers originated and are concentrated around a locality called Houegbo. Female farmers are nine in absolute number and constitute $12 \%$ of the sample, a proportion lower than the total proportion of the graduates $(17 \%)$. They are more concentrated in the Borgou region and form $50 \%$ of the zone's sample population. Analysis in the next sections will provide an understanding of this distribution. Other characteristics of farmers relate to their occupations before entering the training programme, their age and educational level at entrance.

\subsubsection{Educational level of the farmers}

Farming used to be considered as the job of the illiterates, an activity employing only the lowest social strata, the peasants. Only children of peasants can become farmers. Farming used to be viewed as spontaneous undertakings that do not 
require special skills or training. What do the current data say regarding these general views about agricultural production? Six $(8 \%)$ farmers have declared to have been university students before they entered Songhaï. Five of them emphasised however, that they could not go further and had to stop in the first year. Only one stopped in the second year of university studies. More than the half $(68 \%)$ of the farmers did not get involved in any other activity after they have abandoned the general education at secondary school level. Those engaged in farming activities after they have abandoned school account for $12 \%$. The remaining $(12 \%)$ comprises two professional drivers, two traders and one joiner. It also includes other professionals such as maritime freight forwarder, electrotechnician, and secretary and upkeep agent. Whether or not they were involved in other activities before the Songhai training, all the farmers have attended school and reached a certain level of education.

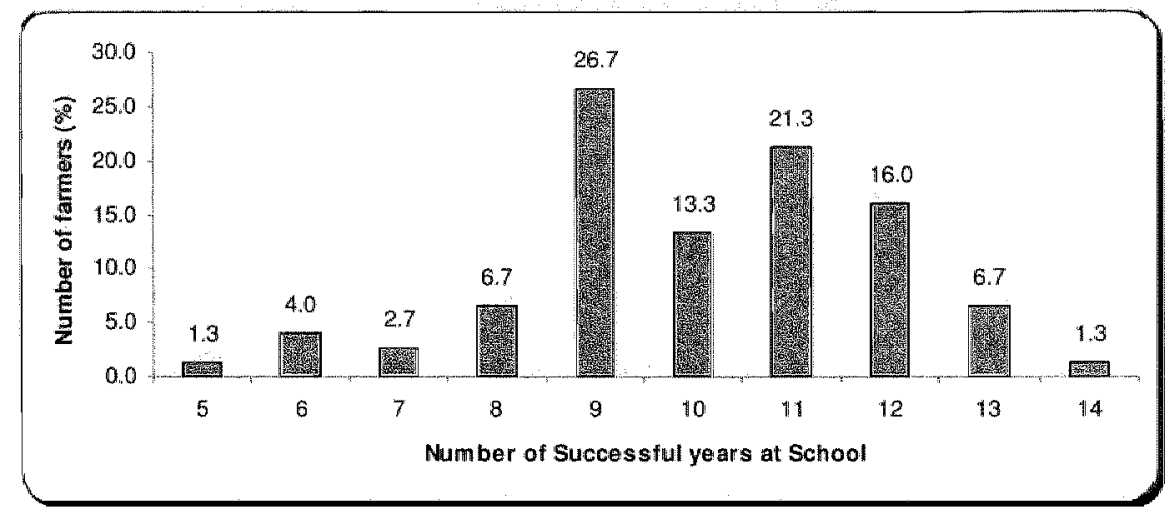

Figure 7.1: Percentage Distribution of the Farmers According to Their Level of Education Source: Based on Empirical/Field research data

Figure 7.1 above shows that the highest proportion of the farmers (26.7\%) stopped with general education (where the main taught subjects include mathematics, physics, chemistry, history, geography and languages) after nine years. In addition, $90.7 \%$ of these farmers were forced to leave general education after eight to $\mathbb{1 3}$ years of schooling. In effect, this corroborates with the relative age (at entrance) distribution of the farmers. At enrolment, $86.7 \%$ were between 18 to 25 years old. The remaining $(13.3 \%)$ is shared between those who are $26(5.3 \%), 28$ $(2.7 \%), 29(4.0 \%)$ and 32 (1.3) years old. Note that in Benin, the educational system distinguishes primary, secondary and university school levels. There is no restriction on entry age because all localities, and mostly the remote ones, do not have access to education at the same time. Depending on the areas, children may start their first schooling from five, six, seven, eight, even ten years. Primary 
school education lasts six years while the secondary school setting requires six or seven years of successful education before access to university. Though the data seems to challenge the old picture of agricultural production, alone they are not sufficient for drawing any sound conclusion. Other parameters may support or weaken the image they intend to provide.

\subsubsection{Knowing about Songhaii}

Whatever the purpose it is to serve, information can be launched through one and spread out through many channels, may it be interpersonal or mass communication means. This paragraph does not concern how Songhaï diffuses information about itself. It does not focus on the means by which Songhai advertises its training programme. Instead, the paragraph tackles the issue from the opposite side. It presents the means by which the farmers got to know about Songhaï and its training programme as displays Table 7.2. Slightly above one third $(34.7 \%)$ of the interviewed farmers declared being informed by a friend. Radio, as a means of mass communication, is ranked as the second source of information $(26.7 \%)$. The third $(21.3 \%)$ most-cited source of information by the farmers is their relatives (parents, brothers, uncles). Institutions (NGO and churches), proximity to the Songhai Centre and TV filled up the rank. An attempt to group these means into interpersonal and mass communication channels places the former at the first place with $64 \%$ of the interviewed. In effect, it was individuals in NGOs and churches who informed the young about the Songhai training programme. Together with the friends and relatives they form interpersonal source of information. Is this awareness about the importance of interpersonal communication that motivated the farmers' network?

Table 7.2: Source of Information about Songhai and its training progranme

\begin{tabular}{lcccccccc}
\hline Sources of lnformation & Zonel & Zone2 & Zone3 & Zone4 & Zone5 & Zone6 & Zone7 & Total \\
\hline & 1 & 6 & 1 & 3 & 6 & 2 & 1 & 20 \\
Radio & 0 & 1 & 0 & 1 & 0 & 1 & 0 & 3 \\
TV & 9 & 3 & 2 & 8 & 0 & 1 & 3 & 26 \\
Friends & 4 & 3 & 1 & 5 & 2 & 0 & 1 & 16 \\
Relatives & 2 & 2 & 0 & 0 & 0 & 0 & 0 & 4 \\
From being in $\mathrm{P} / \mathrm{N}$ & 1 & 0 & 1 & 1 & 2 & 0 & 1 & 6 \\
NGO/Church & 1 & & & & & & &
\end{tabular}

Source: Field data 
The previous paragraph seems to convey the idea that the farmers embarked on the training because they received information about it. And it ultimately confers a useful character to all messages to everyone. But such a generalisation would not be acceptable. A message becomes useful for someone if it meets with an existing fertile ground. Other major reasons might precede the information or come together with it. Many farmers explained that the passion they have for farming activities motivated their decision. However, it is clear that having passion for an activity does not necessarily lead to training in the field. From that point of understanding they explained that they share everyday life with peasant farmers; they see the extent of their endeavours and the scope of their results. The peasants work everyday, they do their best but the harvest in terms of quality and yield is meagre either in crop or animal production. When once there was a time that $T \& V$ agents came to assist the peasants, it was clear that they had some knowledge the peasants did not have. Therefore, acquiring knowledge that allows better performance than that of the peasants was the ultimate need of 52 out of 75 farmers. Ten other farmers stressed the self-employment character of farming activities and added that they do not pay off without the use of new production techniques and technologies. Five farmers revealed that it was because they were amazed by what they saw during a visit of Songhai that motivated their decision. For the rest, it was the quest for short duration training and the advice of relatives or friends that warranted their choice. Decision to go for training mostly precedes the choice of an appropriate educational institute.

There are public schools, NGOs and cooperatives that also provide training in agriculture in Benin. Attendance to any of them depends first on knowing that they exist. To begin with, $84 \%$ of the farmers affirmed that they knew about other educational and training institutes before choosing Songhai. Only $16 \%$ have mentioned that they chose Songhai as it was the only agricultural training centre they knew. This part brings to light the factors that counted in favour of Songhai. A number of reasons contributed to affect the choice of the farmers. The most important factor related to the content and the process of Songhai training. As mentioned earlier, the Songhai training is a sort of apprenticeship where the learners learn by doing. In classic apprenticeship, the learner observes the master at work and tries to do like him/her. There is no theoretical course, and in many cases the learner does not ask questions. At Songhaï however, the students have the right to ask questions and basic theory accompanies the practical works.

First, it is the dominance of the practices over theory that has attracted the farmers. Secondly the farmers affirmed that the Songhail training programme is multidisciplinary and grants general-purpose skills. The production system, that 
constitutes the background for the training, integrates crop and animal productions to fish farming and processing activities. It gives many production opportunities. In contrary, public educational schools are too theoretical while NGOs and cooperatives are too specialised in just few areas. The farmers presented these facts as required but not sufficient conditions to enter Songhaï. Together, other two factors emerged as sufficient: admission criteria and scholarship. Songhaï does not exclude someone just because of his age or educational level. Finally, Songhai is a sort of boarding school; it houses all students, nourishes them and gives them training without charge.

\subsubsection{Facing the realities of the training process}

Mediocre ethic at work is one of the major problems the Songhail centre wants to address through the training process. Punctuality and ardour at work, vigilance and rigour in the execution of different tasks, regular self-criticism and selfassessment, sound observation, analysis and anticipation of certain events are all elements of the good ethic Songhaï inculcates in the students. The students are thus led to live the real life of integrated farming production. In practice, this implies the completion of a series of regular activities beginning from early morning through mid-day to the evening and, even, at the night. A farmer engaged in an integrated production, combining one staple crop, market gardening and animal husbandry, has very little time for resting. Very early in the morning, he starts with the cleaning of mangers or feeding dishes. During this operation, there is a need to observe the animals very carefully to detect probable diseases among them. When an illness occurs, the farmer provides the required care. $S$ /he has to water, if necessary, the garden plants or the nurseries before blazing sun. S/he will also need to go to the field of the staple crops in addition to thinking of making feeds for the animals. At any time a farmer may be required to intervene or perform specific tasks, no matter the weather. In such circumstances, the uninitiated and learners may find farming too demanding over and with respect to their initial expectations. Indeed, up to $86.7 \%$ of the farmers stated that they were highly motivated at beginning of the training. However, the hardness of the work has used up part of this enthusiasm and up to $64 \%$ of them have admitted that they found the training very difficult and many times they thought of giving up.

\section{What makes the difference?}

To recall, 63 out of the 75 farmers revealed that it was among other training institutes they chose Songhail. Apart from more favourable admission conditions 
and certain facilities, it was the quest for practical agricultural technical knowledge, which makes someone a real and versatile farmer that validated their preference. Many farmers affirm that they have had opportunity to meet, discuss and even work together with farmers from other educational and training institutes. Through these interactions, they seem to discover the real image of Songhai. Here they dared share their views about how they actually do evaluate the Songhail training programme with respect to the others and in accordance with their initial expectations.

The farmers think that the Songhaï training programme is poor in theory and only in the field one realises it. In the public educational centres, the students are heavily endowed with theoretical knowledge and this renders them analytically stronger. However, they severely lack the practical know-how, which is fundamental in farming. Each year, Songhail receives, for short duration training on practical things, many students from other educational institutes. The prospective Songhaï farmers are always those who help the masters in guiding them. Songhaï farmers are more capable of carrying out multiple activities and with much more endurance. Contrary to other institutes, Songhai does always invites, encourages and sponsors its former students to acquire additional knowledge in new emerging fields and to upgrade the knowledge they previously acquired. In effect, there are new fields of specialisation at Songhai that were not open at the time of some students. In some cases, given market opportunities, a farmer may need to have more knowledge in a specific field at Songhail or elsewhere. In this connection many farmers were led to attend some theoretical or practical courses in various domains as Table 7.3 presents. Does it mean that the farmers' expectations from the programme are met?

Thable 73 Additional trathing or course participation atter graduation from Songhat

\begin{tabular}{|c|c|c|c|c|c|c|c|c|}
\hline Trainding Counde & Zome1 & Honez & Zone3 & Zone4 & Zones & Zone6 & Zane7 & Total \\
\hline Yoking & 1 & 0 & 1 & 0 & 1 & 0 & 0 & 3 \\
\hline Bovine/catille ralsing & 2 & 0 & 0 & 0 & 0 & 0 & 0 & 2 \\
\hline Poultry production & 2 & 4 & 1 & 3 & 0 & 0 & 1 & 11 \\
\hline Management /Enhepreneu: & 3 & 4 & 3 & 7 & 4 & 1 & 1 & 23 \\
\hline Grassecutter & 1 & 1 & 1 & 1 & 0 & 0 & 0 & 4 \\
\hline Credit management & 2 & 0 & 0 & 0 & 2 & 0 & 0 & 4 \\
\hline Processing & 2 & 0 & 0 & 0 & 1 & 1 & 0 & 4 \\
\hline larming in general & 1 & 3 & 0 & 0 & 1 & 0 & 0 & 5 \\
\hline Beakeaping & 0 & 1 & 1 & 0 & 0 & 0 & 0 & 2 \\
\hline Pig raising & 0 & 1 & 1 & 0 & 0 & 0 & 1 & 3 \\
\hline Rabbit raising & 0 & 0 & 0 & H. & 1 & 0 & 0 & 2 \\
\hline Law and justion & 0 & 0 & 0 & 光 & 1 & 0 & 0 & 2 \\
\hline Agric. Product conservation & 0 & 0 & 0 & $\mathbb{1}$ & 0 & 1 & 0 & 2 \\
\hline
\end{tabular}

Source: Field research data 
Box 71 Agricultural production requires endurance at work

1. The Songhat training process is not what is difficult. It is agricultural production which is compelling. Indeed, setting [up my] own forvt is more afficult than the training process. And all najor problens occur after graduntion, mainly during the process of farm business staring (Gangnon)

Bertin Gangnon ( 26 years) set up his farm with only 30.56 (his father donated him) on a land he inherited from his mother. He started with the production of tomatoes, which he currently combines with sucessful production af pineapple for expont Bertin is located in the Northerin-Atlantique region and has acknowledged a financial support from PISEA. But the amount allocated to thim appears too little regarding the land he aims to exploit and the narket opportunities for the production.

2. I would not succed in my own farming business if I hadit acquired endurance during the tratining process when we were often forced to wowk all the time ord at any time Indeed, I felt many times to be treated as a slave but now I realise hat there was no other way and it has a great pay off (Akala)

Akala Aliyou (31 years) can be seen as a very suecessful famer in the Ouene region, speclalising in the production of rice, natze, market gardening and cassava in combination with layer hens. He advocated that it is the market opportunities in the region and the appropriateness of the lands that warranted his production specialisation He owns more than one thousand Tens, a good level of production in the country context. Akala Aliyou was the first to introduce perfumed nice production in his locality. He stressed that he would increase the scope of his activities if more credits were avallable to him. The Songhai credit fame seems not very favourable, he mentioned.

Roughly all farmers $(94.7 \%)$ affirmed that they owe much to the Songhai training programme, which has enabled them to gain technically meaningful knowledge in farming. Further, the farmers mentioned that they have benefited from the rigorous moral, psychological and physical training.

"We have really acquired the fundamental knowledge and skills required to carry out daily notwities as agriculturat entrepreneuss. The most intportant is the practical techical know-fiow, which is more wseful in forming. Moreover we have acquired the sense of observation and andlysis that do not confine us in copying jwist what exists."

The farmers have, however, recognised that the knowledge they have does not suffice to face all challenges of farming undertakings. They also acknowledged 
that the dynamic process of change implies that a training centre cannot give students all skills and knowledge they need over time. In all cases, the farmers insisted that they have gained outstanding knowledge in the training. For all intents and purposes, they support the idea that the Songhaï training has granted them remarkable advantages over those farmers without training (the peasants). Consequently, they are called "Farmers" or "Agricultural Entrepreneurs" and the others, "Peasants". What is the difference or what makes them agricultural entrepreneurs?

Differently but toward the same goal, the farmers tried to explain that what they consider as their advantages are the shortcomings of people they know very well through regular interactions. The intention is to stress the benefits of the training and not to undervalue the indigenous knowledge.

"We have been living with them (peasants) for long and we were one of thew. We know what they do and we know what we were doing. The peasants are our parents and brothers, our friends and neighbours. Even after training, we continue to work together with them; they need as and wet need them. Without training, we know what our approach to farming and our practices would continue to be."

In addition to the general personal qualities of entrepreneurs (as mentioned in the previous chapter), the following constitutes the advantages the farmers expressed and claimed they have over those without any formal training in the field.

"Definitely, we have gained thorough knowledge about cropping systems with a better understanding of sowing seasons. Animal production techniques with the ability to dingrose animal diseases and provide basic treatments or carry out daily animal cares and animal feeds making are absent in "peasant farming". More importantly. we have acquired capacity in designing business plan implyiong farwing enterprise mantagement capacities (seizing market opportunitios, market analysis and production decision making to avoid very risky activities. activity panming, with decent capacity in cost-effectiveness). We have acquired whinestionably. more endurance at work. Finally we gained more social consideration." 


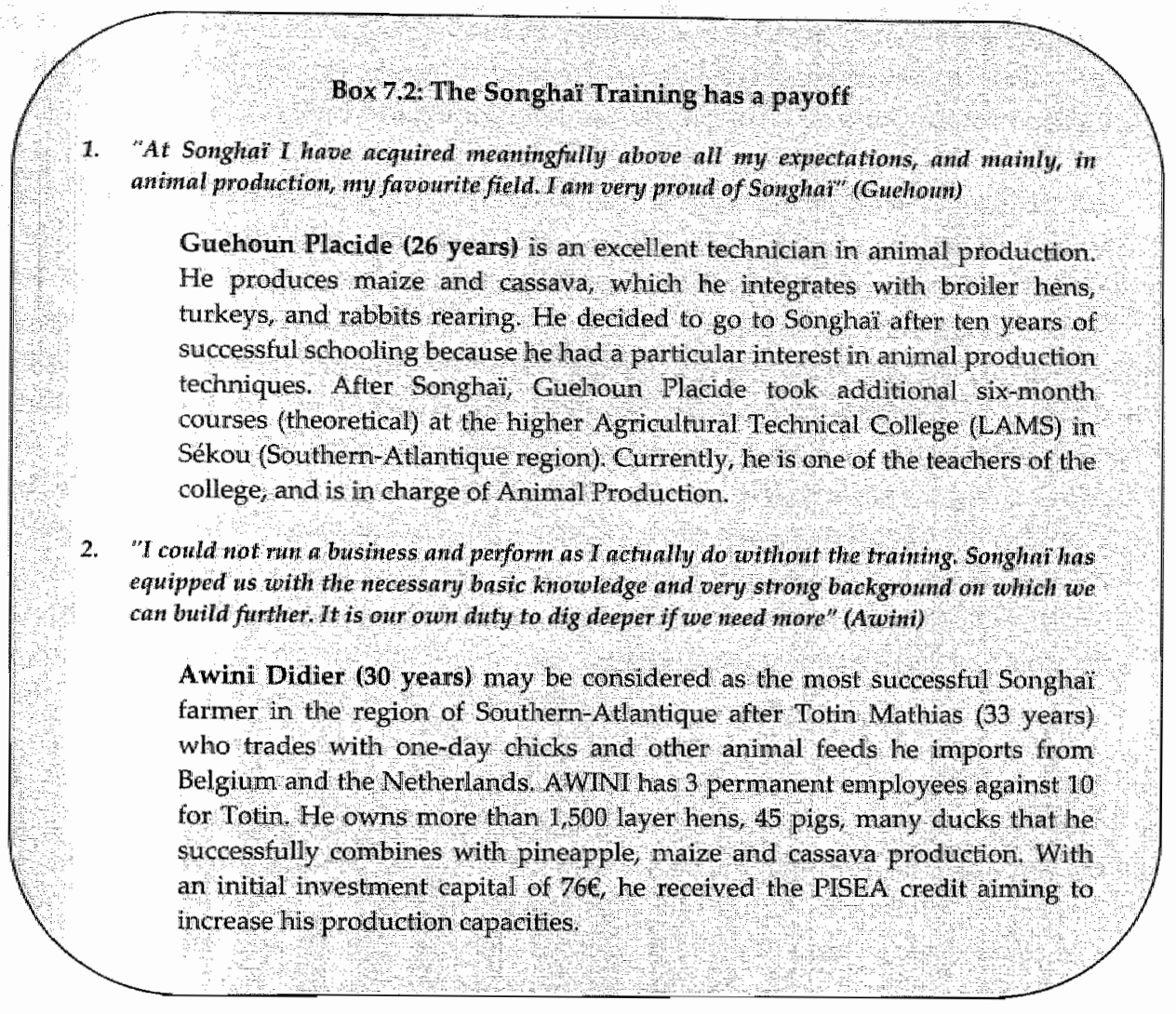

\subsection{Getting started: mastering the means of production}

The agricultural entrepreneur must be able to articulate this/her ideas before shifting to the phase of project realisation. The articulation of the project is an exercise leading to have concrete answers to the questions:
a) What is the main goal?
b) Which product?
c) Which means and techniques of production? Here, it is necessary to make a description of the infrastructures, installations and equipment necessary and to identify the requirements in human resources and their profiles.
d) What are the expected results?
e) What kind of organisation needs to be put in place? 
But the key to success does not lie only in the respect of these safety measures. It lies also in the effectiveness, the rigour in management and especially the incarnation of the true entrepreneurial behaviour and beyond.

Of the interviewed farmers, $66 \%$ mentioned that they set up their business within three months after graduation. While some of them used just the means they had at hand, others declared that they began the process some months before finishing the training thanks to the help of their parents and brothers who were preparing the ground for them. Of the farmer sample, $12 \%$ needed more than 24 months (two to several years) after graduation before they set their farms. Some of this category of farmers explained that they needed to work for others and gain capital necessary for the activities they aimed to pursue. In other cases it was a deliberate choice to work for others for more experience. The remaining $20 \%$ belongs to the category of those who set up a farm during a period of six to 12 months $(18.7 \%)$ and between 12 and 24 months (1.3\%). Figure 7.2 below displays the years of settlement of the farmers.

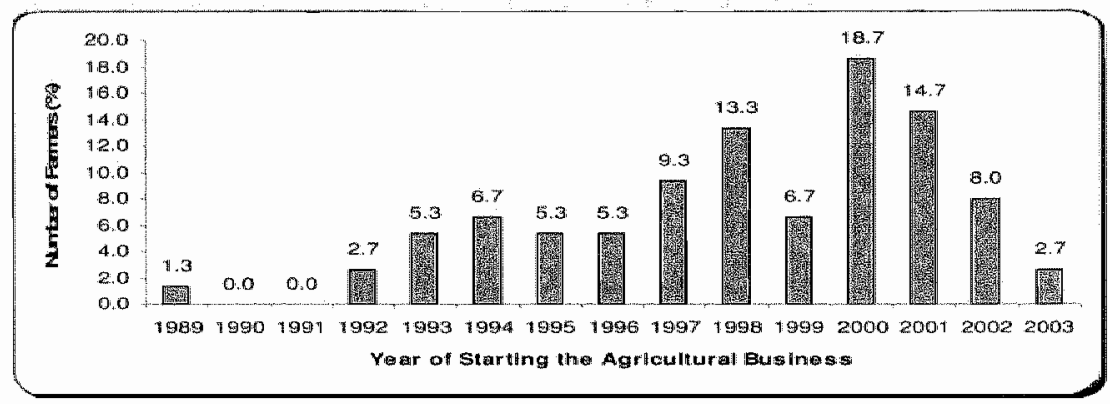

Figure 7.2: Distribution of farmers according to the years of seltlement

Figure 7.2 shows that one quarter of farmers in the study sample set up their business between 1992 and 1996. Almost three quarters (70.7\%) have however, established their enterprises between 1997 and 2002. Apparently, the figure presents a declining trend regarding the ability of the students to set up farms after graduation. Since 1992, a general growing trend is observed until 2000 with a slight fall and stagnation in 1995 and 1996 followed two years later (in 1999) by a break. From 2001, a clear declining trend sparks attention of all readers. This may not be necessarily interpreted as a radical fall in the number of graduates who established their business. Sometimes it takes longer time for many graduates to practically establish as farmers. Studies a few months or years after may show the reverse of the current trend. Another readable picture that derives from the figure is the age of the enterprises; they are relatively young. More than 
half $(50.7 \%$ ) of the farms are not older than five years, and up to $40 \%$ are six to ten years old, for a total of $90.7 \%$ that are ten years old or younger.

\subsubsection{Land}

First, a comprehensive definition of land better serves the purpose. Land is a concept that includes arable land, vegetation, surface and underground waters and their products. Land is thus taken to be synonymous to natural resources (Musahara, 2001). In simpler terms, land may be primarily defined as spaces for agricultural production (plants, livestock, and processing). A major characteristic of land is that it is given by nature and it is impossible to expand it. The possibility of recovering hard land surfaces for crop production or settlements does not increase country or world total land area. This attribute makes land a precious asset in general. Moreover, it constitutes a valuable and indispensable input to farming activities in particular. Access to it as well as the rights to its use and transfer is established by land tenure.

The mode of access to land through the exploitation of a family common land has the highest frequency with 28 farmers out of 75 . Here family land means land of the father or the mother of the farmer. In practice, children are entitled to use their parents' land for any purpose if they are single, meaning that they still depend on the care of the father. Therefore, the lands these farmers have been exploiting could be used by any of their single brother or sister. They may be asked, at any time, to concede part of the portion they are using to any of the family member if necessary. The land remains the property of the parents.

Next to already mentioned form of access to land, gift of land ranks second. Gift normally takes place as an anticipated inheritance within the life lime of the person leaving an inheritance, for example when a grown son gets married and requires more land. By this mode of access to land, the beneficiary becomes a landowner without any payment. It occurs as a gesture from a land owner to a relative or a subordinate to whom he feels obligated. In Benin this act of donation is sanctioned by a certificate as an authentic and legal ownership document. The fundamental difference with the family common land use is that the land is no more the property of the donor. This unusual mode of access to land is mostly used by the Songhai farmers. Its main advantage is that it allows the farmers to peacefully undertake any activity and without fear that they can be one day expropriated from it. Where appropriate, the land can serve for guarantee for credit, if necessary. Through this form of access, $20 \%$ of the farmers became land awners 
There is an established land market whereby transfers are spoken about openly. Purchase and sale of land are part of everyday reality. It is an act by which the beneficiary becomes the legal owner against the payment of the agreed amount of money (generally in cash) to the initial owner (Biaou, 1998). The prices differ according to the quantity and quality of the land, the site of the plots, and also according to how closely the seller and buyer are related. It also depends on the current financial situation of the seller (Biaou, 1998). While 14 farmers were found who set on the land they have purchased, eight farmers declared that the land they are using was inherited from a parent (father or mother).

Borrowing is an act by which owners give the right of use over land to an individual or a group of individuals on a time basis without a fixed or quantitatively meaningful service in return. Initially, the objective is to help someone who is landless to produce and enjoy a relatively large freedom of choice in reference to the management of resources (Biaou, 1998). Depending on the duration and the region, the borrower can be permitted or restricted from planting trees, constructing a house or setting out fish ponds; all of which can later grant the borrower the right of ownership over the land. Embarrassing with this form of access to land is the possibility of the lender to retain the right to take land back unannounced (Biaou, 1998). This is seen as a barrier to many investments. The Songhai farmers said that, to avoid this unpleasant situation, they have established a contract with the lender for a fixed period. The borrowing act can be renewed upon agreement of both parties. Six farmers have been found under this contract.

In the case of renting, as a mode of access to land the tenant farmer acquires the right of use of land against a regular payment of money or goods or amount of work, which is fixed at the outset. Several variants of renting are recorded in Benin with duration of contract more or less clearly defined in advance, thus allowing the tenant a clear planning horizon for investment (Biaou, 1998). The degree of autonomy with regard to cropping pattern, land use and management decisions depend upon the form of the lease and the agreed conditions. Four out of 75 farmers had to use this mode of land access. 


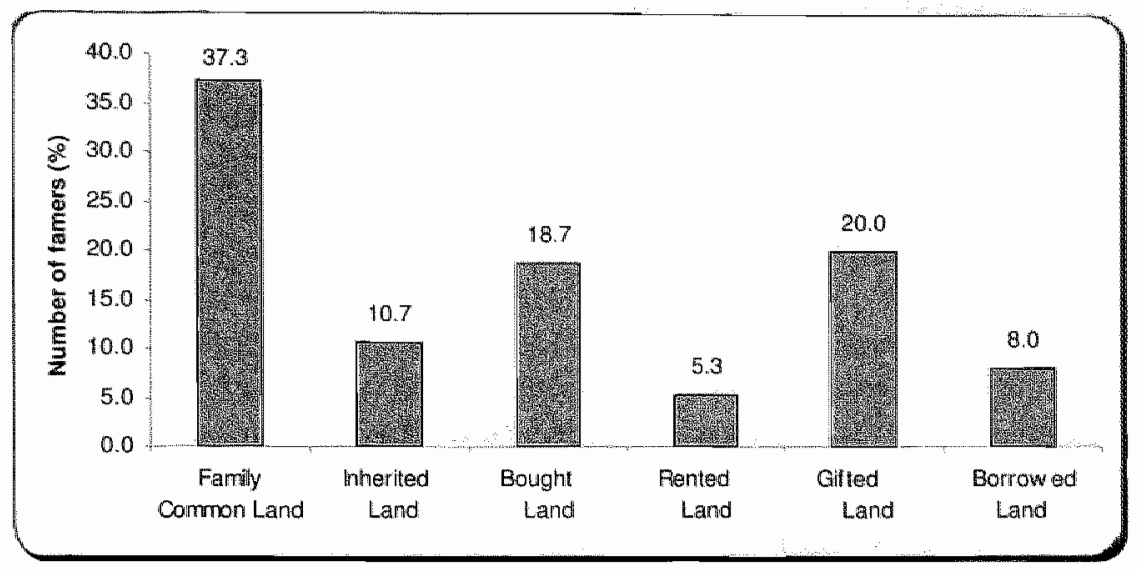

Figure 7.3: Source of Exploited Lands

There is a link between the access to land and agricultural efficiency through two main mechanisms. The exercise of secure property rights on land plots eliminates the uncertainty of expropriation, stimulates farmers to handle long-term investments with their own financial resources. Furthermore, this encourages the farmers to make the best allocation of their land resources by adopting the best cropping systems. The possession of land property is a sure guarantee for a lender and makes him more likely to grant loans to the farmers. However, Platteau (1993) observes that empirical results on relationships between land property rights, land improvements and agricultural productivity in SSA, are generally non-conclusive. Nevertheless, what counts here, are the elements of innovations contented in these modes of access to land. Indeed, only land access through the use of family common lands and inheritance are really ordinary at farming level. Concerning the others, there is a need to dig deeper.

Donation of land to one's child usually happens when the child gets married and there is a need to help him with more land. Giving land to a son, who is single with the requirement of establishing ownership documents and for the purpose of setting a 'so-called' farming enterprise, is really new to the Benin's society. It seems like asking to obtain from one's parents the share of heritage one would get after their death. Tackling the issue requires special skills so that the parents, and other brothers, all understand the concern. What if the parents are still very active? What if the farmer has brothers and much younger who also may be led to ask for their shares? In this case, it is really innovative from the part of the 15 farmers who have proven bargaining skills so that they convinced the other family members of the importance of donating land to them. Buying land also falls in the same category as access through a gift. Purchasing farming land for a 
single son is remarkable. If a farmer has been able to persuade his parents to purchase land for him, this is basically attributable to the training. Traditionally, people are required to rent or borrow land in the case of subsistence production. The tenants or borrowers are usually landless seeking just to meet everyday bread needs. Here the purpose is fundamentally commercial. Together, the renter and borrowers farmers are ten in absolute number.

Finally, with respect to the mode of access to land (Figure 7.3), the analysis distinguishes two categories of farmers. Those who set their farms on family common land added to those using the lands they have inherited, form the first category. These farmers have not demonstrated innovative capacity with respect to the factor at stake. They may have these skills, but they have not been constrained to apply them. Someone who inherited a land surface sufficient, at least, for his current needs, will not aspire to buy, rent or borrow. The second category comprises farmers exploiting purchased or donated lands and those using rented or borrowed lands. When production conditions constrain farmers to search and implement new ideas, these ideas are also called innovations and they promoters are thought of as innovators. Through this understanding, $52 \%$ of the farmers have been able to access land as the result of the training. Whatever the mode of access to land, what should follow is starting its exploitation, which does not happen without money.

\subsubsection{Capital}

One of the conditions for the students to graduate is the presentation and the successful defence of a business project, an agricultural business plan to serve as the basis of their enterprise activities. The students achieved this document taking account of several factors, one of which the importance of capital to which they have or may have immediate access to. Market opportunities and profitability added to location (land quantity and quality, climate) play a key role in this achievement. Before examining the main production activities of the farmers and the most important factors supporting these choices, the analysis concentrates on the importance and the sources of their initial investment capital. The initial investment capital is defined as the amount of money, whether in cash or in forms of inputs or any other means of production the farmers used to start their activities. Table 7.4 displays the data.

The table shows five sources for the initial investment capital (IIC). Personal (strictly) source of investment is the most important. Of the farmer sample, 31 farmers have declared that they financed their business through the savings from 
previous incomes. Further analysis shows that nearly half of the personal source of IIC is less or equal to 50,000F CFA (76.26) while in generall, $83 \%$ account for less than 200,000F CFA (3056). If in general many farmers originate from rural or poorer families, one might ask how it happened that up to $13 \%$ of personal sources are high. They range between 300,000F CFA and 5,000,000F CFA. (457.4€ and $7,622.56$ ). These are, mostly, farmers who set their business many years after graduation. They earned the capital through working for others.

The second source for initial investment financing comes exclusively from donations that the farmers received from relatives (parents and brothers), and 24 farmers admitted to benefit from this type of assistance. The highest IIC $(1,000,000 \mathrm{~F}$ to $5,000,000 \mathrm{~F}$ CFA and more - 1,524.5€ to 7,622.5€) came in this form and the number of beneficiaries constitute $5.3 \%$ of the total sample. The beneficiaries revealed that they used the money for the acquisition of land and build basic infrastructures. Eight farmers $(10.67 \%)$ falling under this category received between 200,000 and 500,000 F CFA (305€ to 762.36). Among the remaining 12 farmers (of this category) seven received no more than $50,000 \mathrm{~F}$ CFA (76.2€) for the start-up of their business.

Two other sources of IIC dispute the third place with each eight farmers. Indeed, some farmers mentioned that their source of IIC was not unique; relatives added to the personal capital they primarily had. The other source of ICC is the Songhai credit. What is apparent is that only one out of the eight beneficiaries received loans slightly above 200,000F CFA (305€). The others obtained much less. Finally, five farmers mentioned that they were granted loans from some of their family members. These loans were not the least. Up to three of these farmers had received from a minimum of $300,000 \mathrm{~F}$ CFA $(457.4 €)$ to approximately $5,000,000 \mathrm{~F}$ CFA $(7,622.56)$.

The analysis has revealed the fundamental role relatives played in helping farmers. In terms of either the number of the farmers that have benefited from their financial assistance or the amount of capital they brought, family members constituted the most important source of support. For all intents and purposes, is there any indication that the sources and the amounts of the IIC depend on the farmers' own skills as the results of the training? Is this just normal as a cultural matter? Without hesitation, a lot of people would answer yes to the question. In effect, many parents and other relatives spend a lot of money supporting the activities of their children or allies. If the farmers would not have demonstrated a persuasive and effective commitment to their job, would the relatives still inject their money? What is noticeable here is the changing mentality toward farming. 
The change lies in the recognition that agriculture cannot develop by remaining a footnote of training. Definitely, it is the merit of the training that support to farming becomes more and more important.

It is through training that people acquire new techniques of farming that help improve outputs. Not only the Songhail farmers incarnate this change, but they do also develop and demonstrate new ethics at work and human values that deserve particular interest and attract many people. In various ways, many farmers, though they only partlly agree with Songhaï in many respects, stated:

"At Songhai one acquives openess, broader view and in particular new approach to deal with enem the mast wsual issues. Added to technical knowledge these values make one a new enthusiastic man burning to become the anchor of the family and of the willage."

\subsubsection{Production activities}

A common feature to entrepreneurship and innovation is "what you can do with what you know to gain an advantage on the market place". Whatever their potentials, the farmers are expected to demonstrate thoroughly meaningful production functions. Many farmers start their business with vegetal production and then combine with livestock or processing. Actually, crop production seems less investment demanding and therefore affordable for all. As displayed in table 7.5. up to $53.3 \%$ of the farmers produce maize while $36 \%$ and $29 \%$ are involved respectively in the production of cassava and market gardening. Almost half of the farmers $(49.3 \%)$ have correlated their production choice with the amount of their initial investment capital.

For 34 farmers, it was output market opportunities and profitability that guided the choice. Respectively $42.7 \%, 32.0 \%$ and $24.0 \%$ of the farmers could engage in layer hens, pigs and broilers/cockerel productions. Appropriateness of lands (quantity and quality) added to personal vocations also affected the choice of the farmers. Those located in the suburbs of cities do not possess enough land for crops such as maize, cassava, soybeans and pineapple. They usually involve animal husbandry and market gardening. Further, many farmers admitted that they were interested only in animal husbandry. Another constraint was the origin of the farmers. Those who were born in cities and did not farm before found crop production on large surfaces too difficult to bear, in the absence of agricultural machinery and adequate human labour force. To remain in the focus, the study further investigates the ability of the farmers to apply diverse innovations in their farms. 
Table 7.4: Distribution of farmers according to the Sources and Amount of their Initial lnvestment Capital (IIC)

\begin{tabular}{|c|c|c|c|c|c|c|c|}
\hline MC in Frames CFA & $\begin{array}{l}\text { Strictly } \\
\text { Personal }\end{array}$ & $\begin{array}{l}\text { Personal a } \\
\text { Donated by } \\
\text { Relatives }\end{array}$ & $\begin{array}{l}\text { Donated by } \\
\text { Relatives }\end{array}$ & $\begin{array}{l}\text { Songhai } \\
\text { Credit }\end{array}$ & $\begin{array}{l}\text { Borrowed fromi } \\
\text { Thelatives }\end{array}$ & Total & $\begin{array}{l}\text { Total } \\
\text { (yil) }\end{array}$ \\
\hline & & & & & & & \\
\hline $\mathrm{HC} \leq 50,000$ & 14 & 2 & 7 & 3 & 0 & 24 & 32.0 \\
\hline $50,000<\| \mathbb{C} \leq 100,000$ & 8 & $a$ & 3 & 4 & $\mathbb{1}$ & 16 & 21.3 \\
\hline $100,000<\mathrm{MC} \leq 200,000$ & 4 & 1 & 2 & 2 & 1 & 10 & 13.3 \\
\hline $200,000<\mathrm{IIC} \leq 300,000$ & 1 & 2 & 2 & $i$ & 0 & 6 & 8.0 \\
\hline $300,000<\operatorname{MC} \leq 500,000$ & 2 & 0 & 6 & 0 & 1 & 9 & 12.0 \\
\hline $500,000<1 \mathrm{nC} \leq 1,000,000$ & 1 & 0 & 0 & 0 & 1 & 2 & 2.7 \\
\hline $1,000,000<$ IIC $\leq 5,000,000$ & 1 & 2 & 2 & 0 & 1 & 6 & 8.0 \\
\hline $\mathbb{I I C}>5,000,000$ & 0 & 0 & 2 & 0 & 0 & 2 & 2.7 \\
\hline Total & 31 & 8 & 24 & 8 & 5 & 75 & 100.0 \\
\hline Total in $(\%)$ & 41.3 & 9.3 & 32 & 10.7 & 6.7 & 100.0 & \\
\hline
\end{tabular}

1FCFA $=0.001525 €$ or $1 €=655.95$ F CFA

Source: computed from field data

\subsection{Farmers' innovative patterns}

\subsubsection{First producers and suppliers as innovators}

Here, the condition that defines innovation is the ability of a farmer to be the first person to introduce the production of specific crops or the rearing of given animal species in his region or local market. The product has to be new to the farmer's region or to the market he supplies. Table 7.6 summarises farmers' responses to the question of whether they have been the first farmer to introduce 
the production of certain crop varieties or animal species and supply certain local markets. The notions of first producer and local market were clearly explained. Local market designates the surrounding communities, (geographical proximity) which are the first buyers of the products. It also designates physical open markets that the farmers supply. Retail traders from other regions also buy from such markets. The farmers undertook market research before engaging in any production activity. This marketing study also allows them to record, if any, existing producers in the fields. They know whether they will be facing any competition in the near future. Then the farmers really knew the needs of the local market to which they have been the first to introduce the innovation. Table 7.6 gives a more detailed picture of the innovators. It presents them with respect to the different regions and according to the types of innovations.

When the farmers were asked whether they had been the first producer and supplier of any agricultural product to their local markets, $47(62.7 \%)$ answered in the affirmative. The distribution of these innovators according to the main farming activities reveals that $29.3 \%$ account for crop production with market gardening $(13.3 \%)$, Soybeans $(6.7 \%)$ and perfumed rice $(4 \%)$. Then follows animal production with $21.3 \%$, of which layer hens $(12.0 \%)$, broiler hens $(4.0 \%)$ and big pig $(4.0 \%)$ account for the lion's share. Processing activities were not the least. They account for as many farmers as there are involved in animal husbandry $(12.0 \%)$. They are unevenly distributed between special soap $(5.3 \%)$, and $2.7 \%$ for each of cloth dyeing and improved gari.

Table 7.6 also clearly shows that innovators in processing activities are concentrated only in zones 7,4 and 2 with respectively four, three and two farmers. Both the innovators in zone 6 are found to be crop producers. Zones 5,4 and 1 seem to compete in terms of number of innovators with respectively 11 , ten and nine farmers. While zone 5 largely dominates in animal production with 7 farmers, zone $\mathbb{1}$ takes the leadership in crop production with 6 farmers. Among the zones, in which there is at least one innovator in each of the three farming production fields, zone 4 ranks first before zones 2 and zone 7 . Out of the ten innovating farmers, four, three and three are respectively involved in crop, animal and processing activities. At this point, a warned reader may ask for the motivation behind these differences. For example, the notion of integrated production, which is itself an innovation, can produce a satisfactory explanation for the disparities observed. 
Table 7.5: $\quad$ Main production areas of the farmers

\begin{tabular}{|c|c|c|c|c|c|}
\hline Crop / Livestock & $\begin{array}{l}\text { Nber of } \\
\text { Farmers }\end{array}$ & $\begin{array}{l}\text { Nber of } \\
\text { Farmers (\%) }\end{array}$ & Crop / Livestock & $\begin{array}{l}\text { Numb, of } \\
\text { farmers }\end{array}$ & $\begin{array}{l}\text { Numb. of } \\
\text { Famers }(\%)\end{array}$ \\
\hline Vegettal production & & & Livestock production & & \\
\hline Maize & 40 & 53.3 & Layer hens & 32 & 42.7 \\
\hline Cassanat & 27 & 36.0 & Pigs & 24 & 32.0 \\
\hline Market gardening & 22 & 29.3 & Broiler hens/ cockerel & 18 & 24.0 \\
\hline Soybeans & 10 & 13.3 & Turkeys & 11 & 14.7 \\
\hline Tomatoes & 10 & 13.3 & Sheep/goats & 8 & 10.7 \\
\hline Pincapples & 9 & 12.0 & Grass-cutters & 7 & 9.3 \\
\hline Beans & 9 & 12.0 & Rabbits & 7 & 9.3 \\
\hline Groundnuts & 5 & 6.7 & Ducks & 6 & 8.0 \\
\hline Yams. & 5 & 6.7 & Irash & 3 & 4.0 \\
\hline Pepper & 5 & 6.7 & Cattle/Bovines & 1 & 1.3 \\
\hline Banana & 3 & 4.0 & & & \\
\hline Oil palm tree & 3 & 4.0 & Processing & 9 & 12.0 \\
\hline Nun"series & 3 & 4.0 & & & \\
\hline Orange tree & 2 & 2.7 & & & \\
\hline Rice & 2 & 2.7 & & & \\
\hline Sugar cane & 1 & 1.3 & & & \\
\hline Cashew mut tree & 1 & 1.3 & & & \\
\hline cotton & 1 & 1.3 & & & \\
\hline
\end{tabular}

Source: Field research data

Table 7.6: First producers and suppliers as innovators - distribution according to production activities and with respect to regions

\begin{tabular}{|c|c|c|c|c|c|c|c|c|}
\hline & Zone1 & Zone2 & Zone3 & Zone4 & Zone5 & Zone6 & Zone? & Total \\
\hline Vegetal production & 6 & 2 & 3 & 4 & 4 & 2 & $\mathbf{1}$ & 22 \\
\hline Market gardening products & 3 & 2 & 1 & 3 & 0 & 1 & 0 & 10 \\
\hline Soybeans & 0 & 0 & 0 & 0 & 3 & 1 & 1 & 5 \\
\hline Perfuntued Rice & 2 & 0 & 0 & 0 & 1 & 0 & 0 & 3 \\
\hline Sugar Cane & 1 & a & 0 & 0 & 0 & (1) & 0 & 1 \\
\hline Pinexpple & 0 & 0 & 1 & 0 & 0 & 0 & 0 & 1 \\
\hline Mursery (Gardnen) & 0 & 0 & 0 & 1 & 0 & 0 & 0 & 1 \\
\hline Banana (on large surface) & 0 & 0 & 1 & 0 & 0 & 0 & 0 & 1 \\
\hline Livestock & 3 & 1 & 1 & 3 & 7 & 0 & $\mathbb{\|}$ & 16 \\
\hline Layer hens & 2 & 0 & 1 & 3 & 2 & 0 & $\mathbb{1}$ & 9 \\
\hline Broilier hens /cackerel & 0 & 1 & 0 & 0 & 2 & 0 & 0 & 3 \\
\hline Bigpigs & 1 & 0 & 0 & 0 & 2 & 0 & 0 & 3 \\
\hline Rablbits & 0 & 0 & $\theta$ & 0 & 1 & 0 & 0 & 1 \\
\hline Processing & 0 & 2 & 0 & 3 & 0 & 0 & 4 & 9 \\
\hline Special sorap & 0 & 0 & 0 & 1 & 0 & 0 & 3 & 4 \\
\hline Clloths dyeing & 0 & 1 & 0 & 0 & 0 & 0 & 1 & 2 \\
\hline Inmproved Gari & 0 & 0 & 0 & 2 & 0 & 0 & 0 & 2 \\
\hline Arvirnal feeds & 0 & 1 & 0 & 0 & 0 & 0 & 0 & 1 \\
\hline & 9 & 5 & 4 & 10 & 11 & 2 & 6 & 47 \\
\hline
\end{tabular}

Source: Empiricalifield research data 


\subsubsection{Integrated production practitioners as Innovators}

One of the activities that make Songhai an innovator is the successful introduction and application of the notion of integrated production system. To recall, the integrated production consists of carrying out production activities which reciprocally provide inputs to each other. The inputs may be, depending on the cases, a final or semi-final product. Crudle cassava or maize grains can be used to feed cockerels and pigs. Soya and maize grains are ground together with other products to feed livestock. While the plant penicetum is, for example, produced to feed grass-cutters, many farmers cultivate vernonia with the prime objective of feeding fowls to prevent and treat parasitical diseases. Indeed, vernonia is a human-consumable vegetable, which is also highly appreciated in daily diets (in Benin). In some cases, the exchanged inputs are simply wastes that would otherwise serve no positive purpose. Whatever the forms of these exchanged inputs take, the integrated production makes the farmers less dependent on some inputs they would have to buy. It also allows them to produce at lower costs while using cheap but more qualitative inputs, which are environment friendly. Indeed, a basic principle of the integrated production is the exploitation of local resources. The integrated farming producers bear in mind the fundamental principle underlying entrepreneurship: the search for profitability. So, how and what farming activities the Songhai entrepreneur farmers actually integrate?

Integrated production system results from the production objectives a farmer has set. It consists of calculated interactions the farmer intends to create between different activities given various social, economic and technical factors. These factors shape the starting point of the system. Indeed, some activities need to mature before they can provide inputs to others. At the same time, some activities can very early (before the time of the main and expected outputs) become a regular source of inputs. The integrated production system implies that an initial activity could be set just in order to provide raw materials for the further ones. Expected outputs from a secondary actiwity may be intended to complement the existing one. Within the same understanding, the need to exploit wastes from ongoing activities may motivate the creation of a profitable one. Having previously analysed the main production areas Table 7.5 of the farmers, it: becomes easier to picture the framework of their integrated systems. The interactions exist between crop and livestock productions as shows Table 7.7.

Many farmers produce different crops while also rearing various mammals and fowls. On the other side, while some farmers specialise in only vegetal 
production or processing, others found it more appropriate to rely just on livestock. Thus, the attempt to determine the number of famers involved in integrated production systems, confronts double counting. Should a farmer producing, for example, maize and cassava in combination with pigs and layer hens, be rated as four farmers for carrying out maize-pigs, maiza-layer hens, cassavapigs and cassava layer hens? To avoid this problem, the analysis distinguishes the number of innovators farmers from the number of innovations. If the same innovation, maize-layer hens is been carrying out by five different farmers for example, each of the farmers is innovating, and the analysis considers all of them as inmovators. If one single farmer is producing market gandening-poultry, mizepoultry and cassava-pigs for example, the analysis records the farmer as innovator only once. The column entitled TIF registered the number of farmers involved in that production.

Table 7.7: Distribution of farmers engaged in an integrated production system

\begin{tabular}{|c|c|c|c|c|c|c|c|c|c|}
\hline Integrations & TIF & Zonel & Zone2 & Zones & Zome4 & Zones & Zome6 & Zone 7 & Total \\
\hline Market garden-Poultry & 11 & 3 & 2 & 1 & 2 & 0 & 0 & 0 & 8 \\
\hline Market gardem-Pigs & 6 & 2 & 1 & 1 & 0 & 0 & 0 & 0 & 4 \\
\hline Market gard-Grass-cutters & 1 & 0 & 0 & 0 & 其 & 0 & 0 & 0 & 1 \\
\hline Maize-Poultry & 19 & 3 & 3 & 1 & 0 & 0 & 0 & 0 & 7 \\
\hline Maize-Pigs & 10 & 0 & 0 & 0 & 0 & 1 & t & 0 & 2 \\
\hline Maize-Grass-cutters & 2 & 0 & 0 & $\mathrm{O}$ & 1 & 0 & 1 & 0 & 2 \\
\hline Soya-Poultry & 4 & 0 & 2 & 0 & 2 & 0 & 0 & 0 & 4 \\
\hline Soya-Pigs & 1 & 0 & 0 & 0 & 1 & 0 & 0 & 0 & 1 \\
\hline Cassavaw Poullty & 10 & 0 & 1 & 0 & 1 & 0 & 0 & 0 & 2 \\
\hline Cassava-Pigs & 10 & 0 & (1) & 0 & 0 & 2 & 0 & 0 & 2 \\
\hline Cassava-Rabbits & 1 & 0 & 0 & 0 & 0 & 1 & 0 & 0 & 1 \\
\hline Pineapple-Poultry & 4 & 0 & 2 & 0 & 2 & 0 & 0 & 0 & 4 \\
\hline Pineapple-Pigs & 1 & 0 & 0 & 0 & 1 & 0 & 0 & 0 & 1 \\
\hline Banana-Poultry & 2 & 0 & 0 & 0 & 0 & 2 & 0 & 0 & 2 \\
\hline Oil Palm-Poultry & 1 & $\mathbb{1}$ & 0 & 0 & 0 & 0 & 0 & 0 & 11. \\
\hline Total & 83 & 9 & 9 & 5 & 10 & 4 & 3 & 2 & 42 \\
\hline
\end{tabular}

Source: field research data

The analysis reveals that, according to a factor-integrated production system, 42 farmers are innovators. Each of them is found carrying out, as main activities, at least two linked productions. Statistical accounting shows that $19 \%$ of these 
innovators link market gardening production with poultry (layer and broiler hens, cockerels, turkeys and ducks) while $16.7 \%$ combine maize with poultry productions. The same share of farmers $(9.5 \%)$ carries out the following combinations of market gardening-pig, soya-poultry and pineapple-poulty. Then follow maize-pig, maize-grass-cutters, cassava-poultry, cassava-pigs and bamanapoultry sharing each and equally $4.8 \%$ of the innovators. The input contributions these production fields receive from each other alone do not make farming. Other mearis of production including tools, machines, techniques and know-how are also vital.

\subsubsection{New Technology Users as Innovators}

This paragraph reports on how the training has influenced the adoption of certain technologies, and 49 farmers have declared that they are using various new methods or techniques (regarding soil preparations, plant seedlings, animal cares, pest control, harvest, conservation, etc.) in the performing of daily or seasonal farming tasks. Respectively, 17 and 47 farmers have acknowledged the adoption of new crop varieties and new animal species. Organic fertilizer (compost) is made and used by 15 farmers, while cow-driven techniques and hired tractor registered respectively 6 and 4 users.

\subsubsection{Access to credit}

Financial assistance opportunities are apparently not alarming to Songhai farmers; 52 out of 75 farmers have benefited from financial assistance in the form of subsidies and credits from different sources. Songhai itself has been the main financial assistance provider. It has granted 23 credits, 11 subsidies and 7 financial assistances combining credit and subsidies and, all in favour of 28 farmers. Indeed, farmers that have demonstrated good performance after a first credit or subsidy were entitled to another. A set of 24 farmers were able to grasp finances from diverse sources of which PISEA (Programme d'Insertion des Sans Emploi dans l'Agriculture), PADME (Projet d'Appui au Développement des Micro Entreprises), CLCAM (Caisse Locale de Crédit Agricole Mutuel), CARDER (Centre d'Action Régionale pour le Développement Rural) and FEDIBA (Fonds. d'Entraide et de Développement des Initiatives à la Base). These institutes granted respectively $13,7,3,2$ and 3 financial assistances in forms of credits. among the study sample. Further, four farmers declared been financially supported by foreign institutions located in Benin (American Embassy) and others outside the country. In sum, 74 subsidies and credits were granted to 52 
farmers from almost ten different sources. Out of the remaining 23 farmers that have never had access to financial assistance, 9 claimed that they deliberately rejected credit opportunities offered to them. Seven of these farmers appeared credit averse: "I don"t like credit; I hate being indebted; I don't think one can succed in farming enterprise when he begins with bearing load of credit..." Others would highly appreciate boosting their activities using credit but affirmed that many credit conditions do not match with farming activities. Actually, only 14 farmers were found who did not yet have access to any financial assistance.

\subsubsection{Job creation}

Generally speaking, the labour force engaged in agriculturel includes farmers; stock raisers; farm managers and foremen; farm labourers; the personnel of establishments primarily engaged in custom threshing, ploughing, silo filling, hay bailing, chicken hatching, egg grading, seed cleaning, etc.; and the personnel of establishments engaged in tree pruning, tree spraying, tree surgery, landscape gardening and flower growing, etc. In the framework of the study sample characterised by nascent farming enterprises within the global context of developing country agriculture (acute lack of mechanisation and other agricultural infrastructure facilities), farm labourers are the most needed labour force. Seasonal recruitment is the primary means of obtaining agricultural labour; then follows some permanent positions.

\section{Box 7.3. Labour force matters}

"I live in a region where fishing dominates over all other activities. It constitutes the main source of income and food for the local populations. This however, does not exclude the practise of crop production or animal husbandry. When people need cash money, they can choose between going for fishing or working on somebody's farm. In my case, very harcly I can afford to pay 1000 FCFA $(1.5256)$ per day to a labourer while it is easier for him to gain such money from fishing. In the worst situation, he can have fish for food with his family. Thus, it is the lack of an agricultural labour force that currently constitutes the major problem 1 face. Physically and alone, I cannot do much. I am not progressing as I thought. I cannot satisfy the demand for banana plantains $1 \mathrm{am}$ the only large producer in the region. Can a researcher like you help acquire agricultural machinery?

Sossa Codjo (32 yearis) is setled in the Mono region.

1 Agricultural Labour Force and Services, Natural Resources Canada. The Atlas of Canada, 2004. hetp:/atlas gc.ca. 


\section{Box 7.4: Credit and agricultural production cycle: some mismatches \\ "Credit settings do not match with agricultural production cycles while Micro finance institutes appear insensible to farming concerns"}

"Except from PISEA, almost all other micro finance institutes grant credit for a maximum duration of 12 manths. Moreover, the reimbursement of the first instalment begins 30 days after the cash is withdrawn. When a farmers' association tried to negotiate with them, they have accepted to bring the reimbursements forwards by three or six months. But in any case, the farmer has to reimburse the whole credit within 12 months. These kinds of credit conflict with our investment plans. The worst is that credit institutes appear insensible to farming concerns, they consciously ignore agricultural production realities. When a farmer remains powerless against climatic hazards such as inadequate rains (insufficient or too much) leading to very bad harvests, and about which they are aware, they do not want understand. When a farmer remains helpless against an epidemic disease, such as swine fever, credit institutes however, still claim the immediate reimbursement:"

Farmer TNZT

\section{Some Effects of Assessment Needs: "Credit Agents Biother Too Much"}

"I was told about credit opportunities and I deliberately declined the offer because I witnessed the aftermath issues. Credit agents bother too much with questions. They regularly come, at least quarterly, to see the evolution of the farm activities. They bring with themselves long questionnaires with all kind of cameras recording and taking pictures. They talk too much and have a tendency to put on their only asset the whole effort we made as if their money itself and alone could have any multiplying effect. They can visit you on a market day, on sowing day or on the day you are performing an important task. The day they come, becomes sadly a wasted day. Moreover, they want give advice on things that do not fall under the sphere of their expertise..."

Farmer FNZO

Of the farmer sample, $63(84 \%)$ mentioned that they employ approximately 606 seasonal workers per year. The most demanding activities relates to crop production to perform tasks such as clearing weeding and harvesting. The duration of employment depends on farm size, the number of workers the farmer can find at the recruitment time and the difficulty of the tasks. At the same time, 
the extent of employment requirement depends on location, the tasks to perform and the availability of the labour force. Under such circumstances, nine farmers claimed that they acutely lack labourers in the due seasons. Different factors explain shortage of seasonal farm labour. In Box 7.3, a farmer shares his concrete case.

On the other hand, farmers engaged fundamentally in animal husbandry or an integrated production system, need permanent employees. Gathering ingredients required for making animal feeds, animal care and other family concerns are time consuming. For example, producers of fowls point out that ${ }^{\text {at }}$ at their early age, the chicks require permanent supervision that keeps them out of other necessary tasks. Of the sample, 23 farmers employ 45 permanent workers added to the average 9.6 seasonal labourers per year. In effect, many farmers with permanent employees also use seasonal labour. Permanent job creation in small-scale agriculture implies that the production activities generate regular: income on a daily, weekly or monthly basis, at least. It also requires that the activities carried out have, theoretically, high rates return to investment. It also means successful commercialisation of the goods and services that are produced.

\subsubsection{Surmounting competition: access to output markets}

Innovation is the tool that entrepreneurs use to solve problems, create what people really need or value and generate profits to fund the production cycle. An agricultural entrepreneur farmer's capacity to innovate goes beyond a mere ability to adopt new technologies. Thus innovation has been also defined as the act of starting something for the first time, the act of introducing something new to a given market and the ability to master the main factors of production. Innovation is also about improving productivity and being more efficient. The ultimate test of innovations is the market. The ability to have the needed share on the existing markets or to exploit new market opportunities is also innovation, by definition. The analysis thus examines the innovativeness of the farmers with respect to factor market (competition).

The farmers were asked whether they are facing competitors on the market place regarding the commercialisation of their productions. They are also asked to explain how easy or hard it has been to sell their productions. Of the sample, 68 farmers acknowledged the existence of many producers and importers on their respective markets. However, 53 of these farmers admitted that they easily sell their products despite the competition. They stressed that the quality of their 
products warrants their success. Ten farmers have acknowledged that they hardly sell their productions. The main competitor farmers producing eggs in zone 5 are facing is Songhaï itself. In effect, Songhai has enormous and, even, underexploited production capacities on its site of Savalou. According to the farmers, ather competitors are, mostly, importers of market gardening products from neighbouring countries, mainly Nigeria and Togo.

\subsubsection{New ways of sourcing and harnessing information}

The farmers that were interviewed recognised that most of the knowledge and understanding necessary to operate farming business functions is not unique and that specific knowledge such as market fluctuations or environment related issues tends to be a permanent need. They mentioned that they constantly sought to learn and improve; and they recognised that a good way of doing so was by means of knowledge-sharing through relationships. They seek to build relationships with all those who can bring valuable insights to the development of their farms. They are involwed in agricultural professional associations and trade bodies, either at local, regional or national level, or with their peer Songhai farmers and other surrounding farmers. Because they are said to be agents of development, the farmers also create a favourable environment for knowledgesharing with local communities.

In general, farmers usually gather or create various associations when there is a need or when opportunities arise for some public, NGO or project "cake" sharing (Nzamujo, 2002). These sorts of village or farmers' associations last as long as a special government programme, or a given development project is still running. Under such a framework, the farmers' associations or groups break with the end of the "cake". But when the challenge is to sustain their businesses and succeed in their activities, when changes in mentality (ways of thinking) added to the new values and work ethics propelled farmers to build their own network of information and knowledge sharing, this mechanism deserves to be called innovation. Actually, piercing new ways in harnessing knowledge in a coherent and productive way is an innovation. When farmers begin to initiate contact with researchers, and when they know what information and knowledge they need and for which purpose and when, something new is happening, moving and pushing. A number of facts support the statements. 
Box 75 . They don't learn how to commercialise what they leath to produce

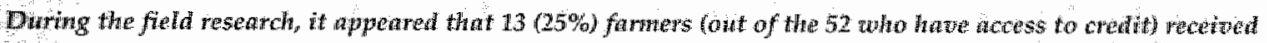

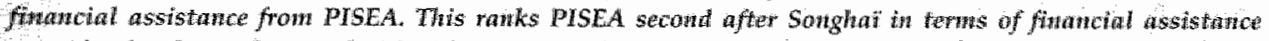

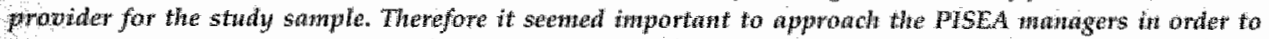

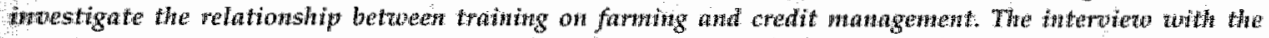
National Deputy Coordinator is reported below. it was also possible to consult an evaltathon report (afiut four years of activity of PISE:A).

What wearrants the intportance that PISEA assigns to the training of its clients (constituted of promotors of ngricultural enterporists)?

PISEA: A promoter does not need to be a highly qualified agricultural protessional, but a minimum Kknowledge in farming is required. PISEA evalinates a promoter based on his technical and managerial capacities. He must prove that he has practical knowledge of activities related to the project for which he is requesting financial assistance. Beariog this in mind, PISEA granted credits to mone promoters trained athe Centres de Promotion Rame (CPR) than plamed (160\%). Indeed, a necent ewaluation shows that wint four Years of activity, IISEA funancially supported 96 promoter from the CPR against 60 planned. PISEA also granted credis that allowed $276(69 \%)$ jobless young people, instead all 400 plamned, to set up an agricultural business. Finally $212(106 \%)$, against 200 planned, already existing businesses, and which hotd projects on farming, were supported by PISEA.

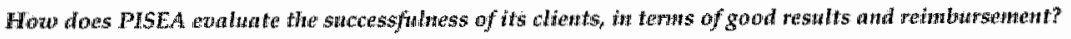

PISEA: An ewaluation/assessment made by an international company (Syd Group - Afrique Negoce Consell) dassifies the businesses funded by PISEA into four categories based on given performance indicators (level of productivity, thechnical knowledge and technology use, level of organisation and mastering agricultural enterprise management techniques, level of incomes and profits, and reinbursement of credtits). It found only $18 \%$ as well pertorming and $32 \%$ as relatively good functioning enterprises. The remaining, $24.4 \%$ and $23.6 \%$, fall respectively into the categories of hardly standing and unsuccesstul (stop working) enterprises. The evaluating company named the following as the main factors of success:

- The good command of production and nanagement tediniques by the promoters.

- The use of qualified labour torce.

- Regular and proximty of followisp.

factors that have led some promolers to failure comprise, basically, the lack of experience and insutficierit knowledge in agricultural entrepreneurshp and the lack of adeguate command of production and management technques. Based on these findings, the assessment mossion made the following recommendations among which the following concern the agricultural enterprise promoters:

- Providing training and upgrading credit to recipients in management and production techniques related to their diomains of undertaking.

- Organising exchange visits between successfull and hardly going promoters.

- Prioritising financing to promoters with experience in agricultural production.

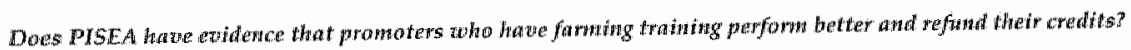

PISEA Credit refunding depends essentially on two factors including success in the undertaken activities and goodwill of the borrowers. So far, PUSEA reconded a rate of refunding of $36.23 \%$. Understanding that your question relates to factor success, the answer is simple. PISEA believed that young people trained at the CPR could perhorm better and reimburse their loans. Sumprisingly, this was not the case. Ar the CPR they learned only how to produce; they didn't learn how to commercialise their products. The CRR promoters pride themselves on hawing large fams but they usualyy fail at managing them. They have foo many shortcomings in activity planning and in marketing their productions. This is due to the type of training that is prowided to them. 
Of the sample, 61 farmers have claimed membership in the RENAFERS (Reseau National des Fermiers Songhaï-National Network of Songhaï Farmers), 65 $(86.7 \%)$ acknowledged personal relationship with local farmers, while $37(49.3 \%)$ notified that they are members of various farmers' association either at local, regional or national level. Out of the 75 farmers, $30(40 \%)$ have more or less regular contact with researchers (from INRAB- Institut National des Recherches Agricoles du Bénin, CARDER- Centre d"Action Régionale pour le Développement Rural, FSA - Faculté des Sciences Agronomiques and IITAInternational Institute for Tropical Agriculture) and other specialists (such as veterinary and credit specialists), and $31(41.3 \%)$ farmers have relationship with various exporters of agricultural products (pineapple, cashew nuts, soybeans, maize, cassava, yams, etc.). Out of the 39 farmers knowing about the Chamber of Agriculture of Benin, II claim its membership. The farmers stressed that they search for other sources of knowledge if the problem or the task at stake, technically, lies beyond the framework or competencies of the local coordination of the RENAFERS as conveys Box 7.6.

\subsubsection{Farming enterprise function against farming production function}

If the farmers were subjected to almost the same conditions during the training programme and are expected to perform more or less equally, they face diverse social and economic situations after graduation. Differing personal interests, heterogeneity in output markets and unequal access to resource inputs added to natural environment explains the observed variety of crops and livestock produced. For the entrepreneur farmers, this means that production decisionmaking does not depend only on quantifiable variables like those determining production functions. Hence, the viability of production activities depends more on a mixture of factors, both quantitative and qualitative. This subsection postulates that the farmers themselves capture better the extent to which different factors affect their businesses. This leads to farmers' enterprise function as determined by the farmers themselves. It is different from agricultural production function, which does not capture the farming in its dynamics. The premise of this work is an empirical procedure for capturing flexible agricultural production viability as viewed by the farmers themselves. 


\section{Box 7.6: Farmers piercing new sources of information and knowledge}

We started many activities through talking to one another and we share knowledge and ideas to generate and inspire thoughts on how to solve particular problems. This happens through individual liberal visits, group visits or through the quarterly meetings of all Songhail farmers in the zone/region. The quarterly meetings take place on the different farms on a rotary base. The meetings usually begin with new information, if there is any, from Songhai or from the national committee of the RENAFERS. The locall coordination committee and also any farmer bring news from the region. The news may relate to market fluctuations (changes in prices, imput and output market opportunities》, new technologies or financial assistance prospects.

After this opening section, the nominated farmers (for the session) are invited for a presentation, either on their successful experiences or on their failure. We seek to understand which factors and how and why they came to affect the issues described. The cases of failure serve to warn other farmers and keep them abreast againsk falling into similar situations. Successful experiences aim at encouraging and inspiring new ideas for strengthening right deeds or correcting ongoing errors. In all cases, we try to situate responsibilities: the role various factors (the farmer him/herself, technology, economy, society or natural environment) have played in shaping the concerns. We seek for solutions and bring advice.

Participants are allowed to raise particular social (conflict with other farmers), economic (lack of adequate cash money to respond to specific activity requirements) or technical problems. The Ouemé regional coordination, for example has a specific credit line for which the members can apply in acute circumstances. The amount of credik with an interest rate of $5 \%$ per year, waries between 10,000 CFA and 50,000 FCFA. (15 $\in$ and $76 €$ ). Other interesting relationships tie the farmers to local peasants.

In a group or individually, we have been developing valuable relationships with the peasants of our surroundings. We reciprocally share experiences. At the beginning, the peasants usually nurture on in-dept social and cultural issues of the localities, given that not all of us are established in their native villages. In addition, the peasants help us in finding rural labour force. On our side, we usually invite them to our farms so that they can observe and appreciate differences in farming practices and consequent results. They are very curious, and raise many questions. We provide them, depending on the case, either theoretical or practical answers. Our most frequent and important contributions to their activities, rest essentially, clepending on the case, on animal cate services or crop farming practices. The peasants are always delighted to share their knowledge with us.

The need to present a business plan and successfully defend it as part of final examinations at Songhai has led us to familiarise ourselves with "how to search through books and other publications. In effect, many of us have various scientific publications from CTA (Centre for Tropical Agriculture) based in the Netherlands. Moreover, thanks to our relationships with warious researchers and specialists, we gain important knowledge through the books we easily borrow from them. Before we return the books, we prepare a number of questions and try to arrange a discussion meeting with them in order to have explanations on things we could not understand. We also do ask them about new trends in agricultural innovations, and we are usually curious about the concerns of their work.

Consequently, many researchers find it easier to test their research results on our farms while, at the same time we benefit from their experiences. In addition, we appear the best partners for European and American students coming for field research on farming in Benin. Their stay on our farms, unquestionably, brings both sided advantages. We get to know something more and others allso will know about us. 
During the tête-â-tête interview, the farmer was asked to rank five factors according to the importance of the contribution of each of them to the evolution of his activities. More concretely, to begin with, and then progressively, the interviewer asked the farmer to name (from the remaining) the factor that has helped him the most in reaching actual results. These factors include technical knowledge, access (availability or amount) to investment/financial capital, access to input and output markets and information networks. At the beginning, a short definition and explanation of the meaning of each term was provided to the farmer. The goal is to warn him and help him provide an answer as objectively as possible. The interviewer always tried to find a counter example to challenge the farmer's first answer and then asked him to think more and provide the ranking. The farmer is warned, for example, that because of the lack of money, many Songhaï graduates could not set up their own farms; so acquiring technical knowledge is not enough. At the same time, he understood that having money without appropriate agricultural knowledge and inputs or enough market shares, production results are very meagre. He also acknowledged that without information from various sources, one cannot achieve many things.

a) Technical Knowledge: It means all new agricultural knowledge (new techniques, methods and know-how) the farmers have acquired during the training process. It covers vegetal and livestock production as well as processing activities. Integrated production practices and management techniques are also included.

b) Investment/Financial Capital: It simply means access to all sort of financial assistance, no matter the source, which could be familial subsidies or credit, Songhaï subsidies or credit and other national and international sources of credits or subsidies.

c) Input marke:t Accessing the desired quantities and qualities of many production inputs within the required period of time and at reasonable prices/costs, is not always possible for the farmers. A farmer mentioned how he delayed to start his farm with pig rearing after he borrowed money to build required infrastructure and endeavoured to ensure initial animal feeds for the first three months. Unfortunately, Songhai, the main supplier of these animals and on which he counted could not satisfy the demands of all its former students. Finally, the real start-up of the project delayed almost six months and he got only the half of the number he requested. Other farmers referred to the higher transport costs of input supply to villages when compared to those undertaking in the suburbs of cities or are closer to cities.

d) Output market: Conquering a market or having an adequate share in a market place constitutes a key factor for successful entrepreneurship. Producing and 
supplying products that meet market demands is a deal for entrepreneurs. Timing production so that the outputs can meet the specific events during which demands increase is also important. Finally certain products are region or area specific with respect to either size of markets or consumption habits of the people.

e) Information network: Constitutes all sources of information the farmer has through his personal involvement in relationships with other individual farmers and farmers' associations. It also includes his/her knowledge of various institutions and other individual professionals with which s/he has useful contact in the framework of farming undertakings. The information network also defined as social capital (Zepeda, 2001) measures the ability of the farmer to utilise social networks and institutions to get information and knowledge about imput and output markets (which market places have or need what and at which prices), potential sources of credits and existing bodies of agricultural and related professionals.

Figure 7.4 exposes the farmers" "enterprise function" with respect to the above listed factors. It clearly shows how the farmers value the positive contribution of these various factors to their businesses. The most important contributing factor: is ranked number one, the second-most contributing factor is ranked number two, and so on. The farmers were not asked to make a general assessment of how these factors may contribute to the development of a farming enterprise. Instead, the assessment provided by a farmer rests, de facto, on only the framework of his/her personal activities, given the social, economic and natural environments in which s/he operates.

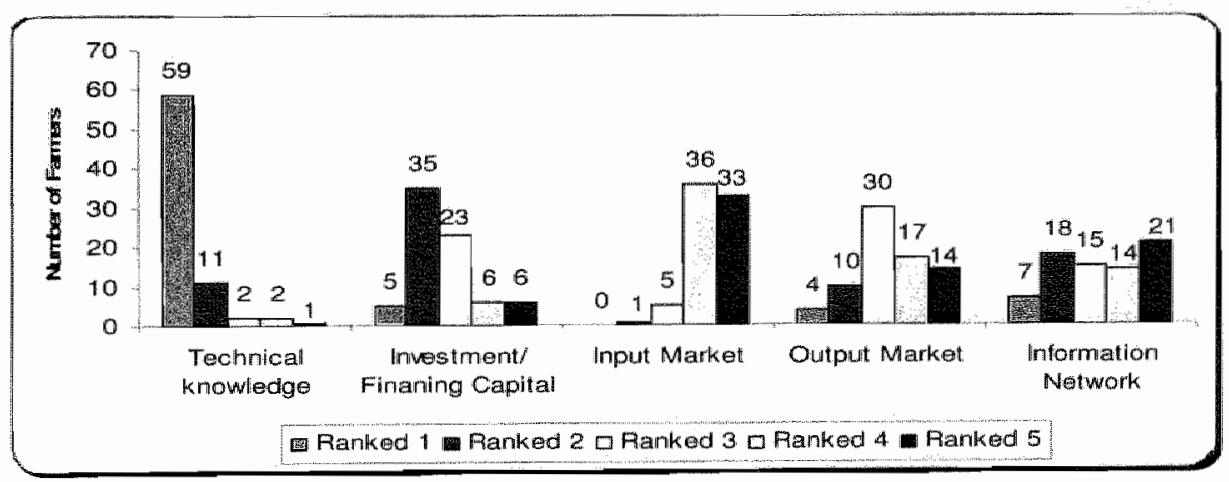

Figure 7.4: Materialising farmers' enterprise function 


\section{Box 7.7: Born entrepreneur or trained entreprenewr?}

The wez knowledge I have acquired propelled and motionted me to dare to innowate. Only in the field, after graduation, I happened to realise that the Songhai traiming is actwally outstanding. The technical aptitudes gatned assign faster understanding of my business with linited risks while opperafing in a highly multipnrpose

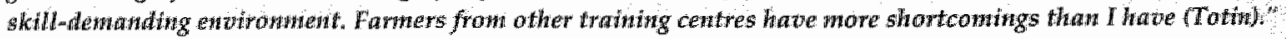

I am Mathas Toth, 33 years old agricultural entrepreneur. Ten years ago, I was pushed by the economic situation of my fatier who is T\&V agent to leave school. I specialised in mathematics and physics and was just a few months: short of the ggeneral entrance exams for university. I began to farm using awailable familly land (belonging to my father) when one day I heard about Songhai on the radio. It attracted me, so I chose to go there. I had information about the existernce of other traning centres, but I didn't know much about them. My expectation was to gain the pronised knowledge as advertised and to be able to get a return on it. I need to admit that I found the training: process very difficult, but was encouraged permanently by my family and friends throughout the two and half years.

After graduation, my mother gave me $80,000 \mathrm{~F}$ CFA (1220) while my father allowed the exploitation of a portion of his land. I started with the production of market gardening, which is a common activity in my region. From there, I decided to innovate with the production of quail eggs that Songhai was the first to introduce in Benin. The kechniques of rearing this bird could be acquired only at Songhai. These eggs which were unknown in the country have a therapeutic virtue of healing asthma. I chose to market them through hotels, restaurants and bars. Within a few months the diemands increased and I needed to expand my production capacities. I turned to my father for more (200 $\mathrm{M}^{2}$ ) of land but he didn't understand me and refused. He thought I was claiming my share of heritage while he is still aliwe. Indeed, he is polygamous with many children.

In order to satisfy the demands I became an intermediary, or a sort of middle-man between the other (wery few) producers and my dients. It followed that I hired a small office with a secretary who received the orders in my absence. While operating this way, I realised that some quail eggs producers were also involved in market gardening and meed seeds. Through a friend, I got to know a supplier in Japan and from which I imported very good seed and easily adaptable to our climatic conditions. Because I didn't have enough money to buy in larger quantities, the Japanese conceded the exclusive deal to a French business man (located in France) and who had to supply Benin wia a representative company the established. When my profit margin drooped to $10 \%$, I abarndoned the business and thrned to retail trade in the commercialisation of animal feeds.

In the process I noticed that some of my clients who are involved in fowl production mainly layer and broiler hens, import the chicks from Nigeria and France. The only local producer was not performing well. Then, I sought and tound through the internet a Belgian producer of one-day chicks. The annual average imports approximate 300,000 chicks while in 2003, the total import reached 390,000 units in absolute number. This Belgian supplier contacted me with animal feed producers in the Netherlands who, currently, supply me. Because at Songlaail the technical knowledge I have acquired grants me capacities for composing certain animal feeds, and in order to exploit sone of the existing local raw materials, I decided to create a unit for animal feed production. At present, I own the biggest animal feed production unit in Benin.

The animal production unit the animal feed store and the store for raw materials are concentrated in the same place. The objective is to reduce the production cost of animal feeds. Indeed, rarely a farmer can produce all the raw materials he needs to compose the feed for his animals. Usually the farmers buys the raw materials at one place, transport them lo another one for grinding and from there to his farm. Farmers that have training know the ingredient composites of the feed they need. They bring they own formulas and made the feeds. Those who arte engiged in the business because of the capital they have need our assistance. We make the feeds for them according to a specific formula based on the species and the age of the animals they produce.

Currently, I have ten permanent employees and I use more than 100 occasional ones every year. The total turnover of my enterprise in the year 2003, was 495 millions F CFA (754,6246), leading to an annual average growth rate of $248.05 \%$ of the initial capital $(122 \mathrm{6}$. However, during the first semester of this year, that is to 30 June 2004 it readned $378,000,000 \mathrm{~F}$ CF $4(576,258 \mathrm{E})$. The current evolutions give right to expect between 800 millions and $900,000,000 \mathrm{~F} C \mathrm{~F}$. $(1,220,0006$ to 1,372,0006). Honestly, Il would not undertake such business and then perform as I actually do without been trained at Songhai. The biggest problem I have relates to very high transport cost charged by Air France, which holds a monopoly position as SABENA and SwissAir collapsed. 
Technical knowledge is considered as the greatest contributing factor and ranked number one by 59 farmers. It is followed by information network, to which seven attributed the most significant value and ranked it first. While no farmer viewed input market as the most important factor, five and four respectively qualified investment/financial capital and output market as playing the first vital role. It is surprising that only five farmers placed financial assistance at the first place, even, behind information network. Respectively, 35, 18 and 11 farmers ranked as second investment/financial capital, information network and technical knowledge. Only one and ten farmers ranked input market and output market as the second most important contributing factor to their businesses. Again, like in ranking first, the information network factor holds second place in ranking as the second-most valued factor. This corroborates with Carl Menger (1840-1.921 as cited by Lynskey, 2002) who saw entrepreneurial activity as including how to obtain information about the economic situation. The Songhai farmers have been able to experience the importance of this factor in business and this would give right to Norton, Jr and Moore (2002). They drew upon the Bayesian model and argued that entrepreneurs are not risk takers, but rather they assess risks differently from non-entrepreneurs. The Bayesian model. asserts that differing assessments of prospective outcomes may be attributable to differences in prior information. Entrepreneurs make decisions by coupling prior knowledge with current or prospective data.

Output market, investment/financial capital and information network took the leadership with respectively 30,23 and 15 farmers attributing to them rank three. Factors technical knowledge and input market seem not to deserve ranking third most important inputs; only two and five farmers qualified them so. For the first time, input market appears dominating; thirty-six farmers put it the fourth most vital contributing factor. Output market, information network, investment/financial capital and finally technical knowledge followed respectively with 17,14 , six and two farmers considering them as the fourth farming activities development factors. The number of farmers, who have qualified input market as the least contributing factor to their farming enterprises, is 33. Information network and output market followed respectively with 21 and 14 farmers putting them to fill up the rank. While five farmers thought that investment/financial capital has contributed the least to their undertakings, there was one farmer to whom the technical knowledge brought the least. This global description gives insights into what could be called "farmers" enterprise function". 
The farmer enterprise function is a qualitative variable that depends on the five explanatory factors as mentioned above. It does not express the quantity of different input factors required to produce a given level of output. The concerns transcend mere production issues per see. The farmer enterprise function aims to show the proportion in which the key factors in interaction with one another enhance, at least, modestly agricultural entrepreneurship through complementary innovative actions. An arbitrary number from 5 to 1 is associated to each rank-one to rank-five, and a sum is made up of the total points deriving from all rankings associated with each factor. This computing method would attribute a total point of $\left\{\left(59^{*} 5\right)+\left(11^{*} 4\right)+\left(2^{*} 3\right)+\left(2^{*} 2\right)+\left(1^{*} 1\right)=350\right\}$ to factor technical knowledge. The obtained results are plotted on figure 7.5 below.

Technical knowledge is the factor that the farmers valued the most. With 350 total points, it is responsible up to a scale of $31.1 \%$ of the overall evolution of the farming enterprises. It is followed by investment capital, which has totalised 252 points. In terms of percentages, its contribution is rated as 22.4 , much below technical knowledge. More surprising was the number of farmers who put this factor at the second place: 36 farmers (48\%). Though it is the highest number of farmers ranking it second, this number is still less than half of the total respondents. Also, it holds second place in ranking as the third-most supporting factor. The computing grants 201 points to information network, meaning that it has been estimated by the farmers as the third-most important factor that has affected their businesses. Relatively, it accounts in a ratio of $17.9 \%$ before input and output markets which filled up the rank with respectively $17.6 \%$ and $11.0 \%$ effects.

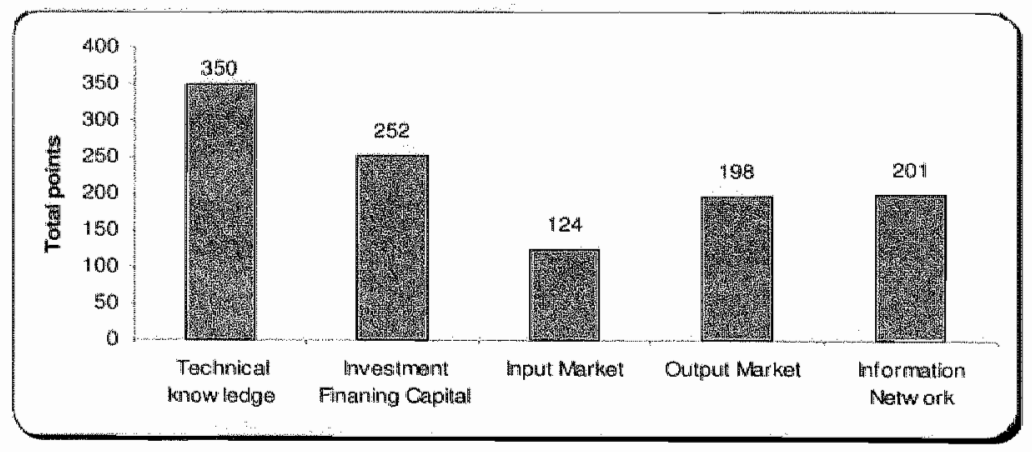

Figure 7.5: Materialising farmers' enterprise function continued 


\subsection{Discussion and Conclusion}

Skills and knowledge are the engines of economic growth and social development (ILO, 2001). The Songhai learning/training programme on skills, knowledge and agricultural entrepreneurship has also become a means of employability. For those who for certain reasons will not undertake their own farming production, it will serve to enhance their mobility in the labour market and offer the potential for increased career choices. Defined broadly, employability is a key outcome of education and training of thigh quality, as well as a range of other policies (ILO, 2001). It encompasses the skills, knowledge and competencies that enhance a worker's ability to secure and retain a job, progress at work and cope with change, secure another job if she/he so wishes or has been laid off, and enter more easily into the labour market at different periods of the life cycle. Individuals are most employable when they have broad-based education and training and basic and portable high-level skills. The entrepreneurial training we have examined have equipped many trainees (about $40 \%$ of graduates) to find jobs and gain more money to constitute the capital for their future enterprise. But the main question the study tried to answer was whether those graduates who established their own farming enterprises have demonstrated behaviours that can be qualified as innovative.

The concept of innovation is broad and generally denotes commercial exploitation of something new or the exploitation of the new thing for commercial purpose. This specific character of innovation explains why the analysis placed it in its historical context of entrepreneurship. The argument is that whatever the source of any "new thing", it is through business mechanisms that it becomes innovation; the ultimate test of innovations is market. In the analysis, the terms business and enterprise, entrepreneur and entrepreneurship, have been used interchangeably. Hereafter, following Hull (2003) enterprise is a referent to the businesses individuals have set up and run. Entrepreneur is a reference to the individuals who set up these businesses. Entrepreneurship refers to the activity or practice of sustaining and growing the business (Hull, 2003). It is argued that the factors, which matter for agricultural enterprise, are those which matter for the business generally: access to input and output markets. What also matters is of course the information as a determinant of entrepreneurship and the attitudes of those farmers who formed and ran the farming enterprises.

Thus the study put on the ground of discussion two sets of issues. A first set comprises a number of factors (or actions), which are normal in the sense that they can be carried out by any individual. The analysis then explored whether 
the entrepreneurs/ farmers have demonstrated any behaviour toward them that could be qualified as inmovation. The elements of this set include access to land, access to credit or finances, and access to information networks. The second set comprises such factors (or actions), which are, by definition, innovations. The analysis examined how the farmers have exploited them through the demonstration of entrepreneurial skills they might have acquired at Songhai. Under this category of innovations fall integrated agricultural production, conquering new markets by being the first producer and supplier of given products, permanent job creation (in the context of agriculture in Benin) and the adoption of appropriate agricultural new technologies. What strengthens the analysis of farmers innovative behaviours is the associated notion of entrepreneurship.

a) As the result of the training, $52 \%$ of the farmers have proven bargaining skills enabling them to access the land required to set up their farming business (see 7.3.1)

b) Out of the total number of 75 farmers, $47(62.7 \%)$ have demonstrated innovative behaviour in terms of been alerted to perceive "an apple in a seed". They have been the first producer and supplier of certain vegetal, animal and processing products (see 7.4.1).

c) The empirical data shows that, according to factor-integrated production, $56 \%$ of the farmers have innovated (see 7.4.2).

d) Of interviewed farmers, $49(65.3 \%)$ acknowledged that they have adopted new agricultural technologies from new methods or techniques (regarding soil preparations, plant seedlings, animal cares, pest control, harvest, conservation, etc.) in the performing of daily or seasonal farming tasks (see 7.4.3).

e) Of the sample, 47 farmers (62.6\%) were found to be rearing animal species that are new to them and the markets they supply. They have definitely acknowledged that they would not be able to adopt the new animal species without the technical knowledge, management skills and bargaining and marketing competencies they acquired at Songhaii (see $7.3 .3)$.

f) Considering the general financial (credit to agriculture) market in Benin, the Songhai farmers have exceptionally demonstrated entrepreneurial and 
innovative skills in accessing this "golden" production factor. Financial assistance opportunities, apparently, are not alarming to them:52 farmers (69.3\%) out of 75 benefited from financial assistance in the form of subsidies and credits from different sources (see 7.4.4).

g) Concerning job creation, 63 farmers ( $84 \%$ ) declared that they each employ approximately 9.6 seasonal workers per year. This is normal in farming production. However, permanent job creation in small-scale agriculture implies that the production activities generate regular income on a daily, weekly or monthly basis, at least. It also requires that the activities carried out have, theoretically, high return rates on investment. That 22 farmers have 45 permanents employees is innovative (see 7.4.5).

h) Following Schumpeter, competition has more to do with innovations than prices. Of the sample, $68(90 \%)$ acknowledged the existence of many producers and importers in their respective markets. However, $53(70 \%)$ of them have been able to have the market share they need for their production. They have explained that the key of their success is, foremost, the quality of their products (see 7.4.6).

i) The Songhaï training/learning processes have led the farmers not only to value the importance of information, but also to recognise where, when, and how to obtain information. The farmers stressed that they search for other sources of knowledge or information if the problem or the task at stake, technically, lies beyond the framework or competencies of the local coordination of the RENAFERS. Out of the 75 farmers, 30 (40\%) have more or less regular contact with researchers from INRAB, CARDERS, FSA and IITA, and $31(41.3 \%)$ farmers have relationship with various exporters of agricultural products. Of the sample, $37(49.3 \%)$ farmers notified that they are members of diverse farmers' associations either at local, regional or national level while $61(81.3 \%)$ farmers claimed membership in the RENAFERS. While the relationships are not mutually exclusive, $65(86.7 \%)$ acknowledged personal relationship with local farmers (see 7.4.7). 


\section{Econometrical Analysis of the Empirical Data}

\subsection{Introduction}

A major concern in African agriculture is the question of how access to agricultural innovation can be improved for all categories of farmers. When attempting to answer this question, many institutional and organisational settings have failed to deliver promises of continued innovations. A common theme among these failures is a lack of understanding of the mixture of skills and socio-economic factors, which together form the power that creates value-added, thus, wealth. What this study makes clear is the multiple sources or determinants of innovations, which are, at the same time, sector and environment dependent.

This chapter supplements the empirical findings discussed in the previous one. It defines two innovative performance variables (dependent). They include the level of innovativeness (LINNOV) of the farmers and the trend of farmers' assets (TAF). It then looks at a set of factors likely to affect these variables within the farmers' business undertakings. To this end, some econometrical tests are used. After this introductory section, the second briefly describes and specifies both the sets of dependent and independent variables. Due to the difference in dependent variables two statistical models are considered. In the third section, a probit model is used to predict the likely effect the selected explanatory variables have 
on the dependent variable TAF. The fourth section examines the probable impacts of independent variables have on farmers LINNOV: To this end, the ordered probit model is used. In both cases the statistical package STATA completes the computations. The fifth and last section summarises through a discussion of the results.

\subsection{Specification of the variables}

\subsubsection{LINNOV of the farmers}

This study argues that agxicultural entrepreneurial training constitutes a major factor motivating agricultural innovations at farmers' level. The previous has given a picture of the innovative patterns of the farmers through the innovations they have adopted and their practices doomed to be characterised as innovations. Based on a broader definition of innovations, the field research has identified and retained a number of innovations, which have already been comprehensively discussed and explained. Table 8.1 below displays some of them.

Table 8.1 Identified innovations at farmers' level and which serve for the base for the determination of variable LINNOV

\begin{tabular}{lll}
\hline Variables/Innovations & Acronym & Measure (Discr \\
\hline & & \\
1. First Producer and Supplier & FPS $\left(I_{5}\right)$ & $(1 / 0)$ \\
2. Integrated Production System & IPS (If) & $(1 / 0)$ \\
3. New Animal Species & NAS $\left(I_{7}\right)$ & $(1 / 0)$ \\
4. New Crop Varieties & NCV $(I / 6)$ & $(I / 0)$ \\
5. New Techniques and Methods of Production & NTP $(1 / 6)$ & $(1 / 0)$
\end{tabular}

Constructing the variable LINNOV

Step 1- Innovative behaviour determination

Innovations are seldom adopted by all people who may have the required potentials for their adoption. Although Songhai farmers are entrepreneurs and innovators by training, it is still questionable how in practice, they have demonstrated their innovation abilities. Chapter seven used some descriptive statistics to illustrate the innovative patterns of the farmers. The objective is to investigate how innovative the Songhaï farmers are. Given the set of selected innovations (as displayed in Table 8.1), the 
analysis seeks to determine the extent to which the studied farmers are innovators in their own respect. The question of whether a farmer is innovative with respect to a specific innovation is a discrete behaviour and is considered as a dichotomous variable: adoption versus non-adoption.

Let BINNOVi denotes the innovative behaviour of farmer $i(i=1,2,3, \ldots$, 75) and $l_{i}$ denotes $j$-th innovation, $(j=1,2,3,4$ and 5$)$

$B I N N O V_{i j}= \begin{cases}1 & \text { if farmer i is innovative with respect to innovation } I_{j} \\ 0 & \text { Otherwise }\end{cases}$

Step 2 - Innovativeness determination-CINNOV

The innovativeness CINNOV $i$ of farmer $i_{f}$ is determined as follows:

$\mathrm{CINNOV}_{i}=\frac{\sum_{j=1}^{5} \text { BINNOV }_{i j}}{5} ;$

With $0 \leq$ CINNOV $\leq \mathbb{1}$

Step3 - Level of Innowativeness (LINNOV) determination

LINNOV is a multinomial ordered variable defined as followed:

LINNOV $\quad \begin{cases}1 & \text { if } 0 \leq \text { CINNOV }_{\mathrm{i}} \leq 0.50 \\ 2 & \text { if } 0.50<\text { CINNOV }_{i} \leq 0.80 \\ 3 & \text { if } 0.80<\text { CINNOV }_{i} \leq 1.00\end{cases}$

\subsubsection{TAF as a performance measure}

One of the challenges in building the research questionnaire (interview guide) was the identification and definition of variables that capture the outcome performance of all farmers. At this point a number of questions were posed concerning such potential variables in a context of great heterogeneity and diversity of the farmers' production activities:

Cultioated land area - It seemed inappropriate to use the cultivated land surface as a performance measure since areas devoted for cereals, tubers and fruits, for 
example, are generally larger than those used for market gardening. Moreover, all farmers are not involved in crop production. Many of them specialise in animal production while others combine different activities. The land surfaces needed for animal production (in the way the farmers do it) and trading activities are much less than those required for crop production.

Yield/yield valtie as performance measure - It was for example clear that one can neither compare the numbers of fowls of different kinds and value nor the numbers of mammals, which are also of diverse types with each other. It could be thought of the possibility of estimating the current values of the assets of the farmers. But great disparities would strike due to the great differences observed in the amount of initial investment capitals of the farmers. Thus, further one could consider taking into account the profits in a given year.

Profit in absolute or relative values with respect to sunken capital in a given year - The major problem related to this indicator lies in transaction costs which are lower for farmers settled in the suburbs of larger cities or for those who are closer to them. The prices of imported inputs are not the same in the cities as in the villages. There is also a bias against farmers established in remoter areas in terms of product prices. In addition to facing higher production costs, they also bear higher transportation costs of their production to bigger cities of more consumers. In other words, the retail traders that supply the big cities do not buy the same products at the same prices from different distances. Also, while some products (mainly vegetables) are perishable and need to be sold immediately whatever the price, others (such as cereals) can be conserved and wait for higher price opportunities. However, their conservation implies additional cost in the face of uncertainty. Concerning animal production, the evidence reveals that after a certain period of rearing, the animals must be sold. Otherwise, their production cost increases (due to the daily feeds) leading to minimal profits or even losses. In this respect a farmer said:

"Cockerel production needs great timing. To be profitable, the rearing period should not exced fine months. Targeting the two events in the year (Christmas and Easter) when the demands for the birds reach the peak, I allways know when to order the thicks, and begin the production..."

If a farmer works with borrowed capital, and has deadlines for reimbursement, the may be led to sell his production no matter the current price. The insight is that the same amount of investment capital can produce big profitability differences depending on the regions of settlement instead of on the ability of the farmers. If a given year is chosen, what if farmers located in certain regions have faced unfavourable climatic hazards or other catastrophic epidemics such as swine fever? All this led to think of qualitative variables that would have less bias. 
When the search for continuous variables as outcomes of innovative performance of the farmers was not fruitful, another, a discrete one was constructed. Indeed, the farmers were asked to state the evolution of their incomes since the start up of his/her businesses. Specifically, each farmer was asked to say whether his/her income has been 1) steadily increasing, 2) just stable, 3) steadily decreasing and 4) evolving in waves since the creation of his enterprise. One statement excludes other possibilities. According to the farmers however two hazard events have conspired to affect the performance of some activities. The first is swine fever, which has had a dlevastating effect on the performance of so many farmers involved in pig production. Secondly there was a promised and guaranteed market for cassava production. This market seemed to have never existed or collapsed. It is overall acknowledged in the country that people who invested in cassava production ran to failure. Thus, if a farmer stated that $s /$ he has a waving trend of assets due only to either of these two factors, the trend is considered as steadily increasing. Surprisingly, the statements of the farmers, repeatedly, included only two of the alternatives: steadily increasing and moving in waves incomes. Based on these answers a binary dependent variable was constructed as follows:

TAFidenotes trend in the incomes of farmer $i(i=1,2,3, \ldots, 75)$

$T A F_{i}= \begin{cases}1 & \text { if farmer i stated "steadily increasing income " } \\ 0 & \text { if farmer istated "waving income" }\end{cases}$

\subsubsection{The independent variables}

A leading argument in this study is drawn from the innovation system concept that assumes multiple sources of innovations. For a system to work effectively, the concept stresses the involvement of all components and interactions between them to exchange various kinds of resources. All the system components should be proactive, implying that the individual components affect each other by their specific characteristics. The study argues that, besides the entrepreneurial skills that make the farmers innovators, other factors may also have certain influential power on their innovative performances. In this respect, a number of such potential factors are explored.

a) The Initial Investment Capital (IIC) - It is defined as the amount of money, whether in cash or in forms of inputs or any other means of production, the farmers have used to start their business activities. It is a continuous 
variable measured in Euros and in absolute values. The objective of using the IIC as explanatory variable is to determine how it affects both the level of innovativeness and the trends in income of the farmers. It is expected that the amount of IIC has a positive impact on the level of the dependent variables LINNOV and TAF.

b) Farming Background of the Farmers (FBG) - Including this variable will inform on how having experiences in agriculture before entering the Songhail training programme affects current performances of the farmers. $F B G$ is a binary discrete variable taking value one (1) if a farmer has had experience and zero $(0)$ otherwise.

c) Educational Level (EDL) - This independent variable denotes the level the farmers have reached in a normal educational system before their admission to Songhaï. It is measured as an absolute number of successful. years at school. For example, if a farmer left the normal educational system in the first year of secondary school, EDL takes value six (6) because the number of successful years before one enters the first year of secondary school is officially six. The analysis will investigate how this variable affects the dependents ones.

d) Age of the Farming Enterprise (AGFE) - This variable competed with the age of the farmers themselves. The argument behind age is experience. Preferring the age of farming enterprise is putting emphasis on the experience of the farmers in their own businesses. The age of the farming enterprise is a continuous variable and is measured in years.

e) Access to Credit (ACC) - In our contextual definition of innovation, the way, how and why farmers struggle to have access to financial assistance is an innovation. Because innovation drives innovation, the research investigates its impact on the dependent variable variables LINNOV and TAF. Discrete and dichotomous, it takes value one (1) if a farmer has been able to get some financial assistance in whatever form.

f) Access to input and output markets ( $A C M$ ) - It is an essential driver for continuous innovation processes. In the first place, it is admitted that finding input sources is a necessary condition for production to take place. Then follows the need to be able to sell the produced goods in the marketplace. In addition to being defined as innovation, the ACM represents an important factor of successful innovations. Set to be a 
dummy variable, it takes value one (1) when a farmer mentioned that, despite all potential competitors, he always sells his products; otherwise, it takes value zero (0).

g) Access to information ( $A C l$ ) - Like $A C M$, this variable denotes the unusual efforts farmers make in order to pierce existing or new sources for additional information and knowledge required for successfuil achievement of their business. It implies interactions, relationships or partnerships, in which a farmer is deliberately engaged. Access to information is a qualitative dichotomous variable, which takes value one (1) if a farmer is deliberately "nvolved in farmers' associations or organisations and network in order to update any useful information or knowledge s/he may need in her/his agricultural business; it takes zero (0) value otherwise.

h) Access to land $(A C L)$ - This variable relates to land tenure issues and denotes the ability or the necessity for a farmer to get land for exploitation. If a farmer exploits a family common land or a land from heritage, ACL is attributed value zero (0) and value one (1) otherwise.

i) Age of the farmers at the beginning of their traininglleaming process at Songhai (AGTB) - According to Songhaï, more mature (older) male students and girls seem more assiduous at work and show more accountability during the training process. Assuming that this behaviour continues after graduation, it could be expected that these farmers demonstrate higher innovative performance. Defined as a continuous variable, AGTB is expected to positively affect the dependent variables.

j) Marital status (MARS) and Number of children (NBCH) - We suspect that being single or married and the number of children may have some effect on the innovative performance of the farmers. For a married farmer variable MARS takes value one (1) and zero otherwise. The explanatory variable $N B C H$ is continuous.

k) The zones or regions - the farmers are distributed across seven regions or zones, with each showing specific characteristics. These range from agroclimatic conditions to business opportunities. Other characteristics of the zones include proximity to big cities or bigger open market centres. Belonging to a zone is a dummy variable with dichotomous value $(1 / 0)$. 


\subsection{Empirical model specification for the analysis of variable TAF}

Building a statistical model that is consistent with discrete choice data-generation implies that the observed variables be random (Griffiths, 1993). Indeed, in conducting the interviews, it was not possible, even in case of targeted farmers, to have appointments with the farmers before visiting them. The interviewed farmers were only those who could be found by chance at home or in their businesses. A probit regression model is used to determine the performance behaviours of the Songhaï farmers since the start up of their agricultural enterprises. The probit model serves to estimate the parameters associated with the variables that explain the probability that an event occurs. In this study, it is used to determine the probability that a randomly chosen Songhai farmer has a steadily well performing business. This performance is expressed in terms of increasing or waving trend of the farmers' assets.

The probit model, which is a nonlinear statistical model, achieves the objective of relating the probability $P_{i}$ to explanatory factors in such a way that the probability remains in the interval $[0,1]$ (Griffiths, 1993). Indeed, the assumption behind the probit model is the normality of the probability distribution function. When the values of a random variable are listed with their chances of occurring, the resulting table of outcomes is called a probability function or a probability density function, or simply a density function. For discrete random variables, the values of the probability density function are the probabilities that a random variable takes the associated value (Pinkney, 2003).

\subsubsection{The probit model}

Let us denote the conditional probability of a binary outcome by $P(y=1 \mid x)$. The probability that $y=1$ is a nonlinear function $F\left(\right.$.) of. $x_{j}$ and the parameters $B, X$ is the vector of independent variables. The probit modell states:

$P(y=1 \mid x)=F\left(\beta_{0}+\beta_{1} x_{11}+\beta_{2 x} x_{2}+\beta_{1} \mid x_{13}+\ldots+\beta_{k x i k}\right)$

$P(y=1 \| x)=\left(B^{n} x\right)$

F (.) is the cumulative distribution function of the standard normal distribution, $\Phi(z)$ and is bound between zero and one. 


$$
\begin{aligned}
F(z)=\varphi(z) & =\int_{-\infty}^{s} \varphi(v) d v \\
& =\frac{1}{\sqrt{2 \pi}} \exp \left(\frac{-z^{2}}{2}\right)
\end{aligned}
$$

For $z=B^{x} x$

$$
\begin{aligned}
& F\left(\boldsymbol{B}^{\prime} \mathbf{x}\right)=\int_{-\infty}^{\beta^{3} r} \varphi(v) d v \\
& F\left(\boldsymbol{B}^{\prime} \mathbf{x}\right)=\Phi\left(\boldsymbol{B}^{\prime} \mathbf{x}\right)
\end{aligned}
$$

\subsubsection{Empirical specification}

$P\left(T A F_{i}=1 . X_{i}\right)=F\left(B_{0}+B_{1} X_{i 1}+B_{2} X_{i 2}+B_{3} X_{i 3}+B_{4} X_{i 4}+B_{5} X_{i 5}\right)$

Where:

$x_{i}$ denotes the dependent variables,

$(i=1,2,3, \ldots, 75)$

$(j=1,2, \ldots, 5)$

$P\left(T A F_{\mathrm{i}}=11 \mathrm{x}_{\mathrm{j}}\right)=\mathrm{F}\left(\boldsymbol{B}_{0}+\boldsymbol{B}_{1} L I N N O V_{\mathrm{i}}+\mathrm{B}_{2} E D L_{\mathrm{i}}+\mathbb{B}_{3} A G F E_{\mathrm{i}}+\mathbb{B}_{4} I I C_{\mathrm{i}}+\mathrm{B}_{5} A C C_{\mathrm{i}}\right)$,

$$
(i=1,2,3, \ldots, 75) ; \quad(j=1,2, \ldots, 5)
$$

\subsubsection{Estimation of the probit regression model parameters $B^{\prime}$}

The outcome variables $T A F_{i}$ are discrete variables with a nonlinear functional relation in the parameters: the functional relation between the probabilities $P_{i}$ that farmers have steadily increasing assets and the explanatory (independent) variables $x_{j}$. Once these assumptions or characteristics about $F($.$) and the$ variables are made, the $B$ parameters can be estimated using the maximum likelihood. The maximum likelihood $\ell($.$) is the product of F($.$) for each$ observation where $T A F=1$ and $1-\mathrm{F}($.$) for each observation where T A F=0$. It is the joint probability density function of the sample of $n$ independent observations (Griffiths, 1993; Green, 2000). 


$$
\ell(\beta ; X, T A F)=\prod_{i=1}^{75} F\left(X_{i} \beta\right)^{F_{A} F_{i}} \prod_{i=1}^{75}\left[1-F\left(X_{i} \beta\right)\right]^{1-T A A i}
$$

The idea of maximum likelihood estimation is to choose, as estimates of $B$, the values of $B$ that maximise the probability of obtaining the sample that is actually observed. Taking the $\log$ of the likelihood function, the $\hat{\beta}$ values that maximise the log-likelihood function are determined.

$\log [\ell(\beta)]=\sum_{i=1}^{75} X_{i} \beta \log F\left(X_{i} \beta\right)+\sum_{i=1}^{75}\left(1-X_{i} \beta\right) \log \left[1-F\left(X_{i} \beta\right)\right]$

$X_{1} B$ represents $B_{0}+B_{1} X_{i 1}+B_{2} X_{12}+\ldots+B_{5} X_{5}$ while $B$ is a vector of $6(=5+1)$ parameters, including the intercept $B$ o.

To obtain the standard errors of the $\hat{\beta}$ as they derived from the maximum likelihood, the $\left(6^{*} 6\right)$ variance-covariance matrix for the $\hat{\beta}$ is computed. The square roots of the diagonal elements of this matrix represent the standard errors of the $\hat{\beta}$.

$$
\operatorname{Var}(\hat{\beta})=\left(\sum_{i=i}^{75} \frac{[f(X, \hat{\beta})]^{2} X_{i}^{\prime} X_{i}}{F(X, \hat{\beta})\left[1-F\left(X_{i} \hat{\beta}\right)\right]}\right)^{-1}
$$

\subsubsection{Clarification of some basic concepts ${ }^{1}$}

\section{Null hypothesis $\left(\mathrm{H}_{0}\right)$ and altemative hypothesis $\left(\mathrm{H}_{1}\right)$}

In statistical hypothesis testing $x_{x}$ one develops a null hypothesis about some phenomenon or population parameter. The purpose of hypothesis testing is to test the viability of the null hypothesis in the light of sample data. Depending on the data, the null hypothesis either will or will not be rejected as a viable possibility. In the case there is no reason for accepting the null hypothesis, the alternative one is accepted, by definition. The null hypothesis is generally the opposite of what the researcher actually believes and wants to demonstrate. Typically, it is a hypothesis of no difference or effect. It is then put forward and it is determined whether the data are strong enough to contradict it. The decision about the rejection of the null hypothesis depends on significance tests.

\footnotetext{
'Drawn on: Thompson (1994), Musc (2001), Fraley(2003)
} 


\section{Statistical significance}

Significance tests are performed to see whether the null hypothesis can be rejected. If the null hypothesis is rejected, then the effects or relations found in a sample are supposed to be statistically significant. If the null hypothesis is not rejected, then the effects or relations are not statistically significant. When a statistic is significant, it simply means that we are reasonably confident that the statistic is reliable. By statistically significant, it is meant that the observed phenomenon (the alternative hypothesis) represents a significant departure from what might be expected by chance alone (the null hypothesis). Significance is a statistical term that tells how sure we are that a difference or relationship exists. A finding is described as statistically significant when it can be demonstrated that the probability of obtaining such a result only by chance is relatively low. This low level is usually called significance level. It is customary to describe one's finding as statistically significant, when the obtained result is among those that (theoretically) would occur, no more than the significance level whenever random samples are drawn. In hypothesis testing the significance level is the criterion used for rejecting the null hypothesis.

\section{The significance level $\alpha$}

The level of statistical significance $a$ is the probability value in statistics used to reject the null hypothesis. It is the percentage chance (the probability) that the null hypothesis is true. Assuming, for example, that $\alpha=0.05(5 \%)$ is the significance level, it implies that it is likely that five times out of 100 the event (the null hypothesis) could occur due to chance. Traditionally, experimenters have used either $0.05(5 \%)$ or 0.01 level (1\%), and sometimes even $0.1(10 \%)$ level although the choice of levels is largely subjective. The lower the significance level, the more the data must diverge from the null hypothesis to be significant. Generally, the significance level is chosen before the statistical analysis is done. Then the significance level is compared to the P-value.

\section{The Probability values ( $P$-value) and confidence intervals}

After the significance level is chosen, a statistical test of the null hypothesis is conducted, which generates a probability value often called P-value. The Statistical software STATA used for the estimation also generates automatically confidence intervals, which are associated with the significance levels. A confidence interval is a range of values that has a high probability of containing the parameter being estimated. The $95 \%$ confidence intervall is constructed in 
such a way that $95 \%$ of such intervals will contain the parameter. It means that if many samples are collected and the confidence interval computed, in the long term about $95 \%$ of these intervals would contain the true parameter. Confidence limits are expressed in terms of a confidence coefficient. The confidence coefficient is simply the proportion of samples of a given size that may be expected to contain the true parameter. Although the choice of confidence coefficient is somewhat arbitrary, in practice $95 \%, 99 \%$ and $90 \%$ intervals are often used, with $95 \%$ being the most commonly used. Finally, the question of what that value means relative to the null hypothesis is considered and interpretations are made.

\subsubsection{Analysis and Interpretation of empirical results}

Table 3.2: Probit estimates of the empirical nodel

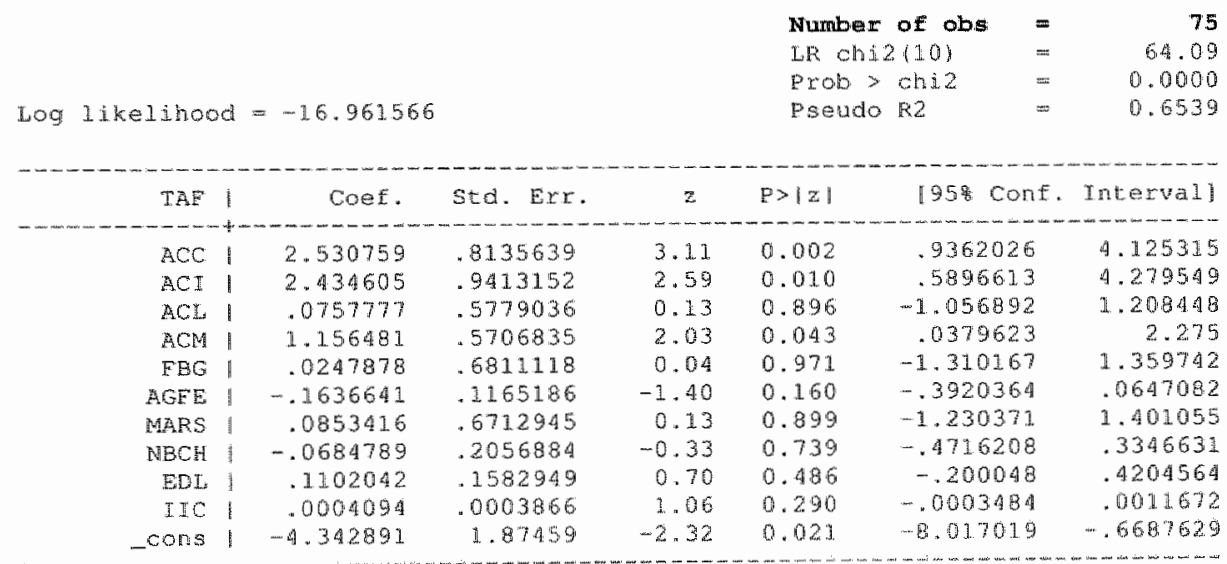

\subsubsection{Goodness-of-fit or statistical significance testing for the whole model ${ }^{2}$}

The Likelihood Ratio LR chi2 $(10)=64.09$ - The likelihood ratio chi-square with 10 degrees of freedom is defined as two times the difference between $\mathrm{L}_{1}$ and $\mathrm{L}_{0}$. The value of $\mathrm{L}_{0}$ is the $\log$-likelihood value $(-49.006566)$ in iteration 0 as provides computations with STATA. It represents the maximum value of the log-likelihood function when all parameters, except the intercept, are set to zero. $L_{1}$ is the log likelihood for the full model with constant and predictors and it is obtained in STATA as the log-likelihood

2 Verbeek (2000) 
value in the last iteration. $L_{t}$ is expected to be greater or equal to $L$ o in the sense that the larger the difference between two values, the better the model fits. In this model the Likelihood Ratio LR chi2 $(10)=63.30$ is then 2 $*\{(-16.961566)-(-49.006566)\}$

The probability value Prob $>$ chi $2=0.0000$ - This $\mathrm{P}$-value is associated the chisquare with 10 degrees of freedom. The value of 0.000 indicates that the model as a whole is statistically significant at any of the traditional significance levels ( $1 \%$ or $5 \%$ or $10 \%)$.

Pseudo $R^{2}=0.6539$ - Pseudo $R$-square is defined as $1-(\mathrm{L} / / \mathrm{Lo})$. Its value is expected to comprise between zero and one $[0,1]$ with a larger departure value from zero implying better goodness-of-fit.

In summary, the overall Goodness-of-fit is a hypothesis testing of joint significance of all slope coefficients where:

$H_{0:} B j=0(j=1,2, \ldots, 10)$ : All slope coefficients equal zero

$H_{1}: B_{j} \neq 0(j=1,2, \ldots, 10)$ : One or more coefficients do not equal zero

The analysis conclusion indicates that the estimated model is statistically significant at significance level 0.05 (STATA uses the 0.05 significance level by default) and that there is no reason for not rejecting the null hypothesis.

\subsubsection{Marginal effects}

In the probit model, a model of discrete choice, the estimated coefficients $\hat{\beta}_{j}$ relates changes in the explanatory variable $x_{j}$ to changes in the probability of the farmers having steadily increasing assets. Unlike the usual linear statistical models, in the probit model these coefficients are not directly interpretable as the effect of change in an explanatory variable on the mean or on the expected value of the dependent variable (Griffiths, 1993) TAF. The sign of a coefficient informs about the direction of the relationship between the corresponding independent variable and the probability that TAF equals one. Given a change in the $j$-th explanatory variable, the rate of change in the probability that farmers have steadily increasing incomes, is called marginal effect. It is given by (Griffiths, 1993): 
$\frac{\partial P_{i}}{\partial x_{i j}}=\frac{\partial F\left(X_{i}^{\prime} \beta\right)}{\partial x_{i j}}=F^{\prime}\left(X_{i}^{\prime} \beta\right) \frac{\partial\left(X_{i}^{\prime} \beta\right)}{\partial x_{i j}}=f\left(X_{i}^{\prime} \beta\right) \beta_{j}$

Indeed, the marginal effect of an independent variable is the derivative of the prediction function, which by default is the probability of success $P$ following probit. With STATA these marginal effects (derivatives) are evaluated at the means of the explanatory variables (by default). After the estimation of the probit model, the use of the $\mathrm{mfx}$ command reports marginal effects as displays Table 8.3.

\section{Table 8.3: Marginal effects after probit}

\begin{tabular}{|c|c|c|c|c|c|c|c|}
\hline variabe & $d y / d x$ & Std. Err. & $z$ & $P>\mid z$ & 958 & $C . D$. & $x$ \\
\hline $\mathrm{ACC} *$ & 75544.48 & 110472 & 4,60 & 0000 & 433402 & 10717 & 602337 \\
\hline ACI & .7750459 & $\begin{array}{r}110412 \\
.19213\end{array}$ & 4.03 & 0.000 & $\begin{array}{l}43368 \\
398469\end{array}$ & $\begin{array}{l}1.711 \\
1.15162\end{array}$ & $\begin{array}{r}-09343.34 \\
344\end{array}$ \\
\hline $\mathrm{ACL} *$ & .0200565 & .1547 & 0.13 & 0.897 & -.233145 & .323258 & .52 \\
\hline ACHN & .3578279 & .21 488 & 1.67 & 0.096 & .063335 & .779991 & .706667 \\
\hline$F B G *$ & .0065117 & .17327 & 0.04 & 0.971 & -.340925 & .353948 & .226667 \\
\hline AGEE & -.0432604 & .02969 & -1.46 & 0.145 & -.101447 & .014926 & 5.76 \\
\hline MARS* & .0230094 & .11848 & 0.12 & 0.901 & -.339183 & .385202 & .76 \\
\hline MECH & -.01181006 & .05440 & -0.33 & 0,740 & -.124888 & .089686 & 1.61 .333 \\
\hline EDIS & .0291296 & .04009 & 0.73 & 0.467 & -.049448 & .107707 & 10.16 \\
\hline IIC & .0001082 & .00008 & 1.43 & 0.152 & .00004 & .000256 & 1116.04 \\
\hline
\end{tabular}

With the probit model, coefficient estimates are presented in terms of probability. Because the probit model is non-linear, the estimates are most accurate for small changes in the independent variables. The interpretation of coefficients for discrete variables differs from that of continuous variables (Griffiths, 1993; Green, 2000). Statistical tests are also reported in the output. The $z$ test is formed by dividing the coefficient by the standard error. It is most easily interpreted by looking at the associated $p$-value. The $p$-value reports the level of statistical significance at which this coefficient would be statistically different from zero. The interpretation of these coefficients should be better understood in terms of hypothesis testing (Griffiths, 1993; Green, 2000). 


\subsubsection{The impact of information (ACI) on the variable TAF}

$H_{0:} B_{1}=0$ : That a farmer belongs to various networks or famers associations in order to access information of diverse sorts, does not affect the probability that the trend of his asset varies.

$\mathrm{H}_{1}: \mathrm{B}_{x} \neq \mathbf{0} \quad$ The probability of having steadily increasing assets may increase if a farmer searches and gains information useful to his business.

The P-value (0.010) for the coefficient associated with the variable $A C l$ (see table 8.2) is a sign for statistically significant explanatory variable at significance level $1 \%$. This means that there is only $1 \%$ chance for the statement conveyed by the null hypothesis to be true. The $95 \%$ confidence interval provided by STATA does not include zero. Thus, by definition, the null hypothesis is rejected. The positive sign of the coefficient (2.434605 IN Table 8.2) tells that when a farmer is connected to information networks, this increases the probability that he/she experiences steadily increasing assets. It is assumed that the information is useful and translates to knowledge input for his enterprise. The marginal effect (see Table 8.3) is positive and very high, (0.7750449). It implies that the probability that his/her assets follow an increasing trend is likely to augment by $77 \%$.

\subsubsection{The impact of access to credit or financial assistance (ACC) on TAF}

$H_{0}: B_{5}=0$ : Financial assistance, to which the established Songhail farmers have access, is not a significant factor influencing the fluctuation of their assets. That is, whether a farmer's assets will increase over time or move in waves does not depend on financial assistance.

$H_{1}: B_{3} \neq 0 \quad$ Additional access to financial means (after settlement) can contribute to boost farming activities thereby affecting the probability of having an increasing trend of the assets.

As displayed in Table 8.2 the $\mathbb{P}$-value 0.002 (a $1 \%$ significance level) and the $95 \%$ confidence interval $[0.9362026,4.125315]$ associated with the estimated coefficient (2.530759) imply that the explanatory variable ( $A C C$ ), has a statistically positive impact on the dependent variable TAF. Thus, with the null hypothesis appealing for rejection, the positive sign of the coefficient value specifies that when the farmers have access to credit after settlement, the probability that their assets follow an increasing trend augments. The relatively high marginal effect value

\footnotetext{
3 For the data, see Table 8.2 - Probit estimates and Table 8.3-Marginal Eftects after probit
} 
(0.7554448, see Table 8.3) means that when a farmer is established with a certain amount of initial investment capital, providing him/her with some additional amount of money, increases by $76 \%$ the probability that he/she will experience positive change of the trend of his assets.

\subsubsection{The impact of ACM on TAF}

$H_{0}: B_{3}=0: \quad$ Having access to input \& output markets by an entrepreneur Songhail farmer has no effect on the probability that his/her assets steadily increase or go in waves.

$H_{1}: \mathbb{B}_{3} \neq 0 \quad$ When a Songhail farmer masters the input factors necessary for the production activity and when s/he then successfully sell the produced items on the market thus, the chance that her/his assets will steadily increase over time augments.

With a p-value of 0.043 the null hypothesis $(\mathrm{Ho})$ is rejected at $5 \%$ significance level and the alternative one $\left(\mathrm{H}_{1}\right)$ is accepted. The $95 \%$ confidence interval 10.0379623 , 2.275 ] for the estimated coefficient (1.156481) does not include zero. The marginal effect is positive $(0.3578279)$ lending itself to the interpretation as follows. If an entrepreneur Songhail farmer has ACM, the probability that he will be experiencing steadily increases of his assets augments to about $38 \%$. Variable ACM thus, constitutes an important factor affecting agricultural entrepreneurship performance at the level of Songhai farmers. Finally the value of predicted probability that $T A F=1$ at the sample means of the dependent variables is very high: 0.8178888 ( $82 \%$ ). The results however, show that variables $A C L$, FBG, AGFE, MARS, NBCH, EDL and ICC do not have statistically significant effect on the dependent variable TAF.

\subsection{Empirical model specification for the analysis of variable LINNOV}

\subsubsection{The ordered probit model}

This section empirically explores the effectiveness of a number of factors (variables) influencing the level of innovativeness of the Songhai farmers. Given the ordinal nature of the dependent variable LINNOV as defined in section 2 of this chapter, the econometric ordered probit model is used. The ordered probit is

\footnotetext{
4 For the data, see Table 8.2 - Probit estimates and Table 8.3 -Marginal Effects after probit
} 
employed with responses coded 1 to 3 (in respect to LINNOV). Let $y_{1}^{*}$ denote an unobservable variable that captures the innovativeness level of the $i$-th farmer and let $y_{i}$ denote its observable counterpart coded 1,2 and 3 on the basis of innovation performance (LINNOV). The level of innovativeness can be expressed as a function of a vector of explanatory variables $\left(X_{i}\right)$ using the following linear relationship (Green, 2000):

$\operatorname{LINNOV}_{i}^{*}=X_{i}^{\prime} \beta+\varepsilon_{i} ; \varepsilon_{i} \sim N\left(0, \sigma^{2}\right)$

It is assumed that LINNOV ${ }_{i}^{*}$ is the latent (unobserved and unmeasured farmers" level of innowativeness) related to the observable ordinal variable LINNOV. In this equation, $X^{\prime}$ represents the transposed matrix of independent variables and $B$ is the vector of coefficients. The observed variable LINNOV can then be specified as follows:

$$
\begin{aligned}
& \text { LINNOV }_{i}=1 \text { if LINNONit } \leq \mu_{1} \\
& \text { LINNOV }_{i}=2 \text { if } \mu_{1}<\text { LINNOV }_{i}^{*} \leq \mu_{2} \\
& \text { LINNOV }_{i}=3 \text { if } \mu_{2}<\text { LINNOV }_{i}^{*}
\end{aligned}
$$

It is possible to interprete $L I N N O V_{i}^{*}$ to mean the farmers' full ability to innovate or the farmers' willingness to innovate. The $\mu\left(\mu_{1}\right.$ and $\left.\mu_{2}\right)$ are unknown parameters (called cuts-points: _cut1, _cut2) estimated jointly with the coefficients $B$ while $\varepsilon$ is assumed to be normally distributed with mean and variance comprised between zero and one $[0,1]$. The dependent variable LINNOV having categorial measure ordered from $\mathrm{j}=1$ to $\mathrm{j}=3$, the empirical ordered probit mode. is expressed as:

$$
\begin{aligned}
& \operatorname{Prob}\left(L I N N O V_{1}=1\right)=\Phi\left(\mu-\chi^{\prime} \beta\right) \\
& \operatorname{Prob}\left(L I N N O V_{1}=2\right)=\Phi\left(\mu_{2}-X^{\prime} \beta\right)-\Phi\left(\mu_{1}-X^{\prime \prime} \beta\right) \\
& \text { Prob }\left(L I N N O V_{i}=3\right)=1-\Phi\left(\mu_{2}-X^{\prime} \beta\right) \\
& \text { In general terms it is: } \\
& \operatorname{Prob}(\text { LINNOV }=j)=\Phi\left(\mu_{j}-X^{\prime \prime} \beta\right)-\Phi\left(\mu_{i-1}-X^{\prime} \beta\right), \quad(j=1,2,3)
\end{aligned}
$$

Here denotes the cumulative distribution function of the standard normal. The estimation of the ordered probit model using STATA is based on the loglikelihood methods. As it is with probit, the marginal effects of the explanatory variable $X$ on the probabilities are not equal to the coefficients. Thus, to allow a comprehensive interpretation of the model, the marginal effects are also computed. The results are presented in Table 8.4 and Table 8.5. 


\subsubsection{Interpretation of the coefficients and marginal effects in the ordered probit model}

Ordered probit coefficients do not easily lend themselves to interpretation (Kaplan, 2001). They are not directly interpretable beyond sign and significance (Verbeek, 2000). The interpretation of the coefficients B is in terms of the underlying latent variable model (here LINNOV*) or in terms of the effect on respective probabilities. For the coefficients $B_{\mathrm{j}}$ are supposed to be positive or negative, the most common agreed interpretations are (Verbeek, 2000) the following. If $\mathbb{B j}>0$, an increase of a unit in a dependent variable $x_{\mathrm{j}}$ leads to an increase of the latent variable ( $\left.L I N N O V^{*}\right)$. Accordingly, the probability that the outcome variable (here LINNOV) takes the highest value increases while the probability that it takes the lowest value decreases. Logically, it is accepted that, for a negative value of $B_{i}$ an increase of a unit value in an explanatory variable $x_{i}$ would decrease the probability that the observed outcome variable (here LINNOV takes the highest value. This implies that the probability of the outcome variable taking the lowest value increases at $\beta_{j}<0$. However, Bhattarai et al. (2004) argue that marginal effects (the probability of change) are the only reliable indicators of such models and that this general rule should take account of their signs. This warrants the meed to compute the marginal effect for each categorical outcome.

Table 8.4 Ordered probit estimates for dependent variable LINNOV.

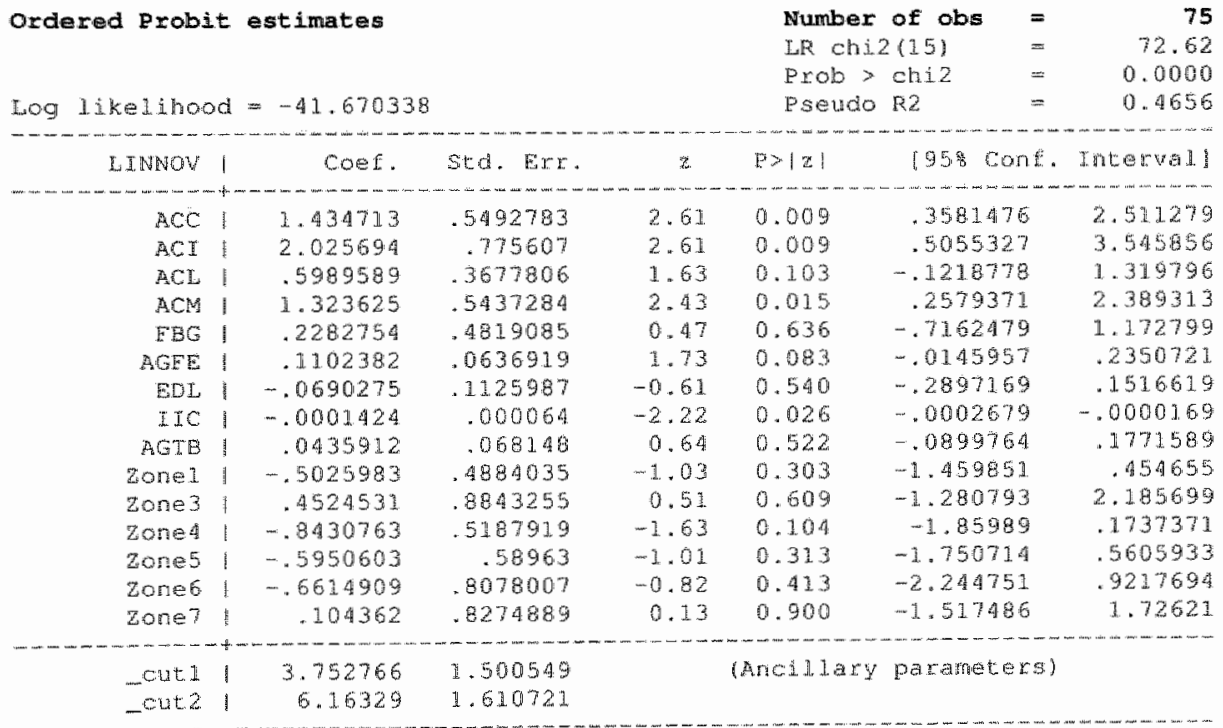


For simple probit with dichotomous dependent variables (zero/one) changes in probabilities from one category to another are straightforward. The change is measured from the level zero to level one. In the ordered multiple categorical (more than two), the marginal effects measure the change in probability from one category of the dependent variable to another based upon one-unit change in the value of the predictors. This empirical model provides three categories. For example, marginal effect at outcome level 2 , implies probability induced changes (by a unit change in one dependent variable while holding all others at their means) of moving from level 1. Using STATA, marginal effects have been computed at outcome (LINNOV) levels 1,2 and 3 (see Table 8.5).

\subsubsection{Goodness-of-fit or statistical significance testing for the whole model ${ }^{5}$}

Hypothesis testing of joint significance of all slope coefficients where:

Ho: $B j=0(j=1,2, \ldots, 15)$ : All slope coefficients equal zero

$H_{1:}: B_{j} \neq 0(j=1,2, \ldots, 15)$ : One or more coefficients not equal zero

The analysis can conclude that the estimated model is statistically significant at significance level 0.01 and that the null hypothesis does not hold following (Table 8.4):

$\Rightarrow$ The likelihood ratio chi-square with 16 degrees of freedom: $L R$ chi2 $(15)=72.62$

$\Rightarrow$ The probability value Prob $>$ chi2 $=0.0000$

$\Rightarrow$ Pseudo $R^{2}=0.4656$

\subsubsection{Impacts of variables IIC, $\mathrm{ACC}, \mathrm{ACI}$ and $\mathrm{ACM}$ on dependent variable LINNOV}

The issue at stake is whether it will be possible to infer that the importance of capital at disposal of the farmers for the startup of their businesses, having access to financial assistance, information and markets are motivating factors increasing the level of innovativeness of the entrepreneur Songhai farmers. The probability values $(0.026,0.009,0.009$ and 0.015 , see Table 8.4) related to the respective coefficients associated with these variables indicate a $5 \%$ significant level (in general). Confidence intervals computed at $95 \%$ do not include zero. From this point it can be assumed that the variables IIC ACC, ACI and ACM (Table, 8.4)

5 Verbeek (2000) 
have impact on the level of innovativeness of the entrepreneur Songhaï farmers. The implication is that when these dummy independent variables change from zero to one, the probability that the outcome variable LINNOV remains at its initial level or moves from it changes. The direct interpretation is that when an established Songhaï graduate:

a) Given the importance of the money he used to start the business,

b) Gets some financial assistance and/or

c) Engages in some network of information searching and/or

d) Can successfully master production imputs and sell the outcome products,

thus, it can be expected that the chance that $\mathrm{s} /$ he innovates more or less increases. $S /$ he is likely to move from the initial (former) level of innovativeness to a higher or lower one. To ascertain the direction of the change, we look at the signs of the coefficients. Except for IIC the coefficients associated with the other variables are positive (see table 8.4). Positive, they imply that a change from zero to one of any of these explanatory binary variables induces negative change in the probability of $L I N N O V=1$ and increases the probability of $L I N N O V=3$. The change at LINNOV $=2$ is ambiguous and leads to look at marginal effects first (Verbeek, 2000; Green, 2000). Also, to assess the importance of the changes there is a need to consider the marginal effects (Table 8.5). A negative coefficient as it is with IIC, means that one additional unit of IIC increases the probability that $L I N N O V$ does not move from one. It then, decreases the probability that $L I N N O V=3$.

As it could be expected, the marginal effects of $A C C, A C I$ and $A C M$ at outcome value $L I N N O V=1$, are negative and relatively high. When a farmer (entrepreneur Songhaii) has access to financial assistance or information or markets, the probabilities that $\mathrm{s} /$ he remains at innovativeness level 1 decrease (respectively by $50.36 \%, 68.71 \%$ and $46.91 \%$ ). At the same time the probabilities that $\mathrm{s} /$ he moves to innovativeness levels 2 and 3 increase, and are higher at LINNOV $=2$ than at $L I N N O V=3$. The chances that an entrepreneur Songhaï farmer moves from

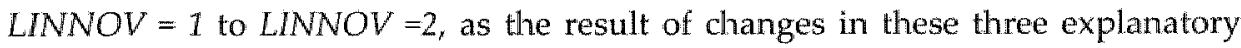
variables, increase (respectively by $42.01 \%, 61.81 \%$ and $39.40 \%$. As previously mentioned, these increases in probabilities for moving to LINNOV $=3$ are lower and amount respectively $8.3 \%, 6.9 \%$ and $7.5 \%$ for a change from zero to one of respectively $A C C, A C I$ and $A C M$. Taken the variable $/ \mathrm{CC}$, the direction seems to diverge. When it increases (by one unit - one Euro), the probability that LINNOV remains at level 1 increases and decreases for LINNOV reaching levels 2 and 3. In all cases however, the marginal effects are very small and less than $0.005 \%$. That IIC has a real significant effect on LINNOV is not conclusive. 
TABLE 8.5 Marginal effects after ordered probit estimates

\begin{tabular}{|c|c|c|c|c|c|c|c|}
\hline vaxdand & $d y / d x$ & gted, ErT. & 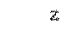 & P>12! & $95: 8$ & C.I. & $x$ \\
\hline ACO & -.5036172 & .18214 & $-2,76$ & 0.606 & -.06054 & -.246623 & 693373 \\
\hline ACL" & -.6871725 & .27368 & -3.96 & 0.000 & -1.02758 & -. . 15364 & .84 \\
\hline BCL $=1$ & -.1904917 & .12223 & -7.62 & 0.104 & $-\ldots 49053$ & .94107 & .52 \\
\hline $\mathrm{ACH}$ & $\cdots .4691459$ & .28502 & -2.54 & 0.012 & -.831778 & -.10551 .4 & .706657 \\
\hline $50 \%$ & -.072799 & .24753 & $-0,49$ & 0.622 & -.361949 & .216352 & .226667 \\
\hline AGE & -.0366236 & .02098 & $-1,75$ & $0.0 \mathrm{~g} 1$ & -.0777 .45 & .004497 & 5.76 \\
\hline EBS & .0229325 & .03765 & 0.51 & 0.545 & -.051280 & .097133 & 10.1 .6 \\
\hline ITO & .0000473 & .00002 & 2.24 & 0.025 & $5.9 e-06$ & .000089 & 1116.04 \\
\hline ACTB & -.014482 & .0228 & -0.64 & 0.525 & -.059174 & .030211 & 22.4933 \\
\hline Zorat 1 & .1782732 & .28066 & 0.99 & 0.324 & -.175815 & .532361 & .226567 \\
\hline $20 \operatorname{sen} 3 * 1$ & -1395588 & 21261 & $-0,61$ & 0.539 & -.547264 & .285146 & .066667 \\
\hline zone4*1 & .3045285 & .192 的 3 & 1.58 & 0.114 & -.072602 & .683639 & .24 \\
\hline $20005:$ & .2173454 & .23642 & 0.96 & 0.39 & -.226225 & .661323 & .133333 \\
\hline $20506 \times 1$ & .247466 & .31796 & 0.78 & 0.436 & -.375724 & .870656 & .053333 \\
\hline zone $7 * 1$ & -.0337227 & .25932 & -10.13 & 0.297 & -.541973 & .474527 & .00 \\
\hline
\end{tabular}

$y=$ PIIMNOV=2) (predict, outcome $(2)) ; y=.69191422$

\begin{tabular}{|c|c|c|c|c|c|c|c|}
\hline yaxable 1 & $d y / d x$ & Std, Eir. & $\mathrm{z}$ & $p>|z|$ & 958 & C.I. & $x$ \\
\hline & & ( & & & & - & \\
\hline $\mathrm{ACO} \times 1$ & .4201293 & .17012 & 2.47 & 0.014 & .086708 & .753551 & .693332 \\
\hline$A C D+1$ & .6191506 & .37699 & $3.5 \mathrm{i}$ & 0.000 & .27302 & .963281 & .84 \\
\hline Aक्षें। & .1511182 & .0988 & 1. .53 & 0.126 & -.042534 & .344771 & .52 \\
\hline$A C E$ K & .3940061 & .1715 & 2.30 & 0.022 & 057866 & .730140 & .706667 \\
\hline FBC: & .0527781 & .10172 & 0.52 & 0.604 & $-.1659 \mathrm{z}$ & .252148 & .226667 \\
\hline MGE & .0280065 & .02751 & 1.60 & 0.110 & -.006314 & .062327 & 5.76 \\
\hline EDL & $\ldots .0175367$ & .02913 & -0.60 & 0.547 & -.074621 & .039548 & 10.16 \\
\hline $\operatorname{IrC}$ & -.0000362 & .00002 & $-1,92$ & 0.054 & -.000073 & $6.7 \times-07$ & 1116.04 \\
\hline $\mathrm{AGH}$ & .0110745 & .01755 & 0.63 & 0.520 & -.023322 & $.64: 5471$ & 22.4933 \\
\hline 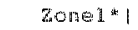 & -.1470227 & .15 .751 & -0.93 & 0. 351 & -.455733 & .161698 & .226667 \\
\hline wond $3 * 1$ & .0804643 & .08716 & 0.92 & 0.3356 & -.090364 & .251292 & .356567 \\
\hline $20004 * 1$ & -.257289 & .77622 & -1.46 & 0.144 & -.602576 & .098098 & .24 \\
\hline 7onesion & -.195529 & .20633 & $-i 0.90$ & 0.369 & -.589927 & .21 .8969 & .133333 \\
\hline $30 \cos 5$ & -.2166351 & .30055 & $-10,72$ & 0.471 & -.805705 & .372433 & .053333 \\
\hline zone $7 * 1$ & .0248932 & . 13387 & $0 . \mathbb{4} 4$ & 0.892 & -.335494 & .38528 & .08 \\
\hline
\end{tabular}

$y=\operatorname{Pr}($ LNNON=3) (Predict, out come (3)); $y=.03549638$

\begin{tabular}{|c|c|c|c|c|c|c|c|}
\hline yatable & $d y / d x$ & SLA. Brt. & z & p>I\%! & $95:$ & C.I. & $x$ \\
\hline $\operatorname{ncc} \times$ & .0874878 & .04537 & 1.598 & 0.0166 & .005435 & .172411 & .693333 \\
\hline $\operatorname{ACT} *$ & 0690219 & .03567 & 1. 稲 & 0.053 & .000038 & .138927 & .84 \\
\hline $\mathrm{ACL}^{2}$ & .0979736 & .03645 & 1.30 & 0.194 & -.024067 & .118815 & .52 \\
\hline $\operatorname{sem}{ }^{*}$ & $.095139 \%$ & .04303 & 1.78 & 0.0181 & -.009299 & .159578 & .706667 \\
\hline $\mathrm{EBC} * 1$ & .0200208 & .04758 & 0.42 & 0.6778 & -.073253 & .113290 & .226667 \\
\hline ACE & .0046131 & $.0661 \%$ & k. 40 & 0.162 & -.00346 & .020701 & 5.76 \\
\hline EDT I & -0053957 & .00934 & -0.58 & 0.564 & -.023713 & .01292 & 10.16 \\
\hline $\operatorname{ltc} 1$ & -.0000111 & .00001 & -1.67 & 0.099 & -.000024 & J. $9 e-96$ & 2116.04 \\
\hline AOTE & .0034074 & .00565 & 0.60 & 0.547 & -.007693 & .014508 & 22.4933 \\
\hline $2,511011 *$ & $\cdots .0312505$ & .02982 & $-1,05$ & 0.295 & -.089692 & .027191 & .226667 \\
\hline 2one $3 *$ & .0900946 & , 3269 & 0.38 & 0.706 & -.209967 & .310156 & .066667 \\
\hline Zoned $*$ & -.0472236 & .03194 & -1.48 & 0.139 & -.109834 & .015375 & .24 \\
\hline Hones: & $\cdots .0320204$ & .02789 & -1.25 & 0.252 & -.086568 & .022627 & . 13333 \\
\hline 23one 6 * & -.0308299 & .02558 & $\cdots 1.21$ & 0.229 & -.080957 & .019298 & .053333 \\
\hline zoner" 1 & .0082235 & .07555 & 0.22 & 0.907 & -.139498 & -257107 & .08 \\
\hline
\end{tabular}

(*) dy/dx is for discrete onarge of dumy vatimbe from 0 to I 


\subsubsection{Impact of factor zone (region) on LINNOV}

$\mathrm{H}_{0}: \mathrm{B}_{3}=0$ : The agro-ecological, social and economic opportunity differences that the various zones present compared to the referential zone, do not affect the farmers' level of innovativeness. More precisely, it cannot be inferred that if an entrepreneur Songhai farmer were located in the referential zone he would have greater chances of becoming more or less innovative than he is in the currently zone.

Hy: $B_{3} \neq 0 \quad$ It is probable that an entrepreneur Songhai farmer would be more or less innovative if he was initially settled in the referential zone, which is different from this current zone of settlement.

In this analysis, zone two is set as referential zone. It is the zone that may be viewed as presenting more business opportunities. At the heart of the zone lies the biggest city accounting for at about one-tenth of the country population size. Apart from land, access to certain resources (information and markets opportunities for example) may be easier. The "traditional" statistical tests $P$ value and confidence interval at $95 \%$ do not indicate statistical significance. Thus, the level of innovativeness of the Songhai farmers does not depend on specific regional socio-economic and environmental factors.

\subsection{Discussion and conclusion}

\section{The strength of the Songhai training/learning framework}

Generally speaking, the mechanism through which information, formal and conceptualised knowledge is generated are decisive factors in the innovation process. They offset the constraints posed by the limited rationality of the economic agents and reduce the insecurity associated with the innovative process (Ventura and Milone, 2004). In the course of this study, the analysis has confirmed the above assertions. It revealed that the Songhai farmers are innovators in the sense of Schumpeter's entrepreneurs and beyond. They have demonstrated their innovativeness through their innovative behaviours and capacities; they continually experiment with new and more efficient practices. Yet, following Ventura and Milone (2004), economic agents do not start from a common footing with regards to the choices and evaluation of opportunities that they are able to make. These choices depend on their expertise, which in turn, derive from their history of learning experiences. This leads to pose the question: Why has the past experience of the farmers not shown significant effects on their 
innovative performances? Three explanatory variables embody this past and include EDL, FBG and their AGTB.

Indeed, the hypothesis testing results have revealed that the levels of innovativeness of the farmers do not depend on explanatory variables EDL, FBG and AGTB. In the same way, the regression of independent variables EDL and FBG on the dependent variable TAF has not shown statistically significant effects. These may be attributed to the quality of the Songhai training framework. It is thus tempting to infer that the content of the training/learning programme, its pedagogical process and the personal motivation of the students themselves have contributed to break initial educational differences and other past experiences and build a new common knowledge background at farmers' level.

The Songhai learning/training, which embraces many theoretical and practical processes as a sort of apprenticeship, is also comparable to what Tennant (1997) describes as characteristics of adult learning. The concerns are contextdependent, focused on specific information and knowledge relevant to more immediate problems with less interest in a standard long-term course of study. This seems consistent with the system perspective that emphasises the social character of agricultural innovations. An important insight is that innovations are deeply embedded in rural social systems. Being an innovator, to some extent, also depends on the economic and social conditions under which one operates. These include production location, markets and resources, and also availability of complementary products and services. Thus, innovations are viewed as interactive processes between the farm and its environment, which provides opportunities for the creation or the development of new resources. The process of innovation therefore depends on the existence of systematic relationships between the farm and its environment. In this connection, the fact that factor region, in general, has not affected the level of innovativeness of the farmers is questionable.

A probable (but not sufficient) explanation to this question resides in the locations of the Songhaï training centres. In Benin, Songhaï disposes of three big training/learning centres. As mentioned in chapter six, Songhaï advocates that the objective of setting such learning infrastructures, in the south the centre and in the north is to respond to specific characteristics of each region. In addition to some core knowledge focus, different patterns of farming systems, agroecological differences and agricultural business opportunities that the regions present are also content of the curriculla. As mentioned in the methodological chapter, farmers are drawn from these three regions divided into seven zones. 
One may ask why we don't consider regions as factors affecting innovativeness level. The answer is simple. While the Songhai centre in the south was set in 1985, the others were created just recently (in 1999). Some of the sample farmers, established in the centre and in the north, were trained in the south. Further the objective of this amalysis is not to compare the performance of the different centres.

In effect, Songhaï itself claims to add more by providing training/learning responding as well to future needs of the farmers. It aims to equip the learners with, at least, the background enabling further knowledge acquisition. These empirical findings are consistent with an innovation systems approach that contends that the diversity in the innovation processes and the routes towards them, do not allow confining innovations under the sole influential power of skills gained through educational processes (Ventura and Milone, 2004). However, what is fundamentally argued here is that skills and competencies are motivating factors for the occurrence of other determinants of innovation processes.

\section{Innovations drive innovations}

Interactions between agricultural production and the socio-economic and institutional environments also play a vital role in supporting innovation processes. Even when economic agents recognise the values of an innovation, it is not certain that they will adopt it. Thus the rolle of institutions that provide services and incentives is very important in determining the uptake of a successful innovation and developing its potential as a tool for triggering broader development processes. In this study, the analysis has proven that availability of various forms of financial assistance to agricultural undertakings and the existence of diverse sources of information as knowledge inputs, which the social, institutional and economic environment provided to the farmers, were statistically significant in influencing the level of innovativeness of the farmers. Indeed, if the capabilities (to generate, diffuse, and utilise technologies that have economic value) couple with economic competences to enhance innovations (Carlsson and Eliasson, 1994), innovations are themselves, and by definition, determinants of innovations (Biggs, 1990). In the context of this study (chapter seven), $\mathrm{ACC}, \mathrm{ACl}$ and $\mathrm{ACM}$ constitute different types of innovations at farmers" level. That these three factors positively influence the level of innovativeness of the farmers is evident. In addition, their impacts on the trend of the assets of these farmers are positive. 


\section{About Finances}

The impact of the IIC on both dependent variables is almost insignificant. The probability of change is too small: $0.005 \%$. It may imply that farmers do not embark on many innovations at the outset of their enterprises. Indeed, $25 \%$ and $50 \%$ of the farmers started their business with an IIC less or equal respectively to 73 euros and 152 euros. These amounts might not allow innovations that require more important amount of capital. Mostly, farmers who set up their enterprises with higher amounts of IIC used them to acquire land. Finally, it can be understood that the amounts of working capital the farmers had at the start-up of their businesses were, in general, very low and the scope of the innovations activities depended rather on their skills and competencies. As Cobbenhagen put it (2000), just acquiring and owning resources is not enough to innovate. Resources determine what a business can do, but not how successful it may become. It follows that the training process, in this case, has accomplished one of the fundamental notions very dear to Songhaï: "use what you have, to get what you want". But, that is not to say that the Songhai training/learning framework constitutes, by itself, the sufficient factor for innovations. Once an agricultural enterprise is set, to survive it will require additional means and resources to boost innovations.

Following Ventura and Milone (2004) it is unlikely that farmers will confine themselves to with the current observable innovations. Rather, they are likely to evolve into complex innovative processes that would ultimately lead to the redefinition of the scope of their undertakings. This highlights the continuous character of the innovation processes. The need to find solutions to the constraints that emerge once the initial project has been embarked upon drives a succession of continuous adjustments while appealing to new financial means (Ventura and Milone, 2004). This explains why access to credit or financial assistance has positive effects on both the dependent variables TAF and LINNOV. Along the same limes, it would be useful to investigate the interdependent relationship between variables LINNOV and TAF. This would ascertain how it is inherent to agricultural production that the modification of an imput leads to different products characteristics or vice versa, and the introduction of a new product leads to the new production function (Ventura and Milone, 2004). Yet, however skilful such extra and in-depth analysis may appear, it is not indispensable for answering the research questions. This chapter also underscores the fact that economic and technical changes do not occur based on the sole capabilities of the economic agents in isolation from the underlying socio-economic conditions and institutional settings. 


\section{Discussion and Conclusion}

\subsection{Introduction}

After my first graduate studies in the Slovak republic, I was impatient to see my parents and my village; I was eager to go back home. I was also excited to acknowledge some concrete achievements of the waves of democracy since 1990 in Benin. I was looking forward to meet some friends and schoolmates from secondary school and revive the kinds of discussions we used to have. Over and over, the discussions turned into to political debates. When it came to answer the concrete question of what should be done in order to advance the country and how it should be carried out, I noticed dual positions.

Many people believe in concepts such as good governance, democracy and decentralisation as the main determinants of a country"s prosperity. The proponents of this general opinion take themselves as poor and think that they cannot do anything to help themselves. They seem to argue that only Western money and Western policy recommendations of how to use the money would bring solutions to "their so-called problems". In contrast, only a few people hold the position that, if a country like Benin, with six millions inhabitants, was given the whole wealth of the Netherlands, for example, it does not have yet the capacity to manage such wealth. I do not believe that the country would be able 
to capitalise with such weallth. People would just "eat" the money within a few years and their situation will become worse than before. Most of the time however, our arguments used to be very vague, lacking sound background. This study indeed, seeks to contribute to the understanding of the theoretical foundations that have shaped the course of economic development policies and strategies.

As I became enrolled in development studies I quickly realised that the systematic study of the causes of economic development, and the formulation of specific prescriptions as to how to trigger economic growth in an interdependent world, seems more complex than I could ever imagine. Moreover, my big dream of crafting a thesis that would be a breakthrough in the field, progressively encountered the limit of the scope of a dissertation focus. I decided to concentrate on the agricultural sector. The main objective became the investigation of the processes (policies, strategies and practical actions), through which agriculture develops. Here again, literature suggests no simple straightforward path to sustain innovation processes as a key determinant to agricultural development. Simply defined, agricultural innovations processes are those allowing farmers to pick up innovations and apply them to their farming businesses. Yet, how to materialise this in the least developed countries remains a subject of divisive debates.

\subsection{Restating the problem}

Looking at the literature, approaches to agricultural innovation generation, diffusion and use have been blamed. From the linear model through participatory approaches to some earlier system thinking of innovation processes, there is huge criticism that they failed to help meeting the great mission assigned to them. Conceptualising agricultural innovation just in technical terms, they have under-emphasised investigations into the broader social, economic and institutional factors that create the framework for successful innovations, which in turn impact the pace of agricultural development. II have argued that actors concerned with the processes of agricultural innovations and development are embedded in institutional settings with inadequate understanding of factors that constrain and those that would trigger successful agricultural innovations. Human resource development tradition, for example, concentrated essentially on institution building, organisational and management work, and capacity building at research and extension levels. Many scientists, agricultural research institutions and policymakers for SSA have fundamentally 
neglected the importance of the role of farmers in the process. Because of the severity of certain sociomeconomic conditions in rural areas, farmers were viewed as victims and powerless to do something for themselves. They were kept aside to be taken care of.

Indeed, the urgency to overcome social malaise in the here-and-now led to insufficient emphasis on longer-term needs. People believe in concepts instead of daring to face the realities of the fields. Donors have been funding concepts and many researchers had only to follow. For a research project to be funded, it needed and it was enough to subtly insert a notion such as "Comnunity based", "Rural community" "Small farmers", "Poverty reduction", "Gender", "Empowerment", "Participatory", "Poorest of the poor". Everybody wants to empower women and the poorest farmers; everybody wants to involve the poor or whole communities in research. Everybody wants to find the best and rapid solutions to the problems of farmers (the poor) through "artificial" mechanisms aining to involve them, listen to them and giving them a voice.

These thoughts and concepts, however brilliant and well sounding they may appear to be, pose problems in practical sense. What does it imply "listen" to farmers? What are the farmers saying that one has to listen to them? How does one take seriously and involve farmers in his work"? Farmers will be passively waiting and one will be giving them a voice in the development process and then their "problens" will be ended or solved!

I cast doubt on the fact that someone can substitute himself to the "poor". Problems are diverse, interrelated and may vary over time as they are also a concern of mental attitudes. They develop, squeeze or take other forms and may have a multiplying effect. In fact, while some problems arise as a consequence of many factors, others may seem spontaneous. Problems are inherent to human life and can never end as long as someone is alive. So it is for problems related to a whole society, which can change but does not die. This explains why the so many initiatives and policy recommendations aiming at "reducing poverty" do not actually reduce poverty. Instead, they reduce the number of the sa-called poor in the sense that these policies worsen their living conditions and constrain them to die sooner. I radically reject the concept of poverty reduction. In fact, we do not see poverty. We see people whose productivity is too low to generate for themselves sufficient earnings to meet the basic needs of their families. We also see people suffering from low incomes due to many other constraints related to local, national or world interdependence system issues. Thus, instead of trying to end an endless, I have proposed to allow people to gain ability and power enabling 
them to deal with undesirable situations. At farmers' level, I called this power the farmer's innovative capacity (or ability) or farmer's capacity (or ability) to innovate. I made this an explicit case through the lenses of a systems approach to innovations and entrepreneurship theories.

\subsection{System of innovation as a conceptual framework}

The debate over how to enhance agricultural innovations for all categories of farmers in the least developed countries still raises many controversies among field specialists. Because technology is deeply embedded in social systems (Kline and Rosenberg, 1986), the system approach to innovations conceptualises R\&D as part of a wider process involving a range of other factors and actors (Lundvall, 1992). In adopting the systems approach, this study has pursued to identify what it suggests as new tools to be used to trigger agricultural innovation processes. The argument is that applying an approach implies knowing how to use the tools it provides and mastering the contours of one's goals.

The study contends that it is neither enough to admit multiple sources for agricultural innovations (Biggs, 1990) nor is it sufficient to merely acknowledge that socio-economic and political factors have a bearing on innovation processes (Kline and Rosenberg, 1986). Further the recognition that interactions (linkages) between the actors that make up the innovation system affect the performance of the system (Foray, 1997) is just a necessary condition. If innovation performance is strongly correlated with institutional environments that promote learning (Johnson et al., 2003) it is because, like any human activity, knowledge has always been the main input (Smith, 1997). Following Clark (2001), the study argues that each innovation system component must have certain knowledge that grants her/him capacity to make sense of the information (as input resource) s/he received by interacting with others.

Capacity development thus becomes a much more important objective of interventions that support innovation processes. Indeed, if institutions are the root of development in the sense that they favour interactions among system components and allow smooth occurrence of linkages as channels for innovation input resources (Johnson, et al., 2003), knowledge is seen as the most crucial resource driving innovations and development (Gregersen, et al., 2004). Acquiring new or more knowledge for capacity development at system level is thus required for achieving developmental goals. The study then concedes that a system performance is determined both by the individual performance of each 
element (individuals, organisations or institutions), and also by how they interact with each other as elements of a collective system. However, the innovation system approach lacks clarity about the notions of interactions or relationships and, in terms of learning, it overvalues institutions (organisations) at the expense of individuals.

This study contends that interactions are purposive and need based. They may be defined as the search for additional resources (of all kinds) required within given innovation processes or innovative activities. Thus, within an innovation system, all elements may not necessarily interact with each other because all may not need each other, even if one admits the existence of indirect relationships. It is economic agents going about their own production and innovative activities and objectives who find themselves with a need to be involved in relationships if they are to succeed. Engaging in relationships becomes a matter of need and also of deliberate choice.

a) Interactions and pelationships are innovation activities dependent - Their occurrence and intensity depend on the area, complexity and scope of the innovation activities at stake. Domains of activities, their complexity, and their size determine the nature, focus and importance of innovation relationships among system components and direct towards potential partners. This applies even in the case of internal interactions within various units of firms, institutions or organisations.

b) Interactions and relationships are resources dependent - The quantity and quality of knowledge and other resources possessed by agents involved in specific innovative activities or processes compared to those required to perform these activities, determines whether or not and with whom to interact. Another issue is that the more innovative individuals or institutions (organisations) possess resources, the more attractive they are to other system components for interactions.

c) Interactions and relationships are time dependent - Relationship between given elements of a system may relate to specific innovation tasks and thus may not last forever. They may end with the innovative activities but may rise again with new emerging activities.

d) Interactions and relationships are capacity dependent - They imply the capacity of the partners to understand each other. More concretely, it involves the 
capability on the part of the recipient to handle and do something useful with the new resources s/he aims at when engaging in relationships.

In reference to the functions of institutions and assuming that institutions are the main root for development, studies and policy recommendations have often valued them over individuals. Whether institutions are defined as patterned behaviours and organisations as formal structures with an explicit purpose (Lundvall, 1992), and no matter how they emerge, this study argues that neither institutions nor organisations do not exist without people. In an innovation system perspective, even if institutions can emerge spontaneously as self-grown (Lundvall, 1992), they stem from the system components and cannot survive if they do not promote innovations and if they are not desired by the elements of the system. Indeed, as Summers (1974) put it, "When one understands the actions of individuals, then one understands the actions of society, for society moves only as its inadividual memóers move".

The study stresses that values and contexts defining institutions or organisations are embedded in people. If new institutional arrangements in agricultural development put emphasis on capacity development in innovation system terms (Hall et al; 2003), they should foremost aim at developing individual capacities with respect to the desired innovations. Collectively or not, individuals are the first movers of innovations. Only through such a lens is it possible to account for all actors involved in agricultural innovation systems. In fact, the idea that all innovation system components should be proactive is not new. Roling (2004) remarks that farmers seem biased within the agricultural innovation systems and they must contribute to the innovation processes through research. He advocates for engaging farmers as co-researchers and empowering them to have clout in the research process $(2004$, p.17). This study however, argues that transforming farmers into researchers would not ensure effective innovations to all categories of farmers; participatory approaches have had limited effects. Producer-user relationships are preferred. It is necessary to redefine innovation processes and related concepts with individuals at heart. To adjust capacity building in national agricultural innovation systems (NAIS) in the least developed countries, the focus should be seized towards farmers with innovative capacity building. This implies a framework of actions and processes through which farmers acquire the capacity to innovate. To this end, the study has suggested an entrepreneurship framework. 


\subsection{Entrepreneurship theory as conceptual framework}

This study classifies itself among those driving at the constant search for an emergence of new ways of generating, promoting and using new knowledge in agriculture. It answers the basic question of how innovations can be encouraged and promoted at the level of all categories of farmers. Assuming that entrepreneurship skills are innovative by definition, the study has argued that a way to strengthen NAIS and enhance agricultural innovations at farmers' level is to shift the focus to agricultural entrepreneurship. The study contends that the availability of high yield crop varieties and animal species is not enough for farmers to adopt them. The promises of increasing agricultural productivity are, however, the starting point.

Adopting new technologies means expanding production beyond subsistence level, and places farmers in market-led productivity improvements that require strategy to strengthen their competitive ability. When farmers can grow more than they consume, conservation, processing, packaging and marketing of the excess is required. Increased agricultural production therefore has a wider impact and requires more competencies from the part of the farmers. The research contends that it cannot be assumed that the farmers have such competencies, though Röling (2004, P.12) affirms the opposite based on West African farmers.

"... The lack of impact of agricultural research in West Africa cannot be blaned on lack of innovativentess on the part of the farmers. West African farmers can be considered among the most innowative in the uvorld... Our favourite example of West African farmer innovativentess is the development, by farmers on the Adja Plateau in Benin of a new farming system based on an oil palm fallow that deals with extremely high population pressure on the land... Snall-scale farmers in West Africa are amazingly inwowatioe..."

There is no way to deny these statements as they are true. During my fieldwork, some Songhail farmers in Houègbo (the Atlantique region in Benin) have acknowledged the adoption by the whole village of new techniques for tomato production from farmers from the Adja Plateau in Benin. There are many other examples of innovativeness of farmers from Adja Plateau and I can mention my father. In his village he was the one who owned a well (source for the water supply he made). For him it was immoral to delay people in getting drinking water from it because from the same well he got water for the counter-season tomato production. Early in the morning, before we went to school, he woke us (my brother and me) up to draw water from the well into barrels. In the evening, after classes, we watered the tomatio field. He contended that there was no gain in waiting for rain and producing tomato at the same time like everybody does. 
He used to articulate the need to act differently from others and the necessity to anticipate profitable opportunities.

Further, Ir. Watoundji Noel, an entomologist who has been working for more than 20 years at $\mathbb{N R A B}$, mentioned to me during my fieldwork:

\begin{abstract}
"Lands are very badly exploited becianse of lack of know-how from the part of the farmers.. Mary forming technigues do not diffuse to all farmers in the country.. Farmers in a small allage in the Couffo region (the Adja Plateaw) hawe developed very good techninues for cotton production due to constrains on land. With the same quantity and quality of other iniputs, the cotton yields in that village double thase of other parts in Berin. However, even farmers in the nearest willages distant less that $15 \mathrm{~km}$ do not know about these techniquds... Training farmers on diverse methods and tectniques is a basic requirement for the diffusion of new farming practices and for an efficient agricultural production..."
\end{abstract}

The claim of this study is the need to upgrade, develop and build new capacities for farmers. It drew from the joint relationship between entrepreneurship and innovation and suggested that building entrepreneurial skills for farmers would trigger their innovative capacity.

Entrepreneur/entrepreneurship has been defined with respect to many activities, functions and behaviours. These include: (1) entrepreneurship as a risk taking activity and the bearing of uncertainty, (2) entrepreneurship as the creation of business organisations, (3) entrepreneurship as the bringing together of factors of production and as management of production and distribution activities and (4) innovation as the wnderlying factor of entrepreneurship. Therefore, defining entrepreneurship as a process of search, discovery and economic exploitation of what people have so far overlooked, means that those involved in the process have the ability to carry out new combinations (innovations) that meets market needs. It implies that market deficiencies exist and can be perceived only by those capable of transforming them into supply. Indeed, as a wise person once observed, "Anybody can see a seed in an apple; the wise person can see an apple in a seed." By analogy, the study makes the connection that "to see an apple in a seed" is to have the potential to become an entrepreneur.

Finally, it is by innovating that entrepreneurs sustain their production activities and become the prime movers of economic growth and subsequent development (Schumpeter, 1934). To argue with Schumpeter that without innovations there are no entrepreneurs, is to ascertain that entrepreneurial endeavours result in innovations. Thus, the promotion of agricultural entrepreneurship is the direct 
enhancement of successful agricultural innovation processes. Then, emerged the basic question of how to "produce entrepreneurs."

The supply of entrepreneurship is affected by many factors, not all of which can easily be controlled or changed (Burnett, 2000). Based on characteristics of entrepreneurs, the study has demonstrated that entrepreneurship educational programmes constitute a key determinant for successful entrepreneurship, no matter the sector. New education initiatives should be created to teach entrepreneurship. By equipping more people with the skills to become entrepreneurs, a country can effectively increase its supply of competent innovators. I believe that entrepreneurial dynamics at farmers' level will revitalise interactions among NAIS components while contributing to strengthening linkages. With entrepreneurial skills, farmers gain innovation capacities and economic competencies allowing them to learn how to make innovations work. Further, another issue warrants and strengthens this viewpoint about the need for entrepreneurial training at farmer level.

Many people want to undertake farming as a new business. But traditional sources of information and learning based on inter-generational transfer of farming knowledge and skills don't meet this need. Many people who are considering a farming career may not come from farm families and thus lack the tools or experience to make effective decisions about farm entry (Growing New Farmers $)^{1}$. The challenge of agricultural entrepreneurial training is to rebuild and strengthen NAIS so that, if not all, the bulk of farmers can access the technical, informational, natural, and capital resources they need to innovate and succeed. This acknowledgement raised the question of the pedagogical contents and processes of entrepreneurial training.

The desired agricultural entrepreneurship training should focus on both theoretical and practical aspects of entrepreneurial behaviour but with greater emphasis on practical issues in a real environment. In this respect, the study has espoused the viewpoint of Mitton (1997) who clearly stresses:

"In entreprenewrship, knowing is nof enough... Entrepmenutwial prowess is not in what you know, but in what you can do with what you know.. No antown of simulation in the classroom will fully prepare sonneone for the hardships and personat anguish hat a business is bound to cause... No amount of positive reinforcenent or feedback in a training course is likely to cowe close to the thrill of acherement after a difficult struggle..."

' http//gnf.bigmindcatalyst.com/cgit 
Finally, what this study aims at and stresses is that, in addition to technical "know-how", the farmers may already possess, they need the "know-who", "knowwhere", "know-what", "know-when" and "know-why". As a matter of academic research requirement, an empirical study was carried out in order to investigate the consistency of what I believe to be true when contrasted to field realities. The first step towards this accomplishment consisted of the identification of an appropriate educational institution. I made an exploratory field research where I found that the "Songhai Centre" or "Songhai" provides the expected framework for an analysis: a case study. The case study is descriptive, illustrative and explanatory in that it intends to understand Songhaï as an institute; it explains the training programme and identifies its effects on farmers' ability to innovate. The case study presents an interesting challenge in that $I$ look at sub-cases within the larger case. The research methodology thus uses an embedded case study method. While I want to investigate the innovative capacity of Songhai farmers (the targeted case) as a result of their full-time enrolment in the training programme, I first describe and present the Songhai Centre as a first sub-case followed by the training programme as a second sub-case.

\subsection{Empirical results}

Three units of analysis including the Songhaï centre, the Songhaï entrepreneurial training process and the Songhaï farmers form the embedded case study embodying the empirical research. Results have been presented in four chapters and related issues broadly discussed. To recall, the main objective of this work has been to answer the main questions:

a) Conceptualising agricultural innovation in system terms, how to enhance continuous innovation processes that ensure the development of agriculture?

b) Conceptualising farmers as components of an agricultural innovation system, what new forms of training and capacity development would be needed to allow continuous innovation processes at farmers' level?

c) Using the Songhaï training framework as an example, how can the innovative capacity of farmers be built other than just through training in new production techniques? 
d) How are the attributes of the Songhai training different from the current models of extension or farmer training?

e) Conceptualising (agricultural) innovation systems in the context of developing countries, what sorts of skills, attributes, habits and practices would be predicted to be involved in building the innovative capacity of farmers?

\subsubsection{The Songhaï centre as unit of analysis}

The Songhaï centre is a socio-economic and rural development actor specialised in production, research and agricultural entrepreneurial training. As such, The Songhai centre is, itself, described as an institutional innovation in many respects. The problem it aims to address may be not new, but its approach is uncommon. In effect, the founder of Songhaï noticed that SSA lagged behind the other regions of the world; it was really in a bad shape (no significant improvement to date). He realised that the power to restore bad things, and create new ones and wealth lies in human being. It is also in the capacity of society to command its surrounding environment. It remains, foremost, in the capacity (skills and competencies) of individuals or organisations involved in various socio-economic systems. The power of a nation or region to cope with the needs of its ever changing social, natural and economic environments, lies in the abilities of its people to renew, through production activities, their consumption to a level equal, at least, to the value of the consumption.

However, for the founder of Songhai, the power of producing wealth goes beyond technical competencies. It also includes social, cultural and institutional values such as spirituality, ethics at work, confidence in oneself and in others, courage and perseverance, passion and love for one's world. It is in this mind he found out that "a bad development equation" was written for Africa. It was then that his passion and love for the continent that propelled him to write "ant equation" embodied in the Songhaï Centre he created. The Songhaï centre is an open dynamic institute that combines indigenous and modern knowledge based on social and cultural, economic and natural environmental realities.

The Songhai Centre initially seems to be a modest farm built around three components to development: crop production, animal husbandry and fish farming, where everything is organically grown in a simple way. The integrated production system is based on minimal inputs and use of local resources. It is 
also based on no soil degradation, no pesticides, no pollution and no waste. Wastes from one production unit become inputs for other components. Here production activities become more profitable because they belong to the system in which the different components strengthen each other by the means of what they provide to the others or receive from them. But the main goal of the Songhai was not production per se. it lies in the conviction of the founder that the only way to fight poverty in Africa is to transform the poor people into active producers using local resources. The social process through which this transformation happens is central to Songhai undertakings: agricultural entrepreneurial training.

\subsubsection{The Songhaï training as unit of analysis}

Through its vision, Songhai wants to bring an alternative answer to the social, economic and cultural crisis that has been threatening SSA. Songhaï admits that agriculture will inevitably play a vital role in the process of the overall development in SSA. It also acknowledges that agriculture cannot be carried out without qualified human resources. This recognition has led the institute to embark on training/leaning processes aiming at promoting agricultural entrepreneurs and professionals. The professionals are technically prepared in agricultural and related activities while strongly equipped with ethics and moral values. They are general-purpose managers with leadership capacities of who willing to transmit their knowledge to others. The main idea is to transform the learners into real actors of development. The requirement is to build human resources of a new standard, capable of seizing a culture of entrepreneurship that is a better guarantee for the self-promotion of the populations at the grassroots.

The principal merit of the Songhai training process consists of setting up a framework of apprenticeship and pedagogical follow-up based on traditional systems, and which combines new knowledge, know-how and know-being. It is also important to stress that the peculiarities and efficacy of the training lie in the fact that it is truly based on the realities of a business organisation. The various activities carried out in the different production units constitute the framework and the support for the teaching. It is a system of follow-up, which privileges a handy relationship between learners and educators in an environment of risk sharing. The strong point of this follow-up lies in the complicity that exists between learners and their educator. This educator is, at the same time, the master of the workshop where the various productions take place. The culture of success fascinates the students and impels them to become like the master. Since 
its creation in 1985, statistics at the end of March 2004 show that Songhai has educated 856 regular students and over 1,250 short-term trainees. In spite of recorded progress, the Songhaï training has some limits

There is a fear that the students can put themselves in a sort of automatism: imitate and build an enterprise in the image of Songhair. To avoid this, the training frame foresees to stimulate the premises and the capacities of the students to innovate. They must be able to make an adequate reading of their environment in order to adapt to it, the knowledge they have acquired. Obviously, Songhaï wants to be an "open book", a source of inspiration where one can swamp as much as s/he wants and needs. Even this reality hides another risk some learners may run: only the smartest and most curious will be able to truly benefit from the system. To avert this threat, the tutoring foresees, at the level of each production and training unit, some minimal requirements of knowledge and know-how, and through which the educators have to lead the learners. Furthermore, the training process in the workshops or production units is not a simple teaching demonstration, but involves participation in the life of the enterprise. It often happens that some important management decisions are only the responsibility of the masters who must have strong managerial capacities and the will to share with the learners the issues of their decision.

In addition, the training system is based on the principle of "nothing worthies action". In this respect, spaces known as application sites have been arranged to make it possible for the prospective farmers to apply and experience real entrepreneurial behaviours. These relate to alertness on economic or market opportunities, decision-making about what activities, how to start them and with which means, management and administration of an enterprise in real environment. The sites of application are then the places of practice of entrepreneurship. However, such training policy produces the anticipated results only under the condition that the teaching framework is dynamic. The follow-up of the activities, the organisation of teaching weeks and other seminars aiming at upgrading and updating knowledge of the farmers, answer this requirement. If Songhai shines by the uniqueness of its production framework and training programme, what about the Songhai trainees (farmers) after graduation: how are they demonstrating innovation abilities? 


\subsubsection{The Songhaï farmers as unit of analysis}

The Songhail leaming/training programme on skills, knowledge and agricultural entrepreneurship has also become a means of employability. For those who, for certain reasons will later or never undertake their own farming production, the training enhances their mobility in the labour market and offer the potential for increased career choices. Defined broadly, employability is a key outcome of education and training of high quality, as well as a range of other policies. It encompasses the skills, knowledge and competencies that enhance a worker's ability to secure and retain a job, progress at work and cope with changes. Individuals are most employable when they have broad-based education and training, basic and portable high-level skills. The entrepreneurial training we have examined has equipped many trainees (about $40 \%$ of graduates) to find jobs and gain more money to constitute the capital for their future enterprise. But the main question the study tried to answer was how graduates who established their own farming enterprises have demonstrated behaviours that can be qualified as innovative.

The concept of innovation is broad and generally denotes commercial exploitation of something new or the exploitation of the new thing for commercial purpose. This specific character of innovation explains why the analysis placed $i t$ in its historical context of entrepremeurship. The argument is that whatever the source of any "new thing", in general, it is through business mechanisms that it becomes innovation. It is argued that the factors that matter for agricultural enterprise are those that matter in general for businesses: access to inputs and output markets. What also matters is of course, information as a determinant of enterprise and the attitudes of those farmers who formed and ran the farming enterprises.

Thus the study put on the ground of discussion two sets of issues. A first set comprises a number of factors (or actions or deeds), which are normal in the sense that they can be carried out by any individual. The analysis then explored whether the entrepreneur farmers have demonstrated any behaviour toward them that could be qualified as innovative. The elements of this set include access to land, access to credit or finances, and access to information networks. The second set comprises such factors (or actions or deeds), which are, by definition, innovations. The analysis examined how the farmers have exploited them through the demonstration of entrepreneurial skills they might have acquired at Songhai. Under this category of innovation, fall integrated agricultural production, conquering new markets by being the first producer and supplier of 
given products, permanent job creation (in the context of agriculture in Benin) and the adoption of appropriate agricultural new technologies. The interviewed farmers formed a sample of 75 randomly drawn established Songhaï graduates as agricultural entrepreneurs. The analysis of the data yielded the following results:

i. As a result of the training, $52 \%$ of the farmers have proven bargaining skills enabling them to access the land required to set up their farming businesses (see 7.3.1)

ii. Out of the total number of 75 farmers, 47 have demonstrated innovative behaviour in terms of been alerted to perceive "an apple in a seed". They have been the first producers and suppliers of certain vegetal, animal and processing products (see 7.4.1).

iii. The empirical data shows that, according to the integrated production factor, $56 \%$ of the farmers have innovated (see 7.4.2).

iv. Out of the 75 interviewed farmers, $49(65.3 \%)$ acknowledged that they have adopted new agricultural technologies in form of new methods or techniques (regarding soil preparations, plant seedlings, animal cares, pest. control, harvest, conservation...) in the performance of daily or seasonal farming tasks (see 7.4.3).

v. Of the sample, 47 farmers (62.6\%) were found to be rearing animal species new to them and the markets they supply. They have definitely acknowledged that they would not be able to adopt the new animal species without the technical knowledge, management skills, bargaining and marketing competencies they acquired at Songhai (see 7.3.3).

vi. Considering the general financial (credit to agriculture) market in Benin, the Songhaï farmers have exceptionally demonstrated entrepreneurial and innovative skills in accessing this "golden" production factor. Financial assistance opportunities, apparently, are not alarming to them: $52(69.3 \%)$ out of 75 have benefited from financial assistance in form of subsidies and credits from different sources (see 7.4.4).

vii. Concerning job creation, 63 farmers (84\%) employ (each) approximately 9.6 seasonal workers per year. This is normal in farming production. However, permanent job creation in small-scale agriculture implies that the production activities generate regular income on a daily, weekly or 
monthly basis, at least. It also requires that the activities carried out have, theoretically, high return rates to investment. That 22 farmers have 45 permanents employees is innovative (see 7.4.5).

viii. Following Schumpeter, competition has more to do with innovations than prices. Of the farmer sample, $68(90 \%)$ acknowledged the existence of many producers and importers on their respective markets. However, 53 $(70 \%)$ of them. have been able to have the market share they need for their production. They have explained that the key of their success is, foremost, the quality of their products and the use of new marketing techniques they learned (see 7.4.6).

ix. The Songhaï training/learning processes led the farmers to not only value the importance of information, but also develop an eagerness to learn where, when, and how to access new information. The farmers stressed that they search for other sources of knowledge or information if the problem or the task at stake, technically, lies beyond the framework or competencies of the local coordination of the RENAFERS. Out of the 75 farmers, 30 have more or less regular contact with researchers from INRAB, CARDERS, FSA and IITA and 31 farmers have relationships with various exporters of agricultural products. While 37 farmers notified that they are members of diverse farmers' associations either at local, regional or national level, 61 claimed membership in the RENAFERS. While the rellationships are not mutually exclusive, 65 acknowledged personal rellationships with local farmers (see 7.4.7).

\subsection{Complementary analysis}

Many institutional and organisational settings failed to deliver promises of continued innovations. A common theme among their failures is a lack of understanding of the mixture of skills and socio-economic factors that underlie agricultural innovation processes. Putting an emphasis on individual farmer abilities within the agricultural innovation system was to argue that some innovation determinants fall under the sphere of control of the farmers. It is also argued that when a farmer can master at least some of the basic elements $s$ /he can control, then it is probable that s/he will find a way, means or methods to remove some of the major exogenous constraints. 
Indeed, the last point of the empirical study has tried to investigate other factors that could have a bearing on farmers innovative performance. Two innovative performance variables (dependent) have been defined. They include the level of innovativeness (LINNOW) of the farmers and the trend of farmers' assets (TAF). Ordered probit model and probit model are used respectively to predict the likely effect selected explanatory variables have on them. In both cases the statistical package STATA completes the computations. Explanatory variables included:

a) Initial Investment Capital (ITC)

b) Farming Background of the Farmers (FBG)

c) Educational Level (EDL)

d) Age of the Farming Enterprise (AGFE)

e) Access to Credit (ACC)

f) Access to input and output markets (ACM)

g) Access to information ( $\mathrm{ACl}$ )

h) Access to land (ACL)

i) Age of the farmers at the beginning of their training at Songhai (AGTB)

j) Marital status (MARS)

k) Number of children (NBCH)

l) Zones or regions

\subsubsection{The strength of the Songhaï training/learning framework}

Through the course of this study, the analysis has revealed that the Songhai farmers are innovators in the sense of Schumpeter's entrepreneurs and beyond. They have demonstrated their innovativeness through innovative behaviours and capacities; they continually experiment with new and more efficient practices. The hypothesis testing results have revealed that the levels of innovativeness of the farmers do not depend on explanatory variables EDL, FBG and $A G T B$. In the same way, the regression of independent variables EDL and FBG on the dependent variable TAF has not shown statistically significant effects. The study infers that it is the quality of the Songhail training, in terms of its pedagogical content and process as well as the personal motivation of the students themselves, which has contributed to break initial educational differences and other past experiences and built a new common knowledge background for the graduates.

In effect, the Songhaï training process, which embraces many theoretical and practical issues, is a sort of apprenticeship, and the concerns are context- 
dependent, focused on specific information and knowledge relevant to more immediate problems with less interest in a standard long-term course of study. This is consistent with a system perspective that emphasises that innovation processes are deeply embedded in social systems. It implies that innovation performance also depends on the economic and social conditions under which one operates. These include production location, markets and resources, and also availability of complementary products and services. The process of innovation therefore depends on the existence of systematic relationships between the farm and its environment. In this connection, the fact that factor region, in general, has not affected the level of innovativeness of the farmers was questioned.

In Benin, Songhai has organised three significant training centres. As mentioned in chapter six, Songhail advocates that the objective of setting such learning infrastructures in the south, the centre and in the north was to respond to specific characteristics of each region. In addition to some core knowledge focus, different patterns of farming systems, agro-ecological differences and agricultural business opportunities that the regions present are also content of the curricula. Also, Songhail itself claims to add more by providing a training that responds as well to future needs of the farmers. It aims to equip the learners with at least the background enabling further knowledge acquisition. These empirical findings are consistent with an innovation systems approach for which diversity in the innovation processes and the routes towards them, do not allow confining innovations under the sole influential power of skills gained through educational processes. However, what is fundamentally argued here is that skills and competencies are motivating factors for the occurrence of other determinants of innovation.

\subsubsection{Innovations drive innovations}

Interactions between agricultural production and the socio-economic and institutional environments also play a vital role in supporting innovation processes. The role of institutions that provide services and incentives is very important in determining the uptake of a successful innovation and developing its potential as a tool for triggering broader development processes. In this study, the analysis has proven that availability of various forms of financial assistance to agricultural undertakings and the existence of diverse sources of information as knowledge inputs, which the social, institutional and economic environment provided to the farmers, were statistically significant in influencing the level of innovativeness of the farmers. Indeed, if the abilities to generate, diffuse, and 
utilise technologies that have economic value couple with economic competences to enhance innovations, innovations are themselves, and by definition, determinants of innovations. In the context of this study (chapter eight), $A C C$, $\mathrm{ACI}$ and ACM constitute different types of innovations at farmers' level. That these three factors positively influence the level of innovativeness of the farmers is evident. In addition, their impacts on the trend of the assets of these farmers are positive.

\subsubsection{Financial assistance}

In general, some resources determine what a business can do, but not how successful it may become. Whatever the amount of the explanatory variable IIC, its effect on both the dependent variables, is negligible. The probability of change is too small: $0.005 \%$. It may imply that farmers do not embark on many innovations at the outset of their enterprises. Indeed, at least $50 \%$ of the farmers started their business with an IIC less or equal to 152 euros. This amount might not allow great fluctuations in innovative patterns of the farmers. Moreover, in most of the cases, farmers who set up their enterprises with higher amounts of IIC used them to acquire land. Finally, it can be understood that the amounts of working capital the farmers had at the start-up of their businesses were very low and the scope of their innovative performances depended rather on their skills, competences and other factors. This confirms the fact that acquiring and owning resources is not a sufficient condition for innovations nor is it a requirement for entrepreneurship. It follows that the training process, in this case, has accomplished one of the fundamental notions very dear to Songhaï, and which it is expected to support: "use what you have, to get what you want". This is not however, to say that the Songhai training alone constitutes the sufficient factor for innovation. Once an agricultural enterprise is set, to survive it requires additional means and resources to boost innovations.

Following Ventura and Milone (2004) it is unlikely that farmers will confine themselves to the current observable innovations. Rather, they are likely to evolve into complex innovative processes that would ultimately lead to the redefinition of the scope of their undertakings. This highlights the continuous character of the innovation processes. The need to find solutions to the constraints that emerge once the initial project has been embarked upon drives a succession of continuous adjustments while appealing to new financial means (Ventura and Milone, 2004). It explains why access to credit or financial assistance has positive effects on both the dependent variables TAF and LINNOV. 


\title{
9.7 Concluding remarks
}

Today, it seems to me incomplete to focus on agricultural innovations in system terms without reference to the notion of Agricultural Knowledge and information System (AKIS). In a recent FAO Communication Roundtable paper, Röling (2004), Emeritus Professor of Agricultural Knowledge Systems, lamented over the misunderstanding and misinterpretation of the concept of AKIS he developed. Compared to the concept of National System of Innovation (NSI), Röling (2004) argues that AKIS does not exist in the real world; it is not composed of given actor categories; and it does not stop at national boundaries. An AKIS is a soft system; its boundaries are arbitrary and depend on the configuration of actors in a given theatre of innovation (Engel, 1995 as cited by Röling, 2004, p.4).

\begin{abstract}
"My notion of AKIS has to do with netuorks of multiple stakeholders, with learning and with interaction. It has to do with the way we make serse of the future and of the opportuntites that are arnilable. An AKIS is not a predefined construct; it emerges from interaction (usually tempomy betwen actors who mutually complement one another's contribwtions. The actors are auare of the fact that they form a system and do their best to maintain it. They talk a lot about their system" Röling $(2004$, p. 5)
\end{abstract}

This definition makes it clear that when farmers, as actors, are themselves aware that they form a system and do their best to maintain it, there is no need to give them a voice; they already have it as a system component. Basically, each individual in a society has a voice. He must endeavour to make his voice heard. Otherwise, as researchers fnous on. what dnoors want. farmers will just voice what people giving them voice want them to say. My wiew is that voice is like power that one needs to fight for. One needs to fight to make his voice heard. To win the battle, he needs to have and use the right weapon. Knowledge of all kinds is, by excellence, what represents the entire weapon. It can become obsolete, then inappropriate for certain circumstances. Therefore, "the challenge is to create social spaces for learning" (Jiggins and Röling, 2003 as cited by Röling, 2004, p. 17) in order to upgrade or add to one's stock of knowledge. For example, the history teaches that in today's most advanced democracies, men didn't give women the right to vote. Women (who are however their mothers, wives and sisters) had to fight for themselves in order to make their voice heard (by men and by themselves) as they were becoming more educated, learned and knowledgeable 
If "an AKIS is a more or less a temporary configuration of actors and institutions considered relevant for bringing inprovement to a situation ... and if it is a voluntary coalition of interest, made up of people who have come to form at theatre of innovation because they have confidence that a useful play can be enacted in that theatre" (Röling, 2004, p.18); then there's no need to make farmers co-researchers. Asking them to participate in research contradicts their interests, which are production, production management and the marketing of production outputs. Indeed, the notion of a system is by essence participatory. Being a system component means providing inputs for other elements and contributing to the achievement of their interests. It also implies receiving from the others, certain kinds of resources necessary for one"s goals within the innovation system. In an innovation system, each component needs to make itself interesting and indispensable for the others. It is the relative importance in terms of what a system component can do (what it gives and receives) which grants him/her negotiating power within a framework of multiple interests. Further, there is more to it.

Within the agricultural innovation system "farmers have no negotiating power" and it urges to "better find ways of giving it to them" (Röling, 2004, p.17). I understand that the Emeritus Professor aims to stress the need for processes through which farmers would acquire negotiating power, given that it is also a skill or competence to acquire and develop. If one could accept, for example, that "a PhD research is a training process through which one learns and acquires research skills", then there is no way to deny farmers going through training programmes that would build up their capacity to innovate. Training increases the ability of the learned farmers to understand and evaluate the information they receive from the other components of the agricultural innovation system (Nelson and Phelps, 1996).

To contribute to research (act as co-researchers), to make their voice heard, to be able to negotiate on equal footing, represent all innovative capacities that farmers need to acquire, develop and constantly upgrade through training and learning processes. Underlying training is the theory that education enhances one's ability to receive, decode, and understand information and that information processing and interpretation is important for performing or learning to perform many tasks (Nelson and Phelps, 1996). Training farmers on agricultural entrepreneurship grants them entrepreneurial skills, which are, by definition, innovative. To seize market opportunities with new ways to marshal the necessary and most appropriate resources, to carry out new combination of the new resources and to produce goods and services... And still there is more needed to innovative capacities at farmers" level. 
As Röling (2004, P.4) argues, "anyone familiar with the West African scene, for example, would agree that... knowledge, information and even tested technologies are not in the minimum; what is lacking are the institutions, marketing chains... "In adopting new technologies of any sort, farmers must also have the ability to predict the results on increasingly competitive markets. To compete, based on the quality of goods and new servicing methods, requires skills that fall under the sphere of innovative capacities the farmers need. In simple terms, trained and learned farmers make good innovators. Innovative capacities acquired through agricultural entrepreneurial training processes render farmers effective elements of agricultural innovation systems. Evidence for this hypothesis is what I revealed through the case study of the experience of Songhail farmers in Benin.

\subsection{Limits of the research}

During the process of this research, I happen to meet many scholars with whom I discussed and shared the research framework including the methodology. A common criticism was the lack of a control group against the Songhail farmers. This remark would imply that the absence of investigation of the innovative behaviours of non-trained farmers constituted the major weakness of the research. In effect, the idea of extending the research to non-trained or peasant farmers was evoked at the stage of the research methodology. At the outset of this consideration emerged the main question of how to exclude spillover effects resulting from the interactions of trained farmers with the others? Indeed, one of the major missions assigned to Songhai farmers is the sharing of their knowledge with their surrounding farmers.

Further, chapter two presented the general environment of peasantry agriculture. It described how most institutional settings failed to promote innovations to the bulk of the farmers. It is the absence of a dynamic innovative behaviour at farmers' level that constitutes one of the major constraints to the development of agriculture. Unless this general state of the least developed countries agriculture is denied, there will be a need to consider a control group. This research therefore, considered the Songhai farmers as a control group tested against what we already know from literature about new agricultural technologies and peasants in the least developed countries. Chapter seven (mainly) provides a very clear analysis and understanding of how this is done. When the interviewed Songhai farmers were asked to mention in what way they think they are better off when compared to non-trained farmers they said (see section 7.2.4): 
"... We hove really acquired the fundonental knowledge and skils required to carry out dally actioities as agricultural entrepreneurs. The wost important is the practical technical know-how, which is nore useful in fanning. Moreover we lawe acquired the sense of observation and analys is that does not confine us to copying just what exists..."

"... We have been living with them (peasants) for lowg and we were one of them. We know what they do and we know what we were doing. The peasants are our parents and brothers, our friends and neighbours. Even after training we continte to work logether with them; they need us and we need them. Without training, we know what our approach to farming and aur practices will continue to be..."

"...Definitely, we have gained thorongh knowledge about cropping systems with a better understanding of sowing seasons. Animal production techutgues with the ability to diagnose animal diseases and provide basic treatnents or carry out daily animal cares and animal feeds making are absent in "peasant farming". More importantly, we have acouired capacity in designing business plan implying farming enterprise management capacities (seizing market opportunities, market amalysis and prodnction decision making to avoid very risky activities; activity planning, with decent capacity in cost-effectiveness). We have acquired unquestionably, more endurance at work. Finally we gained more social consideration..."

\subsection{Further research policy and implications}

The study has fundamentally led to the following:

a) In the quest for socio-economic development, the least developed countries can build upon agricultural development.

b) Agriculture develops when the innovation system, in which it is embedded and which supports it, is strong enough to enhance access to agricultural innovations to all categories of farmers.

c) Strengthening the agricultural innovation system implies:

$\Rightarrow$ Motivating the system components towards appropriate interactions and relationships between themselves and their surrounding world.

$\Rightarrow$ Strengthening individual components' skills and competences within the framework of their undertakings... it is within the framework of their activities that system components interact and build up new relationships 
that have a bearing on their own results and on the performance of the system as whole.

$\Rightarrow$ Without the improvement of individuals skills and competences, raising awareness about the importance of relationships and without the deliberate proactive behaviours and endeavours for better performances at each individual component level, there is nothing called a system one cain strengthen.

d) In the past, many actions, political endeavours and institutional settings have led to build up skills and competences at the level of researchers and extension agents.

e) Policies and institutional settings and approaches aiming at integrating and strengthening relations between farmers or farmers' organisations with other components of the agricultural innovation system, had very little effect. The reason is that farmers do not always have required competences and skills to respond to the ever changing environment of innovation processes.

f) Thus, in the NAIS, farmers appear as the weakest links that need to be strengthened through training and learning mechanisms.

g) The most appropriate training/learning process to equip farmers with innovative capacities is entrepreneurial training that allows them to acquire technical knowledge, management skills, distribution, marketing competences and other skills related to the search for information.

Further research topics and policies should aim at the promotion of excellence centres for agricultural entrepreneurial training. An example of such a training centre already exists in Benin: The Songhai Centre. Other countries could draw inspiration from Songhai and make a design that responds best to the specific socio-economic conditions of their countries.

Further research topics and policies should aim at enhancing more financial assistance to agricultural entrepreneurs. Further research topics and policies should focus on creating more favourable conditions for access to other markets than the local ones. 


\section{References}

ADJEBENG-ASEMt S (1995). Translating Technological Innovation into entrepreneurship in Nigeria: Social and Policy Implications. Techology Policy ard Practice in Africa.Intemational Development Resench Contre.

AGRAWAL, A (1995). Dismantling the Divide Between Indigenous and Scientific Knowledge. Development and Change, Vol. 26. pp 413-439

AHMED, I. and RUTTAN, V.W. (1988). Generation and Diffusion of Agricultural Innovations: The role of institutional factors. Ed. Aldershot (England).

ANDERSEN, E. S (1992). Approaching National Systems of Innovation. National Systems of Innovation: Towards a Theory of Innozation and interactive leaning. Printer Publishers, London.

ANTONITES, A.J (2003). An Action learning approach to entrepreneurial creativity, inmovation and opportunity finding. Business managenent, unuersity of Pretoria, Pretoria.

AROCENA, R. and SUTZ, J (2002). Innovations Systems and Developing Countries. DRLID Working Paper No. 02-05. Aalborg: Danish Research Unit for Industrial Dynamics, Aalborg Unituersity

ASIABAKA, C, C (2002). Promoting Sustainable Extension Approaches: Farmer Field School (FFS) and its role in sustainable agricultural development in African. Available at: h.tp://www.codesria.org/Links/conferences/ifs/Asiabaka.pdf

ASTONE ] (1998). Incorporating local history into planning documents: A case study from Guinea, West Africa. World Development, Vol. 26 No. 9.1998.

AUDRETSCH, D (2001). Entrepreneurship Policy and the Strategic Management of Places. Procedings of Conference on Entrepreneurship Policy: What's Goternment gol to do with it? Cambridge: Kennedy School, Harvard Uninersity.

AVENANT, P.I (1990). Guidelines for successful teaching. Durban, Butterworth

BADIANE, O., (1999). Agricultural Recovery and Structural Transformation in African Countries. International Food Policy Research Institute. Washington $D C$.

BAN van den, A.W., and HAWKINS, H.S (1996). Agricultural extension (2 ${ }^{\text {nd }}$ Ed.). London: Blackwell Science 
BARRETI, C. B, PLACE, F. ABOUD, A. and BROWN, D.R (2000). The challenge of invproved natural resource management practices adoption in African agriculture: A Social Science Perspective. Paper prepared for the Workshop Understanding adoption processes for matural resource nanagenent practices for sustamable agriculture production in Sub-Saharan Africa, Nairobi, July 3-5, 2000. Aoailable at: htp:/www.cnr.usu.edu/resench/crsplicrafpdf

BASALLA, G (1988), The Evolution of Technology. Cambridge University Press.

BAUMOL, W. J (1968). Entrepreneurship in Economic Theory. The American Economic Reolew, 58, p. 64-71.

BAUMOL, W. J (1993). Entrepreneurship, Management and the Structure of Payoffs. Cambridge, MA: MIT-Press.

BAUMOL, W. I (1993b), Formal Entrepreneurship Theory in Economics:

Existence and Bounds. Journal of Business Venturing 8, 197-210.

BHATTARAI, G, HATCH, U. and ZHANG, D. (2004). Landuse Change in WestGeorgia: Combining Socioeconomic and Remote Sensing Data in Econometrics modelling at Watershed Level UsingGIS.

Paper presented at the 2004 Georgia Urban and Regional Information Systems Association Conference, Peachtree City, Georgia, September 22-24, 2004. Available at: http:llowwo gaurisa.org/gugc/ppt/bhatiaraipdf.

BIAOU, G (1998). Régime foncier, crédit rural et utilisation des ressources productives dans les exploitations agricoles du département du Mono au Bénin. Thèse de doctorat d'état de l'Unité de Recherche en Sciences Economiques et de Gestion de lunversité de Cocody à Abidjan, Côte d'Tooire $337 P$.

BIGGS, S.D (1990). A Multiple Source of Innovation Model of Agricultural Research and Technology promotion. World development, Vol. 18, No 11, pp. 14811499.

BIGGS, S.D. and MATSAERT, H. (1999). An actor oriented approach for strengthening research and development capabilities in natural resource systems. Public administration and Development. Vol. 19. pp. 231-262.

BIGGS, S.D. and SMITH, G. (1998). Beyond methodologies: coalition building for participatory technology development. World Development, Vol. 26. pp 239-248.

BLAUG, M (2000): Entrepreneurship before and after Schumpeter", in "SWEDBERG, R, Entrepreneurship -The Social Science View. Oxford: Oxford University Press, $2000^{\prime \prime}$. 
BLAWATT, K (1995), Defining the Entrepreneurs: A Conceptual Model of Entrepreneurship. Proceedings of the $12 \mathrm{~h}$ Anmal Conference of the CCSBE (Canadian Council for Small Business and Entrepreneurship), Thunder Bay, Ontario, October: p. 13-37.

BOGDAN, R. C., \& BIKLEN, S. K. (1992). Qualitative research for education: An introduction to theory and methods. Boston: Allyn and Bacon, Inc.

BOLTON, B and THOMPSON, I (2000). Entrepreneurs: Talent, Temperament, Technique. Butterworth Heinemann, Oxford

BOTKIN, J., DIMANCESCU, D. and STATA $R$ (1983). The Innovators: Rediscovering America's Creative Energy. New York, NY: Harper and Row

BOZMAN, B. (2000). Technology transfer and public policy: A review of research and theory. Research Policy, vol. 29, nos. 40e5, pp. 627-655.

BRANSON, R (1998). DTI Innovation lecture. Available at: http://www.delv.co.uk/delvresult/richard+branson

BROWN, D. (1985). People-centred development and participatory research. Haroard Educational Review, 55(1).

BULL, I. H. T and WILLARD, G (1995). Entrepreneurship: Perspectives on Theory Building. New York: Pergamon

BUNCH, R (2002). Farmer Field Schools: The Perspective of an outsider and friend. International Learning Workshop on Farmer Field Schools (FFS). Emerging Issues and challenges. 21-25 October 2002, Yogyakarta, Indonesia

BUSINESS DAY (1987). Degrees of Confidence, October 27:12.

http://www handels.gu.se/ifsam/Streams/Poster/78\%20POSTER\%20finallpdf

BYGRAVE, W. D. and HOFER, C. W (1991). Theorising about Entrepreneurship. Entrepreneurship Theory and Practice 16, no. 2 (1991): 13-2.2.

CANTILLON, R. (1755). Essai sur la Nature du Commerce en Général. London: Fetcher Gyler. Also edited in an English version, with other material, by Henry Higgs, C.B. London: MacMillan (1931).

CARLSSON, B. and ELIASSON, G. (1994). The Nature and Importance of Economic Competence. Industrial and Corporate Change, $3(1), p p, 687-711$ 
CARLSSON, B. and STANKLEWICZ, R (1991) "On the nature, function and

Composition of technological systems", Jownal of Evolutionary Economics, Na. 1, 93-11.

CARLSSON, B., JACOBSSON, S., HOLMEN, M and RICKNE, A (2002).

Innovation Systems: Analytical and methodologicall Issues. Science Direct Research Policy Volune 31 p. 233-245.

CBC - The Conference Board of Canada (2001). Building Innovative Capacity in the Classroom. Available at:

http://utwio.schaolnetuca/grassroots/e/resources/ toolkit/Kitagawa/5cboc ef pdf

CHAMBERS, R., PACEY, A. and THRUPP, L.A (1989). Farmer First: Farmer Innovation and Agricultural Research. Internediate Technology Publications, London.

CHAN, A (2004). Entrepreneurship: What does it REALLY mean? Available at: htp://wwow firstauatermain.com/insanity.html

CLARK, C and GUY, K (1997). Innovation and Competitiveness. Technopolis. Brighton, $U K$.

Clark, N (2001). Innovation Systems, Institutional Change and the New

Knowledge Market: Implications for Third World Agricultural Development. UNU-INTECH discussion paper, NO. 10.

CLARK, N.G. and MUGABE, I. (2003). Strengthening science and technology policy in the field of enviromment and development: the case of the African Centre for technology studies capacity development programme. In "HALL, A.)., SULAIMAN, R. CLARK, N. and YOGANAND, B. 2003. Post-harvest innovations in innovation: reflection on partnership and leaming. Crop PostHarvest Programme". South Asia, Andhra Pradesh, India.

CLARK, P. K (1987). The cyclical component of U.S. economic activity. The Quarterly fournal of Economics $102(1987), 797-814$

CLARKE, R (1999). A Primer in Diffusion of Innovations Theory. Xamax consultancy, Pty Ltd, Canberra.

COBBENHAGEN, J (2000). Successful Innovation: Towards a New Theory for the Management of Small and Medium-sized Enterprises. Edward Elgar Ed.

COHEN, W. and LEVINTHAL, D. (1990). Absorptive capacity: A newperspective on learning and innovation. Administrative Science Quarterly, 35, p.128-152. 
COHENDET, P. and LLERENA, P (1997). Learning, technical change and public policy: How to create and exploit diversity. In "EDQUTST, C: Systems of innovation: Technologies, unstitutions and organizations. London, Pinter Publishers

CORTRIGHT, J. (2001). New Growth Theory, Technology and Learning: A Practitioner's Guide. Reviews of Economic Development Literature and Practice: No. 4. U.S. Economic Dexelopment Adninistration. Awalable at: http:/rowew impresaconsulting.com/cortright ngt.pdf

DAWSON, C. (2002). Practical research methods. A user-friendly guide to mastering research techniques and projects.

DEMSETZ, H (1983). The Neglect of the Entrepreneur. In "RONEN, J.:

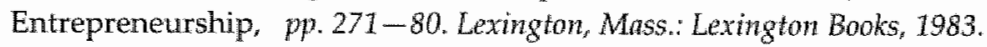

DESHLER, D (1995). Participation motivation in adult education. In HUSAN, T. and POSTLETHEWAITE, T. N. 1995. The international encyclopedia of education $2^{\text {nd }}$ Ed. PP. 4325 4328). New York: Pergmon Press.

DICK, B (1999). Action Research: Available at:

http:/www.scu.au/schools/gcm/ar/whatisar.html.

DODGSON, M and BESSANT, / (1996). Effective Innovation Policy: A New Approach. International Thompson Business Press, London.

DRUCKER, P.F (1986). Innovation and entrepreneurship. London: Pan.

DUNKJN, M.J (1987). The international Encyclopedia of teaching and teacher education. Oxford: Pergannon.

EDQUIST, $C$ (1997). Systems of Innovations. Technologies, Institutions and organisations. PINTER, London and Washington.

EDQUIST $C^{C}$. and JOHNSON, B (1997). Institutions and Organisations in Systems of Innovation. In "EDQUIST, C. 1997. Systems of Innovation. Technologies, Institutions and Organisations". Pinter, London 41-63

EDQUIST, $C$. and LUNDVALL, B-A (1993). Comparing the Danish and Swedish Systems of Innovation. In "NELSON, R (1993). National Innovation Systems: A Comparative Analysis". Oxford: OUP. pp. 265298

EDQUIST, C., (1997). Systems of irnovation approaches: technologies, institutions and organisations. London, Pinter, Cassell Acadernic, $253 p$ 
EICHER, C.K (2001). Africa's unfinished business: Building sustainable agricultural research systems. AEC Staff Paper 2001-10. East Lansing: Agricullural Econonics Department, Michigan State University.

EUGEN, P. and KAUCHAK, D (2001). Educational Psychology: Windows on classrooms. Upper Saddle River. Prentice Hall.

EUROPEAN COMMISSION (1995). Green Paper on Innovation

FAGERBERG, J (1987). A Technology Gap Approach to Why Growth Rates Differ, Research Policy 16:87-99.

FARRINGTON, J and MARTIN, A (1988). Farmer Participation in Agricultural Research: A review of Concepts and Practices, London: $O D A$.

FAWKNER, E. (2002). Do you have what it takes to become an entrepreneur? Part 1 \& 2. Available at:

http:/www.sideroad.com/Entrepreneur/become an entrepreneur 1.html

FAYOLLE, A. (1997). Teaching Entrepreneurship, Outcomes from an innovative experience. International Entrepreneurship Conference. Monetary Bay. California, USA. June 25-27.

FEDER, G. MURGAI, R. and QUIZON, B (2003). Sending farmers back to school: The impact of farmer field schools in Indonesia. Available at: hattp://are berkeley edu/courses/envres seminar/FFSImpact.doc

FERESU, S.(2002). Genetically Modified Food Crops: Environmental, health, social and economic aspects and their concerns on the African continent. Workshop I of the CODESRIA - IFS. Sustainable Agriculture Initiative. December 15-16, 2002. Hotel Africana Kampala, Uganda. Available at:

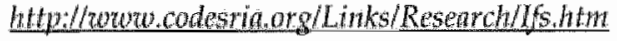

FERRELL, O.C., and GRESHAM, L.G (1985). A Contingency Framework for Understanding Ethical Decision Making in Marketing. Jownal of Marketng. 49:87-96.

FILION, L. J (1997). "From Entrepreneurship to Entreprenology" Journal of Best Papers, 42nd World Conference, International Council for Small Business, San Francisco, 176-192. Available at:

http://www.usasbe.org/knowled ge/proceedings/1997/P207Filion.PDF

FORAY D (1997). Generation and Distribution of technical Knowlledge: Incentives Norms, and Institutions. In "EQUIST, C (1997). Systems of Innovation - Technologies, Institutions and Organizations". London: Pinter 
FORAY, D. (1997). Generation and Distribution of technical Knowledge: Incentives Norms, and Institutions. Eds. EDQUIST, C. Systems of Innowations. PINTER, London and Washington

FOSTER, J., NORTON, G.A., and BROUG, E.J (1995). The role of problem specification workshops in extension: An IPM example. Journal of Extension, 33 (4).

FRALEX, R.C. (2003). The Statistical Significance Testing Controversy: A Critical Analysis. Available at: http:/www uic.edu/classes/psych/psych548/fraley/

FREEMAN, C (1992). The economics of Hope - Essays on technical change, economic growth and the environment. London.

FREEMAN, C (1995). The National Innovation Systems in historical perspective. Cambridge Joumal of Economics. vol. 19, no. 1

FREEMAN, C (2000). A Hard Landing for the 'New Econony'? Information Technology and the United States National Systems of Innovation. Rio de Janeiro: Instituto de Economica da Universidade Federal do Rio de Janeiro - IEALFRJ

FREEMMAN, C (1987). Technology policy and economic performance; lessons from Japan. London, Pinter.

GARLAND, K.P. (1991). Diffusion and adoption of instructional technology. In G.J. ANGLIN, G.J. Instructional technology: Past, present, and future ( $2^{\text {nd }} \mathrm{ed}$.). Englewood, CO: Libraries Unlimited.

GIBB, A.A (1998). Entrepreneurial core capacities, competitiveness and management development in the 21st century. Proceedings of the Internationalising Entrepreneurship Education and Training-Conference. OestrichWinkel, Gernany. July 26-28.

GIBBON, D (2002). Systems thinking, interdisciplinarity and farmer participation: essential ingredients in working for more sustainable organic farming systems. In "POWELL et all. (2002), UK Organic Research: Proceedings of the COR Conference, 26-28th March 2002, Aberystwyth, pp. 105-108.

GIBBS, G. and SIMPSON, C. (2002). How assessment influences student learning - a literature review Student Support Research Group. Milton Keynes: Open University

GORMAN, G., HANLON, D., and KING, W (1997). Some research perspectives on entrepreneurship education, enterprise education and education for small business management: A ten-year literature review, International Small Business Joumal. 15(3), 56-79 
GREEN, W.H. (2000). Econometric Analysis, $4^{\text {th }}$ Edition, New York Uniwersity.

GREGERSEN, B., JOHNSON, B. and SEGURA, O (2004). Institutions and leaming Capabilities in a development perspective. Paper presented at the DRUID Summer Conference 2004 on Industrial dymamics, Innowation and Development. Elsinore, Denmark, /une 14-16, 2004. Available at: htip/lwwwdrwaldk/conferences/stmmer2004/papers/ds2004-97.pdf.

GRESHAM, P.E (1985) Liberty and the Entrepreneur. Reprinted with permission from The Freeman, a publication of the Foundation for Economic Education, Inc. October 1985, Vol. 35, No. 10. Avallable at: http//Nwww.hee org/vnews.php?nid=1557\&printable=X.

GRIFFITHS, W.E., HILL, R.C and JUDGE, G.G. (1993). Learning and Practicing Econometrics. John Wiley \& Son, INC, New York.

GROSSMAN, G. and HELPMAN, E. (1994). Endogenous Innovation in the Theory of Growth. Journal of Economic Perspectives 8 (1).

GUILLEM, M.F, (2001). The Limits of Convergence: Globalization and Organizational Change in Argentina, South Korea, and Spain. Princeton University Press.

HALL, A.J. (2002). Innovation systems and capacity development: an agenda for north-south research collaboration? International Journal of Technology Management and International Development, VOL. 1(3). PP. 146-152

HALL, A.J. and YOGANAND, B (2003). New institutional arrangements in agricultural R\&D in Africa: Concepts and case studies. ICRISAT, Patancheru, India

HALL, A.I, SIVAMOHAN, M.V.K., CLARK, N. "TAYLOR, S, and BOCKETT, G. (2001). Why research partnerships really matters: innovation theory, institutional arrangements, and implication for developing new technology for the poor. World Development. Vol. 29(5), PP. 783-797.

HALL, A.J., SULAIMAN, R. CLARK, N. and YOGANAND, B. (2003). From measuring impact to learning institutional lessons: an innovation systems perspective on improving the management of international agricultural research. Agricultural Systems 78 (2003) 213-241. Available at: wwu elsevier.com/locale/agsy.

HALL, A.J., SULAJMAN, R.V., CLARK, N.G., SIVAMOHAN, M.V.K. and YOGANAND, B (2000). New agendas for agricultural research in developing countries: policy analysis and institutional implications. Knowledge, Technology and Policy, 13(1): 73-91. 
HAMILTON-HOWARD, I and HOWARD, A (2000). Case Studies of Innovation in the Australian Agrifood Industry. Consulancy repont for the Commonweal hepartnent of Agriculture, Fisheries and Forestry - Austrilin

HARRISON, P. (1991). Une Afrique verte. Ed. Karthala et CTA. Tradwit de l'Anglais par BELVAUDE, C. "The Greening of Africa. Breaking Through in the Battle for Lard and Food. London: Paladin Griffon".

HAYAMI, Y and RUTTAN, V. W. (1991). Agricultural development: An International perspective. Johns Hopkins Unizersity Press. Baltimore.

HAYAMI, Y. and RUTTAN, V. W. (1985). Agricultural development. An International Perspective. The Johns Hopkins Unioersity Press. Baltimote and London.

HAYAMI, Y. and RUTTAN, V.W. (1981). Agricultural development: an international perspective. Baltimore, John Hopkins Lnitersity Press, 261 p.

HAYEK, F.A, von (1959). The Use of Knowledge in Society. American Economic Review (1945), 35, p. 519-530. Also in: Individualism and Economic Onder (1959), London. Routledge and Kegan Paul; Chicago. Uniwersity of Chicago Press (1948), 1957). See also: "The Meaning of Competition", 1949, in Individualism and Economic Order, 1959: p. 92-106.

HEFFNER, C.L. (2004). Research Methods. Available at: hitp:lallosuch.com/researchmethods/

HETHERINGTON, I (1994). The forgotten Heroes. Sand tom: the free market foundation.

HINDLE, K. G., and ANGHRN, A (1998). Crash Landing at INSEAD: Initiating a grounded theory of the pedagogical effectiveness of simulation games for teaching aspects of entrepreneurship. In "BIRLEY, S. 8th Anmual Global Entreprevenr ship Research Conference". The Whatton School Imperial College, Fontaineblean, France.

HIRSCHMAN, A (1958). The Strategy of Economic Development. Yale Liniversity Press.

HJORTH, D. and JOHANNISSON, B (1997). Training for Entrepreneurship: Playing and language game. International Enfrepreneurship Conference. Monetary Bay, California, USA.

HOEPFL, M..C. (1997). Choosing Qualitative Research: A Primer for Technology Education Researchers. Journal of Technology Education. Vol. 9 (1) - Fall 1997. 
HOFIMAN, A J and WOLFE, P. (1985). The Travelling Salesman Problem.

Lawler, Lenstra, Rinooy Kan and Shmoys, eds., Wiley, 1-16.

HOFFMAN, K and PADBERG, M. O. Travelling Sallesman Problem. Available at: http//rilg gmu.edu/khoftman/papers/trav sdesman.htm.

HONIG, B (2004). A contingency model of business planning. Acadewy of Managewent Learning and Education 3(3)258-273.

HORTON, D., ALEXAKI, A. BENNETT-LARTEY, S. BRICE, K. N., CAMPILAN, D., and CARDEN, F., (2003). Developing and Evaluating Capacity in Research and Development Organisations. The Hague: International Service for National Agricultural Research.

HOSPERS, G. N. (2003): From Schumpeter to the Economics of Innovation.

Briefing Notes in Economics, No. 56, March. Available at: http://www. richmond.ac.uk/bne

HULL, L. (2003). A Promotion of Enterprise culture: Theory and Practices. Working Paper. Available at: http://www med.govt.nz/irdev/ind dev/cultureimpact/working-paper/working-paper.pdf

HUNTER, M.N. and HAYES, G.W (1996). Do our own research: The doorway to practical solutions. Brisbane, Australia: Queensland Department of Primary Industries.

HUTTNER, S.L (1995). Government, Researchers, and Activists: The Critical Public Policy Interface. In BRAUER, $\mathbb{E}$. Biotechmology. Vol. 12, Legal, Economic \& Ethical Dinetsion, 2nd Edn, $\mathrm{VCH}$, Weinhein

HWA, E-C (1989). The contribution of agriculture to economic growth: Some empirical evidence. In "WILLIAMSON, J. and PANCHAMURTCHI, V.R., The Balance Between Industry and Agriculture in Economic Dewelopment. Vol. $2^{*}$. Sector Propottions. The World Bank.New York

ILO - International Labour Organisation (2001). Learning and Training for Work in the Knowledge Society.

INTER ACADEMY COUNCIL (2004). Inventing a Better Future - A Strategy for Building Worldwide Capacities in Science and Technology. Avolable at: htpu/twowe interacadenycouncilnet

ISHIKAWA, S (1981). Essays on Technology, Employment and Institutions in Economic Development: Comparative Asian Experience. Kinokuniya Company LTD. Tokwo Japan. 
ISNAR - International Service for National Agricultural research (2000). Creating ownership of agricultural research through capacity building. Avallable at: http:/www.isnar.cgiar.org/publications/1999- Af/heme.htm

JALLOH, A (2002). Promoting Appropriate Intercropping Technologies for Sustainable Agricultural Production in Africa: A farmer-centred approach. Available at: http:/twow codesria org/Links/conferences/ifs/lalloh pdf

JESSOP, B. (1999). The social embeddedness of the economy and its implications for economic governance', in ADARAMAN, F. and DEVINE, P. The Socially embedded economy. Montreal: Black Rose Books, 1999

JOHNSON, B. (1992). Institutional Learning. In "LUNDVALL, B-A (1992).

National Systems of Innovation: Towards a Theory of Innovation and Interactive Learning" . London Pinter.

JOHNSON, B. and SEGURA-BONILA, O (2001). Inmovation Systems and Developing Countries: Experiences from the SUDESCA Project. DRUID Working Paper No, 01-12. Aalborg: Danish Research Unit for Indmstrial Dymamics, Unvinersity of Aalbarg

JOHNSON, B. EDQUIST, C. and LUNDVALL, B-A (2003). Economic development and the national system of Innovation Approach. First Globelics Conference. Rio de Janeiro; November $3-6,2003$. Available at: hitp://www.globelicsacademy.net/pdf/BengtAkeLundaall 2.pdf.

JOHNSON, S. D. (1995). Will our research hold up under scrutiny? Journal of Industrial Teacher Education. Vol.32(3), 3-6.

JOHNSTON, B. F and MELLOR, W.J (1961). The Role of Agriculture in Economic Development. In "PETERS, G.H (1995). Agricultural Economics. The international library of critical aritings in Economics 55. Edward Elgar Publishing Limited

KAPLAN, N. (2001). What Europeans Know About Integration, And How It Matters. Columbia University. Available: http.//www columbia. edw/ nogh/havo6 pdf

KAUDIA, A. A (2002). Regenerative Commercial Farming as a Framework for Sustainable Agriculture: Institutional and Socio-economic Aspects. Available at: http:/www.codesria.org/Links/conferences/ifs/Kaudia.pdf.

KENMORE, P.E (1991). Indonesia's Integrated Pest Management: A Model for Asia. Manila, Philippines: FAO Intercountry IPC Rice Program, 1991. 
KTM, L. (1997), Korea's National innovation System in Transition. In "KTM, L. and NELSON, R.R 1997. Technology, Learning and Innovation- Experience of Newly Industrialising Economies." Cambridge University Press.

KING, K. (1992). The external agenda of aid in internal educational reform. World Development Vol. 12(4), pp.257-263.

KING, R.N, and ROLLINS, T.J. (1995). Factors influencing the adoption of a nitrogen testing programme. Joumal of Extension. Available: at hrtp:/woww joe ordjoe/1995august/rb2 html

KIRCHHOFF, B. A (1994). Enfrepreneurship and Dynamic Capitalisn, Westport CT: Praeger.

KIRZNER, I M (1973). Competition and Entrepreneurship. Chicago: Untwersity of Chicago Press.

KIRZNER, I. M (1976), The Economic Point of View: An Essay in the History of Economic Thought, 2nd edition, Kansas City: Sheed and Ward.

KIRZNER, I. M (1979). Perception, Opportunity, and Profit, Chicago: University of Chicago Press.

KIRZNER, I. M (1982) "Uncertainty, Discovery and Human Action: A Study of the Entrepreneurial Profile in the Misesian System." In: Kirzner, I. M. (ed.) Method; Process and Austrian Economics. pp. 139-160. Canada: D.C. Heath.

KIYOSAKI, R.T. and BENNET, H.Z (1993). If you want to be rich and happy, don't go to school. Californa, Aslan publishing.

KLINE, S.J. and ROSENBERG, S (1986). An Overview of Innovation. In LANDAU, R.. and ROSENBERG, N. The Positive Sum Strategy: Harnessing Technology for Economic Growth. Washington D.C. National Academy Press, pp. 275-304

KNIGT, F.H (1921). Risk, Uncertainty and Profit. New York: Houghton Miffin. Also Chicago: University of Chicago Press

KOLSHORN, R (CEFE, Germany) Understanding Enterprise Training and How to do it. Presentation to the Conference Building a Modern and Effective BDS Industry in LAC, May 1999. Available at:

http:/wwwiadb.org/sds/MIC/publication/publication 159700 e.htm

KRUGER, M. E (2004). Creativity in the Entrepreneurship Domain. Doctoral Thesis. Available at: http./4petd.up.ac.zalthesis/availabletetd-08242004-145802/ 
KUBO, M. and FUJISAWA, K. (1997). The Life Span Method A New Variant of Local Search. Technical Report 1, Tokyo Unversity of Mercantite Marne, April 1993. Presented in The Institute of Statics and Mathematics on March 29, 1993. Awallable at: hto:/citeseer.ist.psu.edu/kubog7life,htmil

KUYEK, D. (2002). Intellectual property rights in African agriculture: Implications for small farmers. Genetic Research Action lnternational-GRAINAugust, 2002

LAMBING, P. and KUEHL, C (1997). Entrepreneurship. Upper saddle River. Prentice Hall.

LEWIS, W. A. (1954). Economic Development with Unlimited Supplies of Labour. The Manchester School, Vol. 22, pp. 139-191

LIEBENBERG, A.L and THERON, F (1997). Exploring the myths of community development: a call for a new approach. Avwilable at:

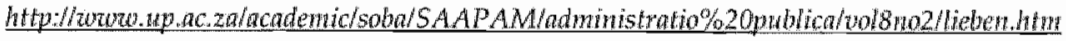

LIEBENSTENN, H (1968), "Entrepreneurship and Devellopment," American Economic Review, Vol. 58, 72-83.

LIGHTFOOT, H.M. (2001). Basic Education Strategic objective. Paper Presented by USAID/Benin Mission Director, May 28-June 1, 2001. Available at: http//wwow eddionline.org/2news/benin2001/basic educ-article.hm

LIST, F (1841). The National System of Political Economy. Longmans, Green and Co., London 1841.

LUNDVALL, B-A, (1992). National Systems of Imnowation: Towards a Theory of lnnovation and interactive learning. Printer Publishers, London.

LUU, N.N (1988). Institutional factors and technological innovations in Vietnam. In "AHMED, I. and RUTTAN, V.W (1998). Generation and Diffusion of Agricultural Innovations: The Role of Institutional Factors". Gower publishing C. Ltd. England.

LYNAM, J.K. and BLACKIE, M.J. 1994. Building effective agricultural research capacity: the African challenge. In: Anderson, J.R., ed., Agricultural technology: policy issues for the international community. Wallingford, UK, CAB International, 106-134.

LYNSKEX, MJ (2002). Entrepreneurship and Organisation: The Rolle of the Entrepreneur in Organisational Innovation. Oxford University Press 
MACHABA, R.P. and LAZBENY, J.A.A (2003). Are Entrepreneurs Made or Born? A Descriptive Analysis of South African Entrepreneurs. Avallable at: htg //Www handels.gu.se/ifsam/Streams/Poster/78\%20POSTER\%20final pdf

MADDALA, G.S. (1992). Introduction to modern Econometrics. 2 Edition. Macmillan Publishing Company, New York, USA.

MAIR, J (2002). Entrepreneurial Behaviour in a Large Tradition Firm: Exploring key drivers. Available at: http//www.ieseedu/research/pdfs/DI-0466-E.pdf.

MALECKI, E. (1997). Technology and Economic Development: The Dynamics of

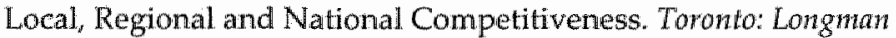

MALERBA, F (2002). Sectoral System of Innovation and Production. Science Direct Research Policy Volume 31 (2002) 247-264.

MANFIELD, W.M. and WEA VER, R.Y (1997). The determination of the teaching methodology of entrepreneurship as established by the underlying philosophy of paradigm. ICSB World Conference Proceedings. San Francisico.

MARSHALL, A (1930). Principles of Economics. London: Macmillan and Co.

MATTA, N.F. and ASHKENAS, R.N(2003). Why Good Projects Fail Anyway. Harvard Business Reverv, September, pp.109-114

MoCOWN, R.L (1991) Research in a farming systems framework. In "SQUIRES, V.R. and TOW, P.G. Dryland farming: A Systems Approach. An Analysis of Dryland Agriculture in Australia. Oxford University Press, Melbourne. pp. 242-249.

MCKELVEX, B (1997). Quasi-natural organisation science. Organisation Science, $8.352-80$

MCMILLAN, D.E, SANDERS, J , KOENIG, D.,AKWABI-AMEYAW and PAINTER, T. (1998). New Land is Not Enough: Agricultural Performance of New Lands Settlement in West Africa. World Development 26(2): 187-211

MELLOR, JW (1986). Agricuiture on the road to ind ustrialisation. In " J.P. LEWIS and KALLAB, V.(1986). Development strategies reconsidered. Nero Brunswick, NI: Transaction Books for the Ooerseas Dovelopment Council

METCALFE, S.(1995). The Economic Foundations of Technology Policy: Equilibrium and Evolutionary Perspectives. In "STONEMAN, P. Handbook of the Economics of Innovation and Technological Change Blackwell Publishers, Oxford (UK)/Cambritge (US). 
MEYER-KRAHMER, F (1998). Industrial Innovation Strategies - Towards an Environmentally Sustainable Industrial Economy. Innovation and Sustainable Development. Heidelberg, Physica Verlag

MILL $L_{y}$ J.S (1848). Principles of Political Economy with Some of Their Applications to Social Philosophy. 9th edition, London: Longman, Green (1886).

MINER, A.S. BASSOFF, P. and MOORMAN, C (2001). Organisational improvisation and learning: A field study. Administratioe Science quarterly. Vol. 46 (2), June: $304-337$.

MITTON, D.D (1997). Entrepreneurship: One More Time-Non-Cognitive Characteristics that Make the cognitive click. Available at: http:/www.babson.edu/entrep/fer/papers $97 /$ mitton/mit $2 \mathrm{htm}$

MOWERY, D. C (1990). The development of industrial research in U.S. manufacturing. American Economic Review, 80(2): 345-349

MUREITHI, J.G. and NJUE, E (2001). Farmer Participatory Research proceeding of a methodology Workshop. Nanynki, Kenya: KARI-Rockefeller Foundation, 5-6 June, 1997.

MUSC - Medical university of South California (2001). Available at: http://www.musc.edu/dc/icrebm/statisticalsignificance.html

NEELY, A. and HII, J. (2001). Innovative capacity of firms in East of England: actions and performance. Centre for Business Perfornunce Cranfield School of Management. Available at: http:/wwow som.crantfield ac. wh/somtresearch/centres/cbp/current

NELSON, R. and WINTER, S (1977). In search of a useful theory of innovation. Research Policy, Vol. 6, pp.36-76.

NELSON, R. R. and ROSENBERG, N (1993). Technical innovation and national systems. In "NELSON, R. R. (1993). National innovation systems: a comparative analysis. Oxford Uniwersity Press, New York. pp. 3-22

NIOSI, J. SAVIOTI, P.P., BELLON, B. and CROW, M (1993). National Systems of Innovation: In Search of a Workable Concept. Technology in Society, 15: 207-227

NORMAN, D.W (2002). The Farming Systems approach: A historical Perspective. Paper presented at the 17th Symposium of the International Farming Systems Association, Lake Buena. Vista, Florida. November 17th-20h, 2002. 
NORMAN, D.W. SIBERT, ID., and MODIAKGOTLA, E (1995). The farming systems approach to development and approprate technology generation. FAO, Rome, 1995.

NORTH, D. C. (1990). Institutions, Institutional Change and Economic Performance. Cawbridge. Cambridge Unioersity Press.

NORTH, D.C. (1995). The Adam Smith Address: Economic Theory in a Dynamic Economic Wonld." Bustness Economics: 7.

NORTH, D.C (1995). The new institutional economics and third world development. In "HARRISS J., HUNTER, J. and LEWIS C. M. (1995). The New Institutional Economics and Third World Development". Routledge, London/New-York, pp. 17-26

NORTON, W.L., Jr., MOORE, W.T. (2002). Entrepreneurial risk: Have we been asking the wrong question? Small Business Economics 18(4) 281-287

NURKSE, R (1961), Equilibrium and Growth in the World Economy. Harond University Press.

NZAMUJO, G (2002). Songhaï, Quand l'Afrique Lève la Tête. Les Editions du Cerf, 2002

OCHENG, C.O. (2002). Sustainable Agriculture in Africa: Towards a new paradigm - The embeddedness approach. Workshop I of the CODESRIA - IFS. Sustainable Agriculture Initiatioe. December 15-16, 2002. Hotel Africana Kampala, Uganda. Available at: http//woww.codestia.org/Links/Research/Ifshm

OKA, T. and SHAW, I. (2000). Qualitative research in social work. A vailable at:

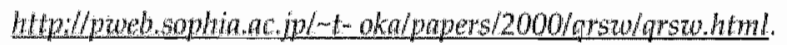

OKALI, C, SUMBERG, J, and FARRINGTON, I (1994). Farmer Participatory Research: Rhetoric and Reality. Intermediate Tedhology Publications, London.

OLOMOLA, A.S (2002). Soctial and Economic Institutions for Sustainable Agricultural Development in Africa. Available at: http//www.codesria.org/Limks/Researchlfs how

OLSON, M. (1996). Big Bills Left on the Sidewalk: Why Some Nations are Rich, and Others Poor. Jowmal of Economic Perspectives 10 (2): 3-24.

OMAMO, S.W. and LYNAM, J. (2003). Agricultural science and technology policy in Africa. Research Policy, 32: 1681-1694.

OUTCALT, C (2000). The Notion of Entrepreneurship: Historical and Emerging Issues. Available at: http://www.celceedu 
PARDEY, Ph. and BEINTEMA, N. M (2001). Slow Magic. Agricultural R\&D a Century After Mendel. Agricultural Science and Technology Indicators Initiative. International Food Policy Resemeh Institute, Washington DC, October $26,2001$.

PARDEY, Ph. ROSEBOOM, J. and BEINTEMA, N. (1996). Agricultural Research in Africa: Three Decades of Development. ISNAR Brigfing Paper Non 19. Avalable at: http:/www isnar.cgiar.org/publications/briefing/Bp19r.htm.

PASOUR Jr, E.C. (1985). Agricultural Technology, Economic Incentives and World Food Problems. Published in The Freman: Ideas on Liburty - july 1985. Avalable at: hittpillwww. fee.org/wnews.php? nid $=1531$

PATEL, P. and PAVITT K (1994). The Nature and Economic Importance of National Innovation Systems. STI Review, No. 14, OECD, Paris.

PATTON, M. Q. (1990). Qualitative Evaluation and Research Methods (2nd ed.). Newbury Park, CA: Sage Publications, Inc

PAVITT, K. (1991). What makes basic research economically useful? Research Policy, 20:109-119.

PETERSON W. L (1978). Returns to Investment in Agricultural research.

Department of Agricultural and Applied Economic, University of Minnesota. Staff Papers Series

PETERSON, W (2002). Agricultural systems and the role of agricuiture in. development. Available at: http://agecom.unl.edupterson/367 notes3. $\mathrm{htm}$

PETHERAN, R. I. and CLARK, R. A (1998). Modified from paper in Australian Journall of Experimental Agriculture (1998) 38, 101-11.5

PINKNEY, M. (2003). Continuous Random variables. Available at: http://wow mathsa.fsnet.co.uk

PLATTEAU, I-P (1993): The evolutionary theory of land rights as applied to SubSaharan Africa: A critical assessment. Facultés Universitaires Notre Dame de la Paix. Faculté des Sciences Economiques et Sociales. Belgium.

PONTIUS, J. DILTS, R. and BARTLETT, A (2000), Firom Farmer Field Schools to Community IPM Ten Years of IPM Training in Asia. FAO Commwnity IPM Programme Jakarta 2000.

PORTER, M. E. (1990): The Competitive Advantage of Nations, New York: Free Press. 
PRETORUUS, M.(2000b). Evaluation of proposed training Methodology to enhance micio and small business start-ups in South Africa. In "procedings of the $46^{\text {in }}$ ICSB World Conference". Brisbane Australia.

QUANG, D. A. and HONG, B.T. (2000). Statistical data analysis. Institute of Information TechnologyHoang Quoc Viet road, Cau giay, HANOI. Avallable at: htp:/www netnam.m/unescocourse/statistics/statistics.htm.

RANDOM HOUSE DICTIONARY OF ENGLISH LANGUAGE (2001), New York. Random House

RASMUSSEN, W. D (1989). Taking the university to the people: The first seventyfive years. Ames: lowa State Uniwersity.

RCA-Report of the Commission for Africa, 2005. Our Common Interest. Available at" httri//www globalpolicy org/socecon/develop/africa/2005/03ourcommoninterest.pdf

ROGERS, E.M. (1995). Diffusion of innovations (4th ed.). New York: The Free Press.

ROGERS, J.D. and BOZEMAN, B. (2001). Knowledge value alliances: an alternative to $R \& D$ project evaluation. Science, Technology and Human Values 26 (1), 23-55

ROLING, N (2004).Communication for development in research, Extension and Education. FAO Communication Roundtable. 6-9th September, Rome, Italy Avallable: http:/www.fao.org/sd/dim kn1/docs/

ROLING, N. (1990). Extension Science. Information systems in agricultural development. Cambridge University Press, LSA.

ROLING, N. (1995). What to Think of Extension? A Comparison of Three Models of Extension Practice. AERDD Bulletin. December.

ROLING, N.G. (1994).Agricultural Knowledge and Information Systems. In BLACKBURN, D.J. $2^{\text {nd }}$ ed. Extension Handbook, Processes and Practices. Thompson Edwcational Publishing Incorporated, Toronto, 57-67.

ROMER, P. M. (1986). Increasing Returns and Long Run Growth. Journal of Political Ecomomy 94: 1002-38.

ROMER, P. M. (1994a). Beyond Classical and Keymesian Macroeconomic Policy. Policy Options 15 (July-August, 1994): 15-21.

ROSEBOOM, J (2004). Adopting an Agricultural Innovation Perspective:

Implications for ASARECA's Strategy. ASARECA Strategic Planning paper N.7. 
ROSENBERG, N (1994). Exploring the Black Box: Technology; economics and history. 8 Critical issues in science policy research. Cambridge University Press. Cambridge, U.K. 1994. PP. 139-158.

ROSTOW, W.W. (1960). Stage of Economic Growth. Cannbridge University Press, London

ROTH, L. C (2001). Enemies of the trees? Subsistence farmers and perverse protection of tropical dry forest. Journal of Forestry 99 Oct: 20

ROTHWELL, R (1994). Towards Fifth-generation Process Innovation. International Marketing Reniew, 11(1):7-31.

RUTTAN, V.W (1998). Models of Agricultural Development. In EICHER, C.K. and STAATZ, J.M. International Agricultural Development. The Joln Hopkins Unizersity Press, London, pp. 155-162.

RUTTAN, V.W (2001). Technology, Growth and Development: An Induced Innovation Perspective. New York, NY: Oxford Uiniversity Press

RUTTAN, V.W (2002). The Role of the Public Sector in Technology Development: Generalisations from General Purpose Technologies. Available at: hitp://wow apec.ummeduffaculty/uruttan/StaffPaper01-11Revised2.pdf

RYAN, B and GROSS, N. C (1943). The diffusion of hybrid seed corn in two lowa communities. Rural Sociology (8) 15-24.

SAY, J-B (1803), Traité d' Economie Politique: ou, Simple Exposition de la Manière dont se Forment, se Distribuent et se Consomment les Richesses. Translation: Treatise on Political Economy: On the Production, Distribution and Consumption of Wealth, Kelley, New York: 1964 (1st edition: 1827).

SAYIGH, Y.A (1959). The Place of Agriculture in Economic Development: Agricultural Situation in India. New Delhi, 1959. 14ti Annual Number.

SCHERR, S. (1995). Economic factors in farmer adoption of agroforestry: Patterns observed in western Kenya. World Development 23: 787-804

SCHUH, G.E (1988). The Role of Agricultural Research in National Development Strategy. In PICKERING, D.C (1998). African Agricultural Research and Technological Development. The World Bank, Washington, D.C.

SCHUH, G.E (1997). Agriculture as an engine of Economic Development. In "BONTE FRTEDHEIM, C. and SHERIDAN K. The Place of Agricultural Research". ISNAR 
SCHULTZ, T. W (1980). Investment in Entrepreneurial Ablity. Scandinavian Joumal of Economics $82,437-448$.

SCHULTZ, T. W. (1964). Transforming Traditional Agriculture New Howen: Yale University Press.

SCHUMPEIER (1934). Entrepreneurship as Innovation. In "SWEDBERG, R. 2000: Entrepreneurship - The Social Science View". Oxford Lniversity press.

SEXTON, D.L (1982). Research needs and issues in entrepreneurship. In "KENT; C.A., SEXTON, D.L. and VESPER, K.H. Encyclopedia of Entrepreneurship: 383389." Englewood Cliffs, Ny: Prewlice-Hall, Lne.

SILLITOE $\mathrm{P}_{x}$ (2000). Let Them Eat Cake: Indigenous Knowledge, Science and the "Poorest of the Poor". Anthropology Today, Vol. 16 (6)

SMITH, A (1776), An Enquiry Into the Nature and Cause of the Wealth of Nations London: Edwin Canman. Also: London: Methuen (1950), Irwin (1963). Reedited in two volumes. See esp.: edition by James E. Thorold Rogers. Oxford: Clarewdon Press (1869).

SMITH, K. (1997). Economic Infrastructures and Innovation Systems". In EDQUIST, C. Systems of Innovations. Eds. PINTER, London and Washington

SOETE, L (1987). The Impact of Technological Innovation on International Trade Patterns: the Evidence Reconsidered. Research Palicy 16: 101-130

SOHNG, S. (1995). Participatory research and community organising. Working paper, presented at The New Social Movement and Community Organising. Conference, Unversity of Washington, 1995.

SOLOW, R. S. (1957). Technical Change and the Aggregate Production Function. Reviow of Economios and Statistics $39: 312-20$.

SPRINGER-HEIZER, A. SCHUETZ, P. and ALBERT, H. (2001). Newsletter of the energing platform on services within Division "Rural Development" (45) of glz. Issue No. 6. May 2001. Available at: htpr/howw.gtzdelenglish/

STELN, H (2003). Rethinking A frican Development. In "HA-JOO, CHANG. Rethinking Development Economics". Anthem Press 2003.

STEINBERG, D.I. JACKSON, R.I., KIM, K.S and SONG, H-K (1982). Korean Agricultural Research: The Integration of Research and Extension. USAID Project Impact Evaluation N.27. 
STEPHAN, P. (1996). The economics of science: Jourmal of Econtwhic Literature, wol. 34, pp.1199-1235.

STREETER, D (2003). Entrepreneurship: What to Teach and How to Teach It.

Symposium on Entreprenewrship - Montreal. Available at:

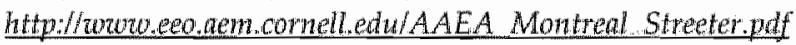

SUMMERS, B (1974). Economic Calculation. Reprinted with permission frow The Freman, a publication of The Foundation for Economic Education, Inc. Vol. 24, No.10. October 1974. Avalable:

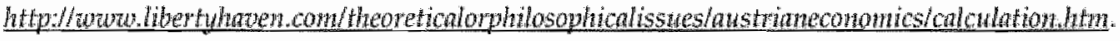

SUNDBO, I (1998). The Theories of Innovation: Entrepreneur, Technology and Strategy. Edward Elgar Publishing Limiled, LK

SURRY, D.W (1997). Diffusion theory and instructional technology. Available at: http:/www.gsu.edw/ wwwitr/diffusion/index.html

TEMEL, T, JANSSEN, W and KARIMOV, F (2002). The Agricultural Innovation System of Azerbaijan: An Assessment of Institutional Linkages. ISNAR publications.

TENNANT, M (1997). Psychology and Adult Learning. Second Edition, Loncion: Routledge.

TESCH, R. (1990). Qualitative Research: Analysis Types \& Software Tools. Falmer Press.

THOMPSON, B (1994). The concept of statistical significance testing. Practical Assessment, Research and Evaluation, 4(5). Available at http://www.ericdigests.org/1995-1/testing.htm

TIMMER, C.P (2001). Agriculture and Economic Growth in Vietnam. Prospects for Economic and Social Progress: Conference on Vietnan in 2001. numilable at: http:/www.ypa-inc. org/conference/pdftimmer.pdt

TIMMONS, I. A (1994), New Venture Creation, Entrepreneurship for the 21st

Century. Irwin, Burr Ridge, Ihinows, Part I. The Opportanity, Pat IW Financing Entreprenewrial Ventures

TODARO, M. P. and SMITH, S.C. (2002). Economic Development. Addison Wesley (8th Ed.). TRELOAR, A (1999). Just Another Technology? How the Dynamics of Innovation can Help Predict the Future of the Browser. Fifth Australian World Wide Web Conference, Southen Cross Unviversity.

TRIBE, D (1997). The Best-Kept Secret. In "BONTE FRIEDHEIM, C and SHERIDAN K. The Place of Agricultural Reseanch". ISNAR 
TRMP, R, (2001). Agricultural Technology Policies for Rural Devellopment. Developmen Policy Review, 19:4, 479-489

TROCM, W.M. (2002). Research Methods Knowledge Base. Avallable at: Ho:lwow social reseapchwt hods net/kbl

UNDP (1994). Human Development Report 1994, New dimensions of human security. New York, Oxford University Press.

UNRISD - United Nations Research Institute for Social Development (2001).

Breaking the Mould: An Institutionalist Political Economy Alternative to the Neo-liberal Theory of the Market and the State. Ha-Joon Chang.

USAID (2003). Initiative to Fnd Hunger in Africa (IEHA). Avallable at:

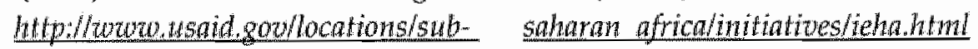

VAN DEN BAN, A.W. and HAWKINS, H.S. (1996). Agricultural extension.

Oxford: Blackwell Science, Ch. 9.

VAN den BERG, H. (2004). IPM Farmer Field Schools: A synthesis of 25 impact evaluations. FAO, Rome.

VENTURA, F. and MLONE, P. (2004). Novelty as the redefunition of Farm boundaries. In WISKERKE, I.S.C. and van der PLOEG, J.D.2004. Seeds of transition - Esaays on novelty production, niches and regimes in agriculture. Royal oan Gorcum, the Netherlands.

VERBEEK, M. (2000). A GUIDE TO Modern Econometrics. John Wiley \& Son, INC, New York.

VERSPAGEN, B.(2001). The economics of technological change. A textbook for engineering and economics students. ECIS - Eindhoven University of Technology.

WALSTAD, W.B (2004). The Multiple Effects of Entrepreneurship on Phillanthropy, Society and Education. Available at htrp://isee gseis.ucla edu/taculty html

WAMBUI, L (2002). Identification and screening of entrepreneurial skills in education. In "Entrepreneurship in Africa. The road to freedom". First international conference. Pretoria, 3-4 October.

WARBURTON, H and MARTIN, A (1999). Local People"s Knowledge and its Contribution to Natural Resources Research and Development. In "GRANT, I.F. and SEAR, C. 1999. Decision Tools for Sustainable Development". Natural Resources Institute, Chntham, UK. 
WENNEKERS, S, and THURIK, R (1999). Linking Entrepreneurship and Economic Growth. Small Business Economics, vol. 13; p. 27-55. Khwer Academic publisher. Available at: http://Www. wiwi.tillfreiberg.de/wipol/pdtfiles/mardy/wennekers thurik 1999.pdf

WHEATLEY, M.J (1992). Leadership and the New Science. Learning about Organization from an Orderly Universe. San Francisco, Berret-Koehler.

WILSON, I (1992). Changing agriculture: An introduction to systems thinking. Kenthurst. Kangaroo Press.

WORLD BANK (1988). African Agricultural Research and technological Development. Proceedings of a High-Level Meeting in Feldafing. Federal republic of Germany. September 24-27, 1987.

WORLD BANK (1996). Achievements and problems in development of national agricultural research systems. Report No 15828, Operation Evaluation Department

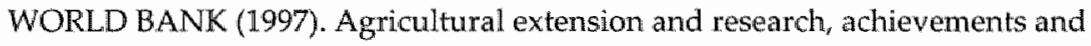
problems in national systems. A World Bank operations conduation study.

WORLD BANK (2001).. Contracting For Agricultural extension. Reviez of Emerging Practices. (AKIS Good Practice Note. Washington, D.C.

WORLD BANK, 2003. Strategic Approaches to Science and Technology in Development. Policy Research Working Paper No. 3026. Available at: http://wwwwods. worldbank.org/servlet/WDSContentServer/WDSP/IB/2003/05/23/

YIN, R. K. (2003). Case Study Research. Applied Social Research Methods Series, Volume 5. Sage Publications, Inc.

ZEPEDA, L. (2001). Agricultural Investment and Productivity in Developing Countries. Department of Consumer Science University of Wisconsin-Madison United States. Available at: http:/hwow fro.org/docmentsl 


\section{Samenvatting (Dutch summary)}

Deze studie neemt verscheidene economische ontwikkelingstheorieën in ogenschouw, stelt de vraag hoe de landbouw zich ontwikkelt en leidt daaruit de visie af dat de landbouwontwikkeling tot stand kan worden gebracht wanneer degenen die betrolkken zijn bij de landbouwproductie en -ontwikkeling met succes nieuwe kennis creëren, ontwikkelen, verspreiden en toepassen om de onproductieve praktijken te ontmantelen en ze te vervangen door efficiëntere. Echter, in de minst ontwikkelde landen, is het merendeel van de bestaande benaderingen van landbouwinnovatieprocessen, gedefinieerd als diegene die de boeren de mogelijkheid bieden om nieuwe kennis te verkrijgen en toe te passen op hun boerderijen, gebrekkig. De institutionele context waarin ze verankerd zijn heeft tot dusver te weinig gedaan om de boeren de mogelijkheid te bieden vernieuwers te worden. Onvermijdelijk zijn de landbouwinnovatiesystemen zwak en inefficiënt, terwijl innovaties niet tot de meerderheid van de boeren worden verspreid.

Deze studie neemt het innovatiesysteemenperspectief en betoogt dat de adoptie van nieuwe technologieën en praktijken niet het eindstadium is in een multi-stap proces. In dit perspectief heeft de adoptie van nieuwe technologieèn een bredere inwloed en vereist meer capaciteiten en bekwaamheden dan de boeren alleen kumnen opdoen. Verder steunt deze studie op de theorieèn van Schumpeter (1934) en betoogt dat de innovaties een onderliggende factor vormen voor ondernemerschap gedefinieerd als een proces van onderzoek, ontdekking en economische uitbating van wat de andere mensen tot dusver over het hoofd hebben gezien. Wat individuen tot ondernemers maakt zijn hun vernieuwende activiteiten die door onderwijs gevoed kunnen worden. De gewenste training omvat zowel theoretische als praktische aspecten van het ondememersgedrag. De belangrijkste doelstelling van deze studie is te bepalen hoe het ondernemerschapstrainingsmodel een dynamiek tot stand kan brengen welke interacties revitaliseert en tegelijkertijd tot de versterking van het landbouwinnovatiesysteem kan bijdragen om zo de innovatiecapaciteiten van boeren te bevorderen.

Een empinische studie werd uitgevoerd om de hypothese te testen dat landbouwondernemerschap de directe bevordering is van succeswolle innovatieprocessen. Een geschikte opleidinginstelling werd geïdentificeerd: het Songhaï Centrum, in Benin. De onderzoeksopzet volgt de casus studiemethode. Alvorens de innovatiecapaciteiten van de Songhail boeren te onderzoeken( de doelgroep) als gevolg van hun voltijdse deelname aan het trainingsprogramma, beschriftt en presenteert dit onderzoek eerst het Songhai Centrum als een eerste sub-casus, gevolgd door het trainingsprogramma als een tweede sub-casus.

Songhaï is een socio-economische en plattelandse ontwikkelingsagent, gespecialiseerd in landbouwproductie, onderzoek en training. Songhai vormt een geïntegreerd productiesysteem. gebaseerd op minimum input en het gebruik van lokale hulpmiddelen. Afvalproducten van een productieafdeling worden input voor andere afdelingen en zo worden de productieactiviteiten winstgevender omdat zij tot een systeem behoren waarin verschillende componenten elkaar versterken door wat ze aan de andere geven of van hen krijgen. De Songhaï training bevordert algemene landbouwondernemers en professionelen die technisch voorbereid zijn en goed toegerust zijn met ethische en morele waarden. Het 
trainingsproces is een leerkader en een pedagogisch vervolg gebaseerd op traditionele systemen die nieuwe kennis, knowhow en savoir-vivre combineert.

Empirische gegevens werden verkregen uit diepgaande interviews gebaseerd op een enquête, met een willekeurige steekproef van 75 boeren uit degenen die een trairning bij Songhaï hebben genoten. De kwalitatieve analyse van de gegevens leidt tot de conclusie dat de boeren die de training hadden gevolgd de bekwaamheid hebben verkregen om nieuwe technologieën toe te passen en de resulterende opbrengsten te beheren, bovenop het implementeren van nieuwe combinaties van de bestaande landbouwproductie inputs of het combineren van nieuwe inputs in goederen en diensten, waarvan sommige nieuw zijn voor de streken of de boeren zelf. Veel boeren zijn concurrerend geworden als gevollg van de kwaliteil wan hun producten en de nieuwe marketinginstrumenten die zij gebruiken. De meeste boeren konden weloverwogen informatienetwerken zoeken en zidh daarop aansluiten op verschillende niveaus.

De kwantitatieve analyse bouwt op twee gedefinieerde variabelen van innovatieprestatie. Deze vormen de afhankelijke variabelen en omvatten "het nivean van vernieuwing door de boeren" en de "trend van de activa van de boeren". Het geordende probit model en het gewone probit model werden respectievelijk gebruikt om de kans te voorspellen, dat een verandering in een bepaalde verklarende variabel effect zal hebben op de twee afhankelijke variabelen. Variabelen die de vroegere vaardigheden van de boeren en de karakteristieken van hum woonomgeving omvatten hebben aangetoond dat er geen significante statistische effecten zijn. Variabelen die de na-training vaardigheden reflecteren hebben wel een effect op de twee affankelijke variabelen.

Deze studie onderstreept ook dat ondernemerschapstraining het keurslijf verbreekt van de traditionele methoden om aan informatie te komen of op basis van traditionele intergeneratie overdracht van landbouwkennis en -vaardigheden te leren. Ten slotte door innovatie te conceptualiseren in systeemtermen, toont deze studie aan dat de landbouw ondernemerschapstraining de deelnemende boeren de innovatiecapaciteiten bijbrengt zonder weike, alle andere pogingen om innovatieprocessen te bevorderen op het niveau van alle andere categorieën van boeren zonder effect zou zijn. 


\section{About the Author}

Before joining UNU INTECH/MERIT Ph.D. Programme in "Economics and Policy Studies of Technical Change", Daniel $\mathrm{N}$. Dalohoun worked as a Financial Manager, specialised in project analysis and assessment with "AMEFRICA CONSULTANTS SARL" and as Statutory Manager and Director of GODWILL SARL in Benin from 1996 to 2000. Prior to that, he worked for the "Premiere Sociéte Slovaco-Française" in Slovakia between 1994 and 1995 as a Financial Manager Assistant. Dallohoun holds MSc. in "Econonic Statistics" and M.Sc in "Computer Assisted Management Systems" from the University of Economics in Bratislava (Slovak republic). He also holds a Master of Arts in "International and Development Economics" from the University of Namur in Belgium. After completing his Ph.D. studies, Daniel $N$. Dalohoun intends to work on issues related to agriculture and economic development. 